\title{
Expression and Regulation of the Insulin-Like Growth Factor Axis Components in Rat Liver Myofibroblasts
}

\author{
Dissertation \\ zur Erlangung des Doktorgrades \\ der Matematisch-Naturwissenschaftlichen Fakultäten \\ der Georg-August-Universität Göttingen
}

vorgelegt von

RUSLAN NOVOSYADLYY

aus Ivano-Frankivsk, Ukraine

Göttingen 2004 
D7

Referent: Prof. Dr. Rüdiger Hardeland Korreferent: Prof. Dr. Detlef Doenecke

Tag der mündlichen Prüfung: 3.11.2004 


\section{Contents}

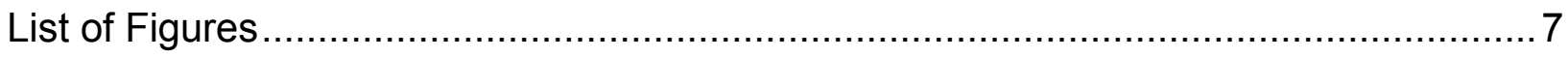

Abbreviations

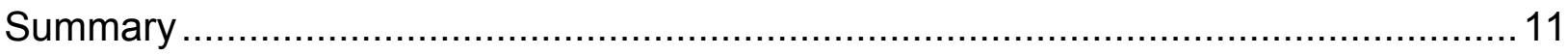

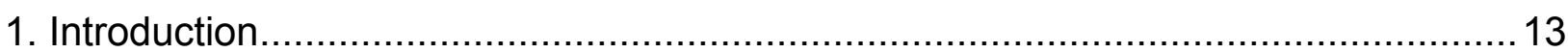

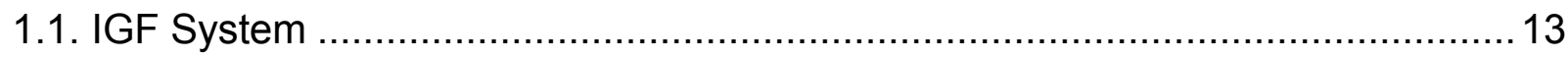

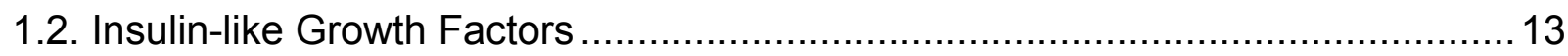

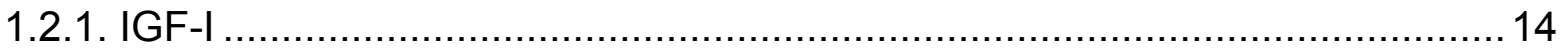

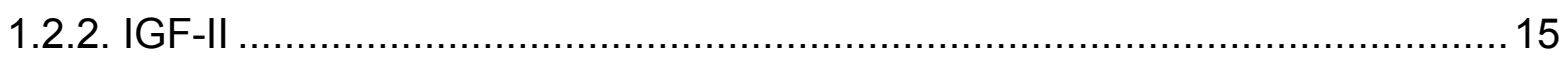

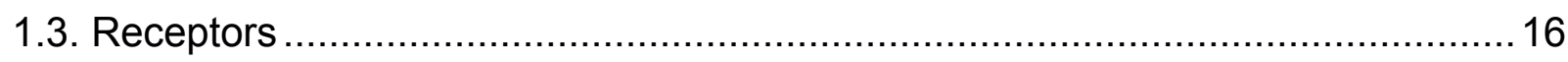

1.3.1. IGF-I Receptor and Insulin Receptor ........................................... 16

1.3.1.1. Structure and Ligand Specificity of IGF-I and Insulin Receptors ............ 16

1.3.1.2. Structure and Expression of IGF-I Receptor Gene ............................. 18

1.3.1.3. Signal Transduction Pathways Induced by IGF-I and Insulin Receptors 19

1.3.2. Cooperation between IGF-I and PDGF Receptors ................................ 23

1.3.3. IGF-II/Mannose 6-Phosphate Receptor ........................................... 26

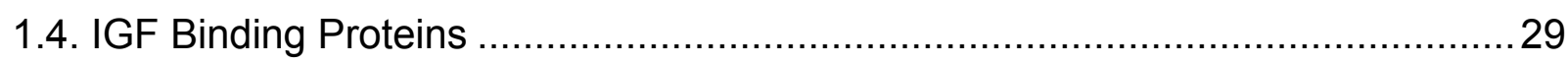

1.4.1. Biochemical Characteristics of IGFBPs ......................................... 30

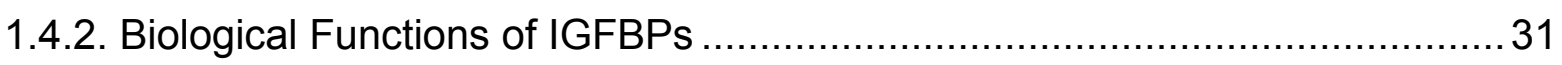

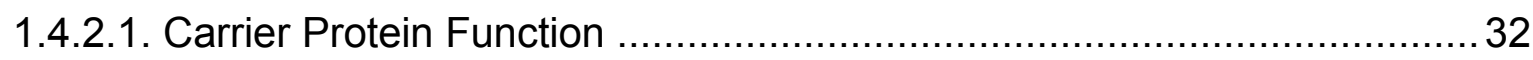

1.4.2.2. Tissue- and Cell-Specific Sequestration of IGFs by IGFBPs .................. 33

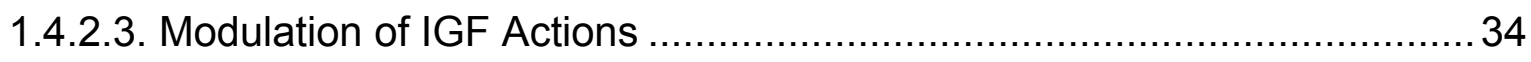

1.4.2.3.1. Modulation of IGF Actions by Posttranslational Structural Modifications

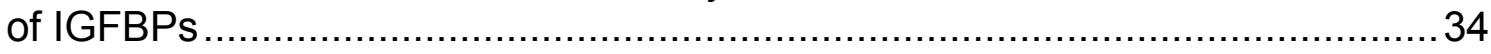

1.4.2.3.2. Modulation of IGF Actions by IGFBP Proteolysis .......................... 37

1.4.2.3.3. Modulation of IGF Actions by Binding of IGFBPs to Cell Surface and

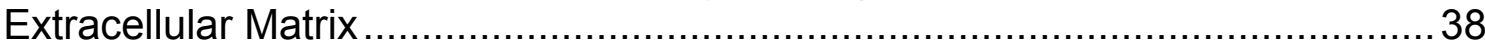

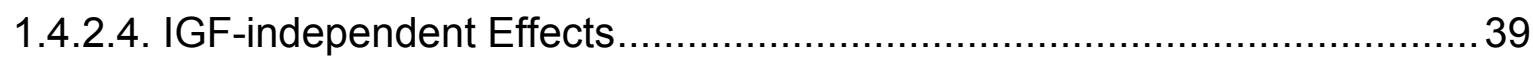

1.4.2.4.1. Cross-Talk between IGFBPs and Integrins............................... 40

1.4.2.4.2. IGFBP Receptors ...................................................... 41

1.4.2.4.3. Nuclear Translocation and Nuclear Effects of IGFBPs .................... 42

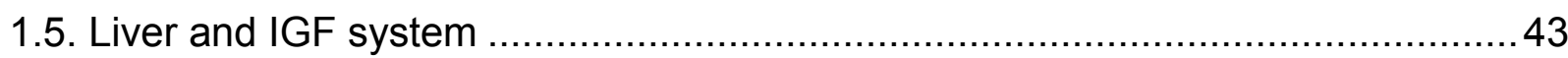

1.5.1. Liver as Central Organ in IGF Homeostasis ....................................... 43

1.5.2. Updated Concept of Liver Fibrogenesis .......................................... 44

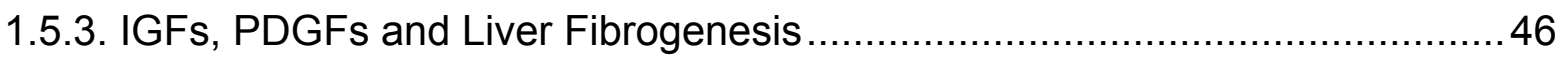

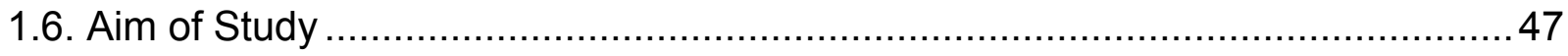




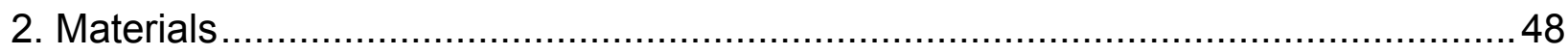

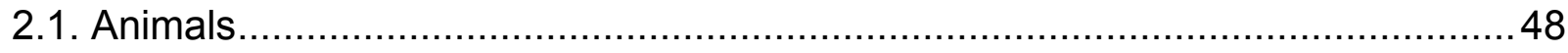

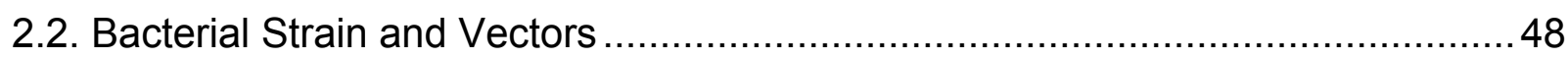

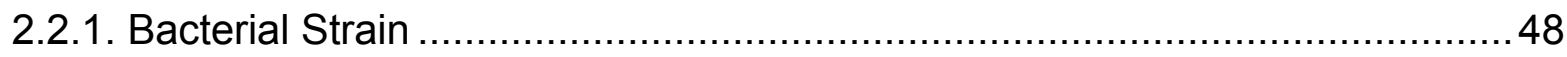

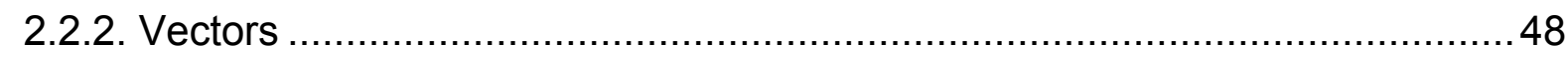

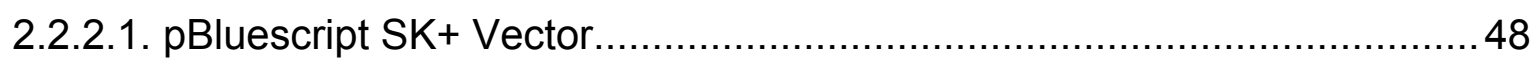

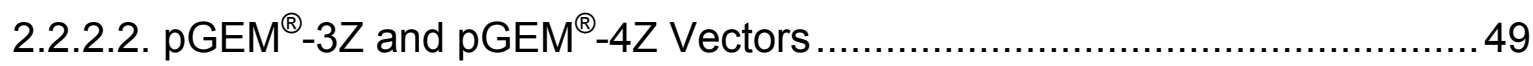

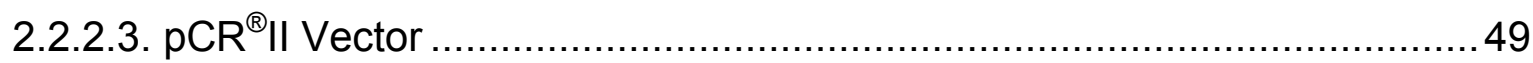

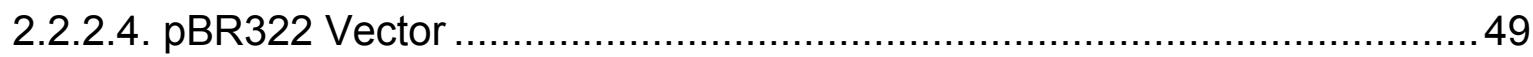

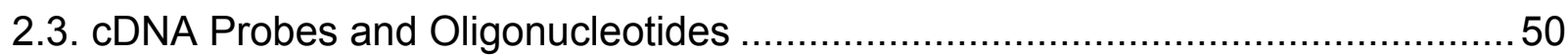

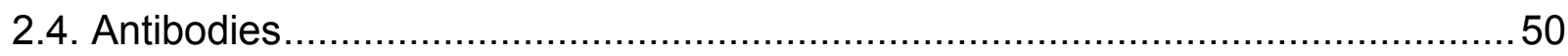

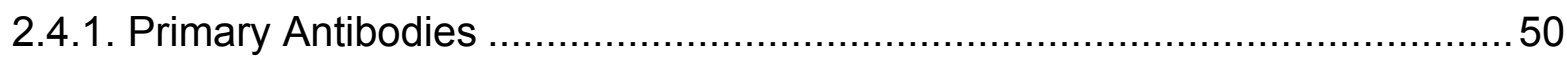

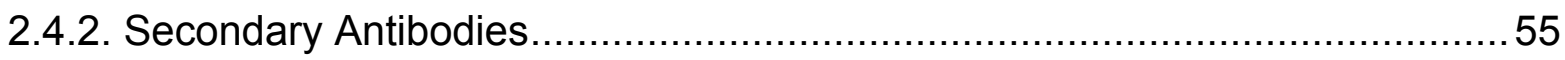

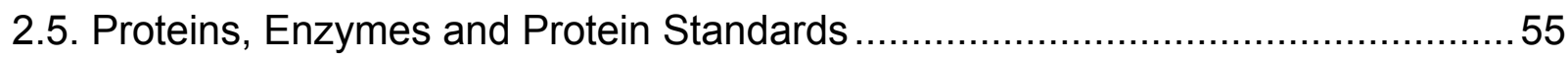

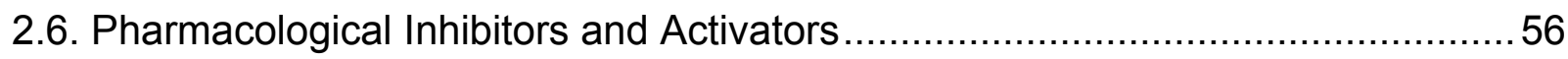

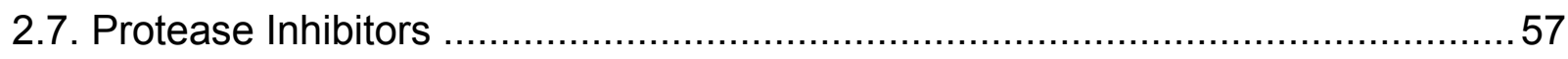

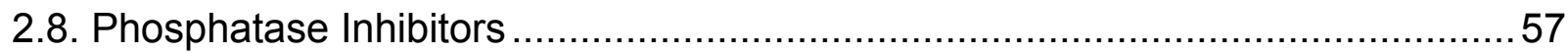

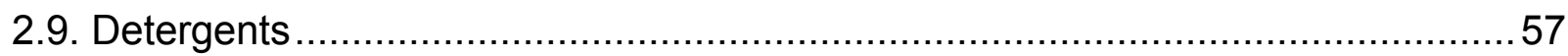

2.10. Detection, Purification and Synthesis Systems (Kits) …................................58

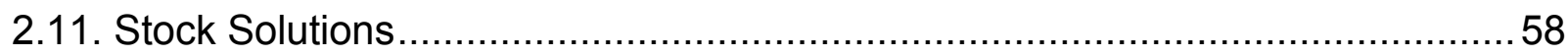

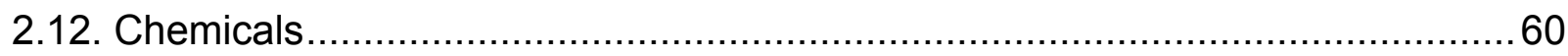

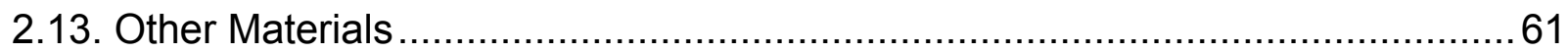

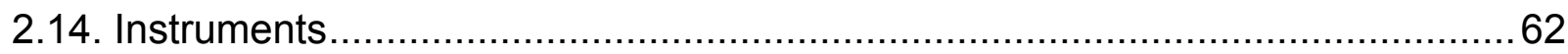

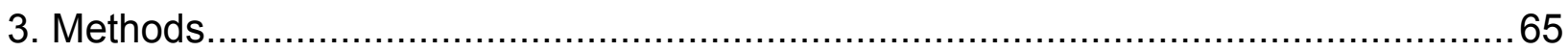

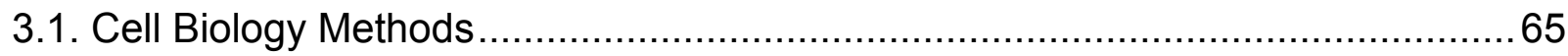

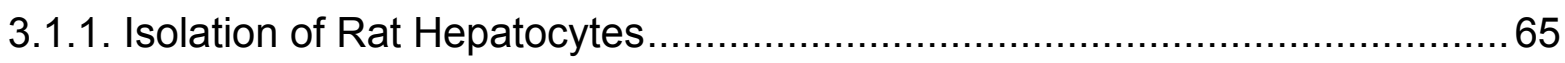

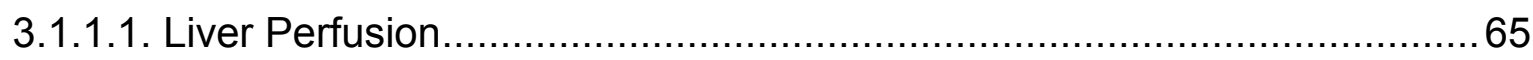

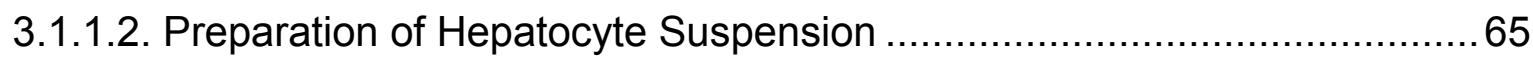

3.1.1.3. Solutions and Media for Isolation and Culture of Rat Hepatocytes...........66

3.1.2. Isolation of Nonparenchymal Liver Cells ...............................................69

3.1.2.1. Liver Perfusion and Preparation of Cell Suspension ...............................69

3.1.2.2. Separation of Nonparenchymal Liver Cells ......................................... 70

3.1.2.3. Purification by Counterflow Elutriation ................................................ 70

3.1.2.4. Isolation of Hepatic Stellate Cells .................................................... 71

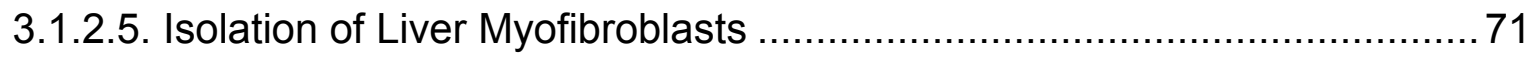

3.1.2.6. Treatment of Cultured Liver Myofibroblasts ......................................... 72 
3.1.2.7. Solutions and Media for Isolation and Culture of Nonparenchymal Liver Cells

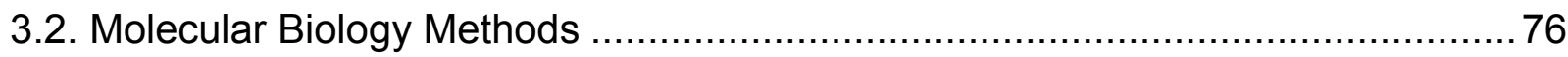

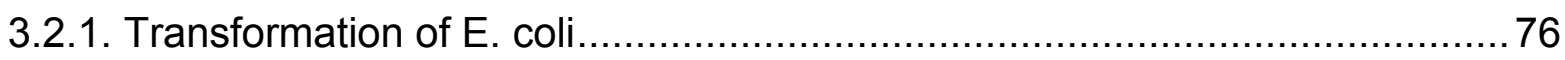

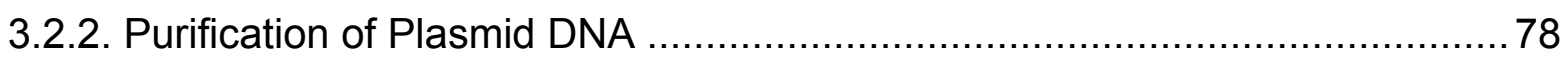

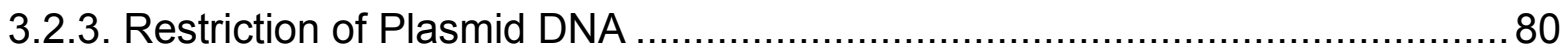

3.2.4. Agarose Gel Electrophoresis of DNA ............................................. 81

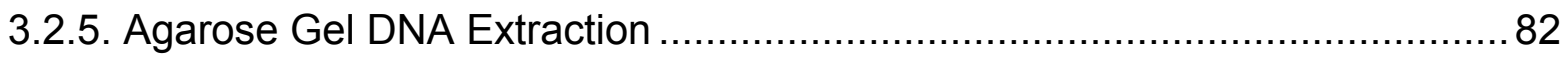

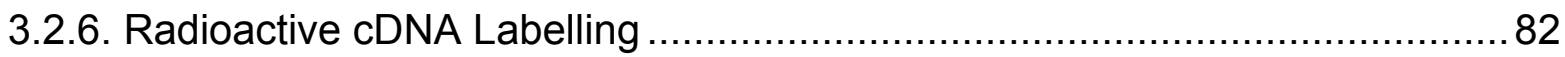

3.2.6.1. DNA Labelling by Random Priming Reaction .................................... 83

3.2.6.2. DNA Labelling by Nick Translation Method ..................................... 83

3.2.6.3. Purification of Labelled DNA ........................................................... 84

3.2.6.4. Measurement of $\beta$-Radioactivity ................................................ 85

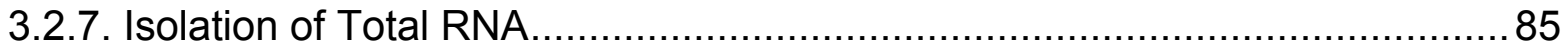

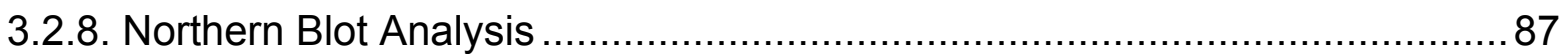

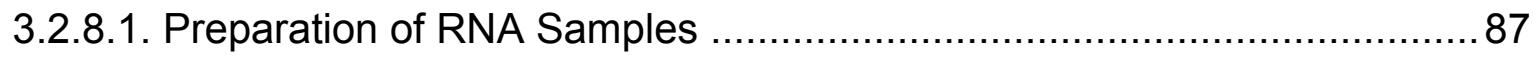

3.2.8.2. Formaldehyde/Agarose Gel Electrophoresis of RNA .......................... 87

3.2.8.3. RNA Transfer to Nylon Membrane ............................................... 87

3.2.8.4. Hybridization of RNA with Radiolabelled cDNA Probe ........................ 88

3.3. Immunochemical and Biochemical Methods ...........................................92

3.3.1. Protein Extraction from Cultured Cells................................................ 92

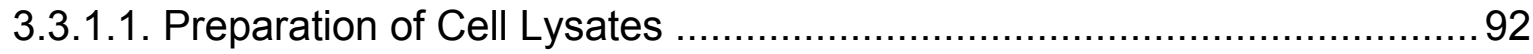

3.3.1.2. Extraction of Nuclear and Cytoplasmic Proteins from Cultured Cells ......94

3.3.2. Measurement of Protein Concentration ................................................. 96

3.3.3. Sodium Dodecyl Sulphate Polyacrylamide Gel Electrophoresis (SDS-PAGE)

3.3.4. Electrophoretic Transfer of Proteins ................................................. 99

3.3.5. Iodination of IGF-I..................................................................... 100

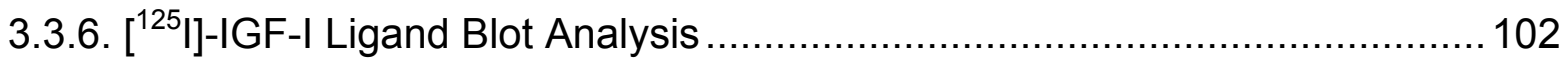

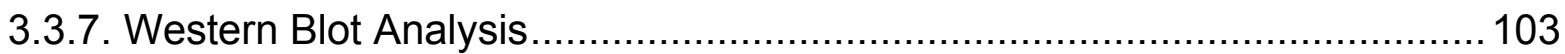

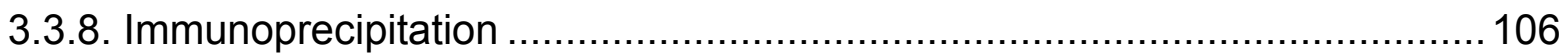

3.3.9. Biosynthetic Labelling and Immunoprecipitation of the IGF-II/M6-PR ......... 106

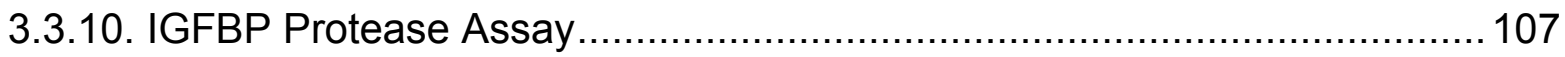

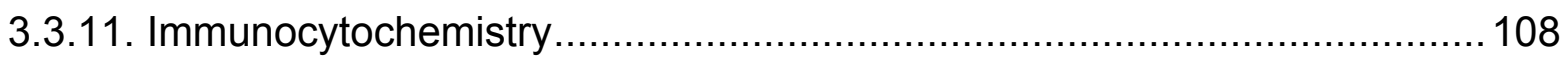

3.3.12. Determination of DNA Synthesis ............................................. 110

3.4. Statistical Analysis................................................................. 113 


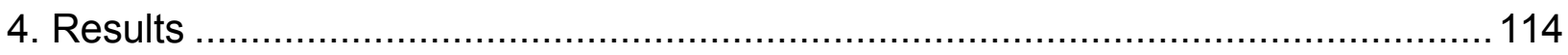

4.1. Morphological and Immunophenotypical Features of Liver Myofibroblasts ....... 114

4.2. Characterization of IGF Axis in Liver Myofibroblasts .................................... 116

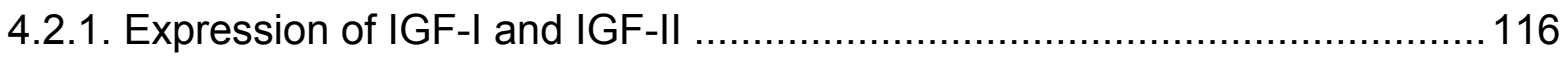

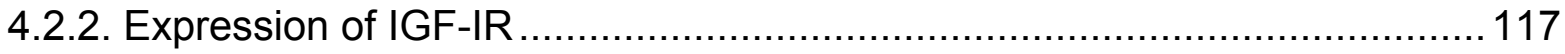

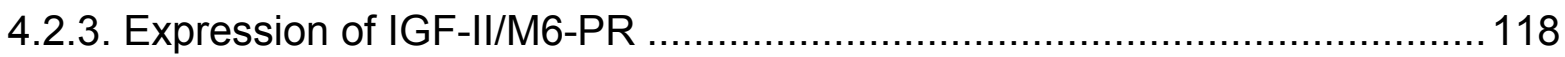

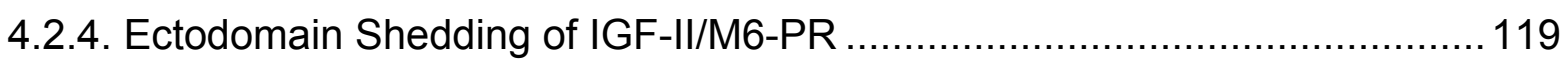

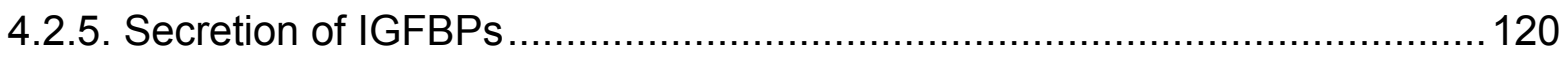

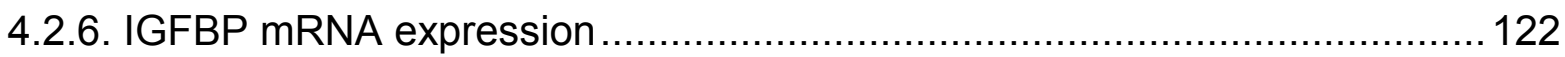

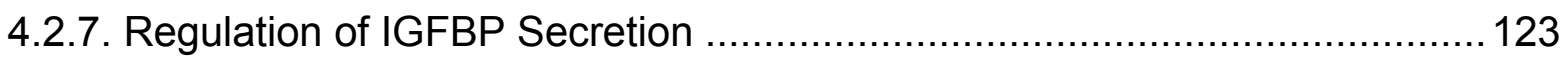

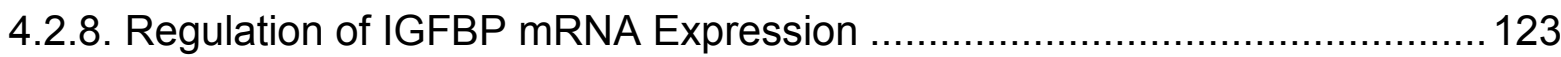

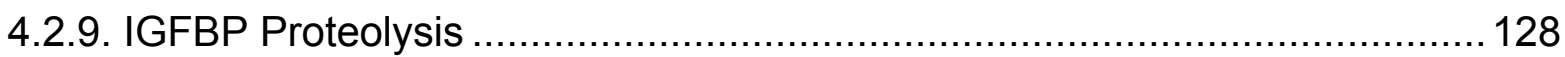

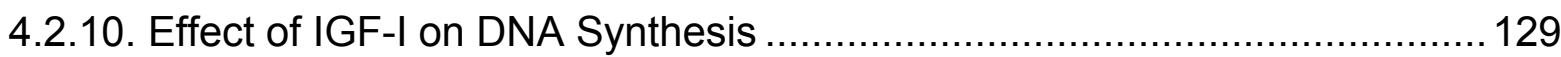

4.2.11. Effect of IGF-I on Synthesis of Extracellular Matrix Proteins ................... 129

4.2.12. Modulation of IGF-I-Stimulated DNA Synthesis by Exogenous IGFBP-2 and

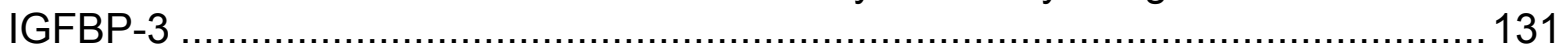

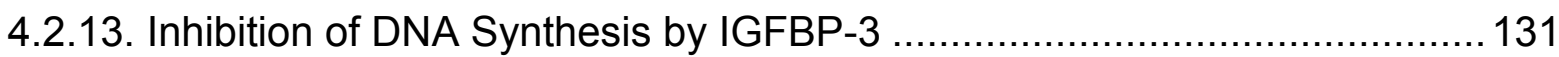

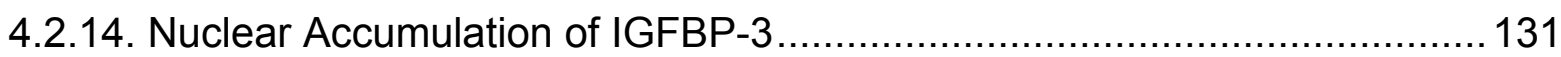

4.3. Cross-Talk between PDGF and IGF-I Receptors in Liver Myofibroblasts .......... 135

4.3.1. IGF-I-Induced Down-Regulation of IGF-IR and IRS-1 ........................... 135

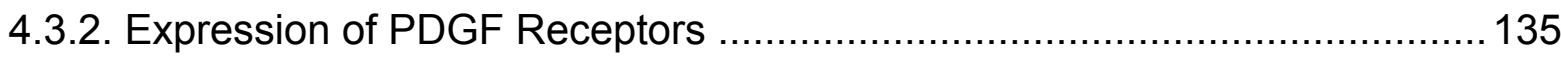

4.3.3. Effect of IGF-IR Blockade on IGF-I- and PDGF-Stimulated DNA Synthesis 138

4.3.4. Differential Regulation of IGF-IR and PDGFR mRNA Expression by PDGF

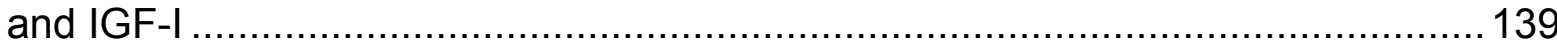

4.3.5. IGF-I- and PDGF-Induced Tyrosine Phosphorylation of IGF-IR, PDGFR, IRS-

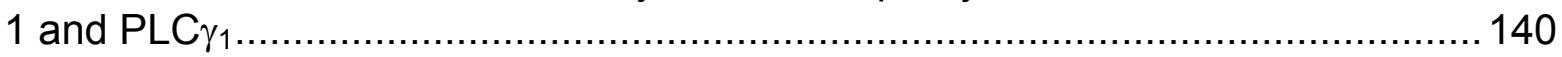

4.3.6. Effect of MAPK Pathway Inhibitors on IGF-I- and PDGF-Stimulated DNA

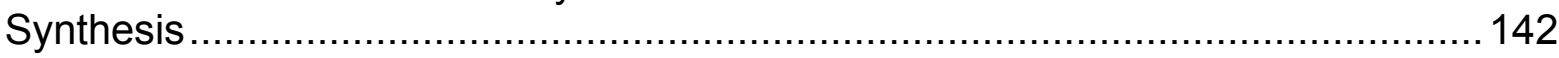

4.3.7. Effect of IGF-I and PDGF on MAPK Activation ......................................... 144

4.3.8. Effect of PLC Inhibitor and Activator on DNA Synthesis ............................ 145

4.3.9. Effect of IGF-IR Blockade on Tyrosine Phosphorylation of PLC $\gamma_{1} \ldots \ldots \ldots \ldots . . .145$

4.3.10. Split Effect of PDGF on IGF-IR Signalling System .............................. 147

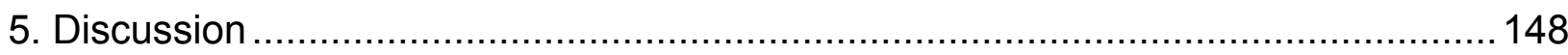

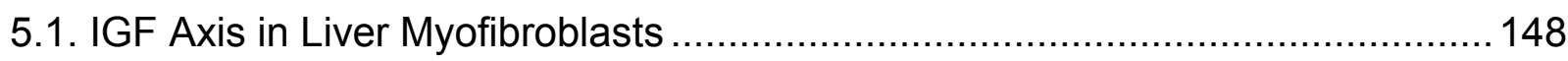

5.2. Cross-Talk between PDGF and IGF-I Receptors in Liver Myofibroblasts:

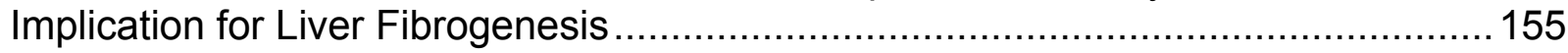

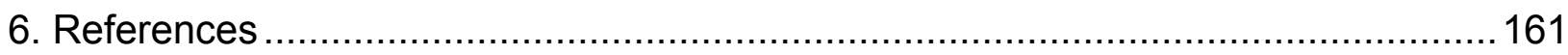




\section{List of Figures}

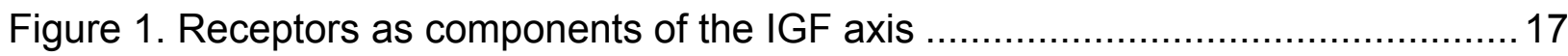

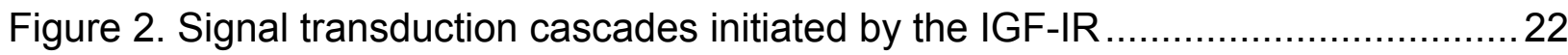

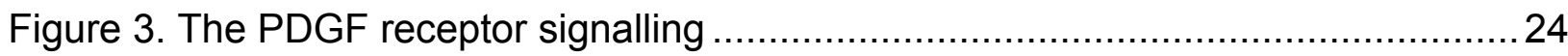

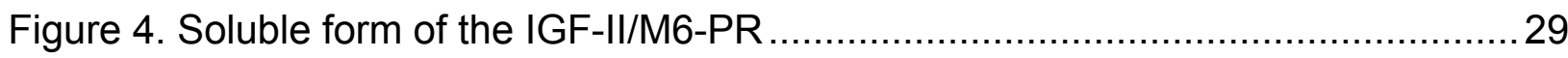

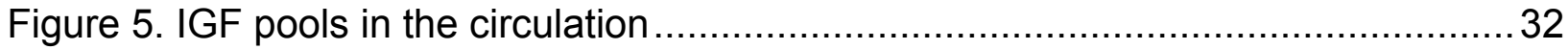

Figure 6. IGFBPs: role in tissue- and cell-specific localization of the IGFs....................33

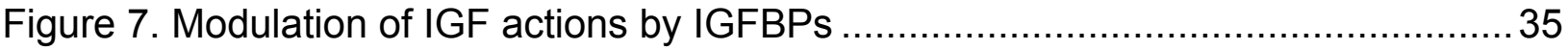

Figure 8. Role of posttranslational structural modifications of IGFBPs in modulation of

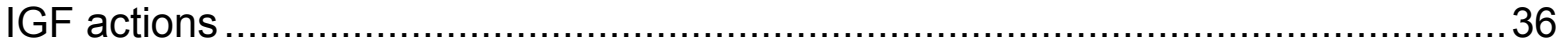

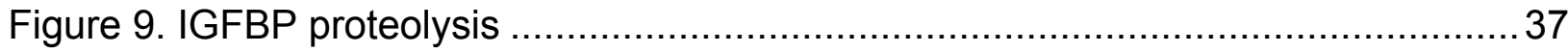

Figure 10. Role of tissue- and cell-localized IGFBP in potentiation of IGF actions........38

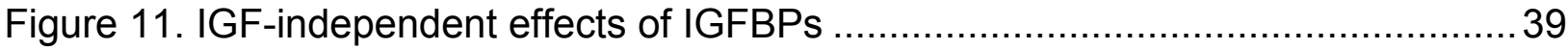

Figure 12. The liver - central organ of the IGF system ........................................... 43

Figure 13. The cellular basis of liver fibrogenesis................................................... 44

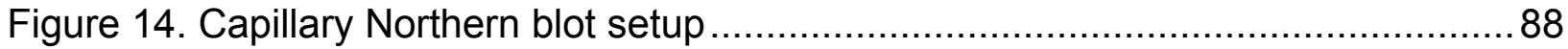

Figure 15. Morphological and cultural features of liver myofibroblasts (LMFs) ............114

Figure 16. Immunocytochemical detection of smooth muscle $\alpha$-actin, collagen type I and

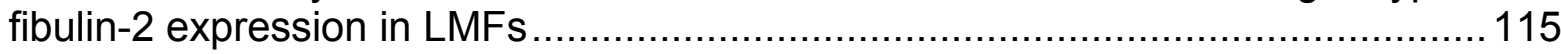

Figure 17. Secretion of fibulin-2 and collagen type I by LMFs after serial passages ... 116

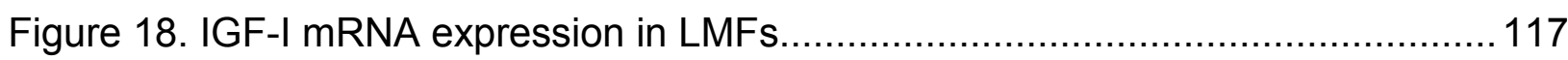

Figure 19. IGF-I receptor (IGF-IR) mRNA expression in LMFs .............................. 118

Figure 20. IGF-II/mannose 6-phosphate receptor (IGF-II/M6-PR) mRNA expression in LMFs

Figure 21. Synthesis and release of the soluble form of the IGF-II/mannose 6-phosphate receptor (IGF-II/M6-PR) in hepatocytes and LMFs....................................... 120

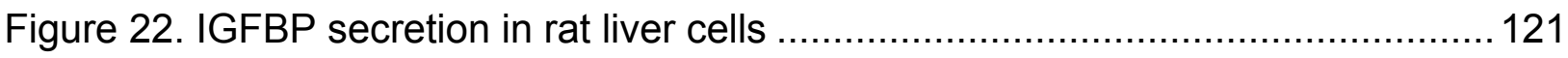

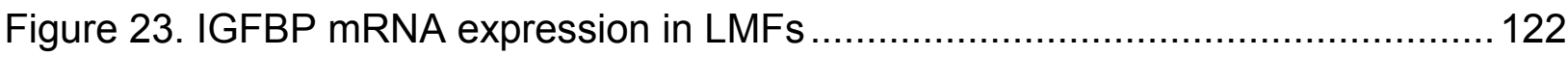

Figure 24. Effect of hormones and growth factors on IGFBP secretion in LMFs ......... 124

Figure 25. Time course of insulin and IGF-I stimulated IGFBP secretion in LMFs ...... 125

Figure 26. Dose-dependent effect of insulin and IGF-I on IGFBP secretion in LMFs.. 126

Figure 27. Time course of IGFBP mRNA expression in LMFs after treatment with insulin

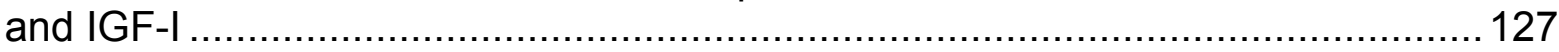

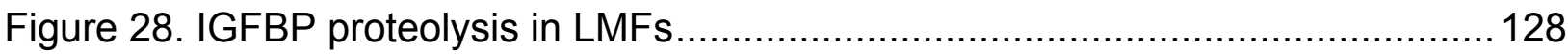

Figure 29. Effect of growth hormone, insulin and IGF-I on DNA synthesis in LMFs .... 129

Figure 30. Effect of IGF-I on synthesis of extracellular matrix proteins in LMFs.......... 130

Figure 31. Effect of rhIGFBP-3 and rhIGFBP-2 on DNA synthesis in LMFs ............... 132 
Figure 32. Intrinsic mitoinhibitory activity of IGFBP-3 in LMFs 133

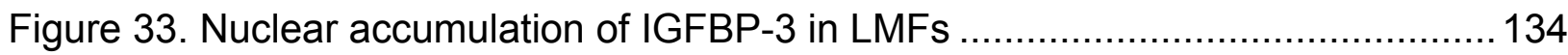

Figure 34. IGF-I-induced down-regulation of the IGF-IR in LMFs...........................136

Figure 35. PDGF receptor mRNA expression and effect of cell density on mitogenic response to PDGF-BB in LMFs

Figure 36. Effect of IGF-IR blockade on IGF-I- and PDGF-stimulated DNA synthesis in LMFs 138

Figure 37. PDGF-induced up-regulation of the IGF-IR expression in LMFs... 139

Figure 38. PDGF-induced stabilization of the IGF-IR and PDGFR mRNA expression in LMFs

Figure 39. IGF-I- and PDGF-induced tyrosine phosphorylation of the IGF-IR $\beta$ subunit, PDGFR $\alpha$ and $\beta$ subunits, IRS- 1 and PLC $\gamma_{1}$ in LMFs 141

Figure 40. Effect of MAPK pathway inhibitors on IGF-I- and PDGF-stimulated DNA synthesis in LMFs 143

Figure 41. Effect of IGF-I and PDGF-BB on MAPK activation in LMFs. 144

Figure 42. Effect of phospholipase C (PLC) inhibitor and activator on DNA synthesis in LMFs

Figure 43. Effect of IGF-IR blockade on tyrosine phosphorylation of PLC $\gamma_{1}$ in LMFs .. 146

Figure 44. Effect of PDGF-BB on synthesis of components of the IGF-IR signalling system in LMFs

Figure 45. Proposed model for the actions of IGF-I, PDGF and their receptors in liver fibrogenesis. 


\section{Abbreviations}

\begin{tabular}{|c|c|}
\hline$A b$ & antibody \\
\hline ALS & acid labile subunit \\
\hline AP & assembly protein \\
\hline APS & ammonium persulphate \\
\hline BCA & bicinchoninic acid \\
\hline bp & base pair \\
\hline BrdU & 5-bromo-2'-deoxyuridine \\
\hline BSA & bovine serum albumin \\
\hline cDNA & complementary DNA \\
\hline CM & conditioned media \\
\hline cpm & counts per minute \\
\hline $\mathrm{CsCl}$ & cesium chloride \\
\hline $\mathrm{ddH}_{2} \mathrm{O}$ & double distilled water \\
\hline DMSO & dimethyl sulfoxide \\
\hline DOK & downstream of kinase \\
\hline DTT & dithiothreitol \\
\hline ECM & extracellular matrix \\
\hline EGR & early growth response \\
\hline ERK & extracellular signal regulated kinase \\
\hline FAK & focal adhesion kinase \\
\hline$g$ & gravity \\
\hline Gab-1 & Grb2-associated binder-1 protein \\
\hline GAG & glycosaminoglycans \\
\hline GBSS & Gey's balanced salt solution \\
\hline $\mathrm{GH}$ & growth hormone \\
\hline GITC & guanidine isothiocyanate \\
\hline Grb2 & growth factor receptor bound-2 protein \\
\hline HBD & heparin-binding domain \\
\hline HPLC & high-performance liquid chromatography \\
\hline HSC & hepatic stellate cell \\
\hline $\lg$ & immunoglobulin \\
\hline IGF & insulin-like growth factor \\
\hline IGFBP & insulin-like growth factor binding protein \\
\hline IGFBP-3R & insulin-like growth factor binding protein 3 receptor \\
\hline IGFBP-rP & IGFBP-related proteins \\
\hline IGF-II/M6-PR & insulin-like growth factor II/mannose 6-phosphate receptor \\
\hline IGF-IR & insulin-like growth factor I receptor \\
\hline IR & insulin receptor \\
\hline IRR & insulin receptor related receptor \\
\hline IRS & insulin receptor substrate \\
\hline JNK & c-Jun N-terminal kinase \\
\hline kb & kilobase \\
\hline $\mathrm{KC}$ & Kupffer cell \\
\hline $\mathrm{kDa}$ & kilodalton \\
\hline KLH & keyhole limpet hemocyanin \\
\hline LB & Luria Bertani \\
\hline LN & liver myofibroblast \\
\hline & mannose 6-phosphate \\
\hline
\end{tabular}




$\begin{array}{ll}\text { MAPK } & \text { mitogen-activated protein kinase } \\ \text { MEK } & \text { MAPK/ERK kinase } \\ \text { MKK } & \text { MAP kinase kinase } \\ \text { MLK } & \text { mixed lineage kinase } \\ \text { MRNA } & \text { messenger ribonucleic acid } \\ \text { NLS } & \text { nuclear localization signal } \\ \text { NSILA } & \text { non-suppressible insulin-like activity } \\ \text { OD } & \text { optical density } \\ \text { PBS } & \text { phosphate-buffered saline } \\ \text { PCR } & \text { polymerase chain reaction } \\ \text { PDGF } & \text { platelet-derived growth factor } \\ \text { PDGFR } & \text { platelet-derived growth factor receptor } \\ \text { PDK } & \text { phosphoinositide-dependent kinase } \\ \text { PH } & \text { pleckstrin homology } \\ \text { PI3-K } & \text { phosphatidylinositol 3-kinase } \\ \text { PKB } & \text { protein kinase B } \\ \text { PKC } & \text { protein kinase C } \\ \text { PLC } & \text { phospholipase } \\ \text { PMSF } & \text { phenylmethanesulfonyl fluoride } \\ \text { PTB } & \text { phosphotyrosine binding } \\ \text { RNA } & \text { ribonucleic acid } \\ \text { rRNA } & \text { ribosomal RNA } \\ \text { RT } & \text { room temperature } \\ \text { RXR } \alpha & \text { retinoid X receptor } \alpha \\ \text { SDS } & \text { sodium dodecyl sulphate } \\ \text { SDS-PAGE } & \text { sodium dodecyl sulphate polyacrylamide gel electrophoresis } \\ \text { SEC } & \text { sinusoidal endothelial cell } \\ \text { SH2 } & \text { Src homology } \\ \text { ShC } & \text { Src-Homology-Collagen protein } \\ \text { SIGF-II/M6-PR } & \text { soluble IGF-ll/M6-PR } \\ \text { SMA } & \text { smooth muscle actin } \\ \text { T及R-V } & \text { type V TGF- } \beta \text { receptor } \\ \text { TAE } & \text { Tris/Acetate/EDTA buffer } \\ \text { TEMED } & \text { tetramethyl ethylene diamine } \\ \text { TGF- } \beta & \text { transforming growth factor } \beta \\ \text { TGN } & \text { trans-Golgi network } \\ \text { URL } & \text { untranslated region } \\ & \end{array}$




\section{Summary}

Hepatic stellate cells (HSCs) and liver myofibroblasts (LMFs) represent major cell populations involved in liver fibrogenesis. Several lines of evidence demonstrate that in contrast to LMFs, HSCs undergo spontaneous apoptosis both in vitro and in vivo, in parallel with their activation. Therefore, LMFs appear to be an essential cell type with the fibrogenic potential in the liver. The IGF system including the insulin-like growth factors I and II (IGF-I, -II), their receptors (IGF-I receptor, IGF-IR; IGF-II/mannose 6phosphate receptor, IGF-II/M6-PR) and six high affinity IGF binding proteins (IGFBPs) participate in the regulation of growth and differentiation of cells of the fibroblast lineage, possibly contributing to the fibrogenic process. Therefore, the purpose of the current work was to study the expression and regulation of the IGF axis components in rat LMFs. Since IGF-I is known as a progression factor for the growth-promoting effects of platelet-derived growth factor (PDGF) in many cell types, the aim of this work was also to study the role of PDGF in proliferation of LMFs and to investigate a possible crosstalk between PDGFR and IGF-IR signalling systems in rat LMFs.

LMFs from passages 1 to 7 constitutively expressed transcripts encoding IGF-I, IGF-IR and IGF-II/M6-PR. A soluble form of the IGF-II/M6-PR was abundantly produced by LMFs, and its release was stimulated by IGF-II and transforming growth factor $\beta$ (TGF$\beta$ ). In LMFs, biosynthesis of IGFBP-3 and -2 was observed that was stimulated by IGF-I, insulin and TGF- $\beta$ and inhibited by PDGF-BB. During cultivation of LMFs IGFBP-3 gene expression was down-regulated, whereas that of IGFBP-2 was up-regulated.

IGF-I stimulated de novo synthesis of type I collagen and had mitogenic activity, whereas long-R ${ }^{3}-I G F-I$, an IGF-I analogue which binds to the IGF receptors but not to IGFBPs, had no effect on DNA synthesis in LMFs. Simultaneous addition of recombinant human IGFBP-2 or -3 with IGF-I diminished the mitogenic effects of IGF-I on LMFs, whereas preincubation of LMFs with IGFBP-2 or -3 potentiated DNA synthesis induced by IGF-I. Exogenous IGFBP-3 revealed also mitoinhibitory activity in LMFs that was independent from IGF-I. Moreover, a relatively high amount of endogenous IGFBP-3 in LMFs was accumulated in the nucleus that might be linked with the intrinsic antiproliferative activity of IGFBP-3.

Recombinant PDGF-BB stimulated DNA synthesis in LMFs and this effect was similar to that of IGF-I. Blockade of the IGF-IR with a selective inhibitor completely abrogated IGF-I- and PDGF-induced mitogenesis in cultures of rat LMFs. In rat liver, $\alpha$ and $\beta$ 
subunits of the PDGF receptor (PDGFR) were exclusively expressed in HSCs and LMFs, and were substantially up-regulated during their in vitro cultivation. IGF-I and PDGF-BB differentially affected the IGF-IR and PDGFR signalling systems. High concentrations of IGF-I induced down-regulation of the IGF-IR and decreased amount of IRS-1, a principal adaptor protein of the IGF-IR. Expression and activation of the PDGFR $\alpha$ was also inhibited by IGF-I. In contrast, PDGF-BB increased the IGF-IR expression and effectively prevented its IGF-I-induced down-regulation. However, PDGF-BB inhibited the IGF-I-induced tyrosine phosphorylation of IRS-1 and substantially decreased the abundance of several IRS proteins in the cell, in particular IRS-1, IRS-2 and Gab-1. PDGF-BB did not affect expression of the PDGFR. Transphosphorylation of the PDGFR and the IGF-IR was not observed in LMFs. PDGFBB effectively induced phosphorylation of all terminal MAP kinases (ERK1/2, JNK, p38 kinase) in LMFs in contrast to IGF-I, which had only a weak effect. Inhibition of MEK, p38 kinase and JNK effectively blocked IGF-I-induced DNA synthesis in LMFs. Inactivation of JNK and p38 kinase also resulted in abrogation of mitogenic effects induced by PDGF-BB. However, the rate of PDGF-induced DNA synthesis was unaffected when phosphorylation of ERK1/2 was blocked. Inhibition of phospholipase $C$ (PLC) in LMFs was associated with a substantial reduction of both PDGF- and IGF-Iinduced DNA synthesis, although in LMFs PLC $\gamma_{1}$ was activated only in response to PDGF-BB, but not to IGF-I. Blockade of the IGF-IR kinase considerably impaired the ability of PDGF-BB to stimulate PLC $\gamma_{1}$ activity in LMFs.

In conclusion, the present study demonstrates that the IGF axis via complex interactions with the PDGFR signalling system may play an important role in the proliferation of LMFs in vitro that might be relevant in vivo for fibroproliferative response during acute and chronic liver injury. 


\section{Introduction}

\subsection{IGF System}

The insulin-like growth factors (IGFs; IGF-I and IGF-II) are structurally related molecules that play essential roles in the regulation of metabolic, proliferative, and differentiation processes mediated by endocrine, autocrine and paracrine mechanisms (Rajaram et al., 1997; LeRoith, 1995). The IGF family is comprised of ligands (IGF-I, IGF-II, and insulin), six well characterized high affinity binding proteins (IGFBP-1 through -6), and cell surface receptors that mediate the biological functions of the ligands (LeRoith, 2001). These transmembrane receptors include the IGF-I receptor (IGF-IR), IGFII/mannose 6-phosphate receptor (IGF-II/M6-PR), insulin receptor (IR) and recently described insulin receptor related receptor (IRR).

\subsection{Insulin-like Growth Factors}

In 1957, a growth factor was identified that was originally designated as „sulphation factor" (Salmon and Daughaday, 1957) because it was capable to stimulate ${ }^{35} \mathrm{~S}$ incorporation into rat cartilage. Froesch et al. (1963) described the non-suppressible insulin-like activity (NSILA) of two soluble serum components (NSILA I and II). In 1972, the names sulphation factor and NSILA were replaced by the term "somatomedin", denoting a substance under control and mediating the effects of growth hormone $(\mathrm{GH})$ (Daughaday et al, 1972). In 1976, two active substances were isolated from human serum, which due to their structural resemblance to proinsulin were renamed „insulinlike growth factors I and II" (Rinderknecht and Humbel, 1976). Both IGFs are polypeptides that share $62 \%$ homology with proinsulin. However, in contrast to insulin and other peptide hormones, they are not stored within cells of a specific tissue but are produced by almost any cell in the body and circulate in approximately 1,000-fold higher concentrations than most other known peptide hormones (D'Ercole and Wilkins, 1984). These properties point to a more universal function of the IGFs in the organism compared with the more specific metabolic role of insulin. 


\subsubsection{IGF-I}

The prepro-IGF-I gene consists of six exons in most mammalian species and is located on the long arm of chromosome 12 in humans. The coding region of prepro-IGF-I is flanked by complex $5^{\prime}$ - and $3^{\prime}$-untranslated regions that results in considerable heterogeneity in mature IGF-I transcripts. For instance, it has been demonstrated that separate start sites present in exon 1 and exon 2 in rat. In exon 1 transcription can be initiated from several different sites over a several hundred base pair region. This broad range of sites exists because there are no core promoter elements such as TATA and CAAT box motifs in exon 1. TATA and CAAT box motifs elements, however, are present upstream of the cluster of start sites present in exon 2. Nevertheless, in most tissues, the majority of transcripts arise from sites in exon 1. A variety of messenger ribonucleic acids (mRNAs), a result of transcription from different promoter sites as well as alternative splicing and alternative polyadenylation, eventually encode for 4 precursor proteins, which result in only one single molecule of IGF-I consisting of 70 amino acids with a molecular weight of 7649 Da (Rinderknecht and Humbel, 1978; Adamo et al., 1993). Similar to insulin, IGF-I molecule has $A$ and $B$ domains connected by disulphide bonds. The $C$ domain connecting $A$ and $B$ domains has 12 amino acids, and a unique $D$ domain is present at the carboxy-terminal end and contains 8 amino acid (Rotwein et al., 1986). The alternative splicing of IGF-I RNA creates carboxy-terminal extension peptides, the E-peptides, which are not part of the mature IGF-I molecules. In addition, there is a truncated form of IGF-I that lacks first three $\mathrm{N}$-terminal amino acids after cleavage from the prepro-IGF-I. This truncated IGF-I has been identified in human brain and has a higher mitogenic potency than the full-length form, perhaps because it does not bind to IGFBPs (Carlsson-Skwirut et al., 1989).

Most of the circulating IGF-I is produced by the liver, although other tissues are capable to synthesize this peptide locally. Therefore, IGF-I has characteristics of both a circulating hormone and a tissue growth factor. Hepatic production of IGF-I is complex. $\mathrm{GH}$, which is produced by the pituitary gland under the regulation of the hypothalamic factors somatostatin and growth-hormone-releasing hormone (GHRH), has a dominant role in induction of IGF-I gene expression, but its stimulatory influence is markedly attenuated by malnutrition (Pollak et al., 2004). IGF-I, in turn, feeds back and negatively regulates the GH secretion from the pituitary (Tannenbaum et al., 1983). GH-regulated circulating IGF-I levels are considered to be the major regulator of postnatal growth. However, recent gene-targeting studies in mice have shown that liver-specific deletion 
of the IGF-I gene using Cre/loxP recombination system reduced the serum IGF-I concentration to approximately $25 \%$. The growth rates and phenotype of these animals were not significantly different compared with wild-type animals (Yakar et al., 1999; Sjögren et al., 1999). This data points to the importance of extrahepatic, autocrine/paracrine production of IGF-I in growth regulation.

\subsubsection{IGF-II}

Human prepro-IGF-II gene consists of nine exons and is located on chromosome 11. The first six exons are noncoding. There are four promoters (P1-4), each promoter is located upstream of exons 1, 4, 5 and 6. A distinct activation pattern of different promoters correlates with IGF-II expression during development. Promoters P2, P3 and P4 are active in fetal liver, whereas after birth activities of P2-P4 decrease and P1 becomes dominant. The IGF-II gene is one of the few known genes with parental allelespecific expression and therefore is referred to as an imprinted gene. In normal cells IGF-II is maternally imprinted and is expressed only from paternal copy of the gene, whereas maternal allele remains transcriptionally silent. Genomic imprinting is an early event occurring during gametogenesis, and is an example of an epigenetic change that is a heritable change in phenotype that does not result from a change in DNA nucleotide sequence. During the formation of germ cells, genes subject to imprinting are marked by methylation according to whether they are present in a sperm or an egg. In this way, the parental origin of the gene can be subsequently detected in the embryo. DNA methylation is used as a mark to distinguish two copies of a gene that might be otherwise identical and to regulate their expression accordingly. In the case of IGF-II, methylation of an insulator element on the paternally derived chromosome blocks its function and allows a distant enhancer to activate transcription of the IGF-II gene. On the maternally derived chromosome, the insulator is not methylated and the IGF-II gene is therefore not transcribed. Physiological implication of genomic imprinting is unclear, however loss of IGF-II imprinting, frequently detected in a variety of tumors (Khandwala et al., 2000), results in biallelic expression of IGF-II, thereby leading to overexpression of IGF-II.

Serum concentrations of IGF-II are higher than IGF-I (400-600 versus 100-200 ng/ml) in humans of all ages (Moschos and Mantzoros, 2002). Circulating IGF-II levels are relatively stable after puberty and not regulated by GH. IGF-II has proliferative and antiapoptotic actions similar to IGF-I since its effects are mediated via the IGF-IR 
(O’Dell and Day, 1998). However, IGF-II plays a fundamental role in embryonic and fetal growth, whereas its role in postnatal period of life is less important as it is substituted by IGF-I. This observation was effectively proved in knockout mouse models for IGF-I, IGF-II and IGF-IR, alone or in combination (Baker et al., 1993). A possible explanation for the relatively lower importance of IGF-II in postnatal life might be the 2to 15-fold lower affinity of IGF-II for the IGF-IR and the equal or greater affinity of IGFBPs for IGF-II than for IGF-I. The combination of higher affinity to binding proteins and lower affinity to the receptor results in relatively more IGF-I than IGF-II interacting with the IGF-IR.

\subsection{Receptors}

\subsubsection{IGF-I Receptor and Insulin Receptor}

\subsubsection{Structure and Ligand Specificity of IGF-I and Insulin Receptors}

Most of the actions of both IGF-I and IGF-II are mediated via the IGF-IR, which is very similar in structure with IR showing approximately $60 \%$ homology at the amino acid level (Ullrich et al., 1986). The IGF-IR and IR belong to the large family of cell surface receptors possessing intrinsic tyrosine kinase activity. The two receptors are structurally related and are composed of two $\alpha$-subunits localized entirely extracellularly and two $\beta$ subunits spanning the membrane and localized primarily intracellularly (Steele-Perkins et al., 1988). Both subunits are glycoproteins linked together by disulfide bonds. They assemble a $\alpha_{2} \beta_{2}$-configuration with ligand binding primarily mediated by the $\alpha$-subunits,

which form a binding pocket. Binding of the ligand to the $\alpha$-subunit leads to conformational changes resulting in stimulation of the $\beta$-subunit intrinsic tyrosine kinase activity with subsequent multisite phosphorylation of the $\beta$-subunit (Sasaki et al., 1985). The prevalent concept is that insulin and the IGFs act as bivalent ligands, both IGF-IR and IR are capable of binding insulin and IGF-I, though each receptor binds its own ligand with a 100-1000 fold higher affinity than the heterologous peptide (Dupont and LeRoith, 2001a). Therefore, it is not surprising that insulin in high doses can bind to the IGF-IR and mimic the effects of IGF-I, and on the contrary, at higher IGF concentrations, the IR can also be stimulated (Jones and Clemmons, 1995; LeRoith et al., 1995). In cells expressing both receptor genes, hybrid insulin/IGF-I receptors can form, comprising an insulin $\alpha$ - $\beta$-half-receptor (,hemireceptor“) and an IGF-I 
"hemireceptor" (Moxham and Jacobs, 1992). The hybrid receptors have ligand specificity profiles more comparable to the IGF-IR than to the IR since they bind IGF-I with an affinity similar to the IGF-IR, but insulin with a much lower affinity (Jones and Clemmons, 1995; LeRoith et al., 1995; Pandini et al., 1999). Moreover, recent evidence suggests that the IR is also responsible for some of the mitogenic actions of IGF-II (Louvi et al., 1997; Morrione et al., 1997). IGF-II is an agonist of the A-isoform of the IR that lacks a 12-amino acid sequence 717-729 encoded by exon 11 due to alternative splicing. This splice variant of the IR is expressed at high levels in fetal and neoplastic tissues (Frasca et al., 1999). IRR and hybrid IR/IRR have not yet been extensively studied, and their ability to bind all the different insulin-like peptides as well as their biological significance remains unclear (Nakae et al., 2001).

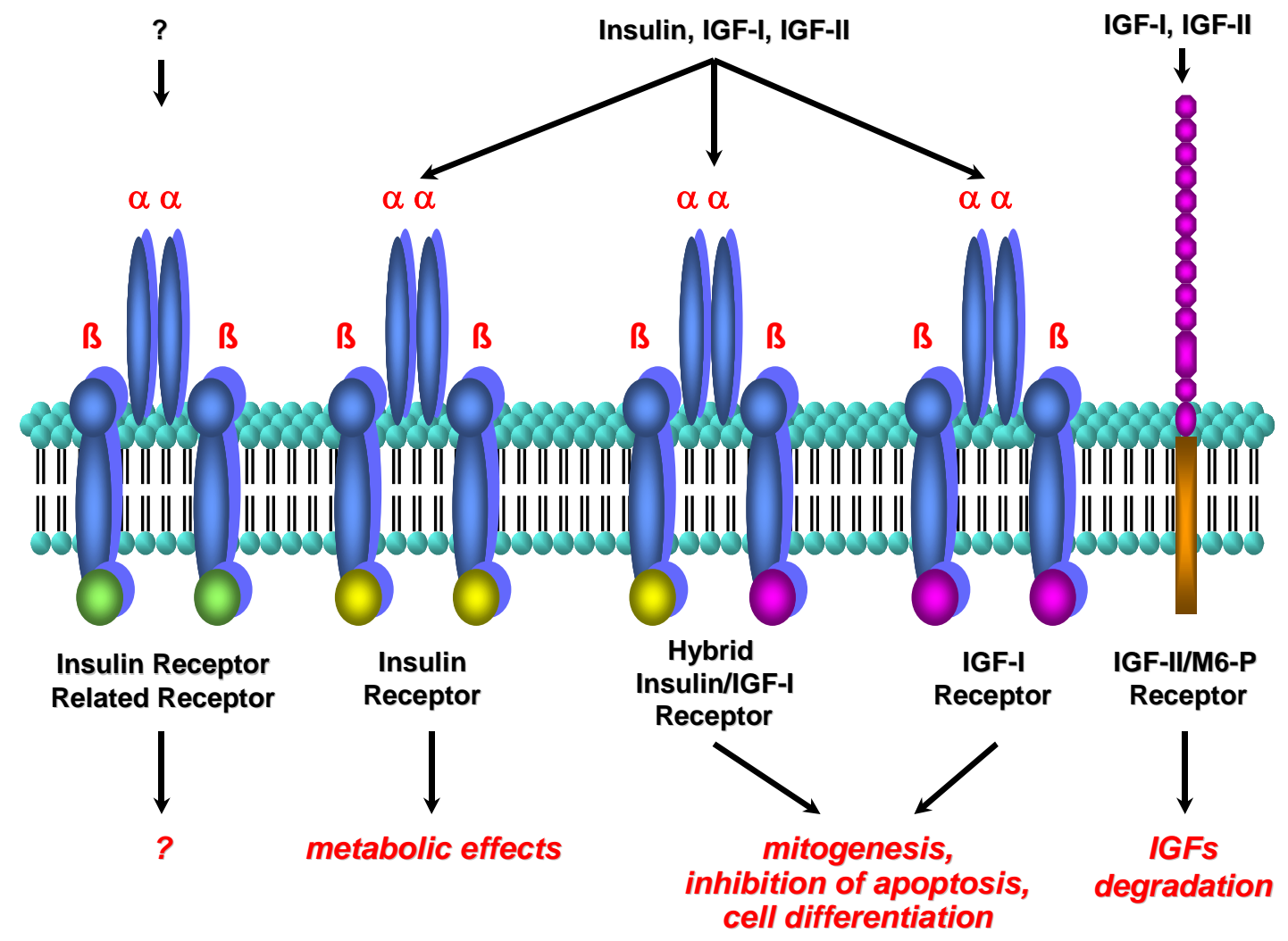

Figure 1. Receptors as components of the IGF axis. The insulin receptor (IR), insulin-like growth factor I receptor (IGF-IR) and insulin receptor related receptor (IRR) are heterotetrameric complexes composed of extracellular $\alpha$-subunits that bind the ligands, and $\beta$-subunits that anchor the receptor in the membrane and that contain tyrosine kinase activity in their cytoplasmic domains. Hybrids consist of a hemireceptor from both IR and IGF-IR. The IGF-II/M6-PR is not structurally related to the IGF-IR and IR or the IRR, having a short cytoplasmic tail and no tyrosine kinase activity. IR is responsible for metabolic effects, whereas IGF-IR and hybrid IR/IGF-IR for cell growth, survival and differentiation. The insulin-like growth factor II/mannose 6-phosphate receptor (IGF-II/M6-PR) functions as scavenger receptor and is responsible for uptake and degradation of the IGFs. This receptor is not considered to have any role in IGF signalling. 


\subsubsection{Structure and Expression of IGF-I Receptor Gene}

The human IGF-IR is the product of a single copy gene located at bands q25 $\rightarrow 26$ at the distal end of chromosome 15 (Abbott et al., 1992). This gene spans more than 100 kilobase pairs $(\mathrm{kb})$ of genomic DNA and contains 21 exons. The exon/intron organization of the IGF-IR gene is strikingly similar to that of the IR gene (Ullrich et al., 1986). The IGF-IR is organized into functional domains that reflect the exonic arrangement of the gene: exons 1-3 code for the $5^{\prime}$-untranslated region (URL), the signal peptide, the non-cysteine-rich $\mathrm{N}$-terminal region, and the cysteine-rich domain of the $\alpha$-subunit, a region that is mainly involved in ligand binding. Exons 4-10 encode the remainder of the $\alpha$-subunit. Exon 11 encodes the Arg-Lys-Arg-Arg peptide cleavage site that generates the $\alpha$ - and $\beta$-subunits from the polypeptide precursor. The region exhibiting the highest amino acid identity in the IGF-IR and IR (80-95\%) is the tyrosine kinase domain in the $\beta$-subunit, encoded by exons 16-20. Comparison of human and rat IGF-IR cDNAs revealed identities of $98 \%$ in the tyrosine kinase domain and $85 \%$ in the C-terminal domain (Pedrini et al., 1994). Northern blot hybridization of human mRNA with an IGF-IR cDNA probe yielded two bands of 11 and $7 \mathrm{~kb}$, although only an 11-kb band was detected in rat tissues (Ullich et al., 1986; Lowe et al., 1989). The IGF-IR mRNA is a low-abundance transcript, although its distribution range includes virtually every tissue and cell type (Bondy et al., 1990; Werner et al., 1989). The highest levels of the IGF-IR mRNA are seen at embryonic stages, and it decreases to much lower levels in the adult animal. In the adult rat, the highest levels of the IGF-IR mRNA are observed in the central nervous system with intermediate levels found in kidney, stomach, testes, lung and heart. No IGF-IR mRNA expression is seen in the liver, the major source of circulating IGF-I in the body.

Control of transcription is a key step in the regulation of gene expression. Different physiological and pathological stimuli that affect the expression of the IGF-IR gene have been shown to act at the level of transcription. The promoter region of the IGF-IR gene has been cloned and sequenced and is highly conserved between human and rodent species. The IGF-IR promoter lacks TATA or CAAT motifs. These two elements, which are generally required for accurate positioning of the transcription machinery and for efficient transcription initiation, are absent in the promoters of many "housekeeping" genes, a class of ubiquitously expressed genes. In spite of the lack of these two regulatory elements, transcription of the IGF-IR gene starts from a unique site within an "initiator" motif, whereas transcription of the IR gene, which also lacks TATA and CAAT 
boxes, starts from multiple sites. The initiator is a discrete promoter element that can direct specific transcription initiation from an internal site in the absence of a TATA element. Initiator elements have been described in genes, which like the IGF-IR, are highly regulated during differentiation and development.

The initiator element is located 940 base pairs (bp) upstream of the ATG translation start codon in the rat gene and $\sim 1000 \mathrm{bp}$ upstream of the coding region in the human gene. Thus, the IGF-IR gene encodes one of the longest $5^{\prime}$-UTRs in eukaryotic genes. The IGF-IR $5^{\prime}$-UTR has the potential to form significant secondary structures, including a number of hairpin structures. In addition, an 84-bp open reading frame that begins and ends within the $5^{\prime}$-UTR at positions $741-824$ has been identified. The function of this long $5^{\prime}-U T R$ has not yet been clarified, although it has been shown that many of the genes containing these large, highly structured $5^{\prime}$-UTRs are involved in the regulation of cellular proliferation. These include growth factors, their receptors, and oncogenes.

Like the $I R$ gene and other widely expressed genes, the proximal 5'-flanking region and most of the $5^{\prime}$-UTR of the IGF-IR gene is extremely GC-rich ( $\left.80 \%\right)$. This region contains several GC boxes (GGGCGG), which are putative binding sites for transcription factor $\mathrm{Sp1}$, as well as potential binding sites for transcription factors of the early growth response (EGR) family (GCGGGGGCG) (LeRoith et al., 1995).

\subsubsection{Signal Transduction Pathways Induced by IGF-I and Insulin Receptors}

Upon activation, the IGF-IR and IR undergo multisite autophosphorylation on intracellular tyrosine residues and activation of the receptor intrinsic tyrosine kinases. For the IGF-IR and the IR, the tyrosine autophosphorylation sites are found at homologous positions in the corresponding domains. For both receptors a cluster of three key tyrosine residues (Y1131, Y1135 and Y1136 in the IGF-IR, and Y1146, Y1150 and $\mathrm{Y} 1151$ in the IR) resides in the kinase catalytic domain and forms a regulatory loop. One key tyrosine residue, Y950 in the IGF-IR (Y960 in the IR), is located in the juxtamembrane domain. When phosphorylated, this tyrosine is part of a recognition motif for several insulin receptor substrates. The $\mathrm{COOH}$-terminus of the IGF-IR contains only one autophosphorylation site, Y1316, whereas the IR contains two autophosphorylation sites, Y1316 and Y1322. The role of the carboxy-terminal tyrosines is not clear, but they can be involved in generation of some differences in signalling between the IR and IGF-IR (Van Obberghen, 1994; Tartare et al., 1994). 
Several lines of evidence indicate that the receptor tyrosine kinase activity, and its multisite autophosphorylation is essential for the biological activity and action of the insulin receptor and the IGF-I receptor (Kahn and White, 1988; Yarden and Ullrich, 1988; Van Obberrghen, 1994).

Activated receptors subsequently phosphorylate other tyrosine-containing cellular substrates. At present the family of IR and IGF-IR substrates includes two major groups of proteins: (1) insulin receptor substrate (IRS) proteins IRS-1, IRS-2, IRS-3, IRS-4 and related to them recently identified proteins referred to as downstream of kinase (DOK), namely IRS-5/DOK4 and IRS-6/DOK5; (2) IRS-like proteins such as Src-HomologyCollagen (Shc) proteins, growth factor receptor bound-2 (Grb2) associated binder-1 (Gab-1) and p62 ${ }^{\text {dok }}$. The IRS proteins lack intrinsic catalytic activity. However, they have (1) N-terminal pleckstrin homology $(\mathrm{PH})$ domain, (2) phosphotyrosine binding (PTB) domain and (3) domain containing several potential tyrosine phosphorylation sites. Upon phosphorylation they serve as binding sites for $\mathrm{SH}_{2}$ domain containing proteins such as adapters for phosphatidylinositol 3-kinase (PI3-K), Grb2 and SHP2. PH domains are considered to bind to acidic motifs in various proteins or to cell lipids in cell membranes, while PTB domains recognize phosphorylated NPXY motifs in proteins. Three Shc proteins (p46, p52 and p66) contain a N-terminal PTB domain, a central glycine and proline rich region homologous to the $\alpha_{1}$ chain of collagen, and carboxyl terminal $\mathrm{SH}_{2}$ domain. In contrast to IRS proteins, Gab-1 does not contain PTB domain and therefore does not directly interact with the receptor, but has $\mathrm{PH}$ domain and a domain with several tyrosine phosphorylation sites. p62 ${ }^{\text {dok }}$ was first detected in chronic myelogenous leukaemia progenitor cells as a constitutively tyrosine-phosphorylated protein. It undergoes phosphorylation induced by several receptor tyrosine kinases, including the IR, but its contribution to insulin and the IGFs action remains unclear.

Although the role of these scaffold proteins merits attention, recent works with transgenic and knockout mice suggest that many responses induced by insulin and the IGFs, especially those that are associated with growth and metabolism, are predominantly mediated through IRS-1 and IRS-2. Being docking proteins, they bring together and coordinate the activity of other adapter proteins, finally resulting in activation of two principal downstream signalling cascades including PI3-K and mitogenactivated protein kinase (MAPK) pathways.

The PI3-K is a dimer which exists as a complex of p85 $\left(\mathrm{SH}_{2}\right.$-containing regulatory subunit) and p110 (catalytic subunit). It is activated when the phosphorylated YMXM 
motifs in IRS proteins occupy both $\mathrm{SH}_{2}$ domains in its regulatory subunit. In the cell membrane the activated PI3-K generates formation of phosphatidylinositol-3,4,5triphosphate from phosphatidylinositol-4,5-biphosphate, which recruits to the plasma membrane particular serine kinases known as phosphoinositide-dependent kinase (PDK1 and PDK2) and activates them. In turn, activated PDK1 and PDK2 promote membrane translocation of some protein kinase $B(P K B)$ isoforms and phosphorylate them. Activated PKB, also known as Akt, is a key target in the PI3-K pathway, which phosphorylates a variety of substrates involved in the regulation of different biological processes including glucose transport, protein synthesis, glycogen synthesis, cell proliferation and cell survival (Dupont and LeRoith, 2001a; White, 2002).

Alternatively, activated IRS proteins also initiate the MAPK pathway. The MAP kinases are a family of serine-threonine kinases that are activated in response to a variety of stimuli (Su and Karin, 1996). The first members identified in the family were p42 and p44 extracellular signal regulated kinases (ERK), now known as ERK1 and ERK2, respectively. After activation, IRS proteins recruit $\mathrm{Grb2}$, an $\mathrm{SH}_{2}$-containing substrate which binds mSOS, a nucleotide exchange factor for Ras that converts Ras from its inactive GDP-bound form to its active GTP-bound form. Ras-GTP interacts directly with the regulatory $\mathrm{N}$-terminal part of Raf-1, thereby activating the serine/threonine kinase in its C-terminus. Phosphorylation of Raf-1 activates the downstream protein kinase, MAP kinase kinase 1 (also known as MAPK/ERK kinase (MEK) or MKK1) or MAP kinase kinase 2 (MKK2). In turn, MKK 1 and 2 phosphorylate ERK1 and ERK2 that leads to activation of ERKs and their translocation to the nucleus where they phosphorylate certain transcription factors including Elk-1 and ATF-2 (De Meyts et al., 1994).

Another class of MAP kinase family members is the stress activated c-Jun N-terminal kinase (JNK). There are 10 identified isoforms of JNK originating from three homologous genes (JNK1, JNK2 and JNK3) with molecular masses of 46 or 54 kDa due to alternative splicing. JNK activation induces the phosphorylation of transcription factors, including c-Jun, Elk-1 and ATF-2, which regulate immediate early gene expression (Kyriakis et al., 1995; Gupta et al., 1996). Although JNKs are responsive mainly to stressful stimuli, several lines of evidence suggest that JNKs can also be activated in response to IGF-I (Monno et al., 2000; Walsh et al., 2002). p38 kinase is a recently described member of the MAP kinase family, which like JNK also activates several transcription factors regulating immediate early gene expression and is primarily activated by environmental stressors (Han et al., 1994). However, there 
is the wealth of evidence now demonstrating also involvement of IGF-I in p38 kinase activation in certain cell types (Cheng and Feldman, 1998; Heron-Milhavet and LeRoith, 2002; Toyoshima et al., 2004; Wu et al., 2004).

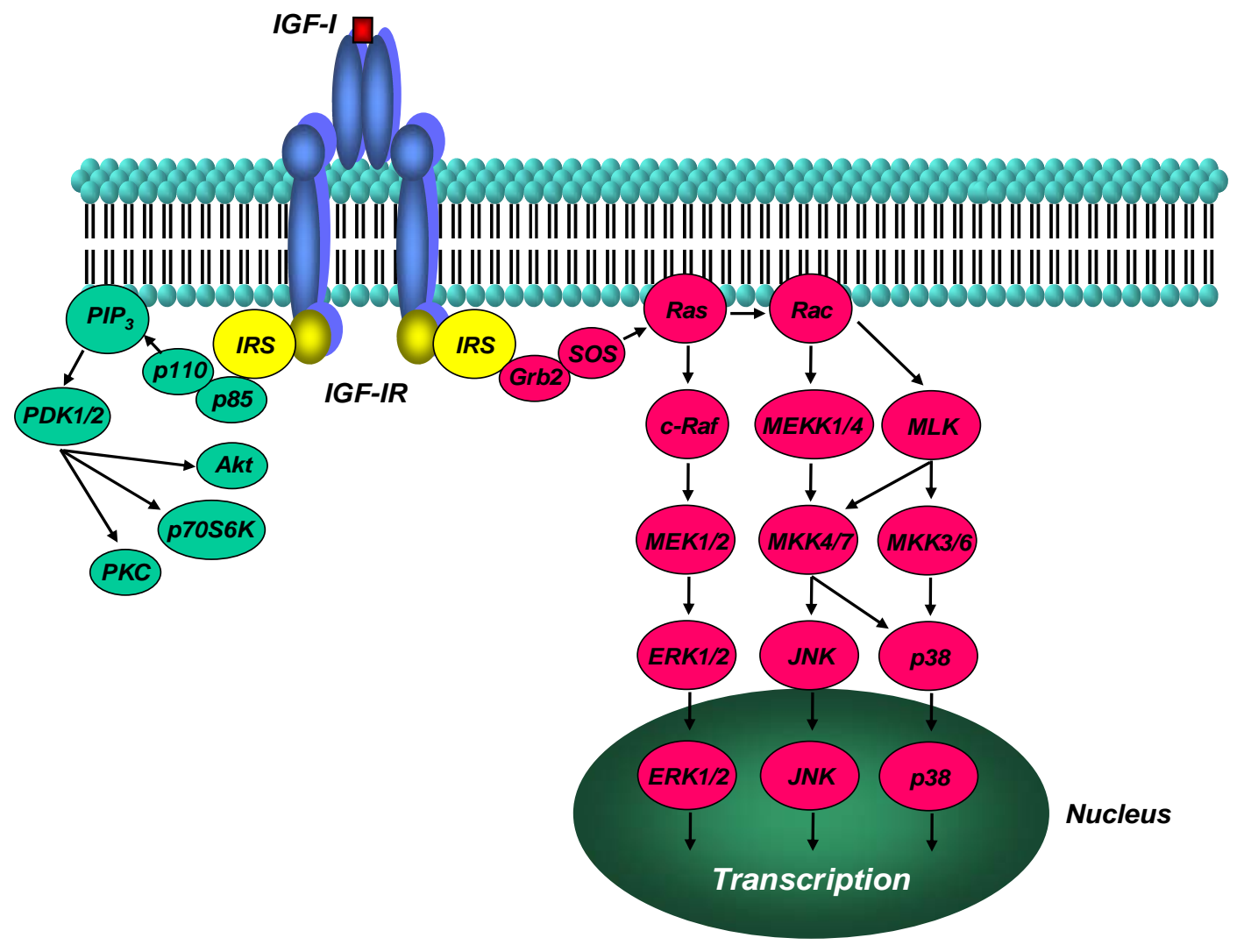

Figure 2. Signal transduction cascades initiated by the IGF-IR. Activation of the IGF-IR kinase results in receptor autophosphorylation and tyrosine phosphorylation of several docking proteins such as insulin receptor substrate (IRS) proteins. Once activated, IRS recruit Src homology 2 (SH2)-domain containing molecules such as Grb2 and the p85 subunit of phosphatidylinositol-3'-kinase (PI3-K). Grb2 via SOS stimulates the activity of the GTPases Ras and Rac, which through the phosphorylation of certain MAP kinases kinases kinases (c-Raf, MEKK1, MEKK4, MLK) and MAP kinases kinases (MEK1, MEK2, MKK3, MKK4, MKK6, MKK7) finally lead to activation of terminal MAP kinases ERK, JNK and p38 kinase. Activated MAP kinases are translocated to the nucleus where they activate a variety of transcription factors. Alternatively, the binding of the p85 and p110 subunit of PI3-K to the IRS proteins generates phospholipids that participate in activation of 3-phosphoinositide-dependent kinase (PDK) 1 and 2 . In turn, they phosphorylated several targets involved in the regulation of different biological processes including glucose transport, protein synthesis, glycogen synthesis, cell proliferation and cell survival.

Both p38 kinase and JNK pathways are initiated by activated Ras, which via activation of the membrane-associated GTPase Rac activates certain MAP kinases kinases kinases, namely MEKK1, MEKK4, and some mixed lineage kinases (MLK). In turn, they phosphorylate MAP kinases kinases 3, 4, 6 and 7 that finally results in activation of p38 kinase and JNK (Minden et al., 1995; Qiu et al., 1995; Zhang et al., 1995; Kuemmerle and Zhou, 2002).

While MAPK has been implicated in mediating mitogenic action of the IGF-I, PI3-K has been shown to be more involved in mediating the metabolic, antiapoptotic and other more differentiated effects of IGF-I (LeRoith et al., 1995; Skrtic et al., 2001; Dupont et 
al., 2001a, 2001b). IGF-I signalling pathways in different cell types have many features in common, although it has been shown that the relative importance of the different pathways can vary between cell types.

As described earlier, IRS proteins play a pivotal role in the IGF-IR/IR signalling and had until recently been considered to be exclusively membranous or cytoplasmic proteins. Recent data, however, demonstrate that substantial fractions of IRS-1 (Prisco et al., 2002; Tu et al., 2002) and IRS-2 (Sun et al., 2003) can be translocated to the nucleus in transformed cells expressing certain oncogenes (V-src, SV40 T antigen) and in IGF-Istimulated normal cells (Prisco et al., 2002; Tu et al., 2002; Sun et al., 2003). In the nucleus, IRS-1 and IRS-2 are accumulated mainly in the nucleoli, where they interact with the upstream binding factor, a protein that regulates RNA polymerase I activity, and stimulate the ribosomal DNA promoter, thereby positively regulating ribosomal RNA (rRNA) synthesis (Tu et al., 2002; Sun et al., 2003). It is speculated therefore that beside their signalling role, IRS proteins may also function as positive regulators of cell growth. In turn, there is also evidence that IRS-3 is translocated to the nucleus, and both PTB and PH domains of its molecule appear to be important for nuclear import. Furthermore, upon translocation, nuclear IRS-3 functions as a transcriptional coactivator of certain genes and, therefore, appears to play an important role in a crosstalk between IGF or insulin and other growth factors (Kabuta et al., 2002). Taken together, these data highlight a diverse range of biological activities of IRS proteins regulating cellular functions.

\subsubsection{Cooperation between IGF-I and PDGF Receptors}

The transactivation of heterologous receptors has become an emerging theme in the complex field of receptor-mediated signal transduction. Evidence for both direct and indirect interaction between the IGF-IR and other growth regulatory signals such as epidermal growth factor (Coppola et al., 1994; Hallak et al., 2002), platelet-derived growth factor (DeAngelis et al., 1995), vascular endothelial growth factor (Gray et al., 2003), basic fibroblast growth factor (Hernandez-Sanchez et al., 1997; Scheidegger et al., 1999), growth hormone (Huang et al., 2004), angiotensin II (Scheidegger et al., 1999; Zahradka et al., 2004), estrogens (Yee and Lee, 2000) and progesterone (Cui et al., 2003) has been demonstrated, thereby expanding the traditional view of highly specific IGF-IR/IGF interactions and rendering the IGF-IR central in cellular response. In terms of liver physiology, an interaction between the IGF-IR and platelet-derived growth 
factor (PDGF) signalling system is of particular interest because it is well known that expression of PDGF receptor (PDGFR) strongly correlates with the severity of histological lesions and collagen deposition in liver cirrhosis (Pinzani et al., 1996).

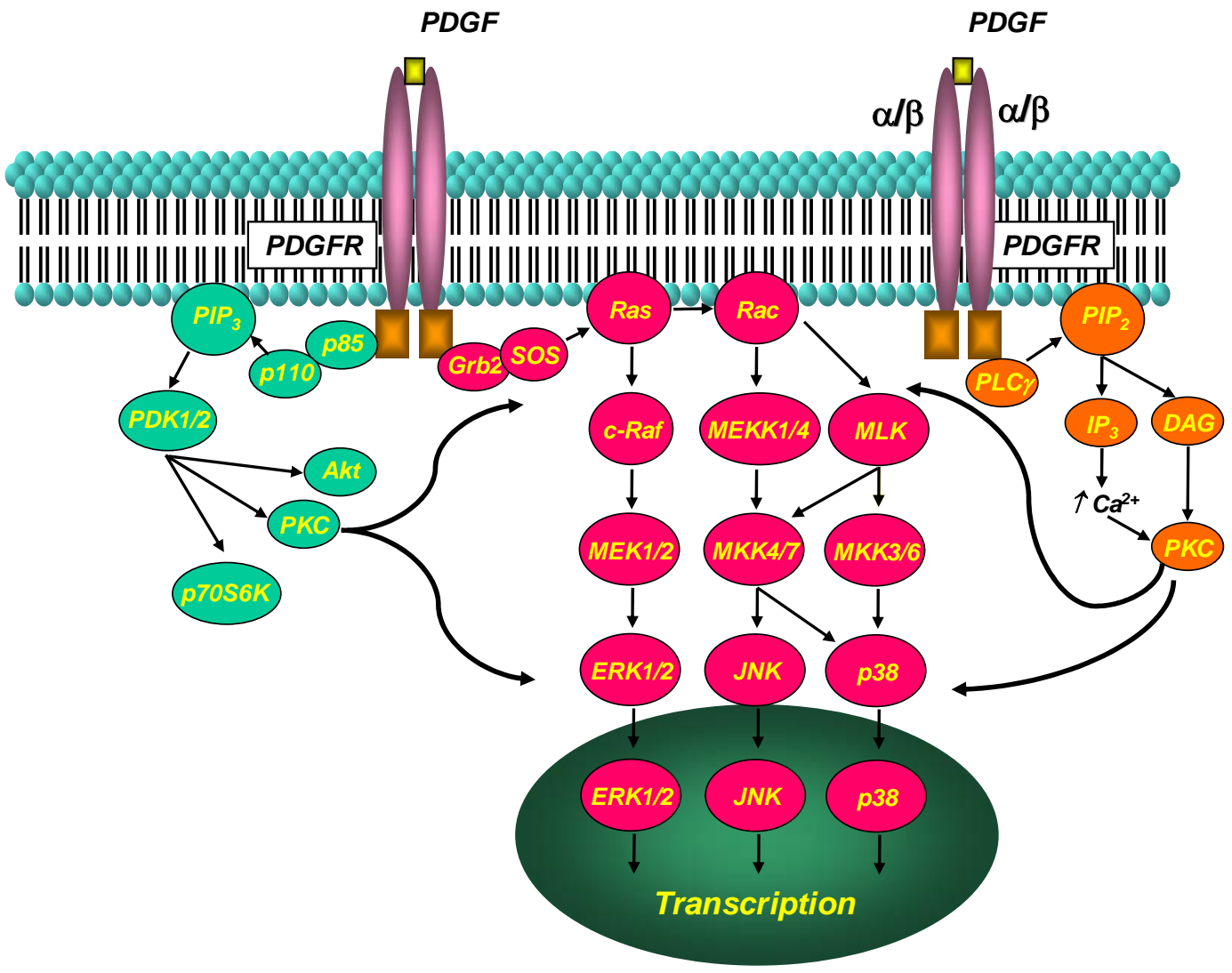

Figure 3. The PDGF receptor signalling. In contrast to the IGF-IR, the PDGFR is a dimer which consists of two subunits. Each subunit has both binding capability and intrinsic kinase activity. There are alpha and beta subunits that differ in their affinity for a ligand, and their different combination leads to a formation of three types of PDGF receptor: PDGFRaa, PDGFR $\beta$ and PDGFR $\beta$. Phosphorylation of the PDGFR also results in activation of PI3-K and MAPK pathways. However, in contrast to the IGF-IR, the PDGFR can recruit Grb2 and PI3-K directly, without IRS proteins and, in addition, the PDGFR recruits PLC gamma 1 (PLC $\gamma)$, which after its activation generates degradation of certain lipids in cell membrane that together with activated PI3-K pathway finally leads to activation of certain isoforms of protein kinase C (PKC), which can effectively potentiate MAPK pathway by regulating proximal and distal components of this signalling cascade.

PDGFR also belongs to the family of receptor tyrosine kinases. However, there are some principal structural and functional differences between the PDGF receptor (PDGFR) and the IGF-IR. In contrast to the IGF-IR which is a tetrameric complex, the PDGFR is a dimer consisting of two subunits. Each subunit has both binding capability and intrinsic tyrosine kinase activity. There are alpha and beta subunits that differ in their affinity for a ligand, and their different combination leads to the formation of three types of receptor dimers: PDGFRaa, PDGFR $\beta \beta$ and PDGFR $\beta \beta$. Upon ligand binding and receptor autophosphorylation, the activated PDGFR also induces activation of two 
principal signalling pathways: MAPK pathway that plays a pivotal role in cell growth and proliferation, and $\mathrm{PI} 3-\mathrm{K}$ pathway, which is critical for regulation of apoptosis. In contrast to the IGF-IR, which is unable to recruit Grb2 and PI3-K directly and therefore requires docking proteins (IRS proteins), the PDGFR can recruit them directly, without IRS molecules. In addition, the PDGFR recruits phospholipase C (PLC) $\gamma_{1}$, which after its activation induces lipid degradation in the plasma membrane with subsequent activation of certain members of protein kinase C (PKC) family (Heldin et al., 1998). At present, there is approximately a dozen of PKC isoforms, which can effectively potentiate MAPK pathway via regulation of proximal and distal components of this signalling cascade in a cell-type specific manner.

In mouse embryo fibroblasts, the mitogenic activity of the PDGFR depends on the IGFIR. Cells derived from mouse embryos with a targeted disruption of the IGF-IR gene were unable to proliferate by the addition of PDGF. Moreover, overexpression of the PDGF receptor beta in IGF-IR negative cells did not restore the capability of these cells to proliferate in response to PDGF. And only reintroduction of the IGF-IR into these cells restored PDGF-mediated cell proliferation (DeAngelis et al., 1995). Thus, the IGF-IR appears to be a point of convergence for mitogenic signals arising from the PDGFR. The molecular mechanisms that account for necessity of the IGF-IR for PDGF-mediated mitogenesis remain poorly understood, although it has been demonstrated that PDGF increases the promoter activity of the IGF-IR gene and also stimulates production of endogenous IGF-I in certain cell types (Clemmons, 1985; Pinzani et al., 1990; Delafontaine et al., 1991; Rubini et al., 1994). Thus, although several tyrosine kinase receptors may independently induce mitogenesis, a hierarchy may exist with the IGF-IR being both sufficient and necessary for mitosis. On the other hand, it has been demonstrated that PDGF markedly affects the insulin-induced intracellular signalling in 3T3-L1 adipocytes. For instance, PDGF induces the phosphorylation of IRS-1 in intact cells on serine and threonine residues and inhibits insulin-induced phosphorylation on tyrosine residues that results in decreased binding of p85 subunit of PI3-K to IRS-1 (Ricort et al., 1997). In this context, it appears very likely that complex cross-talk may also occur in the cell between the signalling pathways induced by PDGF and IGF-I. 


\subsubsection{IGF-II/Mannose 6-Phosphate Receptor}

The IGF-II/M6-PR is structurally distinct from the IGF-IR and is actually identical to the cation-independent mannose 6-phosphate receptor, which lacks tyrosine kinase activity and is not considered to have any role in IGF signal transduction (Braulke, 1999). The IGF-II/M6-PR is involved in uptake of lysosomal enzymes, their transporting between intracellular compartments and in their sorting in the Golgi apparatus (Wang et al., 1994; LeRoith, 2001) as well as in uptake and degradation of IGF-II (Baker et al., 1993). The IGF-II/M6-PR represents a multifunctional receptor that interacts with a variety of ligands. Many of these ligands are glycoproteins that contain mannose 6-phosphate (M6P) residues as a component of their $\mathrm{N}$-linked oligosaccharide side chains. They include numerous lysosomal enzymes and latent precursor of transforming growth factor $\beta$ (TGF- $\beta$ ) (Kornfeld, 1992). In contrast, IGF-II specifically interacts with the IGFII/M6-PR via M6P-independent mechanisms (Brown et al., 2002).

The IGF-II/M6-PR is critical for normal mammalian development. Mice that are deficient in the IGF-II/M6-PR throughout fetal development die around the time of birth from a somatic overgrowth phenotype that is accompanied by severe skeletal, heart and lung abnormalities (Lau et al., 1994; Ludwig et al., 1996; Wang et al., 1994; Wylie et al., 2003). IGF-II/M6-PR-deficient mice can be rescued by a concomitant deficiency of IGFII or the IGF-IR. This indicates that the failure to target IGF-II for lysosomal degradation via the IGF-II/M6-PR is accompanied by subsequent excessive signalling through the IGF-IR that finally results in lethal phenotype.

Almost all mammalian tissues and cell lines express the IGF-II/M6-PR with the exception of several tumor-derived cell lines. The IGF-II/M6-PR possesses the properties of a tumor suppressor gene. Tumor cell growth is inhibited when the IGFII/M6-PR expression is restored to normal level and is increased when its expression is reduced (Kang et al., 1999; O'Gorman et al., 1999; Souza et al., 1999).

In rodents, the IGF-II/M6-PR is already expressed at the two-cell stage when the IR and IGF-IR are not detectable. The IGF-II/M6-PR gene is developmentally regulated with variable expression in different tissues. The IGF-II/M6-PR is strongly expressed during tissue differentiation and organogenesis, and high levels of the IGF-II/M6-PR were found in fetal tissue, which decline in late gestation and in the early postnatal period (Sklar et al., 1989; 1992; Senior et al., 1990; Matzner et al., 1992). 
The IGF-II/M6-PR is also an imprinted gene in most viviparous mammals, and is expressed only from the maternal allele (Barlow et al., 1991). The IGF-II/M6-PR imprinting evolved approximately 150 million years ago in a common ancestor to marsupials and Eutherian mammals, but was subsequently lost about 75 million years ago in an ancestral progenitor to primates (Killian et al., 2000; Nolan et al., 2001). Thus, in contrast to mice, both copies of the IGF-II/M6-PR are functional in humans. Interestingly, in mice, the IGF-II/M6-PR is imprinted in all tissues except for the brain where both alleles are expressed ( $\mathrm{Vu}$ and Hoffman, 2000). It is highly expressed in neurons of the forebrain, in regions involved in emotional behavior, information processing and memory formation (Couce et al., 1992). It indicates that the IGF-II/M6PR can be important for the development of these brain functions. This postulate is reinforced by the identification of the IGF-II/M6-PR as the putative "IQ gene" because in children the IGF-II/M6-PR expression positively correlated with general cognitive ability (Chorney et al., 1998).

The gene coding for the IGF-II/M6-PR is located on chromosome $6 q$ 26-27 in humans and on chromosome 17 in mice. The mouse IGF-II/M6-PR gene is $93 \mathrm{~kb}$ in size and contains 48 exons. The gene contains strong minimal promoter of $266 \mathrm{bp}$ or less. An extended $54 \mathrm{bp}$ footprint within the proximal promoter containing two E-boxes and probable binding sites for Sp1, nerve growth factor-IA and related proteins has also been identified. Mutational analysis has demonstrated that each E-box contributed to more than half of the enhancer activity (Khandwala et al., 2000). The IGF-II/M6-PR protein has four structural domains: (1) N-terminal signal sequence, extracytoplasmic domain, (3) transmembrane domain, (4) C-terminal cytoplasmic tail. The IGF-II binding site is localized in the extracytoplasmic domain. This domain also contains 19 potential $\mathrm{N}$-glycosylation sites and at least two of them are utilized resulting in mature receptors of 275-300 kDa. However, glycosylation of the IGF-II/M6-PR is not required for IGF-II binding. Other posttranslational modifications such as phosphorylation and palmitoylation occur in the C-terminal domain of the receptor but their physiological implication remains, however, unclear. IGF-II binds to the IGF-II/M6PR at molar ratio of $1: 1$ and has 100-fold higher affinity compared with IGF-I (Braulke, 1999).

At steady state, the IGF-II/M6-PR is predominantly present in the endosomes and transGolgi network (TGN). Only a small fraction of this receptor is present on the cell surface. This cell-surface IGF-II/M6-PR undergoes constitutive internalization and recycling (Liu 
et al., 1999). The cycling of the IGF-II/M6-PR between TGN, endosomes and the plasma membrane occurs by vesicular transport, and is mediated by signalling elements localized mainly in the cytoplasmic domain of the receptor. Some of these signals have been identified, e.g. an internalization signal (YKYSKV; signal letter code) and the carboxy terminal dileucine motif (LLHV) required for efficient sorting of lysosomal enzymes in the TGN. The dileucine motif and a proximal casein kinase-2 phosphorylation site at a serine residue in the cytoplasmic domain of the IGF-II/M6-PR promote the recruitment of assembly protein 1 (AP1) onto Golgi membranes. The translocation of ADP-ribosylation factor ARF-1 and AP1 from the cytosol onto membranes is necessary for efficient formation of clathrin-coated vesicles. In contrast, the tyrosine-containing internalization signal forms a type $1 \beta$-turn structure which has been proposed to be required for AP2 binding followed by clathrin-coat assembly. Recently, a novel cytosolic $47 \mathrm{kDa}$ protein (TIP 47) has been identified which is required for IGF-II/M6-PR from endosomes to the TGN. This transport step is rarely shared with other cell surface receptors and needs the rab 9 GTPase and PI3-K but not clathrin coat. The identity and function of another cytosolic protein TIP35 which interacts only with phosphorylated cytosolic tail of the IGF-II/M6-PR is still unknown (Braulke, 1999).

The IGF-II/M6-P receptor is also implicated in the cell-surface activation of latent TGF- $\beta$. After binding to IGF-II/M6-P receptor latent TGF- $\beta$ is presented to plasmin or other proteases associated with the cell surface of the same cell or other cells for proteolytic activation (Liu et al., 1999). Thus, the IGF-II/M6-PR effectively controls the extracellular bioavailability of IGF-II and TGF- $\beta$, thereby regulating cell proliferation and apoptosis.

The IGF-II/M6-PR is one of a number of cell surface receptors, which also exist in a soluble, truncated form. This soluble form of the IGF-II/M6-PR (sIGF-II/M6-PR) is produced by proteolytic cleavage of the membrane receptor by deletion of the transmembrane and cytoplasmic domains during process designated as protein ectodomain shedding and is present in serum, urine and amniotic fluid of rodents and humans. The highest rate of the IGF-II/M6-PR shedding has been observed in the liver of adult rats (Bobek et al., 1992). However, enzymes which are responsible for cleavage of the IGF-II/M6-PR on the cell surface (IGF-II/M6-PR-specific sheddases) have not yet been identified. The sIGF-II/M6-PR binds IGF-II with high affinity in vivo and can bind $\mathrm{M} 6 \mathrm{P}$ in vitro, suggesting that it shares at least some of its ligand specificity with the membrane IGF-II/M6-PR. There is evidence that the sIGF-II/M6-PR is a biologically active molecule. First, it retains the ability to bind IGF-II, preferentially high molecular 
weight prolGF-II, and therefore it effectively inhibits mitogenic effects mediated by IGF-II in different cell types (Scott et al., 1996; Scott and Weiss, 2000). Second, mice overexpressing the sIGF-II/M6-PR have reduced size of some internal organs, probably due to sequestration of freely circulating IGF-II by excess of the sIGF-II/M6-PR that results in inhibition of IGF-II-mediated cell proliferation (Zaina et al., 1998a; 1998b).

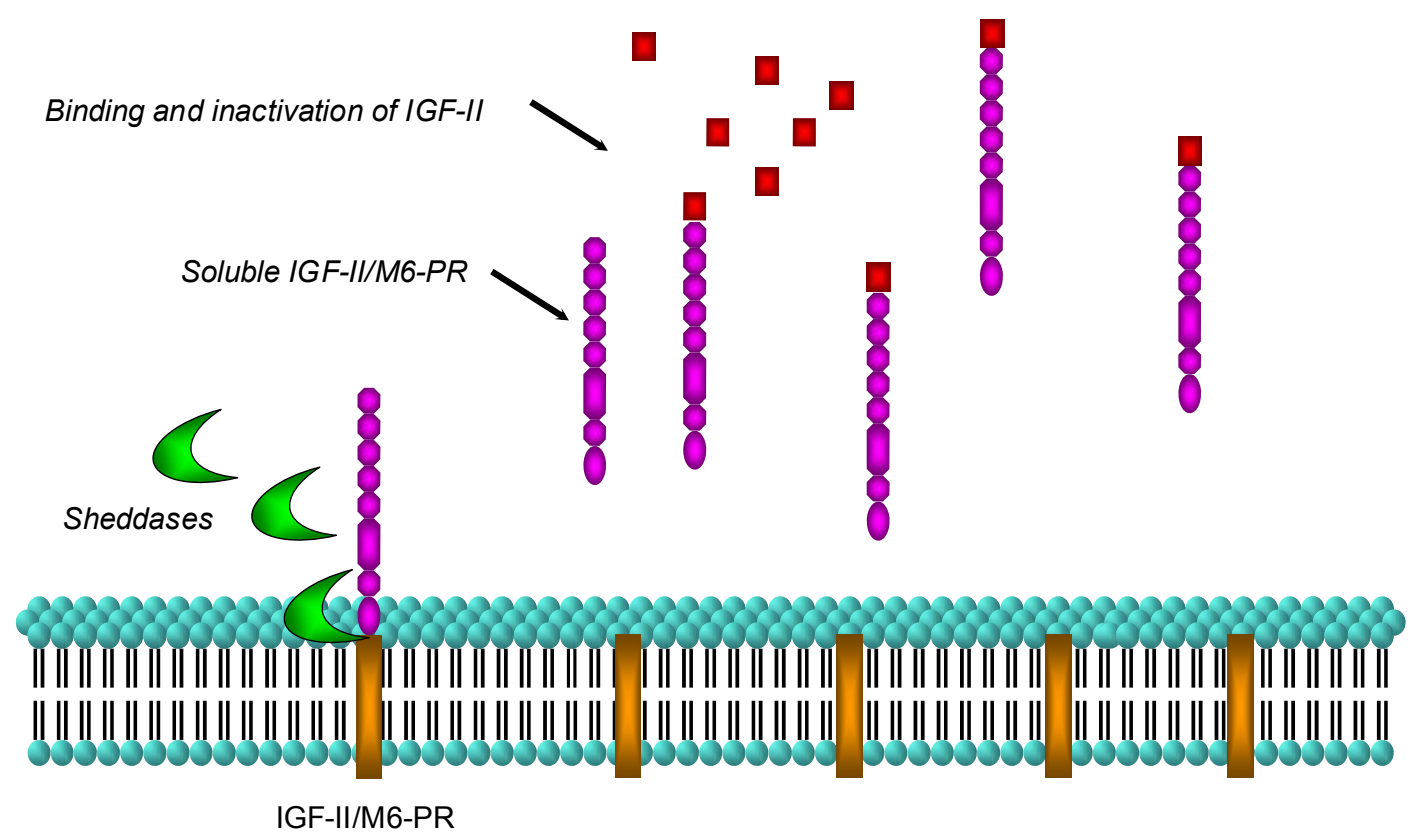

Figure 4. Soluble form of the IGF-II/M6-PR. An important biological property of the IGF-II/M6-PRR is its ability to undergo a process known as protein ectodomain shedding, a release of extracellular part of receptor from the plasma membrane due to proteolysis on the cell surface by enzymes designated as sheddases. This soluble form of the IGF-II/M6-PR receptor can effectively block mitogenic effects mediated by IGF-II.

\subsection{IGF Binding Proteins}

Unlike insulin, the IGFs are present in the circulation and throughout the extracellular compartments almost entirely bound to a family of multifunctional, structurally related, high affinity IGF-binding proteins (IGFBPs), which can modulate mitogenic and metabolic effects of the IGFs.

To date, six IGFBPs with high affinity have been cloned and sequenced. All share structural homology with each other and specifically bind the IGFs. They differ in molecular mass, binding affinities for the IGFs, and posttranslational modifications such as phosphorylation and glycosylation. Recently, a closely related family of genes has been identified that encode proteins with structural homology to the "classical“ IGFBPs, 
but that bind the IGFs and insulin with relatively low affinity. Until now, four IGFBPs with low affinity have been identified and designated as IGFBP-related proteins (IGFBP-rPs) $-1,-2,-3$ and -4 (Baxter et al., 1998; Collet and Candy, 1998).

\subsubsection{Biochemical Characteristics of IGFBPs}

The chromosomal locations of all human IGFBP genes are well known. The IGFBP-1 and IGFBP-3 genes not only reside on the same chromosome, at the locus 7p14-p12, but are only $20 \mathrm{~kb}$ apart, with transcription oriented in a tail-to-tail configuration. The IGFBP-2 and IGFBP-5 genes constitute another gene pair, located 20-40 kb apart on the chromosome 2q. Based on amino acid similarity analysis, IGFBP-1 gene is more closely related to IGFBP-2 gene than to IGFBP-3 gene, which, in turn, is more related to gene coding for IGFBP-5. IGFBP-4 gene, located on the chromosome 17q12-21.1, is more closely related to genes for IGFBP-1 and -2, whereas IGFBP-6 gene, found on the chromosome 12q13, appears to be the most divergent of the IGFBP genes. The similarity in configuration of the human IGFBP genes, especially the gene pairs, is striking, and, together with analysis of the protein sequences, has led to the hypothesis that a tandem gene duplication and inversion occurred early in the evolution of IGFBPs, and subsequent gene duplications primarily involved partial chromosome duplication. The gene structures of human IGFBPs are highly similar, although the sizes of the genes vary from $5.7 \mathrm{~kb}$ for IGFBP-1 to $33 \mathrm{~kb}$ for IGFBP-5, due to variations in the sizes of introns. All of the IGFBPs are encoded by four exons, with the exception of IGFBP-3, which has an extra exon, exon 5, which is not translated. The corresponding exons among the IGFBP genes are equivalent in size, with exon 1 less than $600 \mathrm{bp}$, exons 2 and 3 less than $230 \mathrm{~kb}$, and exon 4 more variable in size (Hwa et al., 1999).

The precursor forms of all six IGFBPs have small secretory signal peptides (20-39 amino acids) and the mature proteins that are all found extracellularly. The primary structure of mammalian IGFBP includes three distinct domains of approximately equivalent sizes: the conserved $\mathrm{N}$-terminal domain, the highly variable midregion, and the conserved C-terminal domain. There is a striking correlation between these protein domains and the exons of human IGFBP genes. The $\mathrm{N}$-terminal domain is encoded within exon 1 in all of the IGFBPs. Exon 2 encodes for the nonconserved midregion. Finally, both exon 3 and exon 4 encode for the conserved C-terminal domain (Hwa et al., 1999). 
Important IGF-binding residues are found in the N-terminal domain, predicted by nuclear magnetic resonance studies on IGFBP-5 and confirmed for IGFBP-3 and IGFBP-5 by mutagenesis studies. Although no other major functional motifs have been identified in this domain, the observation that $\mathrm{N}$-terminal proteolytic fragments of IGFBP3 cause IGF-independent inhibition of mitogenesis implies the existence of another active subdomain in this region. IGF-binding residues are also present in the conserved C-terminal domain demonstrated by the binding activity of natural C-terminal fragments of IGFBP-2 and recombinant C-terminal IGFBP-3 fragments and mutagenesis of IGFBP-5 residues. The observation that residues involved in IGF binding exist in both $\mathrm{N}$ - and $\mathrm{C}$-terminal regions implies the existence of an IGF-binding pocket involving both domains. Other important subdomains have also been identified within the C-terminal domains of various IGFBPs. For example, Arg-Gly-Asp (RGD) integrin-binding motifs are located at residues 221-223 of IGFBP-1 and residues 265-267 of IGFBP-2. Functionally important 18-residue basic motifs with heparin-binding activity have also been identified at residues 215-232 of IGFBP-3 and residues 201-218 of IGFBP-5 and are involved in interaction with acid-labile subunit (ALS) and other ligands, cell and matrix binding and nuclear transport. The central domain of the IGFBPs shows essentially no structural conservation among any members of the family. Three sites of $\mathrm{N}$-linked glycosylation in IGFBP-3 and one in IGFBP-4 are found in this region. Other sites of posttranslational modification also exist in this domain: potential phosphoacceptor sites on all IGFBPs, some of which are phosphorylated in IGFBP-1, -3 and -5 , and proteolytic cleavage sites in some of the binding proteins. Secondary IGFBP-5 binding sites for ALS and heparin and a potential cell-association domain of IGFBP-3 are also found in this region (Firth and Baxter, 2002).

\subsubsection{Biological Functions of IGFBPs}

The six high affinity IGFBPs act as carrier proteins in plasma, control the efflux of the IGFs from the vascular space, prolong half-lives of the IGFs. They regulate their metabolic clearance, provide tissue- and cell-specific localization of the IGFs and modulate biological actions of the IGFs, and, finally, some of them also have intrinsic bioactivities that are independent of the IGFs (Jones and Clemmons, 1995). 


\subsubsection{Carrier Protein Function}

In the body, the IGFs are present in at least three forms: i) unbound, ii) in binary complexes with IGFBPs, and iii) in high molecular weight ternary complexes with IGFBP-3 or -5 and ALS. The latter is a 85 kilodaltons (kDa) leucine-rich glycoprotein, which facilitates protein-protein interactions, and is synthesized exclusively in hepatocytes under the control of growth hormone.

In serum, about $75-80 \%$ of the IGFs circulate in form of ternary complex of $150 \mathrm{kDa}$. Within this $150 \mathrm{kDa}$ complex, the IGFs can not leave the vascular compartment, they are protected from proteolytic degradation and their half-lives therefore are prolonged from 10-20 $\min$ to 12-15 h (Jones and Clemmons, 1995; LeRoith et al., 2001). While IGFBP-3 was the first IGFBP identified as being present in the ternary complex, several lines of evidence suggest that IGFBP-5 is also capable of forming a complex with IGF and ALS (Twigg et al., 1998a, 1998b, 2000).

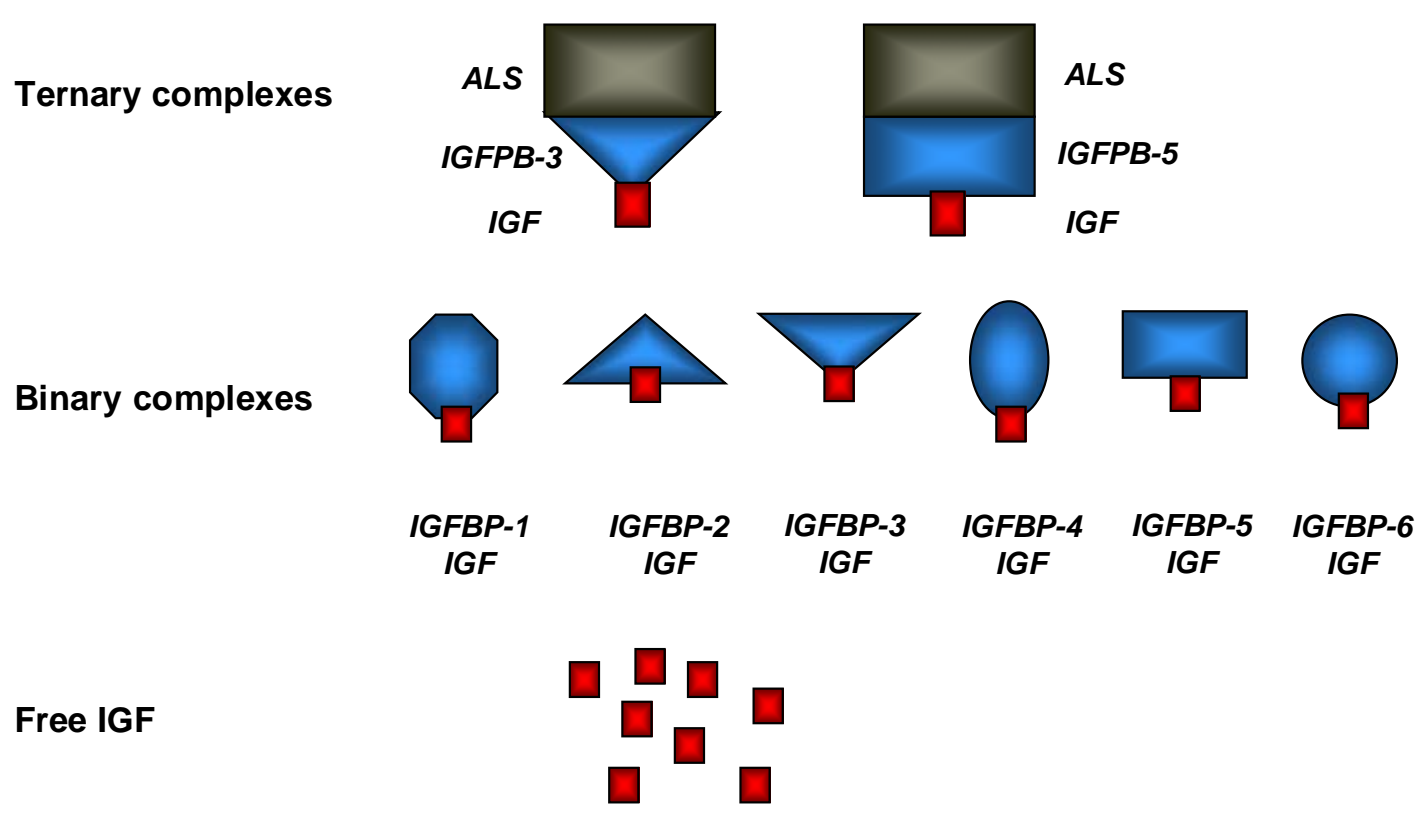

Figure 5. IGF pools in the circulation. The high molecular weight ternary complex consists of $7.5 \mathrm{kDa}$ IGF-I or IGF-II plus 38-43 kDa IGFBP-3 or 22-31 kDa IGFBP-5 and a 85 kDa non-IGF-binding acid-labile component designated as ALS. The binary complexes consist of IGF-I or IGF-II bound to any of six IGFBPs. Free IGFs molecules are the bioactive fraction of total IGFs.

When the IGFs are released from the ternary complex, IGFBPs can form lower molecular mass complexes. These approximately $50 \mathrm{kDa}$ binary complexes, which bind $20-25 \%$ of the IGFs in the circulation (Rajaram et al., 1997), can cross vascular endothelium and are responsible for transportation of the IGFs from the circulation to extravascular tissue compartment (Boisclair et al., 2001; Delhanty et al., 2001). 
Less than $1 \%$ of the IGFs are found in the free form in blood circulation. Free IGFs are postulated to be the bioactive fraction of total IGFs, determining the biological effects of the IGFs (Hasegawa et al., 1996). High ratio of free IGF-I to total IGF-I is observed during rapid growth, indicating that high levels of free IGF-I may be related to the intensive growth of the body during infancy and puberty (Hasegawa et al., 1997; Yamada et al., 1998).

\subsubsection{Tissue- and Cell-Specific Sequestration of IGFs by IGFBPs}

IGFBPs are capable of facilitating storage of the IGFs in extracellular compartment by binding to different matrix proteins localized on the cell surface or in tissues. IGFBP-1 and IGFBP-2 have RGD integrin recognition sequence and bind to the cell surface via $\alpha_{5} \beta_{1}$-integrin, which has previously been described to recognize only fibronectin as a ligand (Drop et al., 1992; Jones et al., 1993; Doerr and Jones, 1996). As it has been

mentioned above, IGFBP-3 molecule contains the 18-residue basic domain, which is implicated in cell surface association. This domain is also present in IGFBP-5. Binding of heparin and certain other glycosaminoglycans (GAGs), as well as cell surface proteoglycans, to this heparin-binding motif IGFBP-3 and -5 has been demonstrated (Firth and Baxter, 2002).

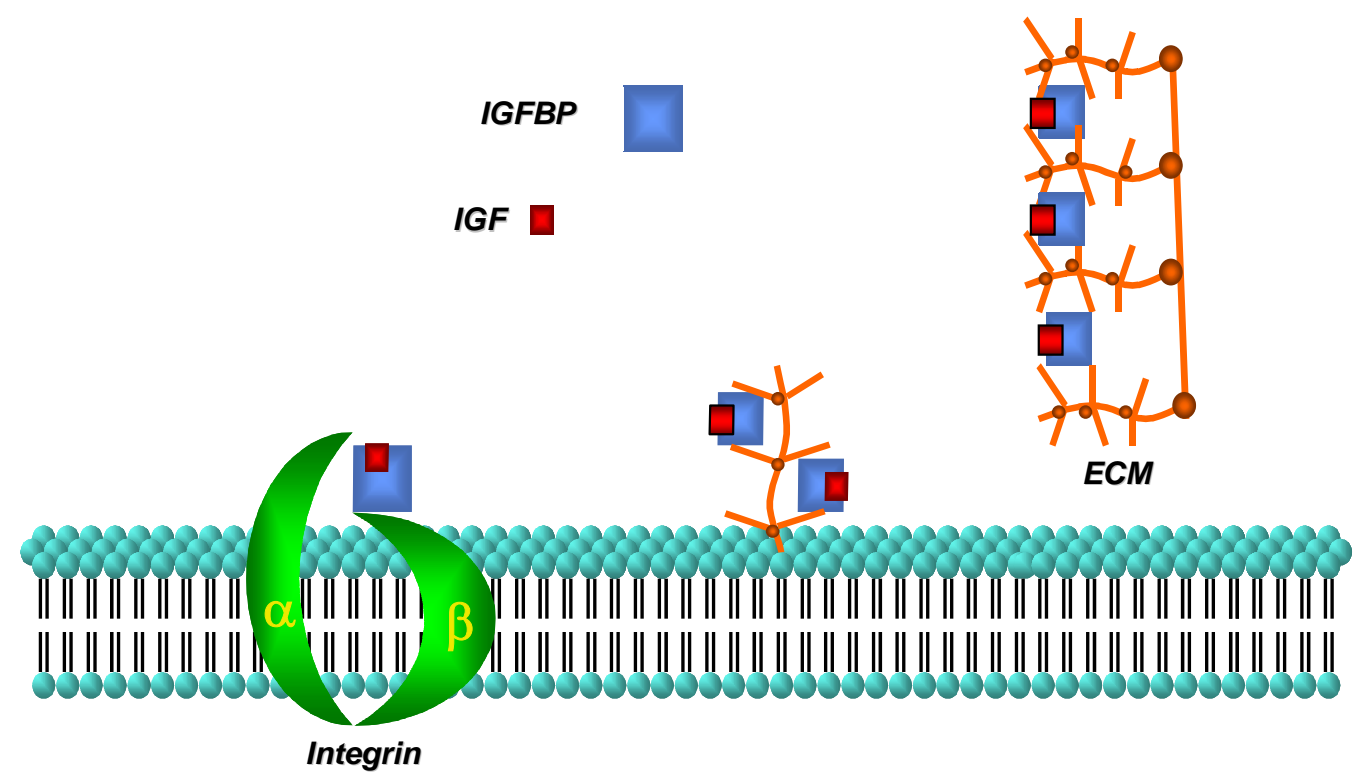

Figure 6. IGFBPs: role in tissue- and cell-specific localization of the IGFs. IGFBP facilitate storage of the IGFs in extracellular compartment by binding to matrix proteins (integrins, glycosaminoglycans, hydroxyapatites etc.) localized on the cell surface or in tissues. 
It has been found out recently that both IGFBP-3 and IGF-I-IGFBP-3 complexes bind fibrinogen, fibrin (Campbell et al., 1999) and plasminogen (Campbell et al., 1998) with high affinity via the heparin-binding domain (HBD). It has also been shown that activation of plasminogen to plasmin, a specific protease for IGFBP-3, is not inhibited by IGFBP-3 binding (Campbell et al., 1998). In addition, fibronectin (Gui and Murphy, 2001) and type I collagen (Liu et al., 2003) binding to IGFBP-3 and IGF-I-IGFBP-3 complexes has also been recently demonstrated. Since all of these proteins are involved in the process of wound healing, these studies suggest a role for IGFBP-3 in concentrating IGF-I at sites of injury, and presumably, after proteolysis of IGFBP-3 by plasmin, IGF-I is released to exert its mitogenic effects. Analogous to IGFBP-3, the HBD region of IGFBP-5 has been demonstrated as binding site for several proteins (Firth and Baxter, 2002). Its ability to bind to various GAGs (Schmid et al., 1996) and hydroxyapatites (Campbell and Andress, 1997) implies that IGFBP-5 may accumulate in bone and thereby sequester the IGFs.

\subsubsection{Modulation of IGF Actions}

IGFBPs are capable to modulate biological actions of the IGFs. The different cellular effects of IGF-I and IGF-II in highly differentiated cell types are mainly inhibited by IGFBPs. In this case, IGFBP molecules, freely circulating in the extracellular space, block IGF action simply by sequestering free IGFs and preventing the binding of the IGFs to IGF receptors (Jones and Clemmons, 1995; Baxter, 2000). However, some IGFBPs may also modulate action of the IGFs both in positive and in negative manner. The same IGFBP can have an IGF-inhibiting or potentiating role that is determined by an interaction between IGFBP and the IGFs, which in turn can be controlled by three different mechanisms: (i) posttranslational structural modifications of IGFBP; (ii) proteolytic cleavage of IGFBP; (iii) binding of IGFBP to cell surface and extracellular matrix (ECM).

\subsection{Modulation of IGF Actions by Posttranslational Structural Modifications of IGFBPs}

Posttranslational structural modifications of IGFBPs include phosphorylation and glycosylation of their molecules. IGFBP-1, IGFBP-3, and IGFBP-5 are all secreted as phosphoproteins (Coverley and Baxter, 1997). Phosphorylation and dephosphorylation status of human IGFBP-1 determines higher or lower binding affinity for IGF, thus 
leading to inhibition or potentiation of IGF effects, respectively. Phosphorylation of IGFBP-1 is catalyzed by casein kinase and occurs only on serine residues of IGFBP-1 located in acidic regions of the molecule. In human, in contrast to the highly phosphorylated IGFBP-1 that inhibits IGF actions, the nonphosphorylated form of IGFBP-1 has 4- to 6-fold lower affinity for IGF-I. This might contribute to sequestration of IGF-I by phosphorylated IGFBP-1 and more complete release of IGF-I in the vicinity of the IGF-IR by the nonphosphorylated form, thereby potentiating IGF-I effects. Although, as described earlier, IGFBP-1 can also interact with cells via the $\alpha_{5} \beta_{1}$-integrin, it is not clear how this interaction is modulated by phosphorylation of IGFBP-1.

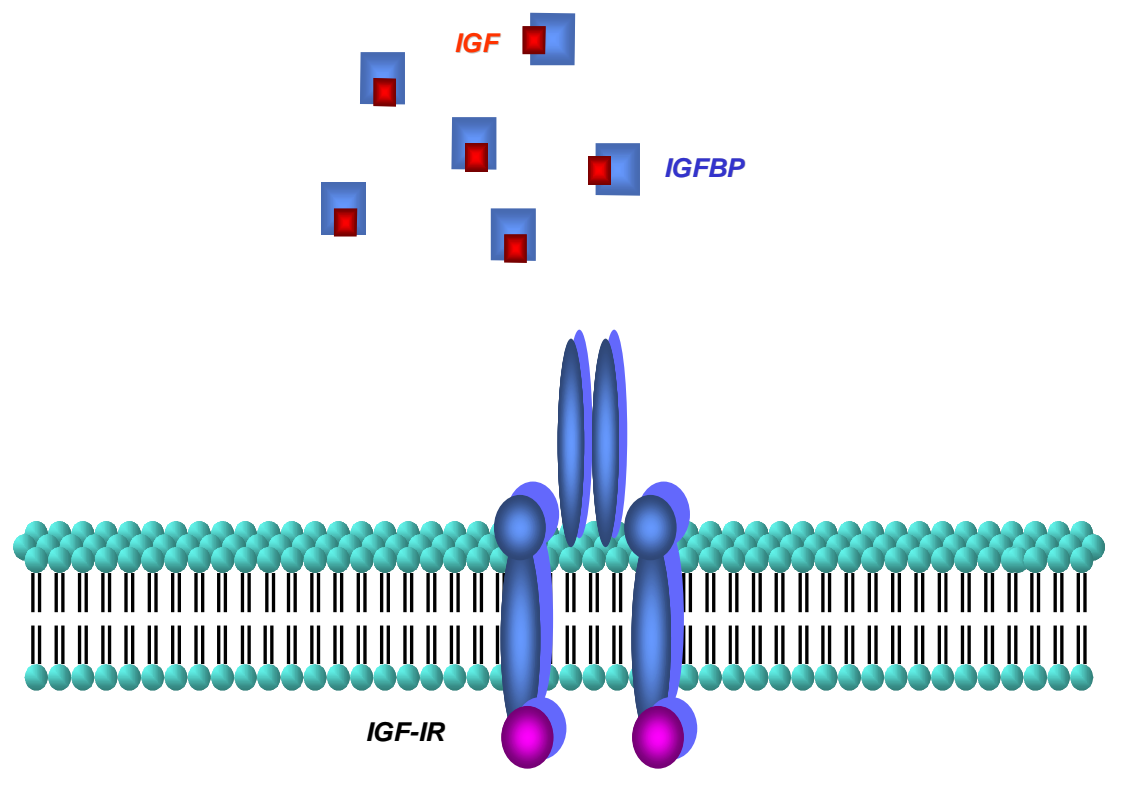

Figure 7. Modulation of IGF actions by IGFBPs. In most cases IGFBPs inhibit action of the IGFs by sequestering free IGFs and thereby preventing the binding of the IGFs to IGF receptors.

There is also evidence that phosphorylation inhibits IGFBP-3 cell binding. Human skin fibroblasts secrete IGFBP-3 into the culture medium as a phosphoprotein, but release of surface-bound IGFBP-3 from fibroblasts using an IGFIR-inactive IGF-I analogue was found to increase total IGFBP-3 but not phospho-IGFBP-3 in the culture medium, implying that surface-bound IGFBP-3 was nonphosphorylated (Coverley and Baxter, 1995). More recently, phosphorylation of IGFBP-3 in vitro by casein kinase CK2 has been shown by direct binding studies to be inhibitory to cell surface association (Coverley et al., 2000).

Some IGFBPs (IGFBP-3, -4, -5, -6) can also be glycosylated. In IGFBP-3, carbohydrate increases the size of core protein from $29 \mathrm{kDa}$ to $40-43 \mathrm{kDa}$. Of the three potential glycosylation sites at $\mathrm{Asn}^{89}, \mathrm{Asn}^{109}$, and $\mathrm{Asn}^{172}$, the first two are always used, carrying 
an estimated $4 \mathrm{kDa}$ and $4.5 \mathrm{kDa}$ of carbohydrate, respectively, whereas the third site alternatively contains either undetectable or about $5 \mathrm{kDa}$ of carbohydrate, accounting for the characteristic doublet form of the protein (Firth and Baxter, 1999). Glycosylation of IGFBP-3 has no significant effect on the binding of IGF-I (Sommer et al., 1993) or ALS (Firth and Baxter, 1999). However, IGFBP-3 forms in which various glycosylation sites have been altered by mutagenesis reveal that decreasing glycosylation tends to increase cell surface association (Firth and Baxter, 1999). This suggests that the carbohydrate present in natural IGFBP-3 might mask potential cell-association sites. Likewise, association of IGFBP-6 with cell surface also appears to be inhibited by carbohydrate. Binding to glycosaminoglycans is greatly inhibited by glycosylation, and the non-glycosylated protein, which is not known to occur in nature, has been shown to bind to cell membranes, whereas the natural, glycosylated form shows no binding (Marinaro et al., 2000). It implies that, as observed in the case of IGFBP-3, cell binding sites of IGFBP-6 are permanently masked by carbohydrate. Several lines of evidence also suggest that non-glycosylated IGFBP is more susceptible than glycosylated IGFBP to proteolysis, thus glycosylated sites of IGFBP molecules may inhibit access to potential cleavage sites of proteases (Bach, 1999).

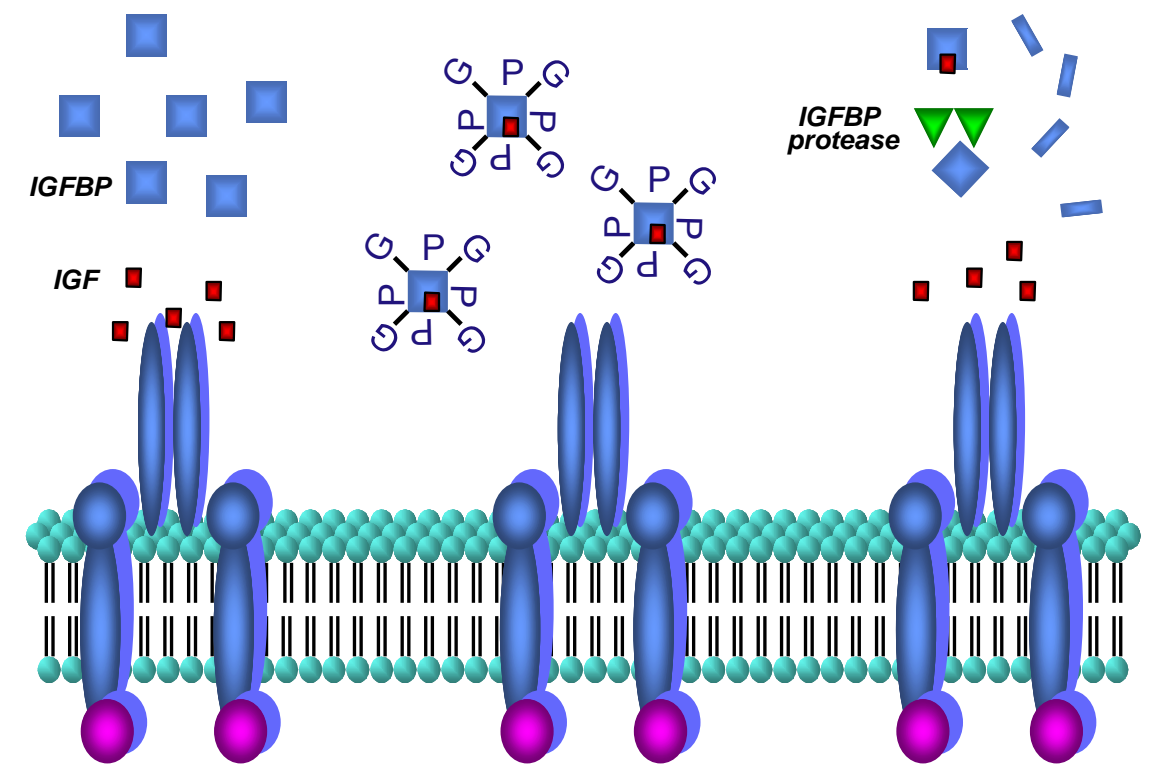

Figure 8. Role of posttranslational structural modifications of IGFBPs in modulation of IGF actions. In human, the highly phosphorylated IGFBP-1 (P) has much higher affinity for IGF-I than its nonphosphorylated form. Glycosylated IGFBPs (G) poorly associate with cell surface and are less susceptible to proteolysis than non-glycosylated IGFBP. 


\subsection{Modulation of IGF Actions by IGFBP Proteolysis}

Limited proteolysis of IGFBPs is believed to be the major mechanism for the release of IGF molecules from IGFBP-IGF complexes generating IGFBP fragments with reduced affinity for the IGFs (Bunn and Fowlkes, 2003). Several IGFBP-specific proteases such as kallikrein-like serine proteases, cathepsins and metaloproteinases, active both within circulation and in extravascular fluids, have been described and characterized. Whereas conditioned media from primary cultures of rat liver cells lacked neutral IGFBP protease activities, the presence of acid-activated IGFBP proteases - most likely lysosomal aspartyl and cystein proteases (cathepsins) - was observed. However, when hepatocytes and $\mathrm{KC}$ were cocultured at neutral $\mathrm{pH}$ in the presence of iodinated IGFBP3, a time-dependent disappearance of intact IGFBP-3 and the generation of IGFBP-3 fragments of different sizes were observed. These data suggest that either endocytosed IGFBP-3 is degraded in cathepsin-containing organelles accompanied by partial recycling and release of IGFBP-3 fragments into the extracellular medium, or that IGFBP-3 is cleaved by protease(s) localized at the cell surface (Scharf and Braulke, 2003).

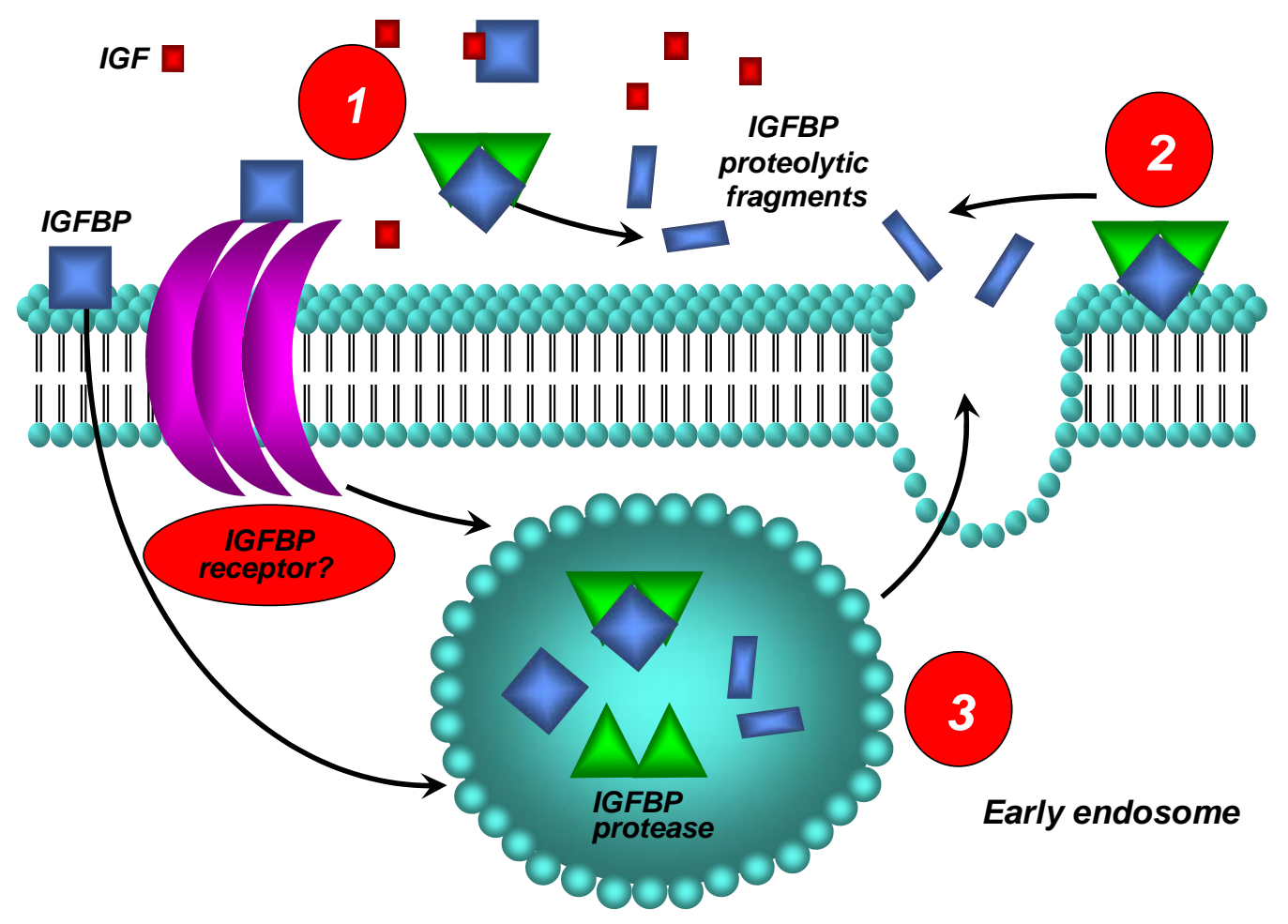

Figure 9. IGFBP proteolysis. It is believed that major sites for IGFBP proteolysis are: (1) extracellular space, (2) cell surface, (3) intracellular organelles. Cathepsin-mediated IGFBP proteolysis in the endosomal recycling compartment is considered to be accompanied by partial recycling and release of IGFBP fragments into the extracellular compartment. 
Proteolytical degradation has been shown for IGFBP-2 to -5. In case of IGFBP-3 and -5, the proteolytic fragments may retain significant affinity for the IGFs, whereas the affinity of IGFBP-2 and -4 fragments is drastically reduced. Furthermore, in case of IGFBP-3 and IGFBP-5, the fragments themselves may potentiate IGF actions even when IGF affinity is substantially reduced (Jones and Clemmons, 1995).

\subsection{Modulation of IGF Actions by Binding of IGFBPs to Cell Surface and} Extracellular Matrix

Increased adherence of some IGFBPs to cell surface or ECM has been shown to be associated with a decrease in affinity for the IGFs and with an increased mitogenic response. It is speculated that a reservoir of local IGFs bound to the IGFBP localized on the cell surface and in ECM can lead to release the IGFs under the different conditions, thus providing a high local concentration of IGF to stimulate the IGF-IR, thus potentiating its local effects (Firth and Baxter, 2002).

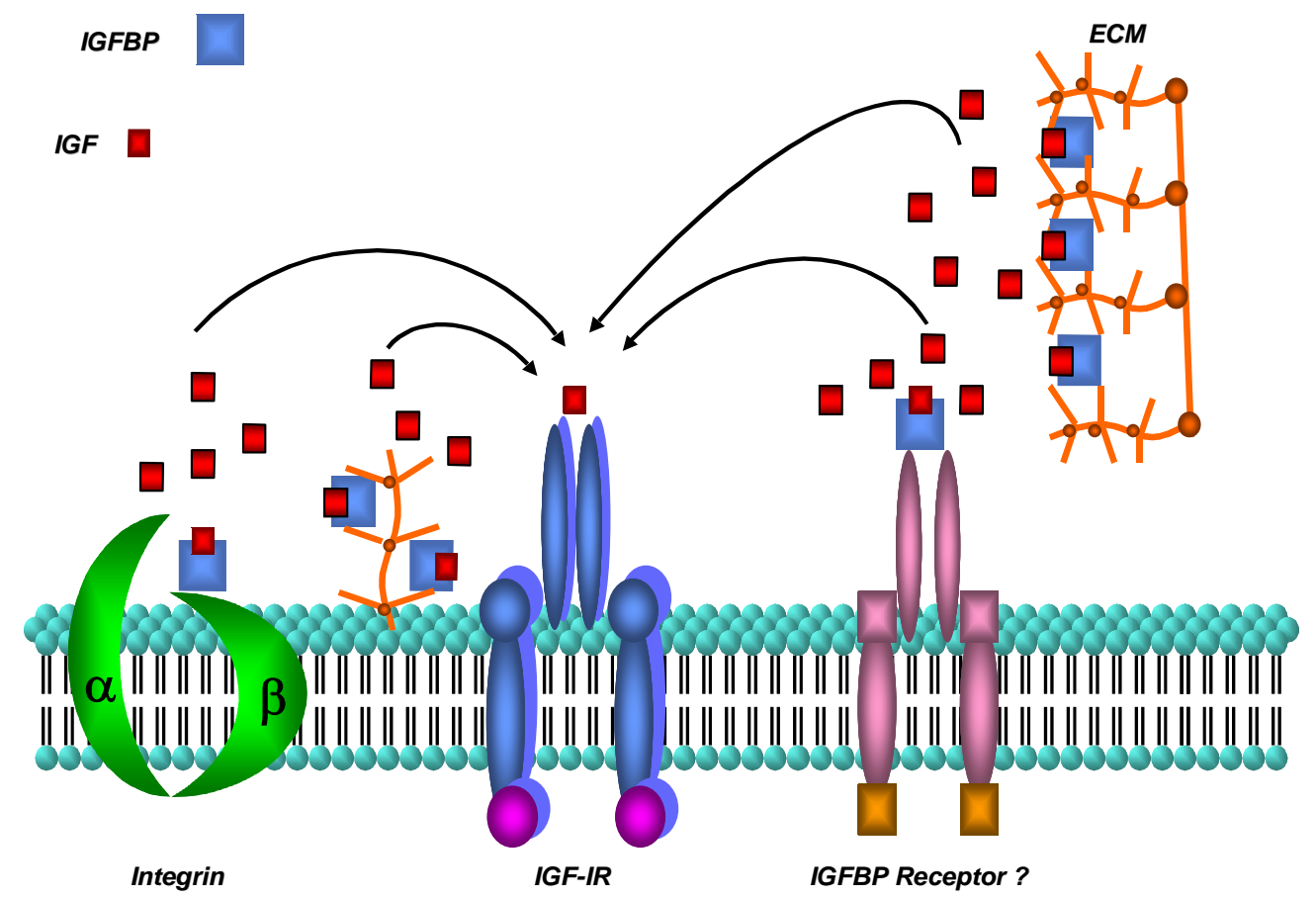

Figure 10. Role of tissue- and cell-localized IGFBP in potentiation of IGF actions. Association of IGFBPs with proteins on the cell surface or in the ECM results in an increase in the local concentration of the IGF in the vicinity of the IGF-IR. Association with the cell surface or with the ECM lowers the affinity of IGFBPs for the IGFs. This decreased affinity allows the release of IGF to the receptor, thereby stimulating biological response. 


\subsubsection{IGF-independent Effects}

Several lines of evidence suggest that IGFBPs also possess intrinsic bioactivity that is IGF-independent. To date, the molecular mechanisms of these IGF-independent actions of IGFBPs are incompletely understood. Conceptually, IGFBPs are believed to exert their direct actions on target cells in three ways: 1) by activation of cell surface receptors or membrane-bound proteins that initiate intracellular signalling responses; 2) by direct importation to the cytoplasmic compartment where they modulate biological effects of intracellular proteins; 3 ) by direct translocation to the nucleus where via interaction with transcription factors (nuclear receptors) they induce their effects directly on gene expression.

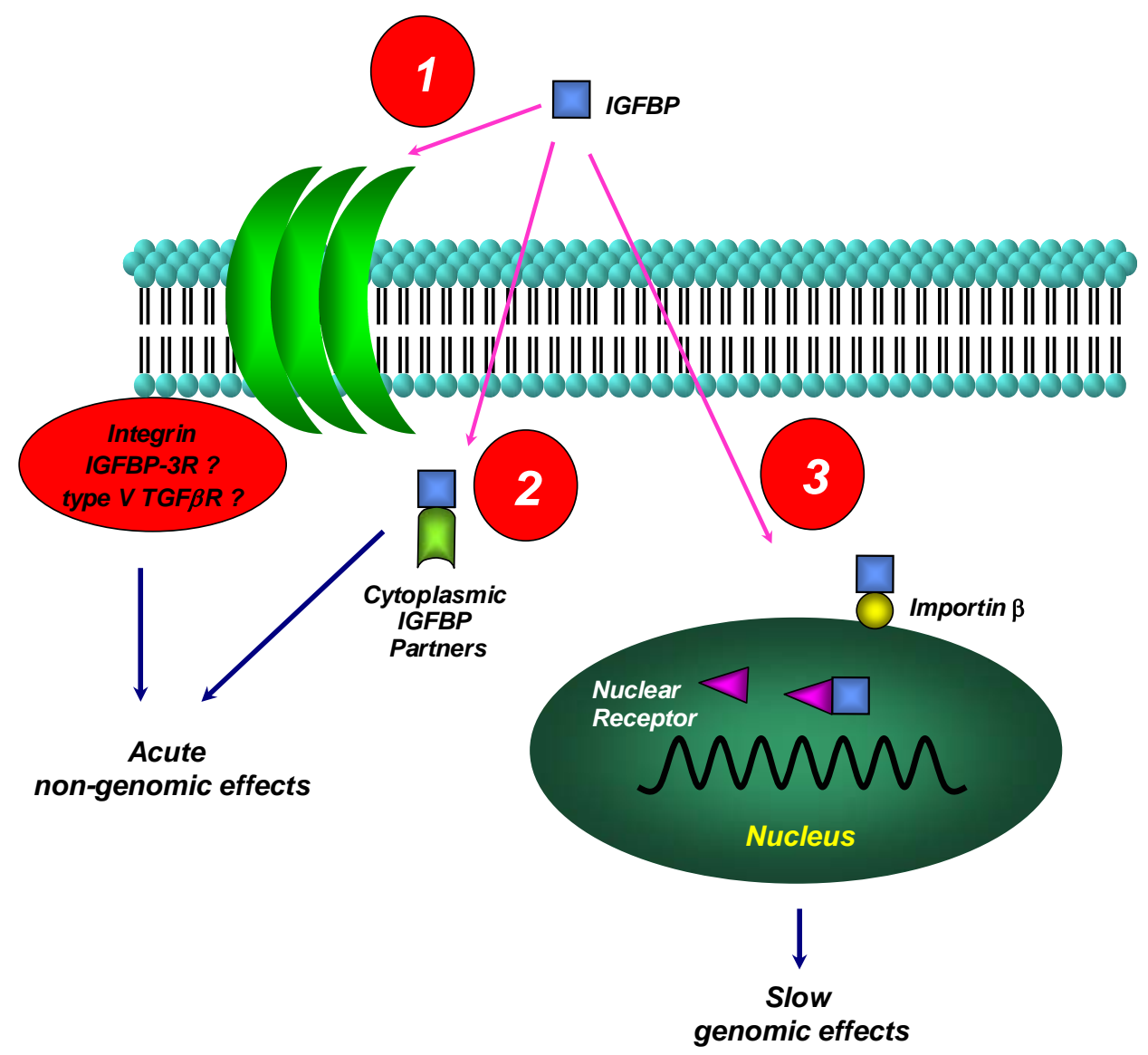

Figure 11. IGF-independent effects of IGFBPs. Cellular response can be induced by IGFBPs in an IGFindependent manner. Conceptually, IGFBP can exert their direct actions on target cells in three ways (pink arrows): 1) by activation of cell surface receptors (integrins, type V TGF- $\beta$ receptor, IGFBP-3R) that initiate intracellular signalling pathways; 2 ) by direct importation to the cytoplasmic compartment where they modulate biological effects of intracellular proteins; 3 ) by direct translocation to the nucleus, mediated by importin $\beta$ nuclear transport factor, where via interaction with transcription factors (nuclear receptors) they induce their effects directly on gene expression. 


\subsection{Cross-Talk between IGFBPs and Integrins}

Direct non-IGF-mediated effects have been demonstrated to result from the interaction of IGFBPs with integrins, which have an important role in anchoring the cell to the ECM and also in activating intracellular signalling pathways with critical effects on cell migration and cell survival. The potential for IGFBP to interact with integrins has been apparent since their structural characterization revealed the presence of the classical integrin recognition sequence, RGD, in the sequences of IGFBP-1 and IGFBP-2. Both IGFBP-1 and IGFBP-2 have been shown to bind to $\alpha_{5} \beta_{1}$-integrin receptor through RGD sequence (Drop et al., 1992; Jones et al., 1993; Doerr and Jones et al., 1996) and to influence integrin intracellular signalling via the focal adhesion kinase (FAK) and MAPK. Gleeson et al. (2001) have demonstrated the ability of IGFBP-1 $t$ bind to the $\alpha_{5} \beta_{1}$ integrin with subsequent activation of FAK and MAPK that leads to stimulation of cell migration. In contrast, Perks et al. (1999) and Schütt et al. (2004) have shown that binding of IGFBP-1 and IGFBP-2, respectively, to the $\alpha_{5} \beta_{1}$-integrin resulted in increased dephosphorylation of FAK and MAPK in tumor cell lines, thereby increasing cell detachment and inhibiting proliferation and migration of tumor cells. Although the other IGFBPs do not possess classical integrin recognition sequences, it has been demonstrated that a number of IGFBPs can alter key integrin actions and signalling pathways, and, moreover, activation of integrins can dramatically alter IGFBP actions. Exposure of human breast cancer cells to IGFBP-3 significantly increased cell attachment to plastic, collagen, laminin indicating an acute effect on integrin function. Exposure to IGFBP-3 also acutely increased the association of FAK with $\beta_{1}$ integrin subunits and decreased FAK phosphorylation demonstrating effects on integrin signalling pathways. In turn, the actions of IGFBP-3 on cell attachment and apoptosis could be abolished through the activation of integrin receptors by exogenous and endogenous fibronectin. Exposure of cells to IGFBP-5 also affected integrin actions and apoptosis, with opposing effects to those of IGFBP-3, but again activation of integrin receptors by fibronectin completely reversed the actions of IGFBP-5 (Holly and Perks, 2002).

It is also believed that binding of IGFBPs to integrin receptors can generate intracellular signals, which could interact with components of the IGF-I receptor signalling pathways and modulate the ultimate signals delivered to the nucleus (Nam et al., 2002). In this regard, it has been demonstrated that ligand occupancy of $\alpha_{v} \beta_{3}$-integrin receptor is required for full activation of the $\beta$ subunit of IGF-IR and its signal transduction element, 
IRS-1, by IGF-I stimulation. It is possible that cells may contain a protein mediating the interaction between $\alpha_{v} \beta_{3}$-integrin and IRS-1 or between $\alpha_{v} \beta_{3}$-integrin and the tyrosine kinase subunit of the IGF-IR (Zheng et al., 1998; Maile et al., 2001). Thus, integrins play an important role in mediating cellular effects of the IGFs and their binding proteins.

\subsubsection{IGFBP Receptors}

IGFBP-3 can inhibit cell proliferation by a cellular signalling pathway independent of the IGFs (Oh et al., 1993; Cohen et al., 1993; Valentinis et al., 1995; Butt et al., 2002). It has also been shown that IGFBP-3 induces apoptosis through a novel pathway independent of either p53 or the IGF/IGF-IR-mediated cell survival pathway (Rajah et al., 1997). Moreover, it has been suggested that IGFBP-3 may act as a mediator of p53dependent apoptosis (Butt and Williams, 2001). But, unlike IGFBP-1 and -2, IGFBP-3 has no RGD sequence, and therefore its IGF-independent effects are hardly realized by binding to integrin receptors. Recently, it has been suggested that type $\mathrm{V}$ transforming growth factor $\beta$ (TGF- $\beta$ ) receptor (T $\beta R-V)$ may function as the putative IGFBP-3 receptor (Leal et al., 1997; 1999). It has also been demonstrated that type I and type II TGF- $\beta$ receptor can be involved in IGFBP-3 signalling as well (Fanayan et al., 2002). In turn, IGFBP-5 also exerts IGF-independent mitogenic activity, and the T $\beta R-V$ is likely the same receptor for IGFBP-5 (Andress, 1998). Furthermore, antiproliferative signalling of IGFBP-3 appears to require an active TGF- $\beta$ signalling pathway, and IGFBP-3 stimulates phosphorylation of Smads, the TGF- $\beta$ signalling intermediates (Baxter, 2001; Fanayan et al., 2002).

Oh et al. (2002) have recently identified a putative IGFBP-3 receptor (IGFBP-3R) using a portion of the IGFBP-3 cDNA encoding the midregion of the protein as bait in the yeast two-hybrid system. This new gene product is widely expressed in human tissues and cell lines. The IGFBP-3R binds specifically to IGFBP-3, but not other IGFBP species. Overexpression of IGFBP-3R has led to a significant increase in binding of IGFBP-3 to the cell surface, and has potentiated IGFBP-3-induced suppression of proliferation. They have also found out that this growth inhibition was due to disruption of cell cycle, as evidenced by significant and specific reduction in the levels of cyclin D1 and retinoblastoma proteins, and induction of apoptosis via activation of caspases, in particular caspase 8 and caspase 3 , in a variety of human cancer cells. 


\subsection{Nuclear Translocation and Nuclear Effects of IGFBPs}

Recently, nuclear localizations of IGFBP-3 and -5 have been reported (Jacques et al., 1997; Schedlich et al., 2000). Nuclear transport of IGFBP-3 and IGFBP-5 was not unexpected because both IGFBP-3 and IGFBP-5 possess basic C-terminal nuclear localization signals (NLS) and the DNA-binding domains of several transcription factors. This nuclear import of IGFBP occurs through a NLS-dependent pathway, mediated by the importin $\beta$ nuclear transport factor (Butt et al., 1999). Recently it has been established that cellular translocation of IGFBP-3 occurs via the transferrin receptormediated endocytosis as well as via caveolic pathway. Interestingly, nuclear translocation of endogenous IGFBP-3 requires IGFBP-3 secretion and re-uptake (Lee et al., 2004). It has also been demonstrated that IGF-I can be internalized and transported to the cell nucleus together with IGFBP-3 (Li et al., 1997). The fact that IGF-I lacks NLS suggests that IGFBP-3 may be responsible for transporting IGF-I to the nucleus. A new mechanism of IGF-independent IGFBP-3 action emerged when the nuclear retinoid $X$ receptor $\alpha(R X R \alpha)$ has been cloned as an IGFBP-3 protein partner in a yeast two hybrid screen. It has been shown that IGFBP-3 and RXR $\alpha$ bind each other within the nucleus, and IGFBP-3-induced apoptosis was abolished in RXR $\alpha$-knockout cells. IGFBP-3 and RXR ligands were additive in inducing apoptosis in prostate cancer cells. IGFBP-3 enhanced RXR response element and inhibited signalling via retinoic acid receptor response element. RXR $\alpha$-IGFBP-3 interaction has led to modulation of the transcriptional activity of RXR $\alpha$ and was essential for mediating the effects of IGFBP-3 on apoptosis (Liu et al., 2000). Recently, Li et al. (2000) have shown that mitogenic effects in the cell were realized when RXR was coupled with the orphan receptor nur77, previously also known as TR3 or nerve growth factor-induced clone B NGFI-B. It has been suggested that the opposing biological activities of nur77 on cell survival and apoptosis were regulated by its subcellular localization, i.e. the mitogenic effects of nur77 occured in the nucleus through target gene regulation, whereas its proapoptotic effects occurred in the cytoplasm through regulation of mitochondrial activity. In this regard, Cohen et al. (2002) have demonstrated that in response to IGFBP-3, nur77 was translocated from the nucleus to the cytoplasm, where it targeted mitochondria with subsequent release of cytochrome $\mathrm{c}$ and apoptosis. Thus, IGFBP-3-induced translocation of nur77 from the nucleus to the cytoplasm may represent a new mechanism, which might play a critical role in regulation of cell cycle and apoptosis by IGFBP-3. 


\subsection{Liver and IGF system}

\subsubsection{Liver as Central Organ in IGF Homeostasis}

The liver plays a central role in the IGF homeostasis (Baruch, 2000) because it is the main source of circulating IGF-I, some IGFBPs and ALS. Within rat liver, the biosynthesis of individual components of the IGF system is attributed to different cell population, i.e. IGF-I, IGFBP-1 and ALS to hepatocytes, and IGFBP-3 to nonparenchymal cells (Scharf et al., 1995a; 1995b; 1996a; 1998; Arany et al., 1994; Gentilini et al., 1998; Zimmermann et al., 2000). Interestingly, despite the wide distribution of the IGF-IR throughout the body, the IGF-IR expression is almost undetectable in hepatocytes, the cells with the highest levels of IGF-I expression (Caro et al., 1988; Hartmann et al., 1990). In contrast, presence of the IGF-IR has been demonstrated in non-parenchymal liver cells such as hepatic stellate cells (Brenzel and Gressner, 1996; Scharf et al., 1998), sinusoidal endothelial cells (Zindy et al., 1992; Zimmermann et al., 2000) and Kupffer cells (Zindy et al., 1992). Moreover, production of the IGFs by these cells has also been observed (Pinzani et al., 1990; Zindy et al., 1992; Scharf et al., 1998).

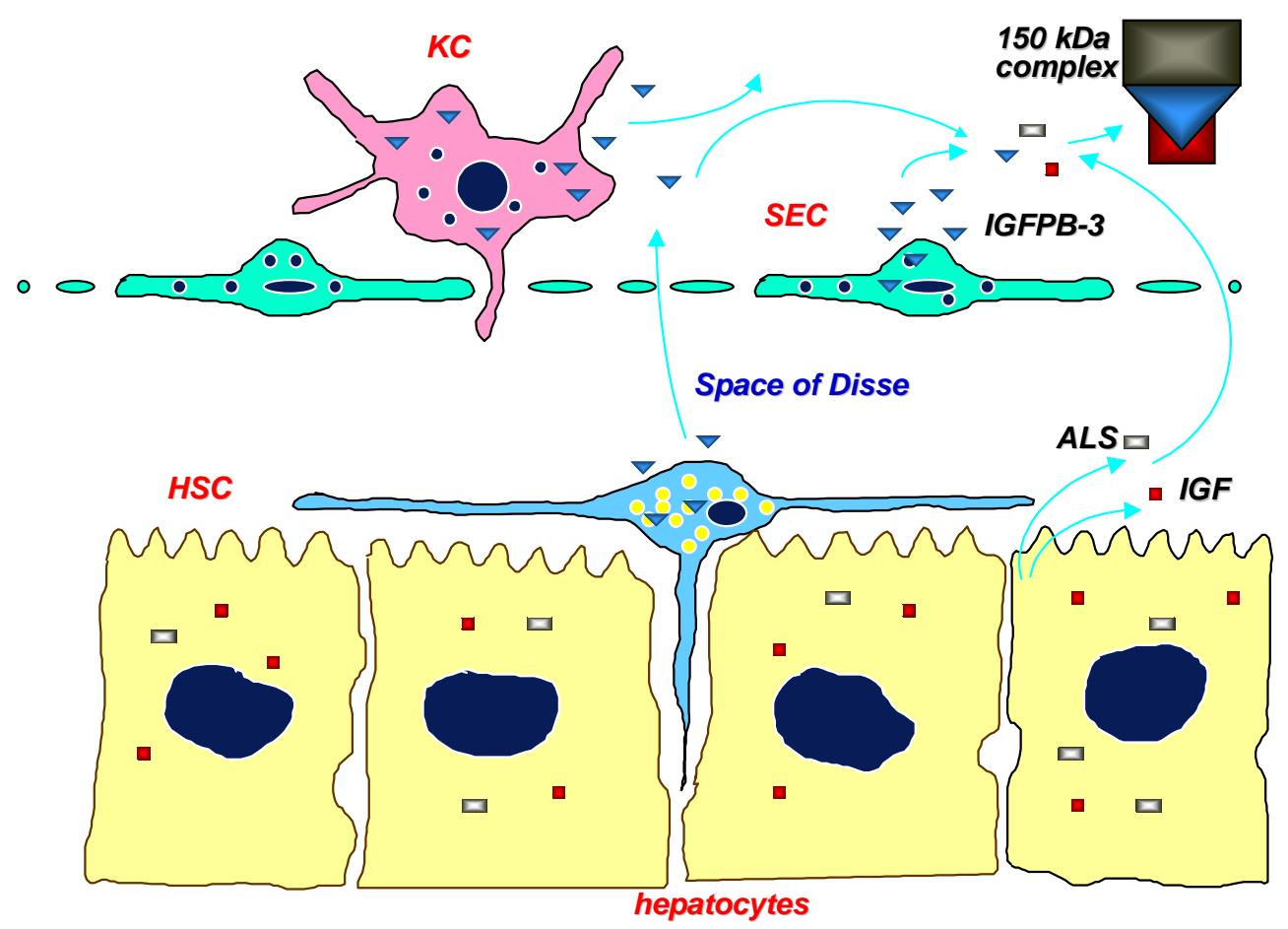

Figure 12. The liver - central organ of the IGF system. It is the main source of circulating IGF-I, IGFBP-3 and ALS, which form $150 \mathrm{kDa}$ ternary complex, the most abundant transport form of the IGFs in the circulation. Within rat liver, the synthesis of IGF-I, IGFBP-3 and ALS is strictly compartmentalized. IGF-I is produced mainly by hepatocytes. Nonparenchymal liver cells, i.e. Kupffer cells (KCs), sinusoidal endothelial cells (SECs), hepatic stellate cells (HSCs), also capable to synthesize and secrete IGF-I. IGFBP-3 is produced by nonparenchymal liver cells, but not by hepatocytes. ALS is exclusively synthesized and secreted by hepatocytes. 


\subsubsection{Updated Concept of Liver Fibrogenesis}

Liver cirrhosis is a common sequela of chronic liver injuries from many causes, including viral infections (hepatitis B and C), alcohol abuse, drugs, helminthic invasions, metabolic diseases due to overload of iron and copper, autoimmune destruction of hepatocytes and bile duct epithelium, or congenital abnormalities. Hepatic fibrosis results from a distortion of the rates of synthesis (fibrogenesis) and degradation (fibrolysis) of ECM molecules (Friedman, 1993; Ramadori et al., 1998). This process in the liver is characterized by a three- to six-fold overall increase and deposition of the ECM components with their subsequent molecular reorganization resulting in an altered composition of fibrotic matrix. Advances in the isolation and characterization of liver cells, in conjunction with progress in molecular biology, have led to important new insights into the cellular basis of hepatic fibrosis.

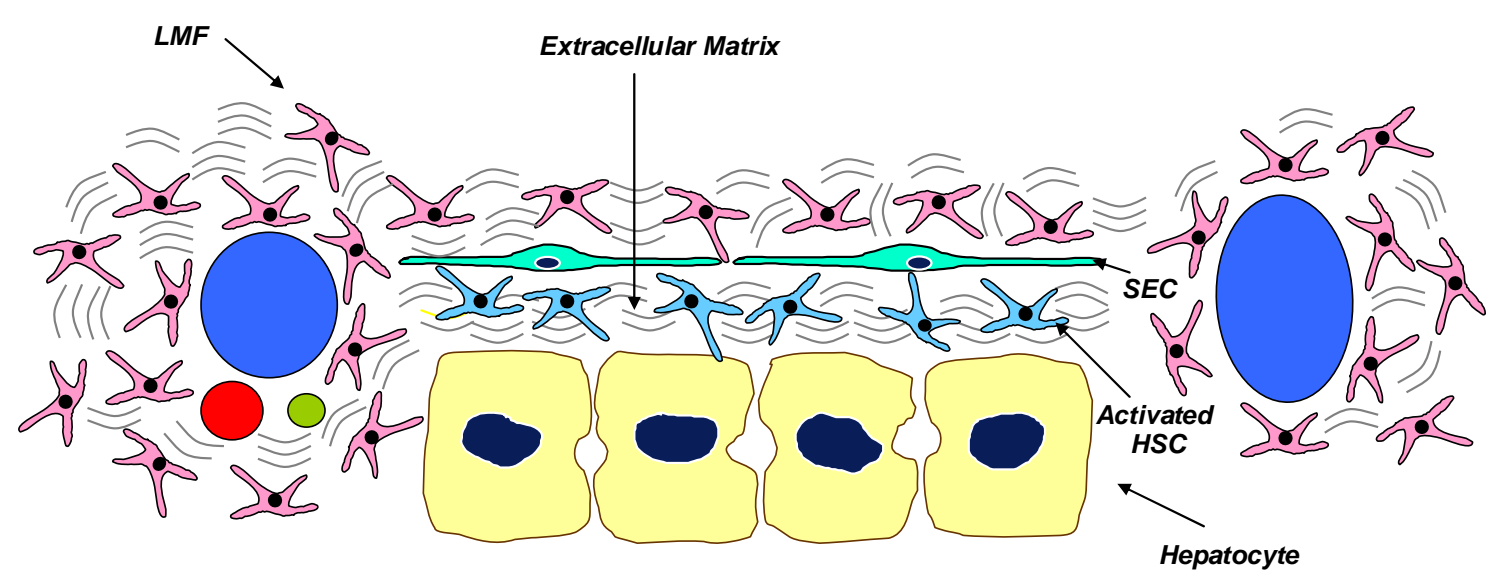

Figure 13. The cellular basis of liver fibrogenesis. Until now, it is believed that hepatic stellate cells (HSC) located in the space of Disse, also known as Ito cells, are the key effectors of hepatic fibrogenesis. With an ongoing hepatic injury these cells are believed to undergo activation with transdifferentiation from this quiescent, vitamin A-rich phenotype to myofibroblast-like phenotype with high proliferative capacity and ability to produce large amounts of extracellular matrix. However, in parallel with the process of their activation HSC undergo apoptosis. Recent data have demonstrated that resident hepatic myofibroblasts located mainly in periportal and pericentral areas within the liver are morphologically and functionally distinct from HSC. The major feature of these cells is that in contrast to HSC they are resistant to apoptosis and they definitely represent a second cell population involved in hepatic fibrogenesis.

Until now, it is believed that hepatic stellate cells, also known as Ito cells, are the key effectors of the fibroproliferative response in the liver (Friedman, 1993; 1999; 2000; Ramadori et al., 1998). In normal liver, this cell population is distinguished by prominent intracellular droplets containing vitamin A and is considered as the primary storage depot for retinoids in the liver. Both in vivo with an ongoing hepatic injury as well as in vitro after plating on culture dishes, these vitamin A-rich cells undergo a phenotypic transition from a quiescent, vitamin A-rich phenotype to myofibroblast-like phenotype (activated HSCs). In contrast to quiescent HSCs, myofibroblast-like HSCs per se are 
highly proliferative and can produce large amounts of ECM proteins (Friedman, 2000). However, several independent groups have clearly demonstrated that HSCs undergo apoptosis both in vitro and in vivo (Saile et al., 1997; Iredale et al., 1998; Fischer et al., 2002; Taimr et al., 2003). Furthermore, upon activation, both HSCs and KCs acquire the ability to produce certain apoptosis-inducing ligands such as CD95L and TRAILs, which via cognate receptors induce apoptosis in HSCs (Fischer et al., 2002; Taimr et al., 2003). Therefore, it is hard to believe that dying cells are responsible for fibroproliferative process in the liver. Moreover, transdifferentiation of one clearly identified HSC to myofibroblast has never been shown in vitro. Thus, it appears likely that myofibroblast-like cells involved in hepatic fibrogenesis may also arise from another cell type within the liver. Recent data have demonstrated that activated HSCs and liver myofibroblasts (LMFs), despite their common features, represent morphologically and functionally different fibroblast populations. Moreover, it has also been found out that the ECM proteins fibronectin and type I collagen, deposited in a fibrillar matrix, are synthesized in higher amounts by LMFs than by HSCs, suggesting similar but not identical roles of these cells during fibrogenesis (Knittel et al., 1999a). Furthermore, HSCs and LMFs are present in normal and diseased livers in distinct anatomical compartments and respond differentially to tissue injury. Acute liver injury results in most exclusive increase in the number of HSCs, while in chronically injured livers both HSCs and LMFs are involved in fibrogenesis (Knittel et al., 1999b).

At present, the precursor pool of LMFs is not identified, in spite of very important clinical relevance. The precursors of these cells could be resident cells of the fibroblast lineage in the liver such as portal fibroblasts, periductal fibroblasts, vascular myofibroblasts, "second layer" cells or capsular fibroblasts. Portal fibroblast, residing under the normal conditions in the portal mesenchyme, can be responsible for periportal fibrosis. Periductal fibroblasts, which constitute a distinct subpopulation of mesenchymal cells in the portal tract, have been suggested to proliferate and transdifferentiate in response to bile duct ligation, causing periductal, periductular and periportal „biliary“ type of fibrosis. In schistosomiasis, vascular smooth muscle cells or vascular myofibroblasts situated in the wall of portal vein branches and portal arteries were thought to perpetuate to matrixproducing cells, thereby leading to periportal fibrosis as well. So called "second layer" cells are myofibroblasts located around the centrolobular vein. They were suggested to cause typical "alcoholic" type of pericentral fibrosis. Finally, capsular fibroblasts 
detected in Glisson's capsule can also be a potential source of ECM in the liver (Cassiman et al., 2002; Ramadori et al., 2002).

Recently it has been suggested that epithelial-mesenchymal transition (transformation or transdifferentiation) may play a role in fibrogenic organ remodeling. Indeed, to date there is evidence suggesting that in renal fibrosis myofibroblasts can derive from tubular epithelial cells by an epithelial to mesenchymal transition (Yang and Liu, 2001; 2002; Strutz et al., 2002). Recent studies have shown that hepatocytes, which are epithelial cells, can also undergo transdifferentiation to the migrating fibroblast-like cells with mesenchymal phenotype under noxious stimuli (Pagan et al., 1995; 1997; 1999). However, it is equally likely that in these cases proliferating LMFs simply replace apoptotic epithelial cells (Powell et al., 1999).

\subsubsection{IGFs, PDGFs and Liver Fibrogenesis}

The possible role of IGF-I in the pathogenesis of liver cirrhosis is obscure. It has been shown that in liver cirrhosis the IGF axis was severely disturbed. Patients with liver cirrhosis had reduced IGF-I, IGF-II and IGFBP-3 serum levels (Moller et al., 1995; Scharf et al., 1996b), which were associated with adverse clinical outcome and complications of advanced cirrhosis such as malnutrition (Mendenhall et al., 1989), insulin resistance (Shmueli et al., 1996), impaired immunity (Mendenhall et al., 1997) and osteoporosis (Gallego-Rojo et al., 1998). Intriguingly, recent in vivo studies have demonstrated that exogenous IGF-I improved liver function and reduced oxidative liver damage and fibrosis in rats with experimental liver cirrhosis (Castilla-Cortazar et al., 1997). Alternatively, recent studies have shown that proliferation of HSCs and accumulation of type I collagen, the principal ECM protein, by these cells in vitro is stimulated in response to IGF-I (Scharf et al., 1998; Svegliati-Baroni et al., 1999; Gentilini et al., 1998; 2000; Pinzani and Marra, 2001). Therefore, it is believed that due to its chemotactic, mitogenic and fibrogenic activity IGF-I is locally released during hepatic injury and triggers HSCs and possibly LMFs, thereby leading to their activation, proliferation as well as to collagen production and, finally, to perpetuation of fibrogenic response within the liver.

Interestingly, although PDGF shares many common features with IGF-I, it has totally different expression pattern in liver cirrhosis. Normal liver has almost undetectable level of PDGFs and their receptors, and healthy individuals have low serum PDGFs levels. Conversely, in liver cirrhosis, hepatic expression and circulating levels of PDGFs are 
considerably higher and positively correlate with the severity of disease (Pinzani et al., 1996; Zhang et al., 2003). Moreover, it has also been reported that blockade of PDGF receptor expression in vivo had beneficial effect in animals with liver cirrhosis (BorkhamKamphorst et al., 2004). At present, however, it is obscure whether there is any pathophysiological link between different expression patterns of IGF-I and PDGFs in liver cirrhosis.

\subsection{Aim of Study}

Recently published data clearly demonstrate that there are functionally different fibroblast populations within the liver. Apart from HSCs, LMFs can be regarded as an essential cell type of fibroblast lineage involved in liver fibrogenesis. Clearly, detailed insights into the mechanism of myofibroblast proliferation in the liver will allow to identify new molecular targets and to develop new therapeutic modalities for more specific, effective, less harmful modes of treatment capable to cease a progression of liver cirrhosis. Some of these targets could be components of the IGF axis. Therefore, the purpose of the current work was to study the expression and regulation of the IGF axis components in rat LMFs, and the specific issues which were addressed in this work are:

1) to assess the capability of LMFs of expressing IGF-I and IGF-II;

2) to study the expression of receptors for the IGFs and to characterize their regulation;

3) to determine IGFBP species produced by LMFs and to elucidate their regulation at transcriptional, protein and posttranslational levels;

4) to evaluate mitogenic and fibrogenic effects of IGF-I in LMFs;

$5)$ to determine the role of endogenous and exogenous IGFBPs in LMFs physiology;

6) to study a cross-talk between PDGFR and IGF-IR signalling systems in rat LMFs and to understand its implication for liver fibrogenesis. 


\section{Materials}

\subsection{Animals}

Adult Wistar rats were purchased from Charles River (Sulzfeld, Germany) and kept at $19-23^{\circ} \mathrm{C}$ under standard conditions with 12-hour light/dark cycles and access to fresh water and food ad libitum. Daily rats received $12-15 \mathrm{~g}$ of a standard laboratory chow diet as well as $12-25 \mathrm{ml}$ of water, and had a 30-40 g gain of weight per week. Animals were used for experiments not earlier than 6 days after arrival. The preparation of liver cells was performed during the first three hours of the light phase. Rats were anesthetized by intraperitoneal injection of pentobarbital $(400 \mathrm{mg} / \mathrm{kg}$ body weight). All animals received humane care in accordance with the institution's guidelines, the German Convention for Protection of Animals and the National Institutes' of Health guidelines.

\subsection{Bacterial Strain and Vectors}

\subsubsection{Bacterial Strain}

E. coli DH5a strain [genotype: supE44, thi-1, recA1, relA1, hsdR17(rK-mK+), thi-1, $\Delta$ lacU169( $\$ 80$ lacZAM15), endA1, gyrA (Nal')] (Stratagene, Heidelberg, Germany) was used for plasmid transformation.

\subsubsection{Vectors}

\subsubsection{1. pBluescript $S K+$ Vector}

For molecular subcloning of rat IGF-I, IGF-II, IGFBP-2 and IGFBP-3 specific cDNA fragments the phagemid pBluescript SK+ (Stratagene) was used. This phagemid derived from the vector pUC19 consists of $2961 \mathrm{bp}$ and has the orientation of the multiple cloning site in which lacZ transcription proceeds from Sacl to Kpnl. The "+" symbol on the pBluescript II phagemid indicates the orientation of the cloned phage f1 intergenic region carrying the sequences required in cis for initiation and termination of phage f1 DNA synthesis and for packaging of DNA into bacteriophage particles. The vector contains T3 and T7 RNA polymerase promoters necessary for in vitro transcription, a multiple cloning region (polylinker) containing sites for different restriction endonucleases, and primer sequences (for universal and reverse primers) necessary for DNA sequencing. 


\subsubsection{2. $p G E M^{\circledR}-3 Z$ and $p G E M^{\circledR}-4 Z$ Vectors}

The $p G E M^{\circledR}-4 Z$ and pGEM $^{\circledR}-3 Z$ vectors were obtained from Promega (Mannheim, Germany). These standard cloning vectors were used to subclone rat IGF-IR and IGFII/M6-PR specific cDNA fragments, respectively, which were further used for Northern blot analysis. The pGEM ${ }^{\circledR}-4 Z$ and $p G E M^{\circledR}-3 Z$ vectors consist of $2746 \mathrm{~kb}$ and $2743 \mathrm{~kb}$, respectively. The vectors carry the lac $Z$ a-peptide and the multiple cloning region arrangement from pUC18 allowing recombinants to be easily selected using blue/white color screening. In addition, the vectors contain both the SP6 and T7 RNA polymerase promoters flanking the multiple cloning region and, therefore, apart from standard cloning they can be used also for in vitro transcription. The vectors are convenient for cloning, because their multiple cloning site provides a selection of restriction sites. The pGEM ${ }^{\circledR}-3 Z$ and $p G E M^{\circledR}-4 Z$ vectors are essentially identical except for the orientation of the SP6 and T7 promoters.

\subsubsection{3. $p C R^{\circledR} / /$ Vector}

The $\mathrm{pCR}{ }^{\circledR}$ II vector was purchased from Invitrogen (Karlsruhe, Germany) to subclone rat PDGFR $\alpha$ and PDGFR $\beta$ specific cDNA fragments. The vector consists of $3932 \mathrm{bp}$ and contains Sp6 and T7 RNA polymerase promoters, necessary for in vitro transcription, a multiple cloning site containing a variety of sites for different restriction endonucleases as well as primer sequences necessary for DNA sequencing.

\subsubsection{4. $p B R 322$ Vector}

The pBR322 vector was obtained from Promega and was used for subcloning of human $\alpha_{2}$ chain of type I collagen cDNA fragment. The vector contains $4361 \mathrm{bp}$ and comprises the replicon rep responsible for plasmid replication, the rop gene coding for Rop protein which promotes conversion of the unstable RNA I - RNA II complex to the stable complex and serves to decrease copy number, the bla gene coding for beta-lactamase that confers resistance to ampicillin and the tet gene responsible for resistance to tetracycline. 


\section{3. cDNA Probes and Oligonucleotides}

The following CDNA probes were used for Northern blot analysis:

1) 700 bp EcoRI-HindIII fragment of rat IGF-I cDNA donated by Drs. Schwander and Margot (Basel, Switzerland);

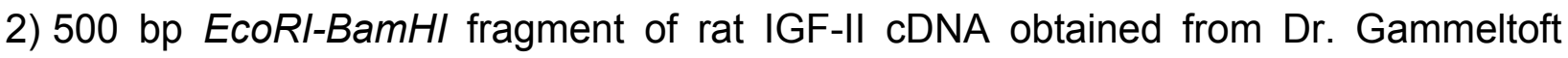
(Copenhagen, Denmark);

3) 265 bp EcoRI-Smal fragment of rat IGF-IR cDNA (Werner et al., 1989) provided by Drs. LeRoith and Roberts (Bethesda, MD, USA);

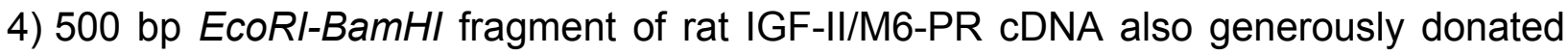
by Drs. LeRoith and Roberts;

5) 397 bp EcoRI-HindIII insert of clone pRBP2-501 coding for rat IGFBP-2 (Shimasaki and Ling, 1991) provided by Drs. Ling and Shimasaki (La Jolla, CA, USA);

6) $699 \mathrm{bp} \mathrm{Apal-BamHI}$ insert of clone pRBP3-AR encoding rat IGFBP-3 (Shimasaki and Ling, 1991) also from Drs. Ling and Shimasaki;

7) $1500 \mathrm{bp} \mathrm{EcoRI-Xhol} \mathrm{insert} \mathrm{of} \mathrm{clone} \mathrm{HF32} \mathrm{coding} \mathrm{for} \mathrm{human} \alpha_{2}(I)$ chain of type I procollagen (Myers et al., 1981) obtained from Dr. Myers (Philadelphia, PA, USA);

8) $308 \mathrm{bp} E c o R I-E c o R /$ fragment of rat PDGFR $\alpha$ cDNA generated by polymerase chain reaction (PCR) by the group of Dr. Knittel (Dept. of Gastroenterology, University of Göttingen) using rat olfactory epithelium-derived cDNAs as a template (Lee et al., 1990);

9) $363 \mathrm{bp} E c o R I-E c o R I$ fragment of rat PDGFR $\beta$ cDNA also generated by PCR by the group of Dr. Knittel using rat brain-derived cDNAs as a template (Herren et al., 1993).

An oligonucleotide 5' AAC GAT CAG AGT AGT GGT ATT TCA CC 3' complementary to $28 \mathrm{~S}$ rRNA (MWG Biotech, Ebersberg, Germany) was used to quantify Northern blots.

\subsection{Antibodies}

\subsubsection{Primary Antibodies}

Anti-IGF-I Antibody (Ab)

A goat polyclonal antiserum (R\&D Systems, Wiesbaden, Germany) raised against E.coli-derived recombinant mouse IGF-I was used for the neutralization of IGF-I endogenously produced by cultured rat liver myofibroblasts. Immunoglobulin (Ig) G specific for mouse IGF-I was purified by affinity chromatography. 


\section{Anti-IGFBP-2 Ab}

A rabbit polyclonal antiserum (Upstate Biotechnology, Lake Placid, NY, USA) raised against bovine IGFBP-2 purified by immunoaffinity chromatography and highperformance liquid chromatography (HPLC) from conditioned medium of Madin Darby Bovine Kidney cells was used for the detection of IGFBP-2 by Western immunoblotting. Species reactivity: human, mouse, rat, bovine, goat, equine, porcine.

\section{Anti-IGFBP-3 Ab}

A rabbit polyclonal antiserum (GroPep, Adelaide, Australia) raised against a synthetic peptide of unique sequence from the central domain of mouse IGFBP-3 was used for the detection of rat IGFBP-3 by Western immunoblotting.

\section{Anti-IGF-II/M6-PR Ab}

For the detection of the IGF-II/M6-PR by immunoprecipitation, rabbit polyclonal antiserum raised against a sequence from the extracytoplasmic domain of the IGFII/M6-PR of rat origin was used. This antibody was kindly provided by Dr. T.Braulke (Dept. of Biochemistry II, University of Goettingen). Species reactivity: rat.

\section{Anti-IGF-IR $\beta A b$}

For the detection of the IGF-IR $\beta$ by Western immunoblotting and immunoprecipitation, an affinity purified rabbit polyclonal antiserum raised against a peptide mapping at the carboxy terminus of the IGF-IR $\beta$ of human origin was used (Santa Cruz Biotechnology, Santa Cruz, CA, USA). Species reactivity: mouse, rat, human.

\section{Anti-PDGFR $\beta A B$}

An affinity purified rabbit polyclonal antiserum (Santa Cruz Biotechnology) raised against a recombinant protein corresponding to amino acids 958-1106 mapping at the carboxy terminus of the PDGFR $\beta$ of human origin was used for the detection of the PDGFR $\beta$ by Western immunoblotting and immunoprecipitation. Species reactivity: mouse, rat, human. 


\section{Anti-PDGFR $\alpha A b$}

For the detection of the PDGFR $\alpha$ by Western immunoblotting and immunoprecipitation, an immunoaffinity purified rabbit polyclonal antibodies raised against a synthetic peptide conjugated with keyhole limpet hemocyanin $(\mathrm{KLH})$ corresponding to amino acids 10351053 of human PDGFR $\alpha$ were used (Upstate Biotechnology). Species reactivity: human, mouse, frog, chicken, rat, zebra fish.

\section{Anti-IRS-1 Ab}

For the detection of IRS-1 by Western immunoblotting and immunoprecipitation, an affinity purified rabbit polyclonal antiserum raised against a peptide mapping at the carboxy terminus of IRS-1 of human origin was used (Santa Cruz Biotechnology). Species reactivity: mouse, rat, human.

\section{Anti-IRS-2 Ab}

An affinity purified goat polyclonal antiserum (Santa Cruz Biotechnology) raised against a peptide mapping at the carboxy terminus of IRS-2 of mouse origin was used for the detection of IRS-2 by Western immunoblotting and immunoprecipitation. Species reactivity: mouse, rat, human.

\section{Anti-Gab-1 Ab}

For the detection of Gab-1 by Western immunoblotting and immunoprecipitation, a rabbit polyclonal antiserum raised against an 31 residue peptide sequence corresponding to C-terminal residues 664-694 of Gab-1 was used (Upstate Biotechnology). Species reactivity: human, mouse, rat.

\section{Anti-PLC $\gamma_{1} A b$}

An affinity purified rabbit polyclonal antiserum (Santa Cruz Biotechnology) raised against a peptide mapping within the C-terminal domain of PLC $\gamma_{1}$ of bovine origin was used for the detection of PLC $\gamma_{1}$ by Western immunoblotting and immunoprecipitation. Species reactivity: mouse, rat, human.

\section{Anti-Phosphotyrosine Ab}

A mouse monoclonal antibody (clone PY20) raised against phosphotyrosine (Oncogene, San Diego, CA, USA) was used for the immunovisualization of the 
immunoprecipitated proteins phosphorylated on tyrosine residues. This antibody was generated by immunizing BALB/c mice with the phosphotyrosine hapten conjugated to a carrier protein and fusing with NS-1 mouse myeloma cells. Resulting hybridomas were selected for reactivity with the phosphotyrosine hapten by ELISA. Species reactivity: all.

\section{Anti-Phospho-ERK Ab}

A mouse phospho-ERK1/2 (Thr202/Tyr204) monoclonal antibody (E10) (Cell Signaling, Beverly, MA, USA) was used to detect endogenous levels of p44 and p42 MAP kinases (ERK1 and ERK2) dually phosphorylated at threonine 202 and tyrosine 204 by Western immunoblotting. This antibody was produced by immunizing mice with a KLH-coupled synthetic phosphopeptide corresponding to residues around Thr202/Tyr204 of human p44 MAP kinase. Species reactivity: human, mouse, rat, hamster, zebra fish.

\section{Anti-Phospho-JNK Ab}

A mouse phospho-SAPK/JNK (Thr183/Tyr185) monoclonal antibody (G9) (Cell Signaling, Beverly, MA, USA) purified from ascitic fluid by affinity chromatography was used to detect endogenous levels of p46 and p54 SAPK/JNK dually phosphorylated at threonine 183 and tyrosine 185 by Western immunoblotting. This antibody was generated by immunizing mice with a KLH-coupled synthetic phosphopeptide corresponding to residues around Thr183/Tyr185 of human SAPK/JNK. Species reactivity: human, mouse, rat.

\section{Anti-Phospho-p38 Ab}

A mouse phospho-p38 kinase (Thr180/Tyr182) monoclonal antibody (28B10) (Cell Signaling) was used to detect p38 kinase phosphorylated at threonine 180 and tyrosine 182 by Western immunoblotting. This antibody was produced by immunizing mice with a KLH-coupled synthetic phosphopeptide corresponding to residues around Thr183/Tyr185 of human p38 kinase. Species reactivity: human, mouse, rat.

\section{Anti-Fibronectin Ab}

A rabbit polyclonal antiserum (Boehringwerke, Marburg, Germany) was used for the detection of fibronectin by Western immunoblotting. Species reactivity: human, rat, mouse. 


\section{Anti-Fibulin $2 A b$}

An affinity purified goat polyclonal antiserum (Santa Cruz Biotechnology) raised against a peptide mapping near the carboxy terminus of human fibulin-2 was used for the detection of fibulin-2 by Western immunoblotting and immunocytochemistry. Species reactivity: mouse, rat, human.

\section{Anti-Collagen I $A b$}

A rabbit polyclonal antiserum (Calbiochem, San Diego, CA, USA) raised against type I collagen purified from fetal mouse skin was used for the detection of type I collagen by Western immunoblotting and immunocytochemistry. Species reactivity: human, mouse, rat.

\section{Anti-Collagen IV Ab}

A mouse monoclonal antibody (clone IV-4H12) raised against type IV collagen (Oncogene) was used for the detection of this matrix protein by Western immunoblotting. This antibody was generated by immunizing BALB/c mice with a purified type IV collagen protein of human origin and fusing with NS-1 mouse myeloma cells. Species reactivity: human.

\section{Anti-Laminin Ab}

A rabbit polyclonal antiserum (Calbiochem, San Diego, CA, USA) was used for the detection of laminin by Western immunoblotting. Species reactivity: rat.

\section{Anti- $\alpha-$ Actin $A b$}

To detect $\alpha$-smooth muscle actin, mouse monoclonal antibody (clone 1A4, IgG2a isotype) was used (Sigma, Munich, Germany). This antibody was derived from the hybridoma produced by the fusion of mouse myeloma cells and splenocytes from an immunized mouse. The KLH-coupled $\mathrm{N}$-terminal synthetic decapeptide of $\alpha$-actin was used as immunogen. This antibody recognizes sarcomeric a-isoform of actin abundantly expressed in skeletal and cardiac muscle.

\section{Anti- $\beta$-Actin Ab}

For the detection of $\beta$-actin, mouse monoclonal antibody ( $\mathrm{AC}-15$ clone) raised against $\mathrm{N}$-terminal peptide of $\beta$-actin was used (Sigma, Munich, Germany). This antibody 
recognizes ubiquitously expressed $\beta$-isoform of actin and does not cross-react with sarcomeric a-isoform. Species reactivity: human, bovine, sheep, pig, rabbit, dog, mouse, rat, guinea pig, chicken, carp, fruit fly.

\subsubsection{Secondary Antibodies}

Peroxidase-Conjugated Swine Anti-Rabbit Immunoglobulins (Ig)

For the detection of a primary antibody of rabbit origin bound to a protein of interest by Western immunoblotting and immunocytochemistry, the secondary horseradish peroxidase-conjugated swine antibodies directed against rabbit immunoglobulins were used (DAKO, Copenhagen, Denmark). Species reactivity: rabbit.

\section{Peroxidase-Conjugated Rabbit Anti-Mouse Ig}

For the detection of a primary antibody of mouse origin bound to a protein of interest by Western immunoblotting and immunocytochemistry, the secondary horseradish peroxidase-conjugated rabbit anti-mouse immunoglobulins were used (DAKO, Copenhagen, Denmark). Species reactivity: mouse.

\section{Peroxidase-Conjugated Rabbit Anti-Goat lg}

For the detection of a primary antibody of goat origin bound to a protein of interest by Western immunoblotting, the secondary horseradish peroxidase-conjugated rabbit antigoat immunoglobulins were used (DAKO, Copenhagen, Denmark). Species reactivity: goat.

\subsection{Proteins, Enzymes and Protein Standards}

$\left[{ }^{125} \mathrm{I}\right]-$ IGFBP-2, recombinant, human

$\left[{ }^{125} \mathrm{I}\right]-$ IGFBP-3, recombinant, human
Dr. Braulke, Department of Biochemistry, Children's Hospital, University Hospital Hamburg Eppendorf, Hamburg, Germany

Dr. Braulke, Department of Biochemistry, Children's Hospital, University Hospital Hamburg Eppendorf, Hamburg, Germany

Promocell, Heidelberg, Germany human

Bovine serum albumin (BSA)
PAA, Linz, Austria 
Collagenase $\mathrm{H}$

Collagenase type I

DNase I

Epidermal growth factor, recombinant, human

Glucose oxidase

Growth hormone, human

IGFBP-2, recombinant, human

IGFBP-3, recombinant, human

IGF-I, recombinant, human

IGF-I, recombinant, human, in powder, for iodination

Insulin, porcine

Long ${ }^{T M} R^{3} I G F-I$, recombinant, human

PDGF-BB, rat, recombinant

Pronase E

Protein A sepharose 4 fast flow

Rainbow $^{\mathrm{TM}}$ colored protein molecular weight markers

Restriction enzymes with buffers

TGF- $\beta 1$, human, recombinant
Roche, Mannheim, Germany

Biochrom, Berlin, Germany

Roche, Mannheim, Germany

Promocell, Heidelberg, Germany

Sigma, Munich, Germany

Nordisk, Mainz, Germany

R\&D Systems, Wiesbaden, Germany

R\&D Systems, Wiesbaden, Germany

PeproTech, Rocky Hill, NJ, USA

GroPep, Adelaide, Australia

Sigma, Munich, Germany

GroPep, Adelaide, Australia

Sigma, Munich, Germany

Merck, Darmstadt, Germany

Amersham Biosciences, Freiburg, Germany

Amersham Biosciences, Freiburg, Germany

Boehringer Mannheim, Mannheim, Germany

PeproTech, Rocky Hill, NJ, USA

\subsection{Pharmacological Inhibitors and Activators}

I-Ome-AG538,

a selective inhibitor of IGF-IR kinase

Agaricus bisporus lectin, a non-selective inhibitor of nuclear import

$m-3 M 3 F B S$,

a specific activator of phospholipase $C$

PD98059,

a selective inhibitor of MEK
Calbiochem, San Diego, CA, USA

Sigma, Munich, Germany

Calbiochem, San Diego, CA, USA

Alexis, Grünberg, Germany 
SB203580,

a selective inhibitor of p38 kinase

SP600125,

a selective inhibitor of JNK

U-73122,

a selective inhibitor of phospholipase $\mathrm{C}$

\subsection{Protease Inhibitors}

Antipain

Benzamidine

Chymostatin

Leupeptin

Pepstatin A

Phenylmethanesulfonyl fluoride (PMSF)

\subsection{Phosphatase Inhibitors}

Sodium fluoride

Sodium orthovanadate

Tetrasodium pyrophosphate

$\beta$-glycerophosphate

\subsection{Detergents}

CHAPS

Nonidet P-40 (NP-40)

Sodium dodecyl sulfate (SDS)

Triton X-100

Tween 20
Calbiochem, San Diego, CA, USA

Alexis, Grünberg, Germany

Calbiochem, San Diego, CA, USA
Sigma, Munich, Germany

Sigma, Munich, Germany

Sigma, Munich, Germany

Sigma, Munich, Germany

Sigma, Munich, Germany

Sigma, Munich, Germany

Merck, Darmstadt, Germany

Sigma, Munich, Germany

Sigma, Munich, Germany

Sigma, Munich, Germany
Roche, Mannheim, Germany

USB, Cleveland, OH, USA

Roth, Karlsruhe, Germany

Serva, Heidelberg, Germany

Serva, Heidelberg, Germany 


\subsection{Detection, Purification and Synthesis Systems (Kits)}

5-Bromo-2'-Deoxy-Uridine Labelling and Detection kit III, Roche, Mannheim, Germany Agarose Gel DNA Extraction Kit, Roche, Mannheim, Germany

BCA Protein Assay, Pierce, Bonn, Germany

EndoFree ${ }^{\mathrm{TM}}$ Plasmid Maxi Kit, Qiagen, Hilden, Germany

NEBlot ${ }^{\circledR}$ Kit, New England Biolabs, Schwalbach, Germany

NE-PER ${ }^{\circledR}$ Nuclear and Cytoplasmic Extraction Reagents, Pierce, Bonn, Germany

Nick Translation Kit, Invitrogen, Karlsruhe, Germany

SuperSignal ${ }^{\circledR}$ West Pico Chemiluminescent Substrate, Pierce, Bonn, Germany

\subsection{Stock Solutions}

All stock solutions were prepared either in double distilled water $\left(\mathrm{ddH}_{2} \mathrm{O}\right)$ or (for experiments with RNA) in RNase-free water; the $\mathrm{pH}$ values of stock solutions are presented as the values at $25^{\circ} \mathrm{C}$.

Ammonium persulphate (APS) $10 \%$

For $10 \mathrm{ml}$

APS $1 \mathrm{~g}$

$\mathrm{ddH}_{2} \mathrm{O}$ to $10 \mathrm{ml}$

The solution was dispensed into $100 \mu \mathrm{l}$ aliquots and stored at $-20^{\circ} \mathrm{C}$.

Citric acid $0.25 \mathrm{M}$

For $100 \mathrm{ml}$

Citric acid

$4.8 \mathrm{~g}$

RNase-free $\mathrm{H}_{2} \mathrm{O}\left(\right.$ Ampuwa $^{\circledR}$ ) to $100 \mathrm{ml}$

The solution was stored at room temperature (RT).

EDTA $0.5 \mathrm{M}$

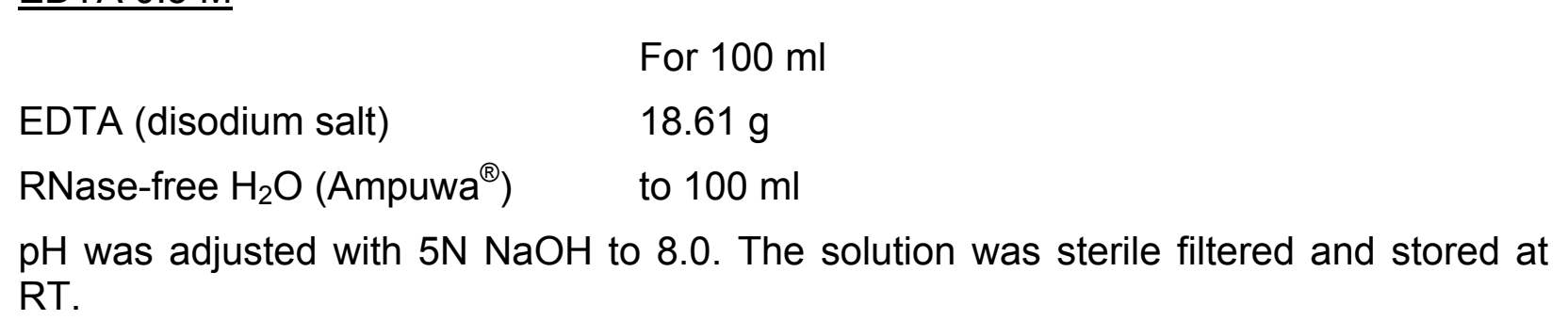


Phosphate-buffered saline (PBS) 10X

For 11

Final concentration

$\mathrm{NaCl}$

$81.82 \mathrm{~g}$

$1.4 \mathrm{M}$

$\mathrm{KCl}$

$2 \mathrm{~g}$

$27 \mathrm{mM}$

$\mathrm{Na}_{2} \mathrm{HPO}_{4}$

$14.2 \mathrm{~g}$

$100 \mathrm{mM}$

$\mathrm{KH}_{2} \mathrm{PO}_{4}$

$2.45 \mathrm{~g}$

$18 \mathrm{mM}$

$\mathrm{ddH}_{2} \mathrm{O}$

to 1 I

$\mathrm{pH}$ was adjusted with $\mathrm{HCl}$ to 7.3. The solution was stored at RT.

SDS $20 \%$

For $100 \mathrm{ml}$

SDS

$20 \mathrm{~g}$

$\mathrm{ddH}_{2} \mathrm{O}$

to $100 \mathrm{ml}$

In the case of SDS precipitation, the solution was warmed until it became clear.

Sodium acetate $2 \mathrm{M}$

For $100 \mathrm{ml}$

Sodium acetate

$16.408 \mathrm{~g}$

RNase-free $\mathrm{H}_{2} \mathrm{O}\left(\right.$ Ampuwa ${ }^{\circledR}$ )

to $100 \mathrm{ml}$

$\mathrm{pH}$ was adjusted with acetic acid to 5.4. The solution was stored at RT.

Sodium citrate $0.25 \mathrm{M}$

For $100 \mathrm{ml}$

Sodium citrate

$7.35 \mathrm{~g}$

RNase-free $\mathrm{H}_{2} \mathrm{O}\left(\right.$ Ampuwa $^{\circledR}$ )

to $100 \mathrm{ml}$

$\mathrm{pH}$ was adjusted with $0.25 \mathrm{M}$ citric acid to 7.0 ; the solution was stored at RT.

$\underline{\text { Tris- } \mathrm{HCl} 2 \mathrm{M}}$

For 1 I

Tris- $\mathrm{HCl}$

$315.2 \mathrm{~g}$

RNase-free $\mathrm{H}_{2} \mathrm{O}$ (Ampuwa ${ }^{\circledR}$ )

to 1 I

$\mathrm{pH}$ was adjusted with $\mathrm{NaOH}$ to 7.4 . The solution was sterile filtered and stored at $4{ }^{\circ} \mathrm{C}$. 


\subsection{Chemicals}

All chemicals were of analytical grade and obtained from commercial sources as indicated.

Amersham Biosciences, Freiburg, Germany

$\left[{ }^{35} \mathrm{~S}\right]$-labelled methionine (specific activity $1,000 \mathrm{Ci} / \mathrm{mmol}$ ), [a- $\left.{ }^{32} \mathrm{P}\right]$-labelled deoxycytidine-triphosphate (specific activity $3,000 \mathrm{Ci} / \mathrm{mmol}$ ), Amplify fluorographic solution, Ficoll ${ }^{\circledR} 400$, Percoll ${ }^{\circledR}$, sodium $\left[{ }^{125} \mathrm{l}\right]$ iodide (carrier-free, specific activity $16.85 \mathrm{mCi} / \mu \mathrm{g}$ )

AppliChem, Darmstadt, Germany

Glycin, nonfat dried milk powder

Biochrom, Berlin, Germany

M199, fetal calf serum, trypan blue, trypsin

Bio-Rad, Munich, Germany mixed bed resin AG 501-X8(D)

Boehringer, Mannheim, Germany

Ampicillin

Chemicon, Temecula, CA, USA

Re-Blot Plus (strong antibody stripping solution)

Difco Laboratories, Detroit, MI, USA

Bactoagar, bacto-trypton, yeast extract

Fresenius, Bad Homburg, Germany

Ampuwa $^{\circledR}$ water

Invitrogen, Karlsruhe, Germany

$123 \mathrm{~kb}$ DNA ladder, agarose, guanidine isothiocyanate, low melting point agarose

MBI Fermentas, St. Leon-Rot, Germany

$6 \mathrm{x}$ loading dye

Merck, Darmstadt, Germany

All standard chemicals, acetic acid, acetone, bromophenol blue, chloramine T, ethanol, $37 \%$ formaldehyde, formamide, glycerol, Kaiser's glycerol gelatin, Meyer's hemalum solution, methanol, $\beta$-mercaptoethanol, penicillin $G$, sodium bisulphite, sodium fluoride, streptomycin

Merial, Hallbergmoos, Germany

Pentobarbital sodium (Narcoren ${ }^{\circledR}$ )

Nyegaard, Oslo, Norway

Nycodenz ${ }^{\circledR}$

PAA, Linz, Austria

Dulbecco's modified Eagle medium (DMEM), L-Glutamine 
Paesel and Lorei, Frankfurt, Germany

Cesium chloride

Pierce, Bonn, Germany

Trifluoroacetic acid

Roche, Mannheim, Germany

Fish sperm DNA

Roth, Karlsruhe, Germany

Acetonitril, hydrogen peroxide, Rotiphorese Gel 30 (30\% acrylamide stock solution with $0.8 \%$ bisacrylamide in proportion $37.5: 1$ )

Promocell, Heidelberg, Deutschland

Endothelial cell basal medium

Serva, Heidelberg, Germany

Ammonium persulfate, ponceau $\mathrm{S}$, tetramethyl ethylene diamine (TEMED), Tris- $\mathrm{HCl}$, Triton X-100, Tween 20

Sigma-Aldrich Chemie, Munich, Germany

All standard chemicals, citric acid, dexamethasone, dimethyl sulfoxide (DMSO), dithiothreitol (DTT), fish gelatine, EDTA, EGTA, ethidium bromide, glucose, HEPES, MOPS, N-lauroylsarcosyl, sodium acetate, sodium citrate

Stratagene, Heidelberg, Germany)

QuikHyb ${ }^{\circledR}$ Hybridization Solution

Zinsser Analytic, Frankfurt, Germany

Scintillation liquid

\subsection{Other Materials}

24-well plates, Petri dishes $(100 \mathrm{~mm})$ for bacterial cultures, Greiner, Frickhausen, Germany

6-well plates, 96-well microtiter plates, Lab-Tek chamber slides, Nunc, Naperville, IL, USA

Cover-slips, 24×55 mm, Menzel-Gläser, Braunschweig, Germany

Culture dishes (35, 100 and 150 mm), Becton Dickinson Labware, Lincoln Park, NJ, USA

Hybond N nylon membrane, disposable NICK columns prepacked with Sephadex ${ }^{\circledR}$ G-50 DNA grade, Amersham Biosciences, Freiburg, Germany

Hybridization glass tubes, Biometra, Göttingen, Germany 
Intravenous cannula with injection port, Braun, Melsungen, Germany

Intravenous cannula with injection port, Klinika Medical, Usingen, Germany

Latex powder-free gloves, Kimberly-Clark, Zaventem, Belgium

Microscope glass slides, 76x26 mm, Menzel-Gläser, Braunschweig, Germany

Nitrile gloves Nitra Tex, Ansell, Kulim, Malaysia

Nitrocellulose Transfer Membrane, Sartorius, Göttingen, Germany

Polyallomer thin-walled centrifuge tubes ( $5 \mathrm{ml}$ ), Beckman, Munich, Germany

Safe-Lock tubes $(0.2,0.5,1.5$ and $2 \mathrm{ml})$, Eppendorf, Hamburg, Germany

Scintillation vials $(5 \mathrm{ml})$, Zinsser Analytic, Frankfurt, Germany

Serological pipettes $(2,5,10,25 \mathrm{ml})$, transfer pipettes, plastic tubes (15 and $50 \mathrm{ml}$ ), Sarstedt, Nümbrecht, Germany

Sterile filter Nalgene, $0.2 \mu \mathrm{m}$, Sartorius, Göttingen, Germany

Sterile filter pipette tips, Biozym, Oldendorf, Germany

Whatman 3MM paper, Schleicher and Schuell, Dassel, Germany

$X$-ray films Hyperfilm ${ }^{\mathrm{TM}}$, Amersham Biosciences, Freiburg, Germany

X-ray films X-Omat AR, Kodak, Rochester, NY, USA

X-ray films, Fuji, Düsseldorf, Germany

X-ray films, Konica, Hohenbrunn, Germany

\subsection{Instruments}

Automatic pipettes, type Reference ${ }^{\circledR}$, Eppendorf, Hamburg, Germany

Automatic pipettes, type Pipetman, Gilson, Bad Camberg, Germany

Bench-top centrifuges, high speed centrifuges, ultracentrifuges and rotors:

Beckman model J2-21 centrifuge

Beckman rotor JE-6B

Centricon T-2070 ultracentrifuge

Centricon rotor TST55.5 - 55000 rpm

Eppendorf bench-top centrifuge, type MiniSpin 5415C

Hettich Mikro Rapid/K centrifuge

Hettich Rotina 3850 centrifuge

Hettich Rotina 48RS centrifuge

Hettich Rotixa/RP centrifuge

Minifuge GL centrifuge

Sigma 3 K30 centrifuge

Rotor Nr 12156 - 16500 rpm

Rotor Nr 12153 - 22000 rpm
Beckman, Munich, Germany

Kontron Instruments, Neufahrn, Germany

Eppendorf, Hamburg, Germany

Hettich, Tuttlingen, Germany

Heraeus-Christ, Osterode, Germany

Sigma Laboratory Centrifuges, Osterode, Germany 
Digital photocamera Canon EOS D60 and software Remote Capture 2.5, Canon, Tokyo, Japan

Eagle Eye ${ }^{\mathrm{TM}}$ system with built-in ultraviolet emitter, video camera and frame integrator, Stratagene, Amsterdam, Netherlands

Electrophoresis power supply Power Pac 300, Bio-Rad, Munich, Germany

Electrophoresis power supply ST305, Invitrogen, Karsruhe, Germany

End-over-end rotator, W.Krannich, Göttingen, Germany

Gamma-counter, Mini-instruments, Burnham-on-Crouch, UK

Gas controlled incubators, Heraeus-Electronic, Hannover, Germany

Geiger hand gamma-counter, Berthold, Oak Ridge, TN, USA

Gel dryer, LKB Bromma, Bromma, Sweden

Horizontal gel electrophoresis system Horizon ${ }^{\circledR} 11-14$, Invitrogen, Karsruhe, Germany

Horizontal gel electrophoresis system Horizon ${ }^{\circledR} 58$, Invitrogen, Karsruhe, Germany

Hybridization oven, Biometra, Göttingen, Germany

Ice machine, Ziegra, Isernhagen, Germany

Incubator with shaking for bacterial culture, model 3-25, New Brunswick Scientific Co., Edison, New Jersey, USA

Liquid scintillation counter Wallac 1409, EG\&G, Turku, Finland

Magnetic mixer with warming, type M21/1 Framo-Gerätetechnik, Eisenach, Germany

Microplate reader MRX, Dynatech Laboratories, Chantilly, VA, USA

Microscope Axioscop with fotocamera MC 100 Spot, Zeiss, Oberkochen, Germany

Microscope Axiovert 25, Zeiss, Oberkochen, Germany

Microwave, Whirlpool, Comerio, Italy

Mini-vertical gel electrophoresis unit Hoefer Mighty Small II, Amersham Biosciences, Freiburg, Germany

Peristaltic pump P-1, Amersham Biosciences, Freiburg, Germany

pH-Meter, Glas-Gerätebau, Bovenden, Germany

Pipette holder with safety valve, filter and wall holder; Hirschmann Laborgeräte, Eberstadt, Germany

Rocking platform, Biometra, Göttingen, Germany

Savant Speed Vac ${ }^{\circledR}$ concentrator, ThermoLife Sciences, Egelsbach, Germany

Scanning densitometer, Molecular Analyst, Bio-Rad Hercules, CA, USA

Sonicator Sonoplus HD 70, Bandelin, Berlin, Germany

Standard dual cooled gel electrophoresis unit Hoefer SE 600, Amersham Biosciences, Freiburg, Germany

Sterile bench, The Baker Company, Sanford, ME, USA

Thermomixer 5436, Eppendorf, Hamburg, Germany 
Thermostat, Heraeus, Hanau, Germany

Thermostatic calculator, model 2219 Multitemp II, LKB Bromma, Bromma, Sweden

Transfer electrophoresis unit Hoefer TE 50X, Amersham Biosciences, Freiburg, Germany

Transfer electrophoresis unit Mini Trans-Blot ${ }^{\circledR}$, Bio-Rad, Munich, Germany

Ultra-pure water system Milli-Q, Millipore, Molsheim, France

UV spectrophotometer, RNA/DNA Calculator GeneQuant II, Pharmacia Biotech, Freiburg, Germany

UV-light crosslinker, Stratalinker ${ }^{\mathrm{TM}}$ 180, Stratagene, Heidelberg, Germany

Vortex, Genie $2^{\mathrm{TM}}$, Bender and Hobein, Zurich, Switzerland

Vortex, with platform, Schütt Labortechnic, Göttingen, Germany

Water bath, W.Krannich, Göttingen, Germany

X-ray film cassettes $10 \times 18$, Siemens, Munich, Germany

X-ray film-developing machine SRX-101A, Konica Europe, Hohenbrunn, Germany 


\section{Methods}

\subsection{Cell Biology Methods}

\subsubsection{Isolation of Rat Hepatocytes}

Hepatocytes were isolated from male Wistar rats by circulating perfusion with collagenase as described previously (Seglen, 1973; Katz et al., 1979) with slight modifications.

\subsubsection{Liver Perfusion}

Rats were anesthetized by intraperitoneal injection of Pentobarbital-sodium and fixed on the preparation desk. The abdomen was desinfected with $70 \%$ ethanol and opened by longitudinal incision along linea alba up to processus xyphoideus giving access to the liver sinus and portal vein. After laparotomy, the vena portae was canulated, vena cava inferior was ligated above the diaphragm to prevent flow of the perfusion media into the circulation. Then the vena cava inferior was cut beneath the liver and canulated as well. The liver was perfused first in a non-recirculative mode through the portal vein with $150-200 \mathrm{ml}$ of $\mathrm{CO}_{2}$-enriched preperfusion medium at a flow rate of $30 \mathrm{ml} / \mathrm{min}$ until the liver was free from blood. Further, in order to break down sufficiently an extracellular matrix, the liver was perfused in a recirculative mode with collagenase perfusion medium until it started to soften (about 7-11 min).

\subsubsection{Preparation of Hepatocyte Suspension}

After perfusion, the liver was excised and transferred to a sterile glass beaker filled with culture medium M199 and supplements. Glisson's capsule was carefully removed and discarded. To obtain a cell suspension, the tissue was disrupted mechanically using sterile forceps. Connective tissue and the remaining liver capsule as well as big cell aggregates were removed by filtration of the primary cell suspension through a nylon mesh (pore size $79 \mu \mathrm{m}$ ). Nonparenchymal cells and cell debris were removed by numerous selective sedimentations $\left(20 \times \mathrm{g}, 2 \mathrm{~min}, 4^{\circ} \mathrm{C}\right)$ in wash medium. The cell pellet was resuspended in culture medium, and hepatocytes were then separated by Percoll ${ }^{\circledast}$ density gradient centrifugation ( $1500 \times \mathrm{g}, 5 \mathrm{~min}, \mathrm{RT})$. Finally, purified hepatocytes were resuspended in serum-enriched M199 with supplements, plated onto 35- and 60-mm Falcon plastic dishes at a density $1 \times 10^{6}$ and $2 \times 10^{6}$ cells per dish, respectively, and incubated at $37^{\circ} \mathrm{C}$ in $5 \% \mathrm{CO}_{2}$ atmosphere and $95 \%$ humidity. After $3-4$ hours of culture, 
supernatans were replaced by fresh serum-free M199, and cells were incubated for the following 20 hours. Cell-free supernatants were collected and frozen at $-20^{\circ} \mathrm{C}$, and cells were rinsed in PBS buffer and frozen at $-80^{\circ} \mathrm{C}$ for subsequent experiments.

\subsubsection{Solutions and Media for Isolation and Culture of Rat Hepatocytes}

All media and solutions for cell culture were prepared in double distilled water, further purified by sterile filtration and stored at $4^{\circ} \mathrm{C}$. All solutions were prepared not more than one day before the isolation.

Krebs-Ringer stock solution

$\begin{array}{lll} & \text { For } 1 \mathrm{I} & \text { Final concentration } \\ \mathrm{NaCl} & 7 \mathrm{~g} & 120 \mathrm{mM} \\ \mathrm{KCl} & 0.36 \mathrm{~g} & 4.8 \mathrm{mM} \\ \mathrm{MgSO}_{4} \times 7 \mathrm{H}_{2} \mathrm{O} & 0.296 \mathrm{~g} & 1.2 \mathrm{mM} \\ \mathrm{KH}_{2} \mathrm{PO}_{4} & 0.163 \mathrm{~g} & 1.2 \mathrm{mM} \\ \mathrm{NaHCO}_{3} & 2.016 \mathrm{~g} & 24.4 \mathrm{mM} \\ \mathrm{ddH}_{2} \mathrm{O} & \text { to } 1 \mathrm{I} & \end{array}$

The solution was equilibrated with carbon dioxide and $\mathrm{pH}$ was adjusted to 7.35 .

Preperfusion medium

For 11 Final concentration

EGTA

$95.1 \mathrm{mg}$

$0.25 \mathrm{mM}$

Krebs-Ringer stock solution

to 11

Collagenase perfusion medium

$\begin{array}{lll} & \text { For } 100 \mathrm{ml} & \text { Final concentration } \\ \text { HEPES } & 360 \mathrm{mg} & 15 \mathrm{mM} \\ \mathrm{CaCl}_{2} \times 2 \mathrm{H}_{2} \mathrm{O} & 58.8 \mathrm{mg} & 4 \mathrm{mM} \\ \text { Collagenase } & 50 \mathrm{mg} & \\ \text { Krebs-Ringer stock solution } & \text { to } 100 \mathrm{ml} & \end{array}$

The medium was prepared directly prior to isolation, equilibrated with carbon dioxide for $30 \mathrm{~min}$ and finally sterile filtered. 
$\underline{\text { Wash medium }}$

$\begin{array}{lll} & \text { For } 1 \mathrm{I} & \text { Final concentration } \\ \mathrm{HEPES} / \mathrm{NaOH} \mathrm{pH} 7.4 & 4.77 \mathrm{~g} & 20 \mathrm{mM} \\ \mathrm{NaCl} & 7.00 \mathrm{~g} & 120 \mathrm{mM} \\ \mathrm{KCl} & 0.36 \mathrm{~g} & 4.8 \mathrm{mM} \\ \mathrm{MgSO}_{4} \times 7 \mathrm{H}_{2} \mathrm{O} & 0.30 \mathrm{~g} & 1.2 \mathrm{mM} \\ \mathrm{KH}_{2} \mathrm{PO}_{4} & 0.16 \mathrm{~g} & 1.2 \mathrm{mM} \\ \mathrm{BSA} & 4.00 \mathrm{~g} & 0.4 \% \\ \mathrm{ddH}_{2} \mathrm{O} & \text { to } 1 \mathrm{I} & \\ & & \\ \text { Percoll } & \\ \text { Percoll } & \\ \text { Gradient puffer } & & \end{array}$

Gradient buffer for Percoll ${ }^{\circledR}$ solution

For $100 \mathrm{ml} \quad$ Final concentration

$\begin{array}{lll}\mathrm{NaCl} & 8.18 \mathrm{~g} & 1.4 \mathrm{M} \\ \mathrm{KCl} & 0.37 \mathrm{~g} & 50 \mathrm{mM} \\ \mathrm{MgCl}_{2} & 0.163 \mathrm{~g} & 8 \mathrm{mM} \\ \mathrm{Na}_{2} \mathrm{HPO}_{4} & 0.28 \mathrm{~g} & 16 \mathrm{mM} \\ \mathrm{KH}_{2} \mathrm{PO}_{4} & 0.054 \mathrm{~g} & 4 \mathrm{mM} \\ \mathrm{ddH}_{2} \mathrm{O} & \text { to } 100 \mathrm{ml} & \end{array}$

$\mathrm{pH}$ was adjusted to 7.35 , the solution was then sterile filtered.

M199 with supplements (stock medium)

Solution A

For $500 \mathrm{ml}$

M199 with Earle's salts without

$\mathrm{NaHCO}_{3}$, in powder

1 bottle (for $1 \mathrm{I}$ )

BSA

$2.0 \mathrm{~g}$

HEPES

$3.6 \mathrm{~g}$

$\mathrm{ddH}_{2} \mathrm{O}$

to $500 \mathrm{ml}$

$\mathrm{pH}$ was adjusted to 7.35 , and the solution was equilibrated with carbon dioxide under the control of $\mathrm{pH}$. 


\section{Solution B}

For $500 \mathrm{ml}$

$\mathrm{NaHCO}_{3} \quad 1.5 \mathrm{~g}$

$\mathrm{dd}_{2} \mathrm{O}$ to $500 \mathrm{ml}$

The solution was equilibrated with carbon dioxide and $\mathrm{pH}$ was adjusted to 7.35. Solution $A$ and Solution $B$ were then mixed and equilibrated with carbon dioxide under the control of $\mathrm{pH}$. Finally, the medium was sterile filtered.

Serum-enriched M199 with supplements

For $100 \mathrm{ml}$

FCS

$4 \mathrm{ml}$

Dexamethasone stock

$100 \mu \mathrm{l}$

Insulin stock

$10 \mu \mathrm{l}$

Penicillin/streptomycin stock

$1 \mathrm{ml}$

M199 with supplements (stock

to $100 \mathrm{ml}$

medium)

$\underline{\text { Serum-free M199 with supplements }}$

For $100 \mathrm{ml}$

Dexamethasone stock

$100 \mu \mathrm{l}$

Insulin stock

$10 \mu \mathrm{l}$

Penicillin/streptomycin stock

$1 \mathrm{ml}$

M199 with supplements (stock

to $100 \mathrm{ml}$

medium)

Penicillin/Streptomycin stock

For $100 \mathrm{ml}$

Penicillin G (sodium salt)

$0.64 \mathrm{~g}$

Streptomycine sulfate

$1.17 \mathrm{~g}$

$\mathrm{NaCl}$

$0.9 \mathrm{~g}$

$\mathrm{ddH}_{2} \mathrm{O}$

to $100 \mathrm{ml}$

The penicillin/streptomycin stock was sterile filtered, aliquoted and stored at $-20^{\circ} \mathrm{C}$. 


\section{Dexamethasone stock solution $(100 \mu \mathrm{M})$}

\section{For $100 \mathrm{ml}$}

Dexamethasone

$3.92 \mathrm{~g}$

$0.9 \% \mathrm{NaCl}$

to $100 \mathrm{ml}$

Dexamethasone was first dissolved in $0.3 \mathrm{ml}$ of ethanol and then adjusted with $0.9 \%$ $\mathrm{NaCl}$ to a final volume of $100 \mathrm{ml}$. The stock solution was then sterile filtered, aliquoted and stored at $-20^{\circ} \mathrm{C}$.

$\underline{\text { Insulin stock solution }(10 \mu \mathrm{M})}$

$\begin{array}{ll}\text { Insulin } & \text { For } 100 \mathrm{~m} \\ \mathrm{BSA} & 6 \mathrm{mg} \\ 0.9 \% \mathrm{NaCl} & 100 \mathrm{mg} \\ & \text { to } 100 \mathrm{ml}\end{array}$

Insulin was dissolved at $\mathrm{pH} 2.5$, neutrilized and then BSA was added. The stock solution was then sterile filtered, aliquoted and stored at $-20^{\circ} \mathrm{C}$.

\subsubsection{Isolation of Nonparenchymal Liver Cells}

Rat nonparenchymal liver cells, i.e. liver macrophages (Kupffer cells, KCs) and sinusoidal endothelial cells (SECs) were isolated by liver enzymatic perfusion, gradual digestion, density gradient centrifugation and counterflow elutriation as previously described (Knook and Sleyster, 1976) with slight modifications.

\subsubsection{Liver Perfusion and Preparation of Cell Suspension}

The laparotomy and canulation were essentially performed as described above (see section 3.1.1.). The liver was perfused with preperfusion medium containing Gey's Balanced Salt Solution (GBSS) and sodium hydrocarbonate, followed by perfusion with enzyme solution 1 containing pronase with subsequent change to enzyme solution 2 containing pronase and collagenase.

After perfusion, the liver was excised and transferred to a sterile Petri dish filled with enzyme solution 3 containing pronase, collagenase and DNase I and was mechanically disruptured with sterile forceps. The cell suspension obtained was stirred in the same perfusion solution for 30 min under the control of $\mathrm{pH}(7.5)$ and finally filtered through the sterile sieve and collected in $50 \mathrm{ml}$ polypropylene tubes. To separate big cell aggregates and major part of the parenchymal liver cells, the suspension was centrifuged for $4 \mathrm{~min}$ at $35 \times g\left(4^{\circ} \mathrm{C}\right)$. The supernatant was then centrifuged, and the pellet was resuspended in $50 \mathrm{ml}$ of GBSS containing $100 \mu$ l of DNase I. 


\subsubsection{Separation of Nonparenchymal Liver Cells}

Nonparenchymal liver cells were separated through $N_{y c o d e n z}{ }^{\circledR}$ density gradient centrifugation as follows: the cell suspension was transferred to four sterile $50 \mathrm{ml}$ polypropylene tubes and centrifuged for $5 \mathrm{~min}$ at $640 \times g\left(4^{\circ} \mathrm{C}\right)$. The supernatants were discarded, and the pellets were resuspended in small volumes $(5-6 \mathrm{ml})$ of GBSS supplemented with DNase I and pooled together in one sterile $50 \mathrm{ml}$ polypropylene tube. $30 \%$ Nycodenz $^{\circledR}(14 \mathrm{ml})$ was added, and the volume was adjusted with GBSS to $24 \mathrm{ml}$. This mixture was divided between four sterile $15 \mathrm{ml}$ polypropylene tubes, and GBSS (1.5 ml per tube) was carefully layered over the content of the tubes. The samples were centrifuged through the gradient for $15 \mathrm{~min}$ at $1,800 \times g\left(4^{\circ} \mathrm{C}\right)$. Subsequently, the interphase brown layer between Nycodenz ${ }^{\circledR}$ and GBSS containing nonparenchymal liver cells was carefully transferred to sterile $50 \mathrm{ml}$ polypropylene tube and centrifuged for $5 \mathrm{~min}$ at $640 \times g\left(4^{\circ} \mathrm{C}\right)$.

\subsubsection{Purification by Counterflow Elutriation}

To purify fractions enriched with KCs and SECs, nonparenchymal liver cells were fractionated by centrifugal counterflow elutriation (Knook and Sleyster, 1976). The pellet obtained in previous steps containing nonparenchymal liver cells was resuspended in 5$6 \mathrm{ml}$ of $0.4 \%$ BSA/GBSS, collected in a sterile $10 \mathrm{ml}$ syringe and injected into the elutriation system. Using JE-6B elutriation rotor assembled according to the manufacturer's instructions and spun at 2,500 rpm in a J2-21 centrifuge (Beckman Instruments), fractions enriched with sinusoidal endothelial cells and large Kupffer cells were collected at flow rates of 19 and $55 \mathrm{ml} / \mathrm{min}$, respectively. The fractions of KCs and SECs were sedimented by centrifugation ( $5 \mathrm{~min}$ at $640 \times \mathrm{g}, 4^{\circ} \mathrm{C}$ ), cells were then resuspended, counted in a Neubauer chamber and plated after evaluation of cell viability by Trypan blue staining. KCs were plated onto $35 \mathrm{~mm}$ dishes at a density of $4 \mathrm{x}$ $10^{6}$ per dish in $1.5 \mathrm{ml}$ of culture medium (serum-enriched M199 with supplements), which was replaced daily. SECs were cultured on type I collagen-coated 24-well plates. For this purpose, plates for SECs cultivation were prepared in advance. Briefly, collagen was dissolved in $10 \%$ acetic acid $(25 \mathrm{mg} / 100 \mathrm{ml})$, and the solution was then diluted with water at a ratio of 1:50. The wells were incubated with collagen for 2 hours and air-dried afterwards at RT. SECs were resuspended in serum-enriched endothelial cell basal medium with supplements and plated at a density $2 \times 10^{6}$ cells per well. Medium was replaced every day. Primary cultures of KCs and SECs at day 2 were washed with PBS 
and incubated for 24 hours in serum-reduced $(0.3 \%$ of fetal calf serum) culture media. Cell-free supernatants were collected and frozen at $-20^{\circ} \mathrm{C}$, and cells were rinsed in PBS and frozen at $-80^{\circ} \mathrm{C}$ for subsequent experiments.

\subsubsection{Isolation of Hepatic Stellate Cells}

Hepatic stellate cells (HSCs) were isolated from female Wistar rats weighing 300-350 g. The liver perfusion and separation of nonparenchymal liver cells from remaining hepatocytes were essentially performed as described earlier. After centrifugation through Nycodenz ${ }^{\circledR}$ density gradient, the upper white layer containing HSCs was transferred to a sterile tube and resuspended in GBSS supplemented with $0.2 \%$ BSA. Then the number of cells was counted, and cell viability was evaluated by Trypan blue staining. Finally, cells were resuspended in DMEM supplemented with $15 \%$ fetal calf serum, $100 \mathrm{U} / \mathrm{mL}$ penicillin, $100 \mu \mathrm{g} / \mathrm{mL}$ streptomycin and $1 \%$ L-glutamine, and plated onto 6-well plates at a density $8 \times 10^{5}$ cells per well in $4 \mathrm{ml}$ of culture medium, which was replaced 2 days after plating and then every third day. Cultures of HSCs were kept at $37^{\circ} \mathrm{C}$ in a $5 \% \mathrm{CO}_{2}$ atmosphere and $95 \%$ humidity. Primary cultures of HSCs at days 2, 4 and 7 were washed with PBS and were incubated for 24 hours in serum-reduced $(0.3 \%$ fetal calf serum $)$ culture medium. Cell-free supernatants were collected and frozen at $-20^{\circ} \mathrm{C}$, and cells were rinsed in PBS and frozen at $-80^{\circ} \mathrm{C}$ for subsequent experiments.

\subsubsection{Isolation of Liver Myofibroblasts}

The liver was perfused as described above. Two independent approaches were used for isolation of rat liver myofibroblasts (LMFs): (1) isolation by density gradient centrifugation followed by counterflow elutriation of fraction enriched with LMFs, and (2) isolation by outgrowth from primary culture of rat hepatocytes.

In the first approach, density gradient centrifugation and counterflow elutriation have been essentially done as described earlier. A fraction enriched with LMFs was collected at a flow rate of $23 \mathrm{ml} / \mathrm{min}$ (Knittel et al., 1999a). This fraction was then centrifuged (450 $x \mathrm{~g}, 10$ minutes, $4^{0} \mathrm{C}$ ), the obtained cells were resuspended in culture medium (DMEM supplemented with $15 \%$ fetal calf serum, $100 \mathrm{U} / \mathrm{mL}$ penicillin, $100 \mu \mathrm{g} / \mathrm{mL}$ streptomycin and $1 \%$ L-glutamine) and plated. Culture medium was replaced 2 days after plating and then twice a week. 
In order to obtain LMFs by outgrowth from primary hepatocytes culture, 24 hours after plating hepatocytes were washed in sterile PBS and new culture medium (DMEM with supplements as indicated above) was then added. In the presence of DMEM and serum hepatocytes were dying, whereas LMFs contaminating hepatocytes culture were proliferating. To eliminate dead hepatocytes, every two days the cultures were rinsed in PBS and medium was replaced.

In both cases, cultured LMFs were allowed to grow until confluence and were then released from the culture dishes by trypsinization and replated at split ratio 1:3 or 1:4. Culture medium was replaced 2 days after passaging and then twice a week. Cells were cultured at $37^{\circ} \mathrm{C}$ in $5 \% \mathrm{CO}_{2}$ atmosphere and $95 \%$ humidity. Cells were subcultured for several passages. Cells from passages 1 to 7 were used for further studies.

\subsubsection{Treatment of Cultured Liver Myofibroblasts}

Before the addition of stimuli, cultures of rat LMFs were washed in PBS and were then growth-arrested in serum-reduced culture medium (DMEM) supplemented with $0.3 \%$ FCS for 1 hour at $37^{\circ} \mathrm{C}$ in $5 \% \mathrm{CO}_{2}$ atmosphere and $95 \%$ humidity, and thereafter cells were incubated in serum-reduced DMEM supplemented with certain hormones and growth factors. Alternatively, in order to study the phosphorylation of the IGF-IR, PDGFR and their signalling intermediates, cell starvation and treatment of cells were performed under serum-free conditions.

After treatment, cell-free supernatants were collected and frozen at $-20^{\circ} \mathrm{C}$, and cells were rinsed in cold PBS and immediately were used for RNA isolation and protein extraction. 
3.1.2.7. Solutions and Media for Isolation and Culture of Nonparenchymal Liver Cells All media and solutions for cell culture were prepared in double distilled water, further purified by sterile filtration and stored at $4^{\circ} \mathrm{C}$, unless otherwise indicated.

10x GBSS (Gey's Balanced Salt Solution)

For 1 I

$\mathrm{NaCl}$

$80 \mathrm{~g}$

$\mathrm{KCl}$

$3.7 \mathrm{~g}$

$\mathrm{MgSO}_{4} \times 7 \mathrm{H}_{2} \mathrm{O}$

$0.7 \mathrm{~g}$

$\mathrm{NaH}_{2} \mathrm{PO}_{4} \times \mathrm{H}_{2} \mathrm{O}$

$1.7 \mathrm{~g}$

$\mathrm{CaCl}_{2} \times 2 \mathrm{H}_{2} \mathrm{O}$

$2.2 \mathrm{~g}$

$\mathrm{KH}_{2} \mathrm{PO}_{4}$

$0.3 \mathrm{~g}$

$\mathrm{MgCl}_{2} \times 6 \mathrm{H}_{2} \mathrm{O}$

$2.1 \mathrm{~g}$

Glucose

$10 \mathrm{~g}$

$\mathrm{dd}_{2} \mathrm{O}$

to 11

Preperfusion medium

\section{For 11}

$\mathrm{NaHCO}_{3}$

$227 \mathrm{mg}$

10x GBSS

$100 \mathrm{ml}$

$\mathrm{dd}_{2} \mathrm{O}$

to 11

The solution was prepared directly prior to isolation; $\mathrm{pH}$ was adjusted to 7.4.

$\underline{1 x \text { GBSS without } \mathrm{NaCl}}$

For 11

$\mathrm{KCl}$

$370 \mathrm{mg}$

$\mathrm{MgSO}_{4} \times 7 \mathrm{H}_{2} \mathrm{O}$

$70 \mathrm{mg}$

$\mathrm{NaH}_{2} \mathrm{PO}_{4} \times \mathrm{H}_{2} \mathrm{O}$

$170 \mathrm{mg}$

$\mathrm{CaCl}_{2} \times 2 \mathrm{H}_{2} \mathrm{O}$

$220 \mathrm{mg}$

$\mathrm{NaHCO}_{3}$

$227 \mathrm{mg}$

$\mathrm{KH}_{2} \mathrm{PO}_{4}$

$30 \mathrm{mg}$

$\mathrm{MgCl}_{2} \times 6 \mathrm{H}_{2} \mathrm{O}$

$210 \mathrm{mg}$

Glucose

$1 \mathrm{~g}$

$\mathrm{ddH}_{2} \mathrm{O}$

to 11

$\mathrm{pH}$ was adjusted to 7.4. 
$30 \%$ Nycodenz $^{\circledR}$

For $100 \mathrm{ml}$

Nycodenz $^{\circledR} \quad 30 \mathrm{~g}$

1x GBSS without $\mathrm{NaCl}$ to $100 \mathrm{ml}$

The solution was dispensed into $14 \mathrm{ml}$ aliquots and stored at $-20^{\circ} \mathrm{C}$.

$\underline{0.4 \% \mathrm{BSA} / \mathrm{GBSS}}$

For $500 \mathrm{ml}$

BSA

$2 \mathrm{~g}$

1x GBSS

to $500 \mathrm{ml}$

Enzyme solution 1

For $60 \mathrm{ml}$

Pronase E $120 \mathrm{mg}$

1x GBSS to $60 \mathrm{ml}$

Enzyme solution 2

For $150 \mathrm{ml}$

Pronase E

$75 \mathrm{mg}$

Collagenase $\mathrm{H}$

$80 \mathrm{mg}$

1x GBSS

to $150 \mathrm{ml}$

Enzyme solution 3

For $100 \mathrm{ml}$

Pronase E $20 \mathrm{mg}$

Collagenase $\mathrm{H} \quad 60 \mathrm{mg}$

DNase I stock $\quad 300 \mu \mathrm{l}$

1x GBSS to $100 \mathrm{ml}$

All enzymes were dissolved in GBSS for 30 min at RT with slight agitation. DNase I was added to the solution immediately before application.

DNase I stock

For $10 \mathrm{ml}$

DNase I

$100 \mathrm{mg}$

$\mathrm{ddH}_{2} \mathrm{O}$

to $10 \mathrm{ml}$

The solution was dispensed into $1 \mathrm{ml}$ aliquots and stored at $-20^{\circ} \mathrm{C}$. 
Serum-enriched M199 with supplements

For $100 \mathrm{ml}$

FCS $15 \mathrm{ml}$

Penicillin/streptomycin stock $\quad 1 \mathrm{ml}$

L-Glutamine $\quad 1 \mathrm{ml}$

M199 to $100 \mathrm{ml}$

Serum-reduced M199 with supplements

For $100 \mathrm{ml}$

FCS $\quad 0.3 \mathrm{ml}$

Penicillin/streptomycin stock $\quad 1 \mathrm{ml}$

L-Glutamine $\quad 1 \mathrm{ml}$

M199 to $100 \mathrm{ml}$

Serum-enriched Endothelial Cell Basal Medium with supplements

For $100 \mathrm{ml}$

FCS $2 \mathrm{ml}$

Penicillin/streptomycin stock $\quad 1 \mathrm{ml}$

Epidermal growth factor,

[100 $\mathrm{ng} / \mu \mathrm{l}]$

$1 \mu \mathrm{l}$

Basic fibroblast growth factor, [100 ng/ $/ \mathrm{ll}]$

$0.1 \mu \mathrm{l}$

Insulin stock

$10 \mu \mathrm{l}$

Endothelial cell basal medium to $100 \mathrm{ml}$

Serum-reduced Endothelial Cell Basal Medium with supplements

For $100 \mathrm{ml}$

FCS $\quad 0.3 \mathrm{ml}$

Penicillin/streptomycin stock $\quad 1 \mathrm{ml}$

Epidermal growth factor,

[100 ng/ $\mu \mathrm{l}]$

$1 \mu \mathrm{l}$

Basic fibroblast growth factor,

[100 $\mathrm{ng} / \mu \mathrm{l}]$

$0.1 \mu \mathrm{l}$

Insulin stock $\quad 10 \mu \mathrm{l}$

Endothelial cell basal medium to $100 \mathrm{ml}$ 
Serum-enriched DMEM with supplements

For $100 \mathrm{ml}$

Penicillin/streptomycin stock $\quad 1 \mathrm{ml}$

FCS $\quad 15 \mathrm{ml}$

L-Glutamine $\quad 1 \mathrm{ml}$

DMEM (with low glucose) to $100 \mathrm{ml}$

Serum-reduced DMEM with supplements

For $100 \mathrm{ml}$

Penicillin/streptomycin stock $1 \mathrm{ml}$

FCS $\quad 0.3 \mathrm{ml}$

L-Glutamine $\quad 1 \mathrm{ml}$

DMEM (with low glucose) to $100 \mathrm{ml}$

$\underline{\text { Serum-free DMEM with supplements }}$

For $100 \mathrm{ml}$

Penicillin/streptomycin stock $\quad 1 \mathrm{ml}$

L-Glutamine $\quad 1 \mathrm{ml}$

DMEM (with low glucose) to $100 \mathrm{ml}$

\subsection{Molecular Biology Methods}

\subsubsection{Transformation of E. coli}

Competent $E$. coli DH5a cells capable to take up linear or circular (plasmid) double stranded DNA were used for transformation.

The competent bacteria $(100 \mu \mathrm{l})$ were thawed on ice. Then $100 \mathrm{ng}$ of plasmid DNA were added directly to the competent cells and the mixture was incubated on ice during 30 min. Cells were subjected then to heat shock by incubating at $42^{\circ} \mathrm{C}$ for 2 min and subsequently cooled down on ice for 2 min. Afterwards, $300 \mu \mathrm{l}$ of SOC medium were added to the cells followed by 40 min incubation at $37^{\circ} \mathrm{C}$ under continuous shaking at $225 \mathrm{rpm}$. After cooling down on ice, transformed cells $(50 \mu \mathrm{l})$ were spread over a LBampicillin agar dish and incubated for $18 \mathrm{~h}$ at $37^{\circ} \mathrm{C}$. 
Media and solutions used for E. coli transformation

SOC medium

$0.5 \%$ yeast extract

$2 \%$ bacto-trypton

$10 \mathrm{mM} \mathrm{NaCl}$

$2.5 \mathrm{mM} \mathrm{KCl}$

$10 \mathrm{mM} \mathrm{MgSO}_{4}$

$10 \mathrm{mM} \mathrm{MgCl} 2$

$20 \mathrm{mM}$ glucose

Luria Bertani (LB) medium

\section{For 11}

Bacto-trypton

$10 \mathrm{~g}$

Yeast extract

$5 \mathrm{~g}$

$\mathrm{NaCl}$

$\mathrm{ddH}_{2} \mathrm{O}$

$\mathrm{pH}$ was adjusted with $\mathrm{NaOH}$ to 7.3 , the medium was autoclaved and stored at $4{ }^{\circ} \mathrm{C}$. Prior to use, ampicillin was added to the medium at the final concentration of $50-100 \mu \mathrm{g} / \mathrm{ml}$.

\section{LB-ampicillin agar dishes}

Bactoagar was added to the LB medium to a final concentration of $1.5 \%$ followed by autoclaving. Subsequently, the medium was cooled down to $55^{\circ} \mathrm{C}$ and ampicillin was added to the final concentration of $50 \mu \mathrm{g} / \mathrm{ml}$. This medium was poured onto $10 \mathrm{~cm}$ sterile Petri dishes and left undisturbed for about $30 \mathrm{~min}$ to solidify. LB-Agar dishes were stored in the dark at $4^{\circ} \mathrm{C}$.

\section{Ampicillin stock solution}

$\begin{array}{ll}\text { Ampicillin } & 1 \mathrm{~g} \\ \mathrm{H}_{2} \mathrm{O} & \text { to } 10 \mathrm{ml}\end{array}$

The powder was dissolved in sterile $\mathrm{ddH}_{2} \mathrm{O} ; \mathrm{pH}$ was adjusted with $\mathrm{HCl}$ to $7.0 ; 500 \mu \mathrm{l}$ aliquots were stored at $-20^{\circ} \mathrm{C}$. 


\subsubsection{Purification of Plasmid DNA}

Purification of plasmid DNA from transformed bacteria was performed using EndoFree ${ }^{\text {TM }}$ Plasmid Maxi Kit (Qiagen).

Qiagen plasmid purification protocol is based on a modified alkaline lysis procedure, followed by binding of plasmid DNA to Qiagen Anion-Exchange Resin under appropriate low-salt and $\mathrm{pH}$ conditions. RNA, proteins, and low molecular weight impurities are removed by a medium-salt wash. Plasmid DNA is eluted in a high-salt buffer and then concentrated and desalted by isopropanol precipitation.

A single colony of transformed $E$. coli was scraped from LB-ampicillin agar dish and inoculated into $2 \mathrm{ml}$ of ampicillin-containing LB medium, followed by incubation for $12 \mathrm{~h}$ at $37^{\circ} \mathrm{C}$ with vigorous shaking at $300 \mathrm{rpm}$. Afterwards, $850 \mu \mathrm{l}$ aliquot of bacteria suspension was mixed with $150 \mu \mathrm{l}$ of sterile $87 \%$ glycerol and stored at $-80^{\circ} \mathrm{C}$ as a bacterial stock, other portion of this starter culture was diluted 1:1,000 in LB medium, and bacteria were grown at $37^{\circ} \mathrm{C}$ for $12-16 \mathrm{~h}$ with vigorous shaking at $300 \mathrm{rpm}$ to a density of approximately $3-4 \times 10^{9}$ cells per $\mathrm{ml}$ that corresponds to $\mathrm{OD}_{600}$ of $1-1.5$. The bacterial cells were harvested by centrifugation at $6,000 \times g$ for $15 \mathrm{~min}$ at $4^{\circ} \mathrm{C}$. The supernatant was discarded and bacterial pellet was effectively resuspended in $10 \mathrm{ml}$ of P1 buffer containing RNase A.

To lyse the cells, $10 \mathrm{ml}$ of P2 buffer were added and mixed by gentle inverting. After 5 min of incubation at RT, $10 \mathrm{ml}$ of chilled P3 buffer were added to the lysate to precipitate genomic DNA, proteins and cell debris. Immediately after precipitation, lysate was transferred to the barrel of QIAfilter Cartridge and kept there for 10 min at RT that was essential for optimal function of QIAfilter Maxi Cartridge. During this incubation, floating layer of the precipitate was formed on top of the lysate. Subsequently, the lysate was cleared by passing the liquid through the filter of the QIAfilter Maxi Cartridge using the plunger. After addition of $2.5 \mathrm{ml}$ of ER buffer, the filtered lysate was incubated on ice for $30 \mathrm{~min}$, and then was applied onto a Qiagen-tip 500 column equilibrated with $10 \mathrm{ml}$ of QBT buffer. When the entire volume of lysate had entered the resin, the column was washed twice with $30 \mathrm{ml}$ of $\mathrm{QC}$ buffer. For all subsequent steps endotoxin-free reagents and plasticware were used. Plasmid DNA was eluted with $15 \mathrm{ml}$ of QN buffer. To precipitate DNA, the eluate was mixed with $10.5 \mathrm{ml}$ of room-temperature isopropanol and centrifuged immediately at $15,000 \times \mathrm{g}$ for $30 \mathrm{~min}$ at $4^{\circ} \mathrm{C}$. The supernatant was discarded and the DNA containing pellet was washed from precipitated salt with $5 \mathrm{ml}$ of endotoxin-free, room-temperature $70 \%$ ethanol, followed by centrifugation at $15,000 \times \mathrm{g}$ 
for $10 \mathrm{~min}$. The supernatant was carefully decanted. The DNA pellet was air-dried for 5$10 \mathrm{~min}$ and then resuspended in a suitable volume (usually 100-500 $\mu \mathrm{l}$ depending on the amount of DNA) of endotoxin-free TE buffer.

To determine DNA concentration and the presence of protein in the probes, the OD at $260 \mathrm{~nm}$ (DNA) and $280 \mathrm{~nm}$ (protein) was measured. One OD at $260 \mathrm{~nm}$ approximately corresponds to the DNA concentration of $50 \mu \mathrm{g} / \mathrm{ml}$. In a protein-free solution, the ratio $\mathrm{OD}_{260} / \mathrm{OD}_{280}$ is 2 . In addition, the integrity and purity of the obtained plasmid DNA was controlled by analytical agarose gel analysis (see section 3.2.4.)

Solutions used for plasmid DNA purification

P1 buffer (resuspension buffer ) $\quad 50 \mathrm{mM}$ Tris $\cdot \mathrm{Cl}, \mathrm{pH} 8.0$

$10 \mathrm{mM}$ EDTA

$100 \mu \mathrm{g} / \mathrm{ml}$ RNase A

P2 buffer (lysis buffer)

$200 \mathrm{mM} \mathrm{NaOH}$

$1 \%$ SDS

P3 buffer (neutralization buffer)

$3.0 \mathrm{M}$ potassium acetate, $\mathrm{pH} 5.5$

QBT buffer (equilibration buffer)

$750 \mathrm{mM} \mathrm{NaCl}$

50 mM MOPS, pH 7.0

$15 \%$ isopropanol

$0.15 \%$ Triton X-100

QC buffer (washing buffer)

$1 \mathrm{M} \mathrm{NaCl}$

$50 \mathrm{mM}$ MOPS, pH 7.0

$15 \%$ isopropanol

QN buffer (elution buffer)

$1.6 \mathrm{M} \mathrm{NaCl}$

$50 \mathrm{mM}$ MOPS, pH 7.0

$15 \%$ isopropanol

TE buffer

$10 \mathrm{mM}$ Tris $\cdot \mathrm{HCl}, \mathrm{pH} 8.0$

$50 \mathrm{mM}$ MOPS, pH 7.0

$15 \%$ isopropanol 


\subsubsection{Restriction of Plasmid DNA}

For radioactive random primed DNA labelling CDNA inserts from certain plasmid clones were used as templates. In order to isolate these fragments from the whole plasmids, digestion of plasmid DNA with restriction enzymes has been performed. Typically, preparative reaction contained $20 \mu \mathrm{g}$ of plasmid DNA in a final volume of $60 \mu \mathrm{l}$. The amount of each component required for restriction reaction was calculated in advance. The following chart was used as a guide:

RNase/DNase-free water (Ampuwa $^{\circledR}$ )

Reaction buffer, 10x

Plasmid DNA

Restriction enzyme I

Restriction enzyme II to $60 \mu \mathrm{l}$

$6 \mu \mathrm{l}$

$20 \mu \mathrm{g}$

$100 \mathrm{U}$

$100 \mathrm{U}$

In sterile $1.5 \mathrm{ml}$ tube placed on ice nuclease free water was first added to a final volume to $60 \mu \mathrm{l}$ followed by addition of buffer and plasmid DNA. Finally, restriction enzymes were added, and contents of tube was mixed gently but thoroughly and microfuged briefly in an Eppendorf bench-top centrifuge. The reaction mixture was then incubated at appropriate temperature (usually at $37^{\circ} \mathrm{C}$ ) for 4 hours. Afterwards, the mixture was subjected to agarose gel electrophoresis in order to separate the cDNA insert from the remaining plasmid DNA. The following restriction enzymes and buffers were used for isolation of certain cDNA inserts in the current work:

$\begin{array}{llll}\text { cDNA of interest } & \text { Enzyme I } & \text { Enzyme II } & \text { Buffer } \\ \underline{\text { IGF-I }} & \text { EcoRI } & \text { HindIII } & B \\ \underline{\text { IGF-II }} & \text { EcoRI } & \text { BamHI } & B \\ \underline{\text { IGF-IR }} & \text { EcoRI } & \text { BamHI } & B \\ \underline{\text { IGF-II/M6-PR }} & \text { EcoRI } & \text { BamHI } & B \\ \underline{\text { IGFBP-2 }} & \text { EcoRI } & \text { HindIII } & B \\ \underline{\text { IGFBP-3 }} & \text { Apal } & \text { BamHI } & A \\ \underline{\text { PDGFR } \alpha} & \text { EcoRI } & - & A\end{array}$




\subsubsection{Agarose Gel Electrophoresis of DNA}

For preparation of $0.75 \%$ and $1.25 \%$ gels, $187.5 \mathrm{mg}$ and $375 \times \mathrm{g}$ of low melting point agarose were mixed with $25 \mathrm{ml}$ of $1 \mathrm{x}$ TAE buffer and further dissolved by microwaving. For visualization of the bands, $8 \mu \mathrm{l}$ of ethidium bromide $(10 \mathrm{mg} / \mathrm{ml})$ were added to the mixture. Then the agarose solution was poured onto the gel casting plate. During gel polymerization, the samples were prepared for loading. For analytical gels, $10 \mu \mathrm{l}$ of respective DNA sample were mixed with $2 \mu$ of $6 x$ Loading Dye Solution. For preparative gels, $60 \mu \mathrm{l}$ of DNA sample (product of restriction reaction) were mixed with $12 \mu \mathrm{l}$ of $6 \mathrm{x}$ Loading Dye Solution. In parallel, molecular weight DNA marker was also processed by mixing of $3 \mu \mathrm{l}$ of the $123 \mathrm{~kb}$ DNA ladder, $7 \mu \mathrm{l}$ of nuclease free water and 2 $\mu \mathrm{l}$ of $6 \mathrm{x}$ Loading Dye Solution. After polymerization, the gel was placed into an electrophoresis chamber filled with $1 \mathrm{x}$ TAE buffer, the samples and molecular weight marker were loaded (12 $\mu \mathrm{l}$ per well), and the electrophoresis was carried out at a constant voltage of $60 \mathrm{~V}$. Finally, DNA bands on the ethidium bromide-stained gel were visualized by ultraviolet shadowing in the Eagle Eye ${ }^{\mathrm{TM}}$ system consisting of UV transilluminator, intensity control unit, video camera and printer. Additionally, after sizefractionation of the restricted plasmid, the bulk of the DNA corresponding to the size of the cDNA of interest was cut out with a sharp scalpel from the gel, transferred to a clean, preweighted reaction tube and saved at $-20^{\circ} \mathrm{C}$ for further manipulations.

\section{0x Tris/Acetate/EDTA (TAE) buffer}

For 11

Tris base

Sodium acetate

EDTA

$\mathrm{dd}_{2} \mathrm{O}$
$122 \mathrm{~g}$

$32 \mathrm{~g}$

$14 \mathrm{~g}$

to 1 I
Final concentration

$1 \mathrm{M}$

$0.4 \mathrm{M}$

$40 \mathrm{mM}$

After EDTA was completely dissolved, $\mathrm{pH}$ was adjusted with acetic acid to 7.4 ; the buffer was autoclaved and stored at RT.

\section{1x TAE buffer}

\section{For 11}

20x TAE buffer

$50 \mathrm{ml}$

$\mathrm{dd}_{2} \mathrm{O}$

to 1 I 


\subsubsection{Agarose Gel DNA Extraction}

To isolate DNA fragments from TAE agarose gels for subsequent random primed labelling, the agarose gel DNA extraction kit (Roche) was used. The extraction of DNA by this kit is based on specific adsorption of nucleic acids to the pretreated spherical silica matrix. Since the binding process is specific only for nucleic acids, the bound material can be easily separated and purified from impurities (salts and proteins) by a simple washing step. Nucleic acids elute from the matrix in a low salt buffer or water. Moreover, the uniformity of the spherical particles enables the isolation of both large and small DNA fragments.

The procedure was started by addition of agarose solubilization buffer to the reaction tube containing electrophoretically separated DNA fragment. Usually, $3 \mu \mathrm{l}$ of agarose solubilization buffer was applied per $1 \mathrm{mg}$ of gel. Subsequently, $10 \mu \mathrm{l}$ of the resuspended silica suspension were added to the tube. The sample was incubated at $60{ }^{\circ} \mathrm{C}$ for $10 \mathrm{~min}$ and vortexed every $2 \mathrm{~min}$. After centrifugation for $30 \mathrm{sec}$ at maximal speed in a table top centrifuge, the supernatant was discarded, and the matrix containing DNA was resuspended after addition of $500 \mu$ l of nucleic acid binding buffer. After centrifugation (30 sec, maximal speed) the supernatant was discarded, and the pellet was washed with $500 \mu \mathrm{l}$ of washing buffer. The sample was centrifuged again, the supernatant was discarded, and the pellet was air-dried for $15 \mathrm{~min}$ at RT. Afterwards, 25 $\mu \mathrm{l}$ of Tris- $\mathrm{HCl}$ were applied on the pellet, and the sample was incubated at $60{ }^{\circ} \mathrm{C}$ for 10 min and vortexed every $2 \mathrm{~min}$. After centrifugation (30 sec, maximal speed) the supernatant containing the eluted DNA was transferred to a new reaction tube. Typically, two elution cycles were performed $(2 \times 25 \mu l)$. Finally, the DNA concentration was measured, and the extracted DNA insert was further stored at $-20^{\circ} \mathrm{C}$.

\subsubsection{Radioactive cDNA Labelling}

Radioactive random primed DNA labelling was performed to label specific CDNA fragments restricted from the respective plasmids coding for rat IGFBP-2, IGFBP-3, IGF-I, IGF-II, IGF-IR, IGF-II/M6-PR and PDGFR $\alpha$. Alternatively, nick translation was used to label full-length plasmids containing CDNA fragments specific for rat PDGFR $\beta$ and human $\alpha_{2}(\mathrm{I})$ chain of type I procollagen, respectively. 


\subsubsection{DNA Labelling by Random Priming Reaction}

Random primed DNA labelling was performed using NEBlot ${ }^{\circledR}$ Kit (New England Biolabs) designed to produce labelled DNA probes using the method of Feinberg and Vogelstein (Feinberg and Vogelstein, 1983), where random sequence octadeoxynucleotides serve as primers for DNA synthesis in vitro from denaturated double-stranded template DNA by the Klenow Fragment of $E$. coli DNA polymerase I. One labelled deoxyribonocleotide is used in the dNTP reaction mixture and is incorporated during primer directed DNA synthesis by DNA polymerase. The resulting labelled DNA serves as a hybridization probe in Northern blot analysis.

50-100 ng of template DNA were dissolved in nuclease free water to the final volume of $33 \mu \mathrm{l}$. The DNA was denatured by heating at $95^{\circ} \mathrm{C}$ for $5 \mathrm{~min}$ and subsequently cooled down on ice for $5 \mathrm{~min}$. The following reagents were added to the DNA in the indicated order:

$5 \mu$ of 10x labelling buffer (includes Random Octadeoxyribonucleotides),

$2 \mu \mathrm{l}$ of dATP,

$2 \mu \mathrm{l}$ of dTTP,

$2 \mu \mathrm{l}$ of dGTP,

$5 \mu$ of $\left[\alpha^{-32} \mathrm{P}\right]-d C T P(50 \mu \mathrm{Ci})$,

$1 \mu$ of DNA Polymerase I - Klenow Fragment (5 units).

The mixture was incubated at $37^{\circ} \mathrm{C}$ for $1 \mathrm{~h}$, the reaction was then stopped by addition of $5 \mu \mathrm{l}$ of $0.2 \mathrm{M}$ EDTA, pH 8.0.

\subsubsection{DNA Labelling by Nick Translation Method}

DNA labelling by nick translation method was performed using Nick Translation System kit (Invitrogen).

Nick translation requires the activity of two different enzymes. DNase I is used to cleave (nick) phosphodiester bonds at random sites in both strands of a double-stranded target DNA. E. coli DNA polymerase I is necessary for integration of deoxynucleotides to the 3'-hydroxyl termini created by DNase I. In addition to its polymerizing activity, DNA polymerase I carries a $5^{\prime} \rightarrow 3^{\prime}$ exonucleolytic activity that removes nucleotides from the $5^{\prime}$ side of the nick. The simultaneous elimination of nucleotides from the $5^{\prime}$ side and the addition of radiolabelled nucleotides to the $3^{\prime}$ side result in movement of the nick (nick translation) along the DNA, which becomes labelled to high specific activity (Kelly et al., 1970). The reaction is carried out at low temperature $\left(15^{\circ} \mathrm{C}\right)$. 
In sterile $1.5 \mathrm{ml}$ tube placed on ice, nuclease free $\mathrm{H}_{2} \mathrm{O}$ was added to the solution containing $1 \mu \mathrm{g}$ of template DNA to the volume of $35 \mu \mathrm{l}$. Consequently, the following reagents were added to the DNA in the indicated order:

$5 \mu \mathrm{l}$ dNTP mix (mixture of dATP, dTTP and dGTP),

$5 \mu \mathrm{l}\left[\alpha-{ }^{32} \mathrm{P}\right]-\mathrm{dCTP}(3,000 \mathrm{Ci} / \mathrm{mmol}, 50 \mu \mathrm{Ci})$,

$5 \mu \mathrm{l}$ Pol I/DNase I mix.

The components were mixed gently but thoroughly and centrifuged briefly in an Eppendorf bench-top centrifuge. The mixture was incubated at $15^{\circ} \mathrm{C}$ for $60 \mathrm{~min}$. Finally, $5 \mu \mathrm{l}$ of stop buffer was added to stop the reaction.

\subsubsection{Purification of Labelled DNA}

Synthesized labelled cDNA probe was separated from non-incorporated nucleotides by gel filtration on Sephadex ${ }^{\circledR}$ G-50 using Pharmacia NICK Column (Pharmacia Biotech). A column was opened according to the manufacturer's instructions and equilibrated with $3 \mathrm{ml}$ of $1 \mathrm{x}$ TE buffer, $\mathrm{pH}$ 8.0. After the entire volume of buffer had entered the gel, random priming reaction mixture was applied onto the column, followed by addition of $400 \mu \mathrm{l}$ of $1 \mathrm{x}$ TE buffer. The flow-through was collected in the tube placed under the column and kept for further measurement of radioactivity. A new reaction tube was placed under the column and the purified labelled DNA was eluted with $400 \mu \mathrm{l}$ of $1 \mathrm{x}$ TE. Finally, the $\beta$-radioactivity in the obtained sample was measured, and labelled DNA was either immediately used for hybridization or stored at $-20^{\circ} \mathrm{C}$ for further experiments.

\section{0x TE}

$\begin{array}{lll} & \text { For } 1 \mathrm{I} & \text { Final concentration } \\ 2 \mathrm{M} \mathrm{Tris-HCl}, \mathrm{pH} \mathrm{7.4} & 50 \mathrm{ml} & 100 \mathrm{mM} \\ 0.5 \mathrm{M} \mathrm{EDTA} & 20 \mathrm{ml} & 10 \mathrm{mM} \\ \text { RNase-free } \mathrm{H}_{2} \mathrm{O} & \text { to } 1 \mathrm{I} & \end{array}$

$\mathrm{pH}$ was checked and, if necessary, was adjusted with $\mathrm{NaOH}$ or $\mathrm{HCl}$ to 7.6. The solution was sterile filtered and stored at RT.

$\underline{1 \times T E}$

For $500 \mathrm{ml}$

10x TE

$50 \mathrm{ml}$

RNase-free $\mathrm{H}_{2} \mathrm{O}$ to $500 \mathrm{ml}$

The solution was stored at RT. 


\subsubsection{Measurement of $\beta$-Radioactivity}

After purification, the radioactivity of labelled cDNA samples was measured using Wallac 1409 liquid scintillation $\beta$-counter (EG\&G, Turku, Finland). $2 \mu$ aliquots from the flow-through and elution fractions were transferred to screw-lid plastic tubes containing $5 \mathrm{ml}$ of scintillation liquid, mixed by inverting and subjected to measurement of $\beta$ radioactivity. The latter was expressed in counts per minute (cpm). The activity value in flow-through fraction was used to evaluate the efficiency of radioactive nucleotide incorporation. For effective labelling this value should not exceed $10 \%$ of the radioactivity value of the cDNA sample.

\subsubsection{Isolation of Total RNA}

Total cellular RNA was isolated from monolayers of cultured rat liver cells by means of guanidine isothiocyanate (GITC) extraction, cesium chloride ( $\mathrm{CsCl}$ ) density-gradient ultracentrifugation and ethanol precipitation according to the method of Chirgwin (Chirgwin et al., 1979).

This method is convenient and efficient way to extract intact RNA from most tissues and cultured cells, even if the level of endogenous RNases is high. Cells are rapidly lysed in GITC-containing buffer, which effectively inactivate RNases. The lysate is layered then onto $\mathrm{CsCl}$ gradient and spun in the ultracentrifuge. Proteins remain in the aqueous guanidine portion, DNA bands in the $\mathrm{CsCl}$, and RNA pellets are concentrated at the bottom of the tube. The RNA is recovered by resuspension of the pellet. The recovery of RNA is usually high unless the capacity of the gradient has not been exceeded.

Culture dishes with both frozen and alive liver cells were placed on ice and $3 \mathrm{ml}$ of GITC-buffer with freshly added $\beta$-mercaptoethanol $(10 \mu \mathrm{l}$ per $\mathrm{ml})$ were immediately applied onto the dish, and cells were scraped with a disposable scraper, transferred to a prechilled RNase-free $1.5 \mathrm{ml}$ tube and homogenized by passing through 24G injection needle connected to the syringe. This step was performed rapidly to prevent RNA degradation. In the meantime, $2 \mathrm{ml}$ of $\mathrm{CsCl}$ buffer were applied into 5-ml polyallomer ultracentrifuge tube. Cell lysate was carefully layered onto $\mathrm{CsCl}$ buffer. The samples were centrifuged overnight (14-20 h) at 35,000 rpm in a Kontron TST55 rotor at $20^{\circ} \mathrm{C}$. Thereafter, the supernatants were carefully removed by aspiration and transparent gelatin-like RNA pellets were reconstituted in $200 \mu$ of RNase-free water and transferred to sterile $1.5 \mathrm{ml}$ reaction tubes. RNA was further precipitated with $400 \mu \mathrm{l}$ of 
$100 \%$ ethanol in the presence of $2 \mathrm{M}$ sodium acetate, $\mathrm{pH} 5.4$ (20 $\mu \mathrm{l}$ per sample) overnight at $-20^{\circ} \mathrm{C}$.

RNA precipitates were sedimented by centrifugation $\left(12,000 \mathrm{rpm}, 30 \mathrm{~min}, 4^{\circ} \mathrm{C}\right)$. Supernatants were discarded and pellets were washed with $150 \mu \mathrm{l}$ of ice-cold $70 \%$ ethanol to remove all traces of sodium acetate. After subsequent centrifugation (12,000 $\mathrm{rpm}, 30 \mathrm{~min}, 4^{\circ} \mathrm{C}$ ) the supernatants were discarded and the pellets were air-dried at RT. Finally, the pellets were reconstituted in $100 \mu$ l of RNase-free water.

To determine the concentration and purity of the RNA obtained, the aliquot of RNA sample was diluted 1:100 in RNase-free water and the extinction at 260 and $280 \mathrm{~nm}$ was measured by the spectrophotometer (GeneQuant II, Pharmacia Biotech). The ratio between OD at $260 \mathrm{~nm}$ and OD at $280 \mathrm{~nm}$ characterized the RNA purity. In a proteinfree solution, the ratio $\mathrm{OD}_{260} / \mathrm{OD}_{280}$ is 2 . In the RNA isolations performed in the current work this ratio was usually in the range between 1.6 and 1.8 due to minor protein contaminations.

\section{GITC buffer}

$\begin{array}{lll} & \text { For } 200 \mathrm{ml} & \text { Final concentration } \\ \text { Guanidine isothiocyonate } & 94.53 \mathrm{~g} & 4 \mathrm{M} \\ 0.25 \mathrm{M} \text { sodium citrate } & 20 \mathrm{ml} & 25 \mathrm{mM} \\ \mathrm{N} \text {-lauroylsarcosyl } & 1 \mathrm{~g} & 0.5 \% \\ \text { RNase-free } \mathrm{H}_{2} \mathrm{O} & \text { to } 200 \mathrm{ml} & \\ \text { The solution was sterile filtered and stored in the dark at } 4^{\circ} \mathrm{C} . & \beta \text {-mercaptoethanol was } \\ \text { added briefly before RNA isolation at the quantity of } 10 \mu \mathrm{l} \text { per } 1 \mathrm{ml} \text { of GITC buffer. }\end{array}$

\section{$\underline{\text { CsCl buffer }}$}

$\begin{array}{lll} & \text { For } 200 \mathrm{ml} & \text { Final concentration } \\ \text { Cesium chloride } & 192 \mathrm{~g} & 5.7 \mathrm{M} \\ 0.25 \mathrm{M} \text { sodium citrate } & 20 \mathrm{ml} & 25 \mathrm{mM} \\ 0.5 \mathrm{M} \text { EDTA } & 40 \mathrm{ml} & 100 \mathrm{mM} \\ \text { RNase-free } \mathrm{H}_{2} \mathrm{O} & \text { to } 200 \mathrm{ml} & \\ \begin{array}{l}\text { pH was adjusted with } 0.25 \mathrm{M} \text { citric acid to } 7.5 \text {; the solution was sterile filtered and stored } \\ \text { at RT. }\end{array}\end{array}$




\subsubsection{Northern Blot Analysis}

Northern blot analysis is a technique for quantitative evaluation of gene expression. Under RNase-free conditions, total RNA is separated in a denaturing formaldehyde/ agarose gel, blotted by capillary transfer to a nylon membrane and fixed by UV crosslinking. Specific transcripts are identified by autoradiography after hybridization with a specific radiolabelled cDNA probe.

\subsubsection{Preparation of RNA Samples}

$10 \mu \mathrm{g}$ of total RNA were mixed with $7.5 \mu \mathrm{l}$ of sample buffer and denatured by heating at $65^{\circ} \mathrm{C}$ for $10 \mathrm{~min}$. The samples were then briefly cooled down on ice and centrifuged $(10,000 \mathrm{rpm}, 1 \mathrm{~min}, \mathrm{RT})$ in an Eppendorf bench-top centrifuge. Finally, each sample was mixed with $3 \mu \mathrm{l}$ of loading buffer, centrifuged (10,000 rpm, $1 \mathrm{~min}, \mathrm{RT})$ and loaded onto the gel.

\subsubsection{Formaldehyde/Agarose Gel Electrophoresis of RNA}

For preparation of $1 \%$ denaturing formaldehyde/agarose gel, $1 \mathrm{~g}$ of agarose was mixed with $72.2 \mathrm{ml}$ of RNase-free water $\left(\right.$ Ampuwa ${ }^{\circledR}$ ), dissolved by microwaving and then slightly cooled down to approximately $70^{\circ} \mathrm{C}$. Subsequently, $10 \mathrm{ml}$ of $10 \mathrm{x}$ running buffer and $16.7 \mathrm{ml}$ of $37 \%$ formaldehyde were added. To visualize RNA bands in the gel, in particular $28 \mathrm{~S}$ and $18 \mathrm{~S}$ rRNA bands, $8 \mu \mathrm{l}$ of ethidium bromide $(10 \mathrm{mg} / \mathrm{ml})$ were added as well. The solution was mixed, poured onto the casting plate and left for polymerization under the fume hood. Thereafter, prepared RNA samples were loaded onto the gel, and the electrophoresis was performed at a constant voltage of $80 \mathrm{~V}$. After electrophoresis, equal loading and integrity of RNA were evaluated by ultraviolet shadowing in the UV transilluminator built-in Eagle Eye ${ }^{\mathrm{TM}}$ system (Stratagene), the gel was then photographed and immediately subjected to RNA transfer.

\subsubsection{RNA Transfer to Nylon Membrane}

Size-fractionated RNA samples were transferred to nylon membranes using capillary transfer system. The system for transfer was assembled as depicted on Figure 14. A plastic tray was filled with $500 \mathrm{ml}$ of $20 x$ SSC buffer and covered with a glass plate. Oblong Whatman 3MM filter paper was soaked in 20x SSC buffer and draped over the glass plate with edges submerging in the buffer. Air bubbles between the Whatman paper and glass plate were squeezed out by rolling a glass pipette over surface. The gel was carefully placed on the filter and covered with $2 x$ SSC buffer. Bubbles were 
carefully removed. Four strips of paraffin were placed in contact with the gel edges to prevent direct absorbtion of buffer by paper towels. Wetted piece of nylon membrane was delicately placed on the exposed gel surface, smoothed out and covered with two additional sheets of Whatman 3MM paper wetted in 2x SSC buffer. Finally, paper towels were stacked on top of Whatman papers to a height of approximately $8 \mathrm{~cm}$, covered with another glass plate and pressed with an $1 \mathrm{~kg}$ blotting weight. The transfer was carried out overnight. After transfer, RNA was cross-linked to the membrane by ultraviolet waves in the Stratalinker ${ }^{\mathrm{TM}} 180$ system (Stratagene).

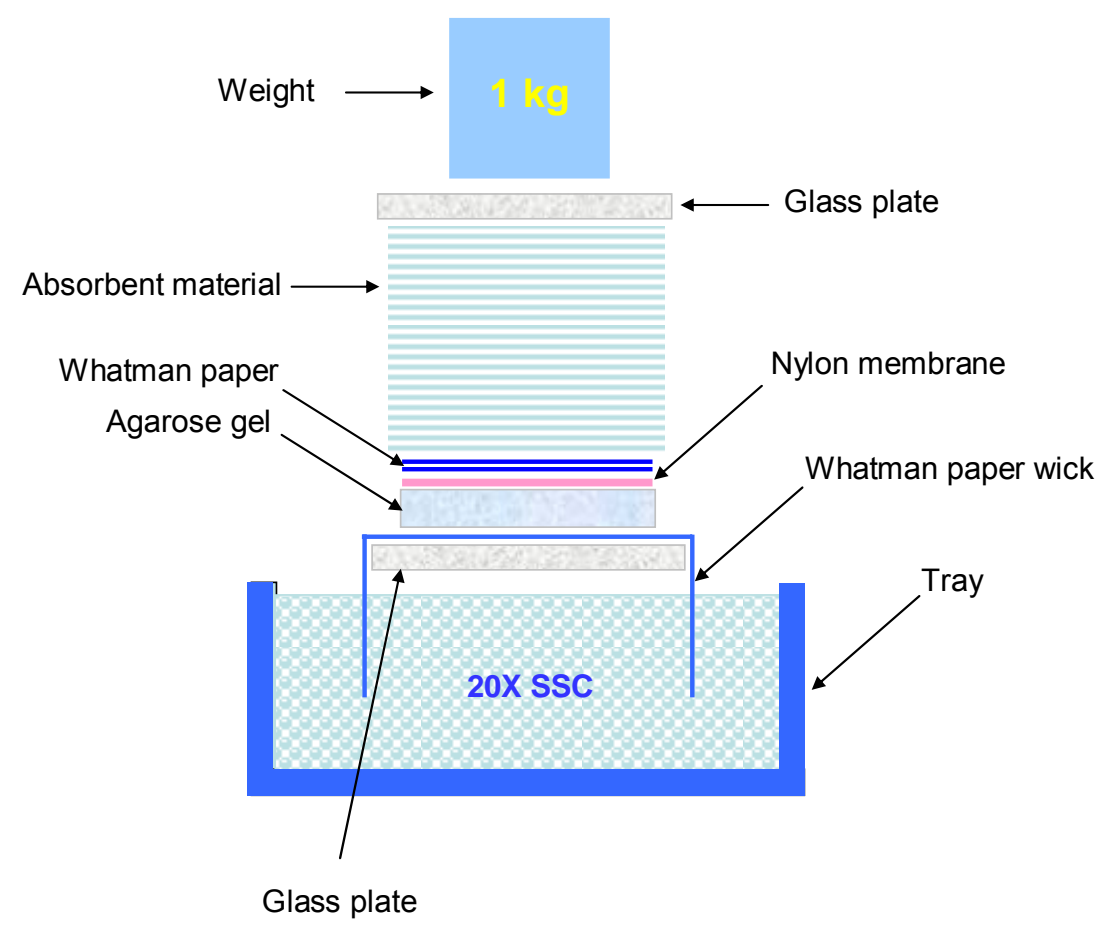

Figure 14. Capillary Northern blot setup. A plastic tray is filled with 20x SSC buffer and covered with a glass plate. Whatman 3MM paper is soaked in 20x SSC buffer and draped over the glass plate with edges submerging in the buffer. The gel is carefully placed on the Whatman paper and covered with $2 x$ SSC buffer. A piece of nylon membrane is placed on the exposed gel surface and covered with two additional sheets of Whatman 3MM paper wetted in 2x SSC buffer. Finally, paper towels are stacked on top of Whatman papers to a height of approximately $8 \mathrm{~cm}$, covered with another glass plate and pressed with an $1 \mathrm{~kg}$ blotting weight.

\subsubsection{Hybridization of RNA with Radiolabelled cDNA Probe}

After cross-linking, the nylon membrane was rinsed with RNase-free water to remove traces of agarose. Afterwards, the membrane was placed into the hybridization tube, and any bubbles between the membrane and internal wall of the tube were carefully squeezed out. To prevent unspecific binding, the membrane was first prehybridized in QuikHyb ${ }^{\circledR}$ hybridization solution at $68^{\circ} \mathrm{C}$ for 2 hours. Radiolabelled probe $(1,500,000$ - 
$3,000,000 \mathrm{cpm} / \mathrm{ml}$ ) was mixed with a double volume of fish sperm DNA and denatured at $95^{\circ} \mathrm{C}$ for $5 \mathrm{~min}$. After cooling down on ice, the DNA probe was applied into QuikHyb ${ }^{\circledR}$ solution inside the hybridization tube. The tube was placed back in the hybridization oven, and hybridization was carried out at $68^{\circ} \mathrm{C}$ for $2 \mathrm{~h}$. After hybridization, the membrane was washed once in $2 x \mathrm{SSC} / 0.1 \%$ SDS for $10 \mathrm{~min}$ at $\mathrm{RT}$, then twice in $0.1 \mathrm{x}$ SSC/0.1\% SDS for $15 \mathrm{~min}$ at $43^{\circ} \mathrm{C}$ (IGF-IR, IGF-II/M6-PR, PDGFR $\beta$ CDNA), $55^{\circ} \mathrm{C}$ (IGFI, IGF-II, PDGFR $\alpha$ cDNA) or $60^{\circ} \mathrm{C}$ (IGFBP-2, IGFBP-3, $\alpha_{2}(\mathrm{I})$ chain of type I procollagen cDNA) and, finally, twice in $2 x \mathrm{SSC} / 0.1 \%$ SDS for $10 \mathrm{~min}$ at RT. To visualize $28 \mathrm{~S}$ rRNA, the membrane was prehybridized in QuikHyb ${ }^{\circledR}$ hybridization solution at $42^{\circ} \mathrm{C}$ for 2 hours followed by overnight hybridization at $42^{\circ} \mathrm{C}$ with the labelled oligonucleotide specific for $28 \mathrm{~S}$ rRNA and washed three times in $2 \mathrm{x} S \mathrm{SC} / 0.1 \%$ SDS for $10 \mathrm{~min}$ at $37^{\circ} \mathrm{C}$. After washing, membranes were wrapped in a saran wrap, placed in X-ray film cassette and autoradiographed during various exposure times. Each membrane was reprobed up to 5 times. Typically, first hybridizations were performed to visualize low abundance transcripts followed by sequential hybridizations with cDNAs complementary to more abundant mRNAs. When reprobing, the membrane was unwrapped, immediately placed in warm $\left(60-80^{\circ} \mathrm{C}\right) 1 \mathrm{x}$ TE buffer and incubated with slight shaking until overall radioactivity (checked by Geiger hand counter) on the membrane surface disappeared. The membrane was then placed in a new hybridization tube and subjected to the next experiment.

10x running buffer

$\begin{array}{lll} & \text { For } 500 \mathrm{ml} & \text { Final concentration } \\ \text { MOPS } & 20 \mathrm{~g} & 200 \mathrm{mM} \\ \text { 2M sodium acetate } & 12.5 \mathrm{ml} & 50 \mathrm{mM} \\ 0.5 \mathrm{M} \text { EDTA } & 10 \mathrm{ml} & 10 \mathrm{mM} \\ \text { RNase-free } \mathrm{H}_{2} \mathrm{O}\left(\text { Ampuwa }^{\circledR} \text { ) }\right. & \text { to } 500 \mathrm{ml} & \\ \text { pH was adjusted with } 5 \mathrm{~N} \mathrm{NaOH} \text { to } 7.0 \text {; the solution was sterile filtered and stored in the } \\ \text { dark at } 4^{\circ} \mathrm{C} \text {. }\end{array}$

$\underline{1 x \text { running buffer }}$

For 11

$10 x$ running buffer $\quad 100 \mathrm{ml}$

RNase-free water $\left(\right.$ Ampuwa $\left.^{\circledR}\right)$ to 1 I

The solution was stored at RT for 1-2 weeks. 


\section{Sample buffer}

Deionized formamide

$500 \mu \mathrm{l}$

$37 \%$ formaldehyde

$169 \mu \mathrm{l}$

10x running buffer

$100 \mu \mathrm{l}$

The solution was dispensed into $1 \mathrm{ml}$ aliquots and stored at $-20^{\circ} \mathrm{C}$ for $2-3$ months.

Deionized formamide

Formamide

$100 \mathrm{ml}$

Mixed Bed Resin AG 501-X8 (D) $10 \mathrm{~g}$

The mixture was stirred for 30 min in the dark at RT, afterwards it was sterile filtered, dispensed into $50 \mathrm{ml}$ aliquots and stored in the dark at $-20^{\circ} \mathrm{C}$.

Loading buffer

10x running buffer

$5 \mathrm{ml}$

RNase-free $\mathrm{H}_{2} \mathrm{O}\left(\right.$ Ampuwa $\left.^{\circledR}\right) \quad 3 \mathrm{ml}$

Ficoll 400

Bromophenol blue $10 \mathrm{mg}$

The solution was dispensed into $0.5 \mathrm{ml}$ aliquots and stored for $2-3$ months at $-20^{\circ} \mathrm{C}$.

$\underline{20 X \text { SSC }}$

\section{For 21}

$\mathrm{NaCl}$

$350.6 \mathrm{~g}$

Sodium citratex $2 \mathrm{H}_{2} \mathrm{O}$

$176.4 \mathrm{~g}$

$\mathrm{ddH}_{2} \mathrm{O}$

to 2 I

The solution was autoclaved and stored at RT.

$\underline{2 \times S S C}$

$\begin{array}{ll} & \text { For } 500 \mathrm{ml} \\ 20 \times \text { SSC } & 50 \mathrm{ml} \\ \mathrm{ddH}_{2} \mathrm{O} & \text { to } 500 \mathrm{ml}\end{array}$

The solution was stored at RT. 


$\begin{array}{lll} & \text { For 1 I } & \text { Final concentration } \\ 2 \mathrm{M} \text { Tris- } \mathrm{HCl}, \mathrm{pH} 7.4 & 50 \mathrm{ml} & 100 \mathrm{mM} \\ 0.5 \mathrm{M} \mathrm{EDTA} & 20 \mathrm{ml} & 10 \mathrm{mM} \\ \text { RNase-free } \mathrm{H}_{2} \mathrm{O} & \text { to } 1 \mathrm{I} & \end{array}$

$\mathrm{pH}$ was controlled and, if necessary, adjusted with $\mathrm{NaOH}$ or $\mathrm{HCl}$ to 7.6. The solution was sterile filtered and stored at RT.

$\underline{1 \times \mathrm{TE}}$

For $500 \mathrm{ml}$

10x TE

$50 \mathrm{ml}$

RNase-free $\mathrm{H}_{2} \mathrm{O}$

to $500 \mathrm{ml}$

The solution was stored at RT.

\section{$\underline{2 \times S S C / 0.1 \% ~ S D S ~}$}

For $500 \mathrm{ml}$

20x SSC

$50 \mathrm{ml}$

$20 \%$ SDS

$2.5 \mathrm{ml}$

$\mathrm{dd}_{2} \mathrm{O}$

to $500 \mathrm{ml}$

The solution was stored at RT. In the case of SDS precipitation the solution was warmed until it became clear.

\section{$\underline{0.1 \times \mathrm{SSC} / 0.1 \% \text { SDS }}$}

$$
\text { For } 500 \mathrm{ml}
$$

$20 \times$ SSC

$2.5 \mathrm{ml}$

$20 \%$ SDS

$2.5 \mathrm{ml}$

$\mathrm{ddH}_{2} \mathrm{O}$

to $500 \mathrm{ml}$

The solution was stored at RT. In the case of SDS precipitation, the solution was warmed until it became clear. 


\subsection{Immunochemical and Biochemical Methods}

\subsubsection{Protein Extraction from Cultured Cells}

\subsubsection{Preparation of Cell Lysates}

The whole procedure was performed at $4^{\circ} \mathrm{C}$ to prevent proteolytical degradation of proteins. After respective treatment, cells were washed with ice-cold PBS, placed on ice and then solubilized in ice-cold lysis buffer $(50 \mathrm{mM}$ Tris- $\mathrm{HCl}, 150 \mathrm{mM} \mathrm{NaCl}, 1 \mathrm{mM}$ EDTA, 1\% CHAPS, pH 7.4) supplemented with protease and phosphatase inhibitors (500 and $1500 \mu \mathrm{l}$ of buffer per $100 \mathrm{~mm}$ and $150 \mathrm{~mm}$ dish, respectively). Solubilized cells were harvested by scraping and transferred to prechilled $2.0 \mathrm{ml}$ reaction tubes, which were incubated on ice for $30 \mathrm{~min}$ and vortexed every $5 \mathrm{~min}$. For better homogenization, cell lysates were passed through $24 \mathrm{G}$ injection needle connected to the syringe. The insoluble material was removed by centrifugation at $10,000 \times g$ for $10 \mathrm{~min}$ at $4^{\circ} \mathrm{C}$, and the supernatants containing cellular proteins were then transferred to new $2.0 \mathrm{ml}$ reaction tubes. Protein concentrations were determined by BCA protein assay (Pierce) using bovine albumin as a protein standard. Cell lysates were stored at $-20^{\circ} \mathrm{C}$ and were further subjected to immunoprecipitation or were directly electrophoresed and immunoblotted as described below.

$\underline{10 x \text { lysis buffer (stock) }}$

\begin{tabular}{|c|c|c|}
\hline & For $100 \mathrm{ml}$ & Final concentration \\
\hline $2 \mathrm{M}$ Tris- $\mathrm{HCl}, \mathrm{pH} 7.4$ & $2.5 \mathrm{ml}$ & $50 \mathrm{mM}$ \\
\hline $\mathrm{NaCl}$ & $0.877 \mathrm{~g}$ & $150 \mathrm{mM}$ \\
\hline $500 \mathrm{mM}$ EDTA & $200 \mu \mathrm{l}$ & $1 \mathrm{mM}$ \\
\hline $\mathrm{ddH}_{2} \mathrm{O}$ & to $100 \mathrm{ml}$ & \\
\hline \multicolumn{3}{|c|}{$\mathrm{pH}$ was adjusted to 7.4 . The solution was stored at $4^{\circ} \mathrm{C}$. } \\
\hline \multicolumn{3}{|c|}{$1 \mathrm{x}$ lysis buffer with supplements } \\
\hline & For $10 \mathrm{ml}$ & Final concentration \\
\hline 10x lysis buffer (stock) & $1000 \mu \mathrm{l}$ & $1 \mathrm{x}$ \\
\hline $10 \%$ CHAPS & $1000 \mu \mathrm{l}$ & $1 \%$ \\
\hline Sodium orthovanadate & $50 \mu \mathrm{l}$ & $1 \mathrm{mM}$ \\
\hline Sodium fluoride & $50 \mu \mathrm{l}$ & $2 \mathrm{mM}$ \\
\hline Sodium pyrophosphate & $500 \mu \mathrm{l}$ & $10 \mathrm{mM}$ \\
\hline$\beta$-glycerophosphate & $500 \mu \mathrm{l}$ & $8 \mathrm{mM}$ \\
\hline
\end{tabular}




$\begin{array}{lll}\text { PMSF } & 20 \mu \mathrm{l} & 1 \mathrm{mM} \\ \text { Benzamidine } & 10 \mu \mathrm{l} & 1 \mathrm{mM} \\ \text { Chymostatin } & 10 \mu \mathrm{l} & 8.25 \mathrm{mM} \\ \text { Pepstatin A } & 10 \mu \mathrm{l} & 1 \mu \mathrm{g} / \mathrm{ml} \\ \text { Leupeptin } & 1 \mu \mathrm{l} & 1 \mu \mathrm{g} / \mathrm{ml} \\ \text { Antipain } & 1 \mu \mathrm{l} & 1 \mu \mathrm{g} / \mathrm{ml} \\ \text { dd }_{2} \mathrm{O} & \text { to } 10 \mathrm{ml} & \end{array}$

The buffer was prepared briefly before use.

\section{CHAPS stock}

$\begin{array}{lll} & \text { For } 100 \mathrm{ml} & \text { Stock concentration } \\ \text { CHAPS } & 10 \mathrm{~g} & 10 \% \\ \mathrm{ddH}_{2} \mathrm{O} & \text { to } 100 \mathrm{ml} & \end{array}$

The solution was stored at $4^{\circ} \mathrm{C}$.

Stock solutions of phosphatase inhibitors

Stock concentration

Sodium orthovanadate

$0.74 \mathrm{~g}$ in $20 \mathrm{ml} \mathrm{H}_{2} \mathrm{O} \quad 200 \mathrm{mM}$

Sodium fluoride

$1.68 \mathrm{~g}$ in $100 \mathrm{ml} \mathrm{H}_{2} \mathrm{O} \quad 400 \mathrm{mM}$

Sodium pyrophosphate

$8.922 \mathrm{~g}$ in $100 \mathrm{ml} \mathrm{H}_{2} \mathrm{O} \quad 200 \mathrm{mM}$

$\beta$-glycerophosphate

$3.456 \mathrm{~g}$ in $100 \mathrm{ml} \mathrm{H}_{2} \mathrm{O} \quad 160 \mathrm{mM}$

Stock solutions of sodium fluoride, sodium pyrophosphate and $\beta$-glycerophosphate were stored in the dark at RT. Activated stock solution of sodium orthovanadate was stored as an aliquot $(500 \mu \mathrm{l})$ at $-20^{\circ} \mathrm{C}$.

$\underline{\text { Stock solutions of protease inhibitors }}$

$\begin{array}{lll} & & \text { Stock concentration } \\ \text { PMSF } & 87.1 \mathrm{mg} \text { in } 1 \mathrm{ml} \mathrm{DMSO} & 500 \mathrm{mM} \\ \text { Benzamidine } & 313.2 \mathrm{mg} \text { in } 2 \mathrm{ml} \mathrm{H} \mathrm{H}_{2} & 1 \mathrm{M} \\ \text { Chymostatin } & 1 \mathrm{mg} \text { in } 0.2 \mathrm{ml} \mathrm{DMSO} & 8.25 \mathrm{mM} \\ \text { Pepstatin A } & 1 \mathrm{mg} \text { in } 1 \mathrm{ml} & 1 \mathrm{mg} / \mathrm{ml} \\ & \text { DMSO:acetic acid }(9: 1) & \\ \text { Leupeptin } & 1 \mathrm{mg} \text { in } 0.1 \mathrm{ml} \mathrm{H}_{2} \mathrm{O} & 10 \mathrm{mg} / \mathrm{ml} \\ \text { Antipain } & 1 \mathrm{mg} \text { in } 0.1 \mathrm{ml} \mathrm{H}_{2} \mathrm{O} & 10 \mathrm{mg} / \mathrm{ml}\end{array}$

Protease inhibitors stocks were stored as small aliquots at $-20^{\circ} \mathrm{C}$. 


\section{Properties of used protease inhibitors}

Antipain: inhibits reversibly serine/cysteine proteases and some trypsin-like serine proteases. Its action resembles leupeptin, but it inhibits plasmin less and cathepsin A more than does leupeptin. Antipain also inhibits papain, trypsin, cathepsin $B$, cathepsin $D$, chymotrypsin, pepsin, and calpain I.

Benzamidine: inhibits reversibly trypsin-like enzymes and serine proteases. It is also a strong competitive inhibitor of trypsin, thrombin and plasmin. Benzamidine is sensitive to oxidation and for the most part interchangeable with pepstatin $A$.

Chymostatin: strongly inhibits a variety of proteases, including chymotrypsin, chymotrypsin-like serine proteases, chymases and lysosomal cysteine proteases such as cathepsins B, H and L. Weakly inhibits human leukocyte elastase.

Leupeptin: reversibly and competitively inhibits serine and thiol proteases such as trypsin, plasmin, proteinase $\mathrm{K}$, kallikrein, papain, thrombin and cathepsin $\mathrm{A}$ and $\mathrm{B}$. Unaffected are $\alpha, \beta, \gamma$, and $\sigma$-chymotrypsins, pepsin, cathepsin $D$, elastase, renin and thermolysin.

Pepstatin A: inhibits acid proteases (aspartyl peptidases). It forms complexes at a molar ratio of $1: 1$ with proteases such as pepsin, renin, cathepsin $D$, bovine chymosin, solubilized $\gamma$-secretase, retroviral protease, and protease B (Aspergillus niger). The inhibitor is highly selective and does not inhibit thiol proteases, neutral proteases or serine proteases.

PMSF: inhibits serine proteases such as chymotrypsin, trypsin and thrombin as well as thiol protease papain. Does not inhibit metalloproteases, most thiol and aspartate proteases. PMSF is very unstable in the presence of water.

\subsubsection{Extraction of Nuclear and Cytoplasmic Proteins from Cultured Cells}

Stepwise preparation of cytoplasmic and nuclear extracts from cultured rat liver myofibroblasts was performed in the current work using NE-PER ${ }^{\circledR}$ Nuclear and Cytoplasmic Extraction Reagents (Pierce). The technique used enables the purification of non-denatured, active cytoplasmic and nuclear proteins in less than two hours. Addition of the Cytoplasmic Extraction Reagents I and II to a cell pellet causes disruption of cell membranes and release of cytoplasmic contents. After recovering the intact nuclei by centrifugation, the nuclei are lysed with the Nuclear Extraction Reagent to yield the nuclear extract. Obtained extracts generally have less than $10 \%$ 
contamination that is sufficient purity for most experiments involving studies of nuclear physiology.

After respective treatment, rat LMFs cultured on $150 \mathrm{~mm}$ dishes were detached by trypsinization and centrifuged at $1,000 \times g$ for $5 \mathrm{~min}$ at RT. The supernatant was discarded. The pellet was resuspended in $1 \mathrm{ml}$ of PBS, transferred to a new $1.5 \mathrm{ml}$ reaction tube and centrifuged briefly in a bench-top centrifuge. The PBS was removed, and the pellet was resuspended in $100 \mu \mathrm{l}$ of ice-cold Cytoplasmic Extraction Reagent I by vigorous vortexing for $15 \mathrm{sec}$. The samples were incubated on ice for $10 \mathrm{~min}$. Subsequently, $5.5 \mu \mathrm{l}$ of ice-cold Cytoplasmic Extraction Reagent II were added, the samples were vortexed for $5 \mathrm{sec}$, incubated on ice for $1 \mathrm{~min}$, again vortexed and, finally, centrifuged in a bench-top centrifuge for $5 \mathrm{~min}$. The supernatant fraction containing cytoplasmic proteins was transferred to a new precooled $1.5 \mathrm{ml}$ reaction tube and placed on ice. The pellet containing intact nuclei was then resuspended in $50 \mu$ of icecold Nuclear Extraction Reagent. Nuclei were allowed to swell on ice for $40 \mathrm{~min}$ and were vortexed vigorously every $10 \mathrm{~min}$ for $15 \mathrm{sec}$. The insoluble material was pelleted by centrifugation in a bench-top centrifuge at maximum speed for $10 \mathrm{~min}$. The supernatants containing nuclear extracts were collected in clean prechilled tubes, and protein concentrations were determined by BCA protein assay (Pierce). Both nuclear and cytoplasmic extracts were stored at $-80^{\circ} \mathrm{C}$ and were further subjected to [ $\left.{ }^{125} \mathrm{I}\right]-\mathrm{IGF}-\mathrm{I}-$ ligand blot and Western blot analyses.

\section{Cytoplasmic Extraction Reagent I, working solution}

\section{For $10 \mathrm{ml}$}

Final concentration

Cytoplasmic Extraction Reagent I $10 \mathrm{ml}$ (stock)

$1 \mathrm{M}$ DTT

PMSF

Benzamidine

Chymostatin

Pepstatin A

Leupeptin

Antipain
$10 \mu \mathrm{l}$

$20 \mu \mathrm{l}$

$10 \mu \mathrm{l}$

$10 \mu \mathrm{l}$

$10 \mu \mathrm{l}$

$1 \mu \mathrm{l}$

$1 \mu \mathrm{l}$
$1 \mathrm{mM}$

$1 \mathrm{mM}$

$1 \mathrm{mM}$

$8.25 \mathrm{mM}$

$1 \mu \mathrm{g} / \mathrm{ml}$

$1 \mu \mathrm{g} / \mathrm{ml}$

$1 \mu \mathrm{g} / \mathrm{ml}$

The buffer was prepared briefly before use. 
Nuclear Extraction Reagent, working solution

For $10 \mathrm{ml}$

Final concentration

Nuclear Extraction Reagent

$10 \mathrm{ml}$

(stock)

$1 \mathrm{M}$ DTT

$10 \mu \mathrm{l}$

$1 \mathrm{mM}$

PMSF

$20 \mu \mathrm{l}$

$1 \mathrm{mM}$

Benzamidine

$10 \mu \mathrm{l}$

$1 \mathrm{mM}$

Chymostatin

$10 \mu \mathrm{l}$

$8.25 \mathrm{mM}$

Pepstatin A

$10 \mu \mathrm{l}$

$1 \mu \mathrm{g} / \mathrm{ml}$

Leupeptin

$1 \mu \mathrm{l}$

$1 \mu \mathrm{g} / \mathrm{ml}$

Antipain

$1 \mu \mathrm{l}$

$1 \mu \mathrm{g} / \mathrm{ml}$

The buffer was prepared briefly before use.

\subsubsection{Measurement of Protein Concentration}

The BCA Protein Assay is a detergent-compatible formulation based on bicinchoninic acid (BCA) for the colorimetric detection and quantification of total protein. This method combines the well-known reduction of $\mathrm{Cu}^{2+}$ to $\mathrm{Cu}^{+}$by protein in alkaline medium (the biuret reaction) with the highly sensitive and selective colorimetric detection of the cuprous cation $\left(\mathrm{Cu}^{+}\right)$using a reagent containing BCA. The purple-colored reaction product of the assay is formed by the chelation of two molecules of BCA with one cuprous ion. This water-soluble complex exhibits a strong absorbance at $562 \mathrm{~nm}$ that is linear with increasing concentrations over a broad working range of $20-2,000 \mu \mathrm{g} / \mathrm{ml}$. Protein concentrations in the assay are determined and reported with reference to standards of a common protein such as bovine serum albumin (BSA). A series of dilutions of known concentration are prepared from the protein and analyzed before the concentration of each unknown sample is determined based on the standard curve.

To measure protein concentration, $25 \mu \mathrm{l}$ of each standard or unknown sample were applied into its own microplate well in triplicate. Subsequently, $200 \mu \mathrm{l}$ of working reagent (mixed 50 parts of BCA reagent $A$ and 1 part of BCA Reagent B) were added to each well, and the plate was gently and thoroughly shaken for $30 \mathrm{sec}$ followed by incubation at $37^{\circ} \mathrm{C}$ for $30 \mathrm{~min}$. The plate was then cooled down to RT, and the absorbance was measured at $570 \mathrm{~nm}$ on a plate reader. 
Working reagent

$\begin{array}{ll} & \text { For } 5 \mathrm{ml} \\ \text { BCA Reagent A } & 5 \mathrm{ml} \\ \text { BCA Reagent B } & 100 \mu \mathrm{l}\end{array}$

The solution was prepared briefly before use.

\subsubsection{Sodium Dodecyl Sulphate Polyacrylamide Gel Electrophoresis (SDS-PAGE)}

For all applications described, a Tris/glycine SDS polyacrylamide gel system was used according to the method of Laemmli (Laemmli, 1970). For $\left[{ }^{125} \mathrm{I}\right]-$ IGF-I ligand blot analysis and $\left[{ }^{125} \mathrm{I}\right]$-IGFBP protease assay, gels of standard sizes were cast, and proteins were electrophoretically separated in the standard dual cooled gel electrophoresis unit Hoefer SE 600 (Amersham Biosciences). For Western blot analysis and immunoprecipitation studies, mini-gels and the mini-vertical gel electrophoresis unit Hoefer Mighty Small II (Amersham Biosciences) were used. The units were assembled according to manufacturer's instructions. In general, a discontinuous gel system was used, which was composed of $4 \%$ (polyacrylamide concentration) stacking gel and 5$12.5 \%$ resolving gel. Resolving and stacking gels were prepared as described below.

To cast the resolving gel, the monomer acrylamide solution was poured inside the gel sandwich and overlaid carefully with water to create a barrier for oxygen, which inhibits polymerization. After polymerization of acrylamide (about $30 \mathrm{~min}$ at RT), the water was aspirated, and the monomer solution of stacking gel was applied over the polymerized resolving gel. The wells were formed by appropriate comb inserted into the sandwich. The gel was polymerized for approximately $20 \mathrm{~min}$. Subsequently, the comb was removed, the wells were rinsed with water, and traces of water were carefully aspirated. The samples were loaded into the wells $(100 \mu$ per well in standard gel and $30 \mu \mathrm{l}$ per well in mini-gel) and were carefully covered with cathode buffer. Thereafter, precooled cathode and anode buffers were poured into the upper and lower buffer chamber, respectively. The gel electrophoresis unit was then fully enclosed and connected to a suitable power supply. Proteins were size-fractionated at a constant current ( $8 \mathrm{~mA}$ per gel in the standard dual cooled gel electrophoresis unit Hoefer SE 600, and 25 mA per gel in the mini-vertical gel electrophoresis unit Hoefer Mighty Small II). Rainbow ${ }^{\mathrm{TM}}$ colored protein marker (Amersham Biosciences) was used as a molecular weight standard. 
Buffer for resolving gel

$\begin{array}{lll} & \text { For } 250 \mathrm{ml} & \text { Final concentration } \\ \text { Tris } & 45.43 \mathrm{~g} & 1.5 \mathrm{M} \\ \mathrm{SDS} & 1 \mathrm{~g} & 0.4 \% \\ \mathrm{ddH}_{2} \mathrm{O} & \text { ad } 250 \mathrm{ml} & \\ \mathrm{pH} \text { was adjusted to 8.8. The buffer was stored at RT. } & \end{array}$

\section{Buffer for stacking gel}

$\begin{array}{lll} & \text { For } 100 \mathrm{ml} & \text { Final concentration } \\ \text { Tris } & 6.05 \mathrm{~g} & 0.5 \mathrm{M} \\ \mathrm{SDS} & 0.4 \mathrm{~g} & 0.4 \% \\ \mathrm{ddH}_{2} \mathrm{O} & \text { to } 100 \mathrm{ml} & \end{array}$

\section{Resolving Gel}

\begin{tabular}{llllll}
\hline & $5 \%$ & $6 \%$ & $7.5 \%$ & $10 \%$ & $12.5 \%$ \\
Rotiphorese Gel 30 & $5.25 \mathrm{ml}$ & $6.3 \mathrm{ml}$ & $7.9 \mathrm{ml}$ & $10.5 \mathrm{ml}$ & $13.1 \mathrm{ml}$ \\
Buffer for resolving gel & $7.5 \mathrm{ml}$ & $7.5 \mathrm{ml}$ & $7.5 \mathrm{ml}$ & $7.5 \mathrm{ml}$ & $7.5 \mathrm{ml}$ \\
$10 \%$ APS & $250 \mu \mathrm{l}$ & $250 \mu \mathrm{l}$ & $250 \mu \mathrm{l}$ & $250 \mu \mathrm{l}$ & $250 \mu \mathrm{l}$ \\
TEMED & $25 \mu \mathrm{l}$ & $25 \mu \mathrm{l}$ & $25 \mu \mathrm{l}$ & $25 \mu \mathrm{l}$ & $25 \mu \mathrm{l}$ \\
$\mathrm{ddH}_{2} \mathrm{O}$ & to $30 \mathrm{ml}$ & to $30 \mathrm{ml}$ & to $30 \mathrm{ml}$ & to $30 \mathrm{ml}$ & to $30 \mathrm{ml}$
\end{tabular}

$\underline{\text { Stacking Gel }}$

$\begin{array}{ll} & 4 \% \\ \text { Rotiphorese Gel } 30 & 1.3 \mathrm{ml} \\ \text { Buffer for stacking gel } & 2.5 \mathrm{ml} \\ 10 \% \text { APS } & 100 \mu \mathrm{l} \\ \text { TEMED } & 10 \mu \mathrm{l} \\ \mathrm{ddH}_{2} \mathrm{O} & \text { to } 10 \mathrm{ml}\end{array}$


$\underline{1 \mathrm{x} \text { anode buffer }}$

For $5 \mathrm{I}$

Final concentration

Tris base

$15.1 \mathrm{~g}$

$250 \mathrm{mM}$

Glycin

$72.0 \mathrm{~g}$

$192 \mathrm{mM}$

$\mathrm{ddH}_{2} \mathrm{O}$

to 5 I

$\mathrm{pH}$ of this buffer was approximately 8.3. The buffer was stored at $4{ }^{0} \mathrm{C}$.

$1 \mathrm{x}$ cathode buffer

For 51

$15.1 \mathrm{~g}$

$72.0 \mathrm{~g}$

$5 \mathrm{~g}$

$0.5 \mathrm{ml}$

to $5 \mathrm{I}$
Final concentration

$250 \mathrm{mM}$

$192 \mathrm{mM}$

$0.1 \%$

$100 \mu \mathrm{g} / \mathrm{l}$

$\mathrm{dd} \mathrm{H}_{2} \mathrm{O}$

8.3. The buffer was stored at $4{ }^{\circ} \mathrm{C}$.

\subsubsection{Electrophoretic Transfer of Proteins}

Electrophoretic transfer was carried out essentially as described by Towbin (Towbin et al., 1979). Prior to transfer, fiber pads, blotting paper and nitrocellulose transfer membrane were soaked in transfer buffer. After electrophoresis, the gel was removed from the sandwich and immersed in transfer buffer. For electrophoretic transfer of proteins, the transfer electrophoresis unit Hoefer TE 50X (Amersham Biosciences) and the Mini-Trans-Blot ${ }^{\circledR}$ Cell (Bio-Rad) compatible with the described system for electrophoresis were used. The transblot sandwich was assembled according to the manufacturer's instructions in the following order starting from the anode side: sponge, 1 sheet of blotting paper, nitrocellulose membrane, gel, 1 sheet of blotting paper, sponge. Air bubbles were carefully squeezed out by rolling a glass pipette over the gel. The assembled transfer cassette was inserted into the transblot cell filled with precooled transfer buffer. Proteins were then electroblotted at a constant current of $350 \mathrm{~mA}$ for $2 \mathrm{~h}$ at $4^{0} \mathrm{C}$. After transfer, the membrane was stained with Ponceau $\mathrm{S}$ to ensure that protein transfer was satisfactory, and thereafter subjected to $\left[{ }^{125} \mid\right]-I G F-I$ ligand and immunoblotting. 
For $5 \mathrm{I}$

$15.1 \mathrm{~g}$

$72.0 \mathrm{~g}$

$500 \mathrm{ml}$

$2.5 \mathrm{ml}$

to 5 I

$\mathrm{dd}_{2} \mathrm{O}$

$\mathrm{pH}$ was adjusted to 8.3. The buffer was stored at $4{ }^{0} \mathrm{C}$.

10x Ponceau S

Ponceau S

Trichloroacetic acid

Sulfosalicylic acid

For $100 \mathrm{ml}$

Final concentration

$\mathrm{ddH}_{2} \mathrm{O}$

$2 \mathrm{~g}$

$2 \%$

$30 \mathrm{ml}$

$30 \%$

$30 \mathrm{ml}$

$30 \%$

to $100 \mathrm{ml}$

The solution was stored at RT.

$1 x$ Ponceau S

10x Ponceau S

For $50 \mathrm{ml}$

$\mathrm{ddH}_{2} \mathrm{O}$

$5 \mathrm{ml}$

to $50 \mathrm{ml}$

The solution was stored at RT.

\subsubsection{Iodination of IGF-I}

IGF-I was iodinated by the chloramine-T method to a specific activity of about $60-80$ $\mu \mathrm{Ci} / \mu \mathrm{g}$. Briefly, $1 \mathrm{mCi} \mathrm{Na}{ }^{125} \mathrm{I}$ (usually $10 \mu \mathrm{l}$ ) was added to the reaction tube containing 10-15 $\mu \mathrm{g}$ of IGF-I. Iodination reaction was started by addition of $10 \mu \mathrm{l}$ of $0.4 \mathrm{mg} / \mathrm{ml}$ chloramine-T working solution and stopped after 10-15 seconds by addition of $20 \mu \mathrm{l}$ of $12.6 \mathrm{mg} / \mathrm{ml}$ sodium bisulphite. The reaction mixture was then diluted with $100 \mu \mathrm{l}$ chromatography buffer (buffer A) and loaded into HPLC column equilibrated with buffers $A$ and $B$ in order to separate $\left[{ }^{125} I\right]$-labelled IGF-I from unreacted product. The column was then run at a flow rate of $1.5 \mathrm{ml} / \mathrm{min}$ and $1.5 \mathrm{ml}$ fractions were collected. Finally, the gamma-radioactivity of each sample was measured, and fractions with highest 
radioactivity rates were selected and stored at $-20^{\circ} \mathrm{C}$. The quality of $\left[{ }^{125} \mathrm{I}\right]$-labelled IGF-I was checked by ligand blot analysis with human and rat serum samples.

$\underline{0.4 \mathrm{M} \text { sodium phosphate buffer }}$

For $100 \mathrm{ml}$

Final concentration

di-Sodium hydrogen phosphate

$7.12 \mathrm{~g}$

$0.4 \mathrm{M}$

dihydrate

Sodium dihydrogen phosphate

$4.66 \mathrm{~g}$

$0.4 \mathrm{M}$

$\mathrm{ddH}_{2} \mathrm{O}$

to $100 \mathrm{ml}$

$\mathrm{pH}$ was adjusted to 7.4. The solution was stored at RT.

$\underline{\text { Chloramine-T working solution }}$

For $1 \mathrm{ml}$

Chloramine-T

$0.4 \mathrm{M}$ sodium phosphate buffer
Final concentration

$4 \mathrm{mg} / \mathrm{ml}$

The solution was freshly prepared before iodination.

Sodium bisulphite working solution

For $1 \mathrm{ml}$

$12.6 \mathrm{mg}$

Sodium bisulphite

$0.4 \mathrm{M}$ sodium phosphate buffer

$1 \mathrm{ml}$

The solution was freshly prepared before iodination.

\section{Buffer A}

Trifluoroacetic acid

For 11

Final concentration

$\mathrm{HPLC} \mathrm{H}_{2} \mathrm{O}$

$1 \mathrm{ml}$

$0.1 \%$

The solution was stored at RT.

\section{Buffer B}

$\begin{array}{lll} & \text { For } 1 \mathrm{I} & \text { Final concentration } \\ \text { Acetonitril } & 700 \mathrm{ml} & 70 \% \\ \text { Trifluoroacetic acid } & 1 \mathrm{ml} & 0.1 \% \\ \mathrm{HPLC} \mathrm{H}_{2} \mathrm{O} & \text { to } 1 \mathrm{I} & \end{array}$

The solution was stored at RT. 


\subsection{6. [125I]-IGF-I Ligand Blot Analysis}

To determine which IGFBPs are secreted by cultured rat liver cells, samples of conditioned media (CM) were analyzed by $\left[{ }^{125}\right.$ I]-IGF-I ligand blot analysis according to Hossenlopp et al. (1986), with slight modifications. For SDS-PAGE, proteins were obtained by overnight precipitation of $750 \mu \mathrm{l}$ of the whole culture supernatant in $1200 \mu \mathrm{l}$ of absolute ethanol at $-80^{\circ} \mathrm{C}$ followed by centrifugation $\left(14,000 \mathrm{rpm}, 15 \mathrm{~min}, 4^{\circ} \mathrm{C}\right)$ in a bench-top centrifuge. The supernatant was then discarded, the pellet was air-dried, resuspended in $100 \mu \mathrm{l}$ of non-reducing sample electrophoresis buffer, heated at $95^{\circ} \mathrm{C}$ for 5 minutes and loaded onto $10 \%$ gel. Alternatively, to study nuclear localization of IGFBP-3, 150-300 $\mu \mathrm{g}$ of nuclear and cytoplasmic proteins were denatured in nonreducing sample buffer by boiling at $95^{\circ} \mathrm{C}$ and also subjected to SDS-PAGE. Electrophoretic separation of proteins and their transfer to nitrocellulose membranes were performed as described above. Molecular weight standard was processed in parallel. After transfer, the nitrocellulose membranes were blocked in Tris-buffered saline supplemented with $1 \%$ fish gelatine at RT for two hours with slight agitation, and were then incubated with $8,000,000 \mathrm{cpm}$ of $\left[{ }^{125} \mathrm{I}\right]-\mathrm{IGF}-\mathrm{I}$ diluted in $30 \mathrm{ml}$ of washing buffer at $4^{\circ} \mathrm{C}$ overnight. Finally, the membranes were washed in washing buffer (three times, $10 \mathrm{~min}$ on each occasion), air-dried, wrapped and exposed to X-ray films at $-80^{\circ} \mathrm{C}$ for various exposure times.

\section{$\underline{2 x}$ sample buffer (non-reducing)}

$\begin{array}{lll} & \text { For } 10 \mathrm{ml} & \text { Final concentration } \\ \text { SDS } & 200 \mathrm{mg} & 2 \% \\ \text { Tris base } & 302 \mathrm{mg} & 250 \mathrm{mM} \\ \text { Glycerin } & 2 \mathrm{ml} & 20 \% \\ \mathrm{ddH}_{2} \mathrm{O} & \text { to } 10 \mathrm{ml} & \end{array}$

$\mathrm{pH}$ was adjusted to 6.8 . The buffer was stored as an aliquot $(1000 \mu \mathrm{l})$ at $-20^{\circ} \mathrm{C}$.

$\underline{1 \mathrm{x} \text { TBS stock for ligand blot }}$

For 21

Tris base

$\mathrm{NaCl}$

$\mathrm{ddH}_{2} \mathrm{O}$
$12.11 \mathrm{~g}$

$18 \mathrm{~g}$

to 2 I
Final concentration $50 \mathrm{mM}$ $150 \mathrm{mM}$

$\mathrm{pH}$ was adjusted to 7.4. The buffer was stored at RT. 


\section{Blocking buffer}

For $100 \mathrm{ml}$

Fish gelatine

1x TBS stock for ligand blot
$1 \mathrm{ml}$

$100 \mathrm{ml}$

The buffer was prepared briefly before use.

Washing buffer

For $100 \mathrm{ml}$

Fish gelatine

Nonidet P-40

TBS stock for ligand blot
$1 \mathrm{ml}$

$200 \mu l$

$100 \mathrm{ml}$
Final concentration

$1 \%$

The buffer was prepared briefly before use.

\subsubsection{Western Blot Analysis}

$10-50 \mu \mathrm{g}$ of cell lysates, nuclear and cytoplasmic extracts as well as proteins extracted from $375 \mu \mathrm{l}$ of medium conditioned by cultured rat liver myofibroblasts were denatured in reducing sample buffer by boiling at $95^{\circ} \mathrm{C}$ and further subjected to SDS-PAGE (5$12.5 \%$ acrylamide). Electrophoretic separation of proteins and their transfer to nitrocellulose membranes were performed as described above. After transfer, the membrane was incubated overnight on rocking platform with blocking buffer at $4^{\circ} \mathrm{C}$. Subsequently, the blot was incubated with primary antibody diluted in antibody dilution buffer for $3 \mathrm{~h}$ at RT. After washing in TBST buffer (six times, five min on each occasion), the membrane was incubated with HRP-conjugated secondary antibody diluted in antibody dilution buffer for $1 \mathrm{~h}$ at RT. The membrane was then washed as before. For the chemiluminescent detection SuperSignal ${ }^{\circledR}$ West Pico Chemiluminescent Substrate (Pierce) was used. Substrate working solution was prepared by mixing of equal volumes of two substrate components. The membrane was incubated with substrate working solution for 5 min at RT, placed between two sheets of transparent plastic films and exposed to X-ray films. The exposure time varied between 5 seconds and 1 hour. Several membranes were reprobed with different antibodies. When reprobing, the membrane was placed in Re-Blot Plus ${ }^{\circledR}$ stripping buffer (Chemicon) and incubated for 20 min at RT with slight agitation. After washing in TBST buffer (three times, 5 min on each occasion), the membrane was again blocked with milk and subjected to the next experiment. 
$\underline{2 x \text { sample buffer (reducing) }}$

$\begin{array}{lll} & \text { For } 10 \mathrm{ml} & \text { Final concentration } \\ \text { DTT } & 31 \mathrm{mg} & 20 \mathrm{mM} \\ \text { SDS } & 200 \mathrm{mg} & 2 \% \\ \text { Tris base } & 302 \mathrm{mg} & 250 \mathrm{mM} \\ \text { Glycerin } & 2 \mathrm{ml} & 20 \% \\ \mathrm{ddH}_{2} \mathrm{O} & \text { to } 10 \mathrm{ml} & \end{array}$

$\mathrm{pH}$ was adjusted to 6.8 . The buffer was stored as an aliquot $(1000 \mu \mathrm{l})$ at $-20^{\circ} \mathrm{C}$.

10x TBS buffer for Western blot

For 21

Final concentration

Tris base

$48.4 \mathrm{~g}$

$200 \mathrm{mM}$

$\mathrm{NaCl}$

$58.48 \mathrm{~g}$

$500 \mathrm{mM}$

$\mathrm{ddH}_{2} \mathrm{O}$

to 2 I

$\mathrm{pH}$ was adjusted with $\mathrm{HCl}$ to 7.4 ; the solution was stored at room temperature.

1x TBST buffer

For 5 I

$500 \mathrm{ml}$

$5 \mathrm{ml}$

to 5 I

$\mathrm{ml}$

$\mathrm{ddH}_{2} \mathrm{O}$ Final concentration

10x TBS stock $1 \mathrm{x}$

Tween 20

The buffer was prepared briefly before use.

Blocking buffer

For $50 \mathrm{ml}$

$2.5 \mathrm{~g}$

to $50 \mathrm{ml}$
Final concentration

Non-fat dried milk powder

1x TBST buffer

The buffer was prepared briefly before use and stored at $4^{\circ} \mathrm{C}$.

Antibody incubation buffer

$\begin{array}{lll} & \text { For } 50 \mathrm{ml} & \text { Final concentration } \\ 5 \% \text { nonfat milk } & 5 \mathrm{ml} & 0.5 \% \\ 1 \times \text { TBST buffer } & \text { to } 50 \mathrm{ml} & \end{array}$

The buffer was prepared briefly before use and stored at $4^{\circ} \mathrm{C}$. 
$\underline{1 \times \text { Re-Blot Plus }}{ }^{\circledR}$ stripping buffer

For $10 \mathrm{ml}$

Final concentration

10x Re-Blot Plus ${ }^{\circledR}$ buffer

$1 \mathrm{ml}$

$1 \mathrm{x}$

$\mathrm{ddH}_{2} \mathrm{O}$

to $10 \mathrm{ml}$

The buffer was prepared briefly before use and stored at $4^{\circ} \mathrm{C}$.

Primary antibodies were used in the following dilutions:

$\begin{array}{ll}\text { Anti-IGFBP-2 } & 1: 250 \\ \text { Anti-IGFBP-3 } & 1: 100 \\ \text { Anti-IGF-IR } \beta & 1: 100 \\ \text { Anti-PDGFR } \beta & 1: 50 \\ \text { Anti-PDGFR } \alpha & 1: 250 \\ \text { Anti-IRS-1 } & 1: 100 \\ \text { Anti-IRS-2 } & 1: 200 \\ \text { Anti-Gab-1 } & 1: 500 \\ \text { Anti-PLC } \gamma 1 & 1: 100 \\ \text { Anti-phosphotyrosine } & 1: 100 \\ \text { Anti-phospho-ERK } & 1: 1,000 \\ \text { Anti-phospho-JNK } & 1: 1,000 \\ \text { Anti-phospho-p38 } & 1: 1,000 \\ \text { Anti-fibronectin } & 1: 250-1: 500 \\ \text { Anti-fibulin 2 } & 1: 100 \\ \text { Anti-collagen I } & 1: 500 \\ \text { Anti-collagen IV } & 1: 100 \\ \text { Anti-laminin } & 1: 250 \\ \text { Anti- } \beta \text {-Actin } & 1: 10,000\end{array}$

Secondary HRP-conjugated antibodies were used in the following dilutions:

Peroxidase-conjugated

$1: 2,000-1: 5,000$

swine anti-rabbit Ig

Peroxidase-conjugated

$1: 2,000-1: 10,000$

rabbit anti-mouse lg

Peroxidase-conjugated

rabbit anti-goat lg

$1: 2,000$ 


\subsubsection{Immunoprecipitation}

Cell lysates containing equal amounts $(500 \mu \mathrm{g})$ of protein were mixed with antibodies (5 $\mu \mathrm{g}$ of antibody per sample) and incubated overnight at $4^{\circ} \mathrm{C}$ with slight agitation on the end-over-end rotator. The immune complexes were then incubated with $100 \mu \mathrm{l}$ of $30 \%$ protein $A$ sepharose bead slurry (30 $\mu \mathrm{l}$ of packed beads) for 4 hours at $4^{\circ} \mathrm{C}$. Subsequently, sepharose beads were collected by centrifugation at 14,000 rpm for 1 min in a bench-top centrifuge. The supernatant was carefully removed by aspiration through the $29 \mathrm{G}$ needle connected to the syringe, the pellet was washed with $500 \mu \mathrm{l}$ of ice-cold $50 \mathrm{mM}$ Tris buffer $(\mathrm{pH}$ 7.4) three times, and the proteins were resuspended in $35 \mu \mathrm{l}$ of $2 \mathrm{x}$ reducing sample buffer and boiled at $95^{\circ} \mathrm{C}$ for $5 \mathrm{~min}$. Finally, dissociated sepharose beads were pelleted by pulse centrifugation at $14,000 \mathrm{rpm}$ for $30 \mathrm{sec}$. The supernatant containing the precipitated protein was carefully transferred to a new $1.5 \mathrm{ml}$ reaction tube. Immunoprecipitates were then size-fractionated by SDS-PAGE and transferred to nitrocellulose membrane. To detect tyrosine phosphorylation of precipitated proteins, the membrane was subjected to immunoblotting with monoclonal mouse anti-phosphotyrosine antibody as described above. To ensure equal loading of the precipitated protein, after evaluation of tyrosine phosphorylation the membrane was stripped of immunoglobulin and reprobed with an antibody that was used for protein precipitation. Membrane stripping was performed as described in previous section.

$\underline{\text { Tris- } \mathrm{HCl} 50 \mathrm{mM}, \mathrm{pH} 7.4}$

$\begin{array}{lll} & \text { For } 100 \mathrm{ml} & \text { Final concentration } \\ 2 \mathrm{M} \text { Tris- } \mathrm{HCl}, \mathrm{pH} 7.4 & 2.5 \mathrm{ml} & 50 \mathrm{mM} \\ \mathrm{ddH}_{2} \mathrm{O} & \text { to } 100 \mathrm{ml} & \\ \mathrm{pH} \text { was adjusted to } 7.4 ; \text { the buffer was stored at } 4^{\circ} \mathrm{C} . & \end{array}$

\subsubsection{Biosynthetic Labelling and Immunoprecipitation of the IGF-IIIM6-PR}

Newly synthesized proteins were endogenously pulse-labelled using methionine-free DMEM containing $100 \mu \mathrm{Ci}\left[{ }^{35} \mathrm{~S}\right]$-methionine per $1 \mathrm{ml}$ of medium. After two hours of labelling, the radioactive medium was removed, and cells were washed with PBS. Subsequently, new culture media supplemented with methionine and certain growth factors were added, and cells were incubated for the next 24 hours. The treatment was then stopped, the supernatants were collected, and proteins were immediately extracted 
from cell layers as described above. Aliquots of cell lysates and culture supernatants containing the same amount of protein-bound radioactivity were subjected further to immunoprecipitation with rabbit polyclonal antiserum raised against the IGF-II/M6-PR of rat origin $(2 \mu \mathrm{l}$ per sample). Immunoprecipitation and SDS-PAGE (5\% acrylamide) under non-reducing conditions were essentially done as described earlier. After electrophoresis, the gel was placed in fixation solution and incubated for $30 \mathrm{~min}$ at RT with slight agitation. After fixation, the gel was incubated in Amplify fluorographic solution (Amersham Biosciences) for $30 \mathrm{~min}$ to increase detection efficiency for ${ }^{35} \mathrm{~S}$. The gel was then dried and exposed to X-ray films at $-80^{\circ} \mathrm{C}$.

\section{Fixation solution}

For $100 \mathrm{ml} \quad$ Final concentration

Acetic acid

$10 \mathrm{ml}$

$40 \mathrm{ml}$

$50 \mathrm{ml}$
$10 \%$

$40 \%$
$\mathrm{ddH}_{2} \mathrm{O}$

before use.

\subsubsection{IGFBP Protease Assay}

$\left[{ }^{125} \mathrm{I}\right]$-labelled recombinant human IGFBPs (rhIGFBPs) kindly provided by Dr. Braulke (Department of Biochemistry, Children's Hospital, University Hospital Hamburg Eppendorf, Hamburg, Germany) were added (5,000-10,000 cpm) to $50 \mu \mathrm{l}$ of medium conditioned by rat liver myofibroblasts with $\mathrm{pH}$ adjusted to the values 4.0 and 7.4 and incubated at $37^{\circ} \mathrm{C}$ for 24 hours. Subsequently, samples were solubilized in $2 x$ sample buffer and subjected to SDS-PAGE (12.5\% acrylamide) under non-reducing conditions as described earlier. After electrophoresis, the gel was placed in fixation solution and incubated for $20 \mathrm{~min}$ at RT with slight agitation. After fixation, the gel was washed in a tap water three times for $15 \mathrm{~min}$, dried and exposed to X-ray films at $-80^{\circ} \mathrm{C}$. Molecular masses of radiolabelled intact rhIGFBPs and/or their proteolytic fragments were estimated by comparing the electrophoretic mobility of the IGFBPs and proteolytic fragments to prestained Rainbow ${ }^{\mathrm{TM}}$ colored protein marker (Amersham Biosciences). 
$\underline{\text { Fixation solution }}$

For $100 \mathrm{ml}$

Acetic acid

Methanol

$\mathrm{ddH}_{2} \mathrm{O}$
$10 \mathrm{ml}$

$40 \mathrm{ml}$

$50 \mathrm{ml}$

The solution was prepared briefly before use.

\subsubsection{Immunocytochemistry}

Rat liver myofibroblasts cultured on Lab-Tek chamber slides were washed in PBS, fixed in methanol (10 minutes) and aceton (10 seconds) at $-20^{\circ} \mathrm{C}$, again washed in PBS, airdried and frozen at $-20^{\circ} \mathrm{C}$. To block endogenous peroxidases, after washing in PBS cells were incubated in solution supplemented with glucose, glucose oxydase and sodium azide for $30 \mathrm{~min}$ at $37^{\circ} \mathrm{C}$. Cells were rinsed again with PBS, and nonspecific binding was blocked by incubation with undiluted fetal calf serum for 30 minutes. The slides were then placed in a humidified chamber, and cells were incubated with primary antibodies for $60 \mathrm{~min}$ at RT. Dilutions of primary antibodies are indicated below. Thereafter, cells were washed three times for 5 min in PBS followed by incubation with secondary peroxidase-conjugated antibodies for $60 \mathrm{~min}$ at RT also performed in a humidified chamber. Secondary antibodies were preabsorbed with rat serum to avoid nonspecific binding. For this purpose, $10 \mu \mathrm{l}$ of rat serum were added to $50 \mu \mathrm{l}$ of secondary antibody and incubated for $60 \mathrm{~min}$ at $37^{\circ} \mathrm{C}$, followed by centrifugation for 5 min at maximum speed in a bench-top centrifuge to pellet precipitate. Afterwards, $50 \mu l$ of supernatant were transferred to a new reaction tube and mixed with $350 \mu$ of PBS and $600 \mu \mathrm{l}$ of $\gamma$-globulin-free serum. After incubation with secondary antibodies, cells were washed as described above, and immune complexes were visualized by diaminobenzidine, which upon oxidation forms a brown end-product at the site of the target antigen. For this purpose slides were placed in a cuvette containing PBS supplemented with diaminobenzidine $(0.5 \mathrm{mg} / \mathrm{ml})$ and $\mathrm{H}_{2} \mathrm{O}_{2}(0.01 \%)$, and cells were incubated for 10 minutes at RT. Finally, cells were washed 2 times for 5 min in distilled water and counterstained in Mayer's hemalum solution for $5 \mathrm{~min}$ at RT. After additional washing step (10 $\mathrm{min}$ in a tap water), the slides were covered with Kaiser's glycerol gelatine and mounted with cover-slips. Images were acquired using a light microscope (Axioskop, Carl Zeiss), digital photocamera Canon EOS D60 (Canon) and software Remote Capture 2.5 (Canon). 
Peroxidase inhibition solution

For $100 \mathrm{ml}$

Glucose

$180 \mathrm{mg}$

Glucose oxidase

$5 \mathrm{mg}$

$1 \mathrm{M}$ sodium azide

$100 \mu \mathrm{l}$

PBS

to $100 \mathrm{ml}$

The solution was prepared briefly before use. The components were dissolved in PBS, the solution was placed in prewarmed cuvette and incubated for 10 min at $37^{\circ} \mathrm{C}$ in a water bath.

Diaminobenzidine working solution

$\begin{array}{lll} & \text { For } 100 \mathrm{ml} & \text { Final concentration } \\ \text { Diaminobenzidine } & 50 \mathrm{mg} & 0.5 \mathrm{mg} / \mathrm{ml} \\ 33 \% \text { hydrogen peroxide } & 33 \mu \mathrm{l} & 0.01 \% \\ \text { PBS } & \text { to } 100 \mathrm{ml} & \end{array}$

The solution was prepared briefly before use. First, diaminobenzidine was dissolved in PBS by stirring for $60 \mathrm{~min}$ at RT in the dark. The solution was filtered, and, finally, hydrogen peroxide was added.

Primary antibodies were used in the following dilutions:

Anti-fibulin 2

rabbit polyclonal antiserum

Anti-collagen type I

rabbit polyclonal antiserum

Anti-smooth muscle $\alpha$-actin

$1: 50$

mouse monoclonal antibody

Secondary HRP-conjugated antibodies were used in the following dilutions:

Peroxidase-conjugated

swine anti-rabbit Ig

Peroxidase-conjugated

rabbit anti-mouse Ig 


\subsubsection{Determination of DNA Synthesis}

DNA synthesis in cultures of rat liver myofibroblasts was evaluated by BrdU Labelling and Detection Kit III (Roche). This kit is based on the cell ELISA principle. Cells are cultured in an 96-well microtiter plate. 5-bromo-2'-deoxyuridine (BrdU), a thymidine analogue, is added then to the culture medium and incorporated into freshly synthesized DNA. Cells which have incorporated BrdU into DNA can be easily detected using a monoclonal antibody against BrdU. Peroxidase-conjugated secondary antibody binds to BrdU via primary antibody. In the final step, the peroxidase substrate is added. The cleavage of the substrate catalyzed by peroxidase yields a colored reaction product. Its absorbance can be determined using a microtiter plate reader and is directly correlated to the level of BrdU incorporated into cellular DNA.

In the current work, rat liver myofibroblasts were plated on 96-well microtiter plates and cultured for 2 days. After starvation in serum-reduced DMEM for 1 hour, cells were incubated with certain growth factors and binding proteins in the presence or absence of specific pharmacological inhibitors for 24 hours. To study the effect of exogenous IGFBP-3 and -2 on IGF-I-stimulated DNA synthesis, LMFs were incubated for 24 hours in the presence of increasing concentrations of rhIGFBP-3 or -2 (50, 100 and 150 $\mathrm{nmol} / \mathrm{L})$ with or without IGF-I (100 nmol/L). In addition, cells were pretreated for 1 hour with rhIGFBP-3 or -2 at the indicated concentrations before IGF-I stimulation for 24 hours. Control wells were incubated with serum-reduced DMEM alone. Cells were labelled with $10 \mu \mathrm{mol} / \mathrm{L}$ of BrdU for $24 \mathrm{~h}$. After treatment, cells were washed in culture medium supplemented with $10 \%$ serum, fixed with precooled ethanol/ $\mathrm{HCl}$ solution at $20^{\circ} \mathrm{C}$ for $30 \mathrm{~min}$, washed again, and then incubated with nucleases (100 $\mu \mathrm{l}$ per well) at $37^{\circ} \mathrm{C}$ for 30 minutes to digest partially cellular DNA. After washing, wells were incubated with monoclonal HRP-conjugated anti-BrdU Fab-fragments $(100 \mu$ per well $)$ at $37^{0} \mathrm{C}$ for 30 minutes, rinsed three times in washing buffer, the conjugate bound to an incorporated BrdU was visualized by soluble chromogenic substrate (ABTS substrate supplemented with enhancer; $100 \mu \mathrm{l}$ per well), and the absorbance was measured using an ELISA reader at $405 \mathrm{~nm}$ with a reference wavelength at $490 \mathrm{~nm}$. 
BrdU labelling solution

For $1800 \mu \mathrm{l}$

Final concentration

BrdU labelling reagent

$20 \mu \mathrm{l}$

$1: 90$

Serum reduced DMEM with

supplements

$1780 \mu \mathrm{l}$

The solution was prepared briefly before use.

Washing medium

$\begin{array}{ll} & \text { For } 100 \mathrm{ml} \\ \text { Penicillin/streptomycin stock } & 1 \mathrm{ml} \\ \text { FCS } & 10 \mathrm{ml} \\ \text { L-Glutamine } & 1 \mathrm{ml} \\ \text { DMEM (with low glucose) } & \text { to } 100 \mathrm{ml}\end{array}$

The medium was stored at $4^{0} \mathrm{C}$.

Fixation solution

$100 \%$ Ethanol

For $100 \mathrm{ml}$

Final concentration

25\% Hydrochloric acid

$70 \mathrm{ml}$

$70 \%$

$\mathrm{ddH}_{2} \mathrm{O}$

$6.7 \mathrm{ml}$

$0.5 \mathrm{M}$

to $100 \mathrm{ml}$

The solution was stored at $-20^{\circ} \mathrm{C}$.

$\underline{\text { Nucleases, stock solution }}$

For $1300 \mu \mathrm{l}$

Nucleases

1 vial

$\mathrm{ddH}_{2} \mathrm{O}$

$650 \mu \mathrm{l}$

Glycerol

$650 \mu \mathrm{l}$

The solution was stored at $-20^{\circ} \mathrm{C}$.

Nucleases, working solution

$\begin{array}{lll} & \text { For } 10 \mathrm{ml} & \text { Final concentration } \\ \text { Nucleases, stock solution } & 100 \mu \mathrm{l} & 1: 100 \\ \text { Incubation buffer } & 9.9 \mathrm{ml} & \end{array}$

The solution was prepared briefly before use. 
$\underline{1 x \text { washing buffer }}$

For $100 \mathrm{ml}$

10x washing buffer concentrate $\mathrm{dd}_{2} \mathrm{O}$

$10 \mathrm{ml}$

$90 \mathrm{ml}$

The solution was prepared briefly before use.

\section{$\underline{\text { Anti-BrdU-POD, stock solution }}$}

For $1250 \mu \mathrm{l}$

Anti-BrdU-POD

1 vial

$\mathrm{dd}_{2} \mathrm{O}$

$1250 \mu \mathrm{l}$

The solution was stored at $4^{0} \mathrm{C}$.

Anti-BrdU-POD, working solution

For $10 \mathrm{ml}$

$100 \mu \mathrm{l}$

$9.9 \mathrm{ml}$
Final concentration

$1: 10$

Anti-BrdU-POD, stock solution

$1 \mathrm{x}$ washing buffer

The solution was prepared briefly before use.

Peroxidase substrate, stock solution

$\begin{array}{ll}\text { ABTS powder } & 1 \text { vial } \\ \text { Substrate buffer } & 1 \text { vial }\end{array}$

The solution was stored at $4{ }^{0} \mathrm{C}$.

Peroxidase substrate, working solution

For $10 \mathrm{ml}$

Substrate enhancer

$10 \mathrm{mg}$

Peroxidase substrate, stock solution

$10 \mathrm{ml}$

The solution was prepared briefly before use. 


\subsection{Statistical Analysis}

Autoradiographs of ligand and Northern blots were scanned (Bio-Rad, Hercules, CA) and densitometrically analyzed (Molecular Analyst, Bio-Rad). The relative densities of bands were expressed as the percentage of increase or decrease compared with the respective untreated control. The BrdU incorporation assay was performed in triplicate using three separate cell isolations. Student's $t$-test was used to evaluate differences between the sample of interest and its respective control. Means \pm standard error of the mean (SEM) are indicated; $p<0.05$ was considered statistically significant. 


\section{Results}

\subsection{Morphological and Immunophenotypical Features of Liver Myofibro- blasts}

Liver myofibroblasts (LMFs) represent a second cell population involved in liver fibrogenesis. In contrast to well-characterized hepatic stellate cells (HSCs), another liver cell population with fibrogenic potential (Friedman, 1993; Pinzani, 1995), detailed morphological and functional analysis of LMF has not yet been performed so far. Therefore, in the current work studying morphological and immunophenotypical features of rat LMFs preceded subsequent experiments.

It has been observed that LMFs were present in primary cultures of rat nonparenchymal liver cells and hepatocytes. These cells appeared after several days of cultivation and demonstrated high proliferating activity, thereby representing a significant cell population in late-stage cultures.

A

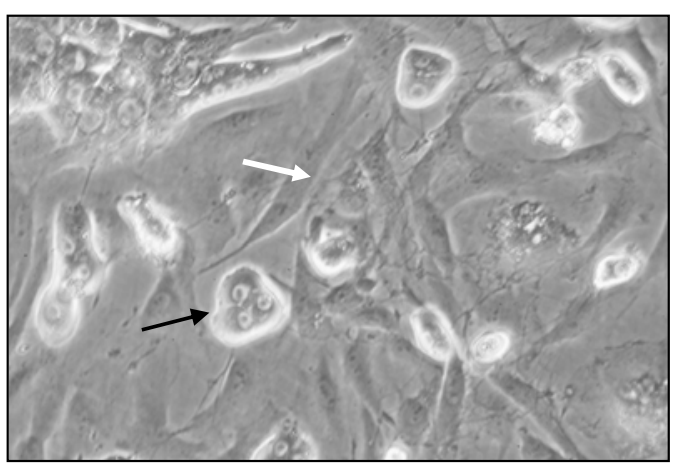

B

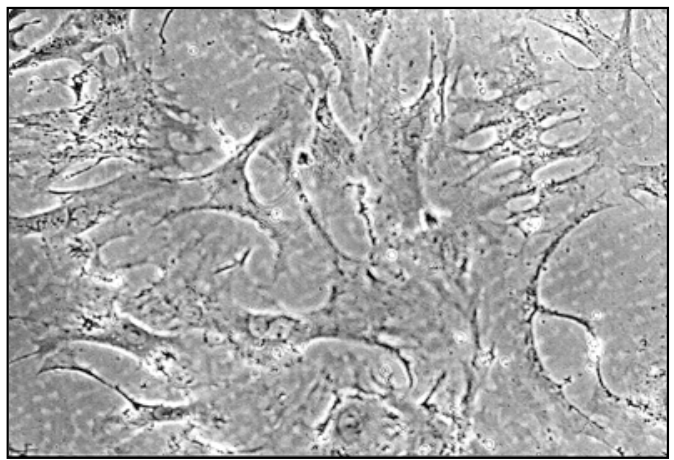

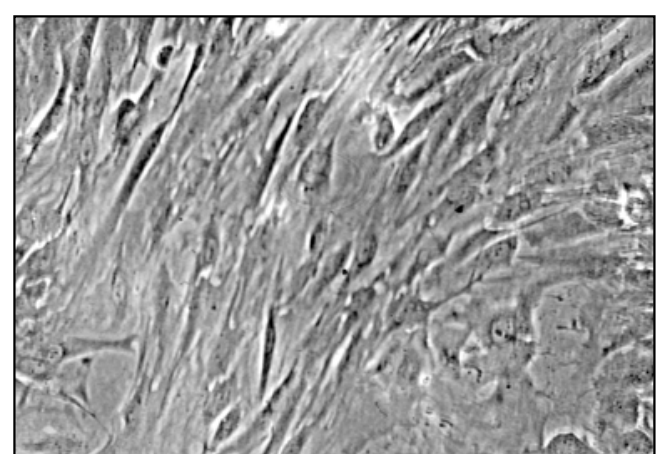

C

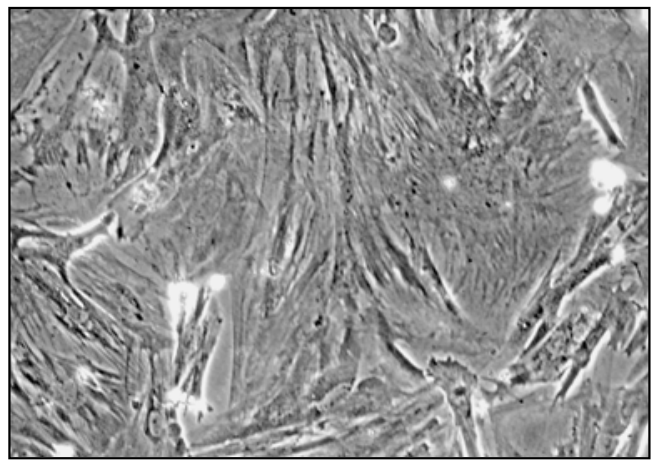

D

Figure 15. Morphological and cultural features of liver myofibroblasts (LMFs). Outgrowth of LMFs from primary culture of rat hepatocytes $(A)$ is observed when serum-enriched medium is added to hepatocytes, which are normally cultured under serum-free conditions. Within 5-10 days, LMFs (white arrow) become predominant in these cultures and form a confluent cell layer in contrast to hepatocytes (black arrow), which die after prolonged cultivation. Hepatic stellate cells (HSCs) at day 7 of culture (B) share some morphological features with LMFs (C, D). In culture, LMFs show fibroblast-like phenoptype (C) with spindle-shaped appearance, and myofibroblast-like phenotype (D) with cross-striated morphology as assessed by phase-contrast microscopy. Original magnification $\times 200$. 
Two experimental approaches were used to isolate LMFs from rat liver: (i) isolation by density gradient centrifugation followed by counterflow elutriation of fraction enriched with MF; and (ii) isolation by outgrowth from primary culture of rat hepatocytes. Outgrowth of LMFs was observed when serum-enriched medium was added to hepatocytes, which are normally cultured under serum-free conditions. Within 5-10 days, LMFs became predominant in these cultures and formed a confluent cell layer after prolonged cultivation (Fig. 15).

In culture, LMFs showed either a fibroblast-like phenotype characterized by spindleshaped appearance, or a myofibroblast-like phenotype with cross-striated morphology. The myofibroblast-like phenotype seemed to increase with age of culture and following passages of cells and possibly represents a state of myofibroblast maturation and differentiation (Fig. 15).

A

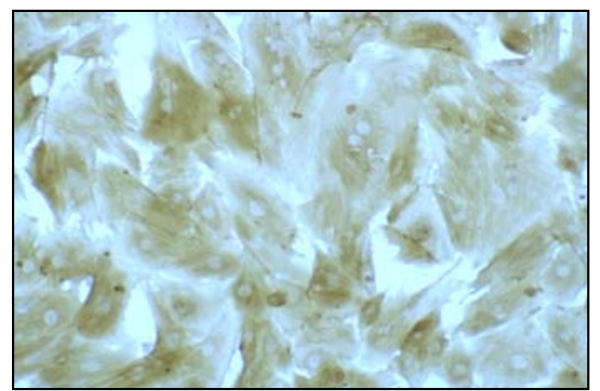

B

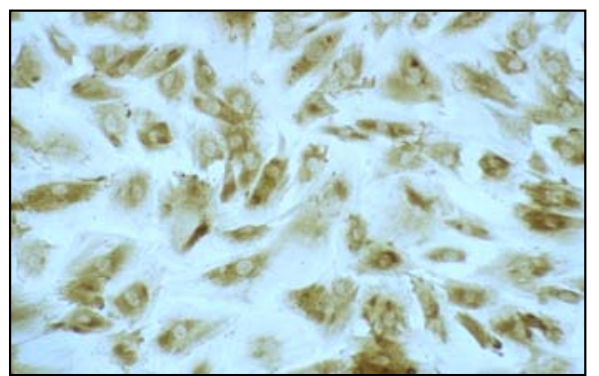

C

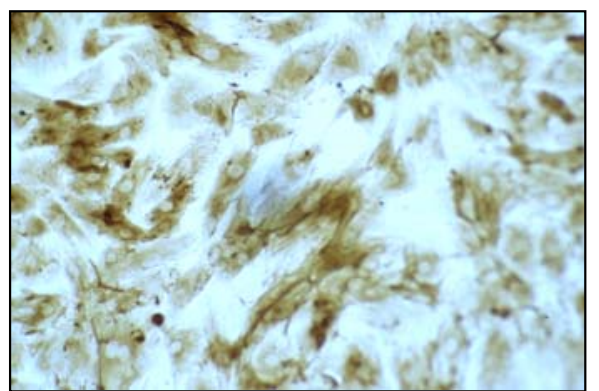

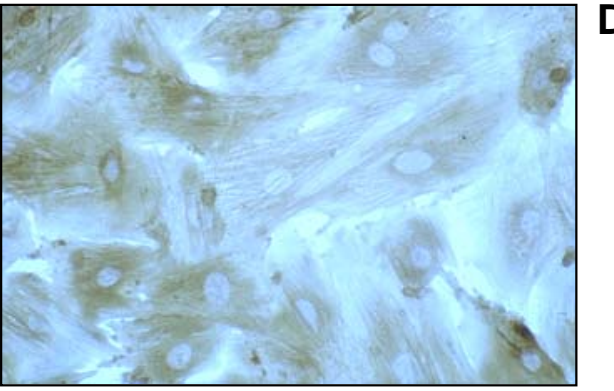

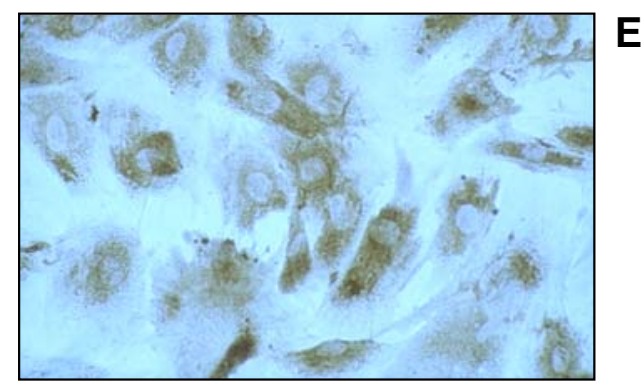

E

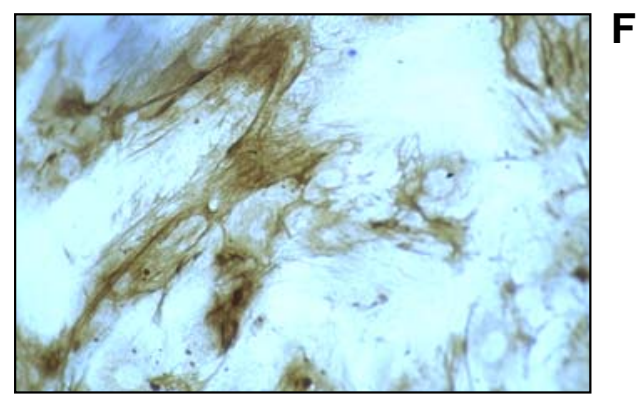

Figure 16. Immunocytochemical detection of smooth muscle $\alpha$-actin, collagen type I and fibulin-2 expression in LMFs. Antibodies against smooth muscle $\alpha$-actin (A, D), collagen type I (B, E) and fibulin 2 (C, F) were used, detected by peroxidase-labelled second antibodies. Negative control was obtained by omitting primary antibodies (data not shown). Original magnification x 200 (A, B, C); x 400 (D, E, F). Immunoreactive material was detected by the peroxidase staining protocol. 
To further characterize rat LMFs, the expression of some cytoskeletal and extracellular matrix proteins, namely smooth muscle $\alpha$-actin (SMA $\alpha$ ), type I collagen and fibulin-2, was studied by immunocytochemistry and Western blot analysis. Rat LMFs obtained from different cell isolations as well as from different passages showed immunoreactivity to SMA $\alpha$, collagen type I and fibulin-2 (Fig. 16). Secretion of fibulin-2 decreased with the number of cell passages whereas that of $\alpha_{1}$ and $\alpha_{2}$ chains of type I collagen increased slightly with passaging of LMFs (Fig. 17). In rat, fibulin-2 has recently been described as specific marker for LMFs, but not for HSCs (Knittel et al., 1999a; Ramadori et al., 2002).

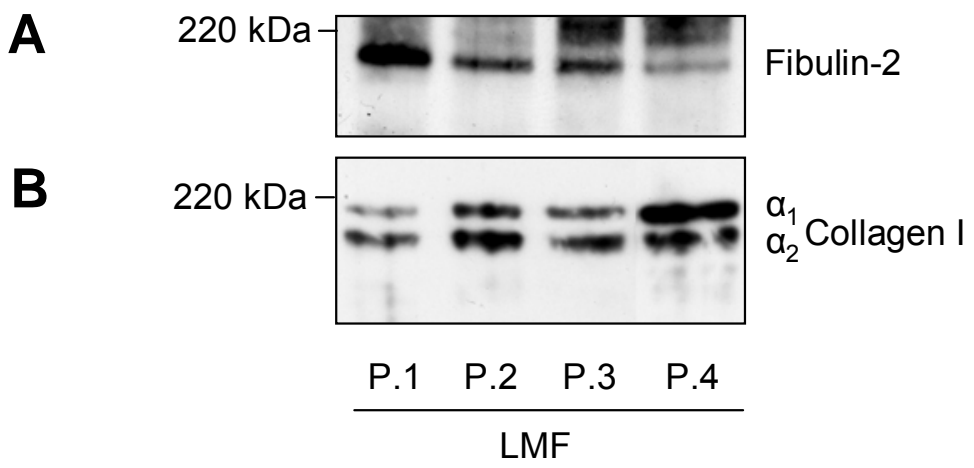

Figure 17. Secretion of fibulin-2 and collagen type I by LMFs after serial passages. LMFs from passages 1-4 (P1-4) were cultivated under serum-reduced conditions for $36 \mathrm{~h}$. Fibulin-2 (A) and collagen type I (B) were detected in conditioned media (CM) from LMFs by Western blot analysis.

\subsection{Characterization of IGF Axis in Liver Myofibroblasts}

\subsubsection{Expression of IGF-I and IGF-II}

The capability of rat LMFs to express the IGFs was evaluated by Northern blot analysis. For this purpose, total RNA obtained from passaged rat LMFs (passages 1-7, P1-7), HSCs at day 2, 4 and 7 of culture as well as from hepatocytes at day 3 after plating (used as positive control in these experiments) were probed for IGF-I expression. These experiments detected a prominent IGF-I messenger RNA (mRNA) transcript at $7.5 \mathrm{~kb}$, while minor bands appeared at 2 and 1.0 to $1.5 \mathrm{~kb}$. In total RNA from hepatocytes, HSCs and LMFs, both the larger and smaller transcripts were detected with similar intensity of bands (Fig. 18). A relatively high level of IGF-I mRNA expression was observed in LMFs. Moreover, steady levels of IGF-I transcripts in LMFs were unaffected during in vitro cultivation and after serial passages of cells. In contrast, HSCs at day 2 of culture had very low level of IGF-I mRNA expression, which increased severalfold after 
their transformation to myofibroblast-like cells (HSCs at day 7 of culture). Transcripts encoding IGF-II were detectable neither in LMFs nor in HSCs (data not shown).

A
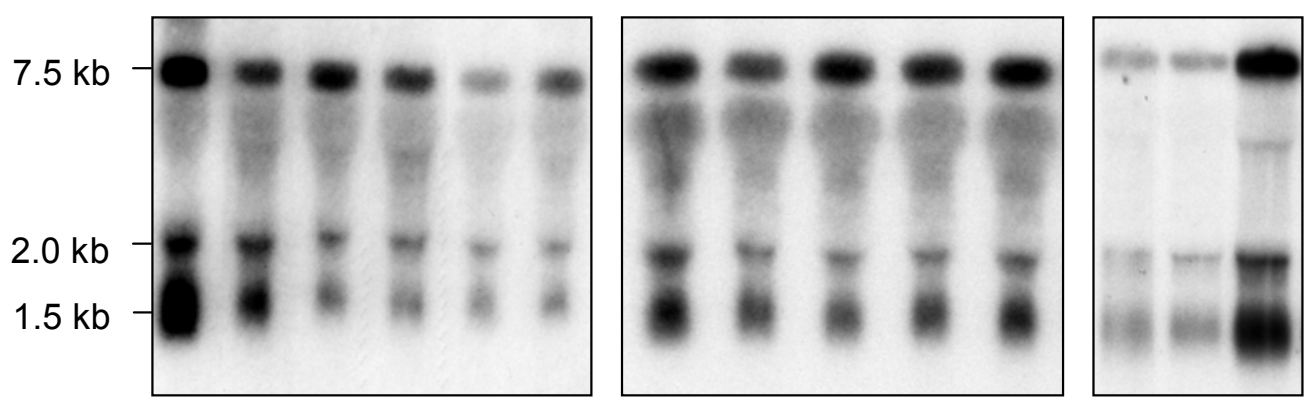

IGF-I

B
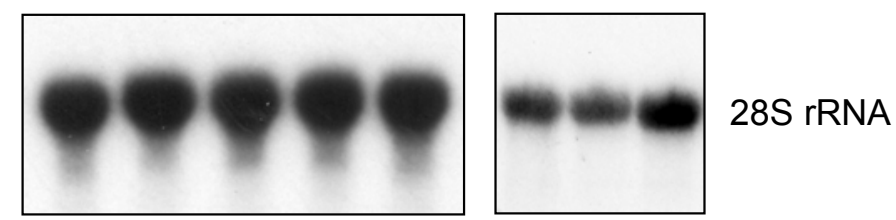

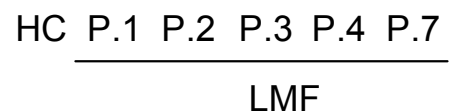

$\begin{array}{ccccc}\text { d.2 } & \text { d. } 4 & \text { d. } 7 & \text { d.10 } & \text { d.14 } \\ \text { LMF }\end{array}$

$\frac{\text { d. } 2 \text { d. } 4 \text { d.7 }}{\text { HSC }}$

Figure 18. IGF-I mRNA expression in LMFs. (A) $10 \mu \mathrm{g}$ of total RNA obtained from rat LMFs (passages 17, P.1-P.7), hepatocytes (HCs) and hepatic stellate cells (HSCs) at different time points of culture as indicated, were separated by $1 \%$ agarose gel electrophoresis, blotted and hybridized with a complementary DNA (cDNA) specific for rat IGF-I. (B) Equal loading of RNA was demonstrated after stripping and rehybridization of membranes with an oligonucleotide complementary to $28 \mathrm{~S}$ ribosomal RNAs (rRNA). The sizes of the hybridization bands (in kb) are indicated on the left.

\subsubsection{Expression of IGF-IR}

The mitogenic effects of the IGFs are mediated via the IGF-IR. Therefoe, the IGF-IR expression was studied by Northern blot analysis, which revealed messenger RNA species for the rat IGF-IR at $11 \mathrm{~kb}$ (Fig. 19). Total RNA obtained from hepatocytes, which were used as a negative control, showed no hybridization signals with the radiolabelled IGF-IR probe, whereas IGF-IR-specific transcripts were detected in KCs, which were used as a positive control. The level of the IGF-IR mRNA expression in LMFs was considerably higher than in KCs. In LMFs, transcripts encoding the IGF-IR were steady expressed during in vitro cultivation and remained unaffected after serial passages of cells. 
A

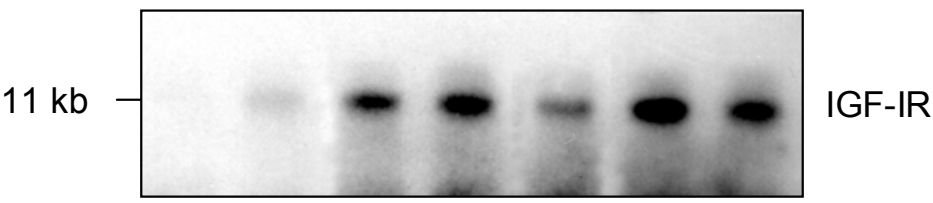

B

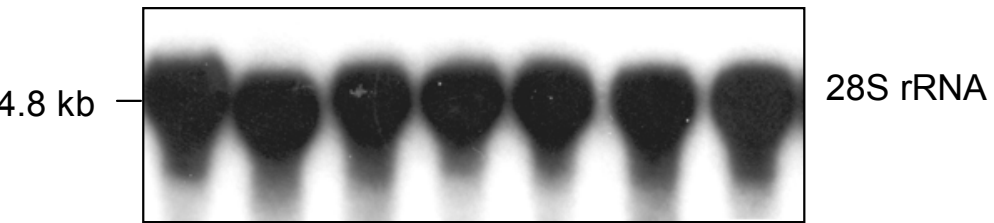

$$
\begin{array}{lllllll}
\text { HC } \quad \text { KC } \quad \text { P.1 } & \text { P.2 } & \text { P.3 } & \text { P.4 } & \text { P.7 } \\
\cline { 3 - 4 } & \multicolumn{5}{c}{\text { LMF }}
\end{array}
$$

C

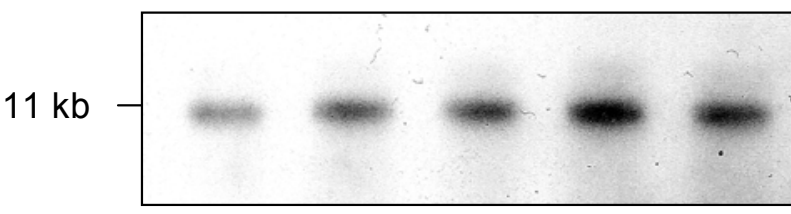

IGF-IR

D

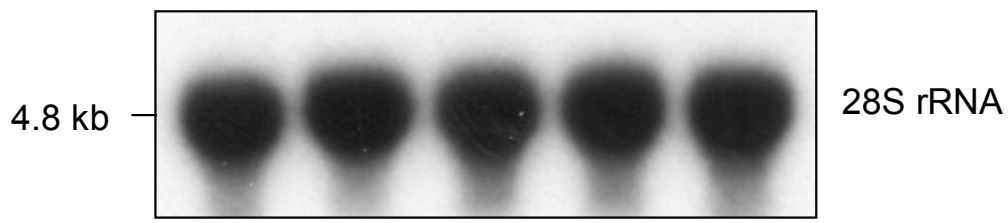

$\begin{array}{lllll}\text { d.2 } & \text { d.4 } & \text { d.7 } & \text { d.10 } & \text { d.14 }\end{array}$

LMF

Figure 19. IGF-I receptor (IGF-IR) mRNA expression in LMFs. (A, C) $10 \mu \mathrm{g}$ of total RNA obtained from rat hepatocytes (HCs), Kupffer cells (KCs), LMFs (passages 1-7, P.1-P.7) at different time points of culture as indicated, were separated by $1 \%$ agarose gel electrophoresis, blotted and hybridized with a cDNA specific for rat IGF-IR. (B, D) Equal loading of RNA was demonstrated after stripping and rehybridization of membranes with an oligonucleotide complementary to $28 \mathrm{~S}$ rRNA. The sizes of the hybridization bands (in $\mathrm{kb}$ ) are indicated on the left.

\subsubsection{Expression of IGF-IIIM6-PR}

In total RNA from LMFs at a different time of culture as well as from passaged cells, Northern blot analysis also revealed mRNA species encoding the IGF-II/M6-PR at $9 \mathrm{~kb}$ (Fig. 20). IGF-II/M6-PR-specific transcripts were detected in hepatocytes, which were used as a positive control in these experiments. The IGF-II/M6-PR was constitutively expressed in LMFs and its mRNA expression was not substantially altered during cultivation of cells and after repeated passages. Conversely, the IGF-II/M6-PR mRNA expression was low in quiescent HSCs (day 2 of culture) and increased severalfold after their in vitro transformation. 
A

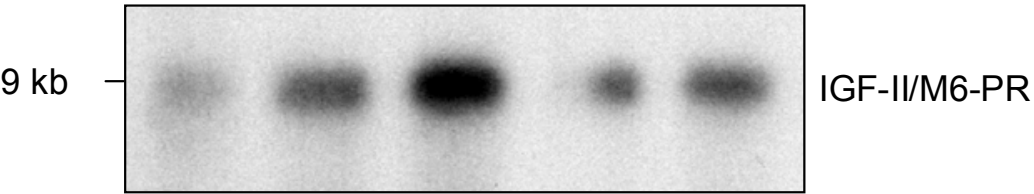

B
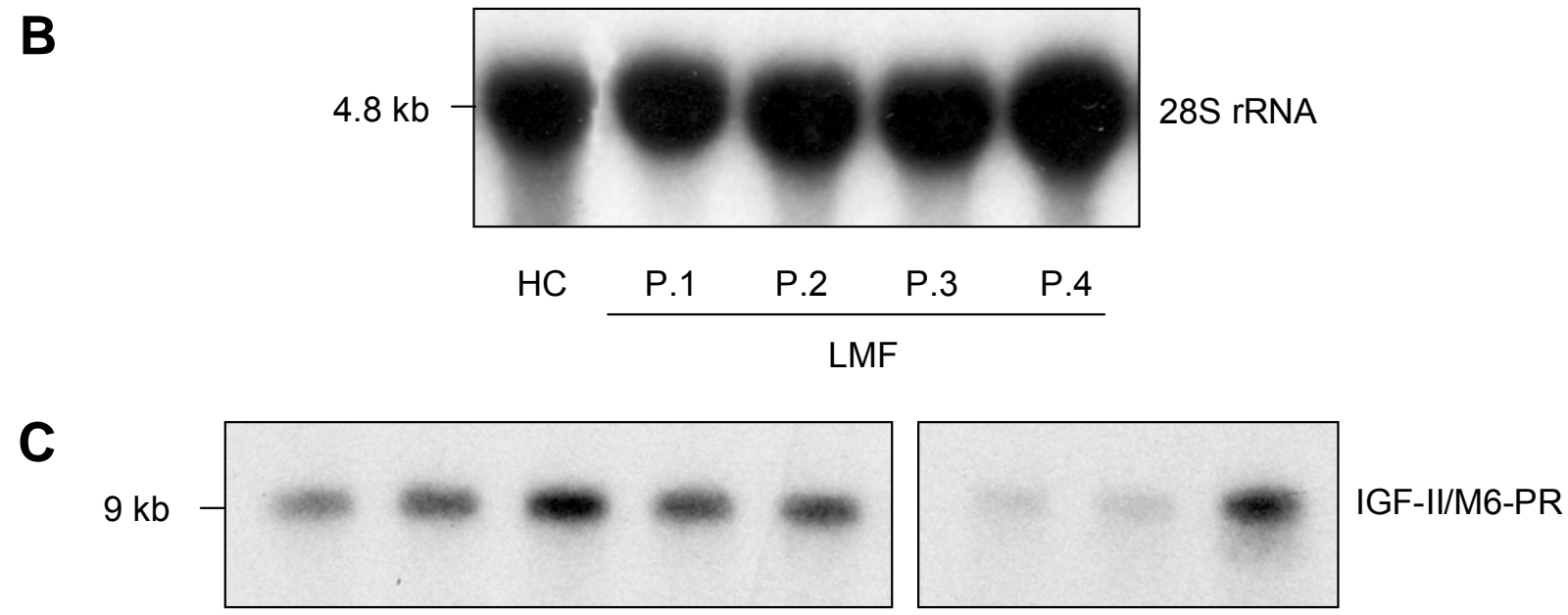

D
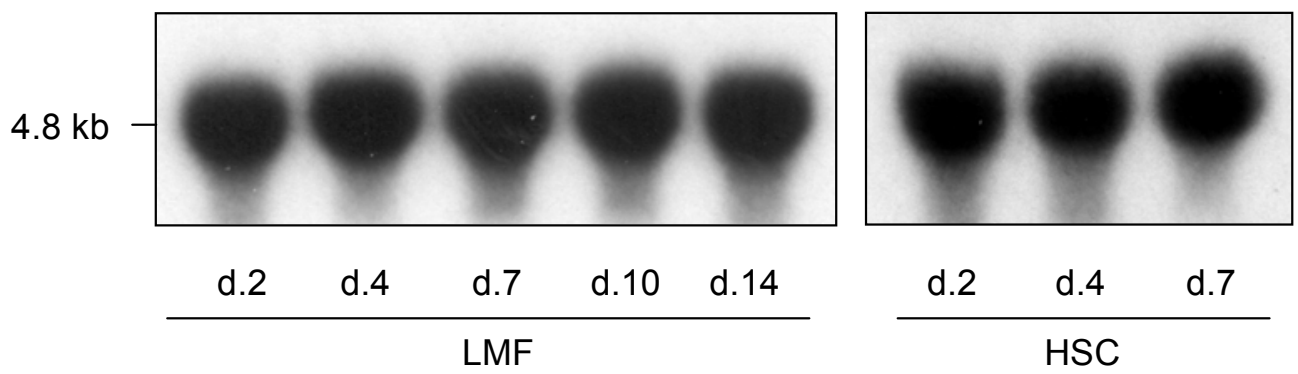

$28 S$ rRNA

Figure 20. IGF-II/mannose 6-phosphate receptor (IGF-II/M6-PR) mRNA expression in LMFs. (A, C) 10 $\mu \mathrm{g}$ of total RNA obtained from rat hepatocytes (HCs), LMFs (passages 1-4, P.1-P.4) and hepatic stellate cells (HSCs) at different time points of culture as indicated, were separated by $1 \%$ agarose gel electrophoresis, blotted and hybridized with a cDNA specific for rat IGF-II/M6-PR. (B, D) Equal loading of RNA was demonstrated after stripping and rehybridization of membranes with an oligonucleotide complementary to $28 \mathrm{~S}$ rRNA. The sizes of the hybridization bands (in $\mathrm{kb}$ ) are indicated on the left.

\subsubsection{Ectodomain Shedding of IGF-II/M6-PR}

An important biological property of the IGF-II/M6-PR is its ability to undergo ectodomain shedding, a release of extracellular part of the receptor from the plasma membrane due to proteolysis on the cell surface. In rat, the liver was shown to be the tissue with highest release of the soluble IGF-II/M6-PR (Bobek et al., 1992). Since hepatocytes and LMFs showed highest levels of transcripts coding for the IGF-II/M6-PR in rat liver, the ability of the IGF-II/M6-PR in these cell populations to undergo ectodomain shedding was studied as well.

For this purpose biosynthetic labelling of cellular proteins with $\left[{ }^{35} \mathrm{~S}\right]$-methionine was performed followed by immunoprecipitation of the IGF-II/M6-PR from cell lysates and 
culture supernatants. These data demonstrate that the IGF-II/M6-PR was highly abundant in conditioned media of both hepatocytes and LMFs. Moreover, in contrast to hepatocytes, both synthesis of the IGF-II/M6-PR and release of its soluble form in LMFs tended to be positively regulated by IGF-II and TGF-beta, the principal ligands of the IGF-II/M6-PR (Fig. 21).

A

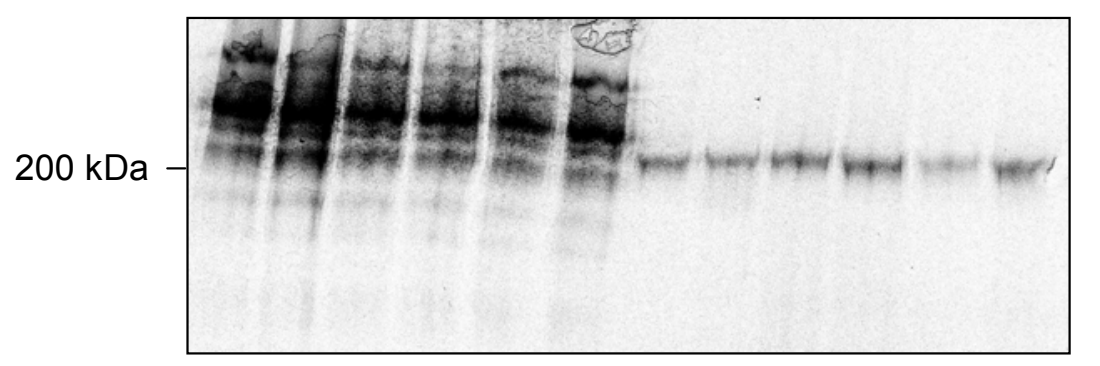

IGF-II/M6-PR

B

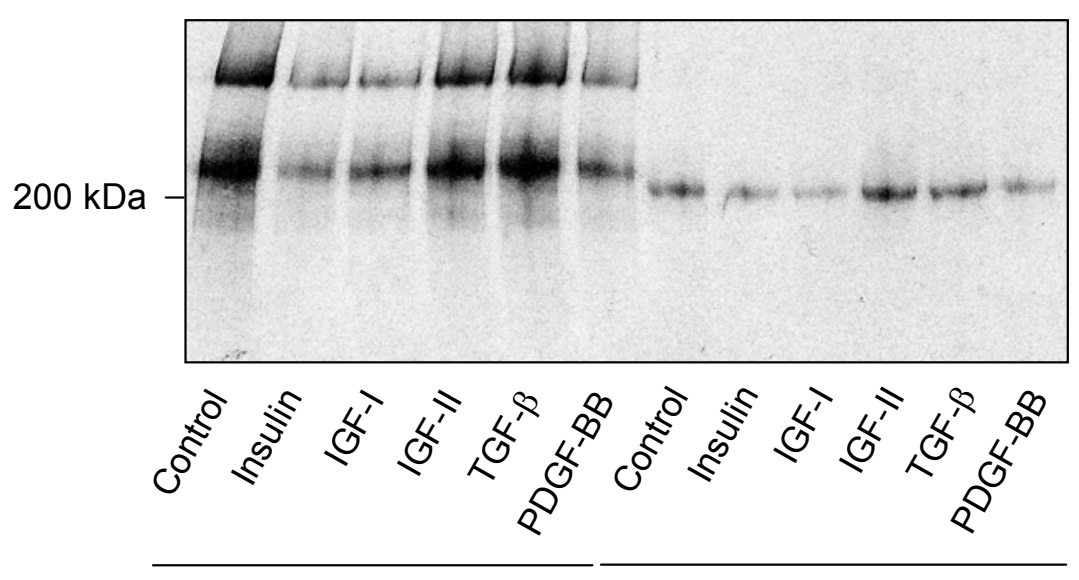

Culture supernatants

Cell lysates

Figure 21. Synthesis and release of the soluble form of the IGF-II/mannose 6-phosphate receptor (IGFII/M6-PR) in hepatocytes and LMFs. Rat hepatocytes (A) and LMFs (B) were pulse-labelled with [ $\left.{ }^{35} \mathrm{~S}\right]-$ methionine in the presence or absence of insulin $(100 \mathrm{nmol} / \mathrm{L})$, IGF-I $(100 \mathrm{nmol} / \mathrm{L})$, IGF-II $(100 \mathrm{nmol} / \mathrm{L})$, TGF- $\beta(10 \mathrm{ng} / \mathrm{mL})$ and PDGF-BB $(10 \mathrm{ng} / \mathrm{mL})$ for 24 hours. Aliquots of whole cell lysates and culture supernatants containing the same amount of protein-bound radioactivity were subjected to immunoprecipitation with antibodies directed against rat IGF-II/M6-PR, followed by SDS-PAGE and autoradiography. The position of the molecular weight standard is indicated on the left.

\subsubsection{Secretion of IGFBPs}

To identify IGFBPs produced by rat LMFs, conditioned media (CM) from cultured rat liver cells and rat serum (used as a reference) were subjected to SDS-PAGE and further analyzed by $\left[{ }^{125}\right.$ I]-IGF-I ligand and immunoblotting. CM of LMFs contained two species of IGFBPs in the molecular range of 34 and 41 to $45 \mathrm{kDa}$ (Fig. 22A). The 34kDa IGFBP comigrated with IGFBP species present in CM from hepatocytes, KCs and SECs. This 34-kDa IGFBP in CM of LMFs showed immunoreactivity with an antiserum raised against IGFBP-2 (Fig. 22B). The 41- to 45-kDa doublet in CM of LMFs showed 
the same mobility after SDS-PAGE than IGFBPs detected in rat serum and in CM of KCs, SECs and HSCs at day 7 of culture. This IGFBP was identified by an antiserum against IGFBP-3. Both IGFBP-2 and IGFBP-3 were detected in supernatants of cells from passages 1 to 4 (Fig. 22C).

A

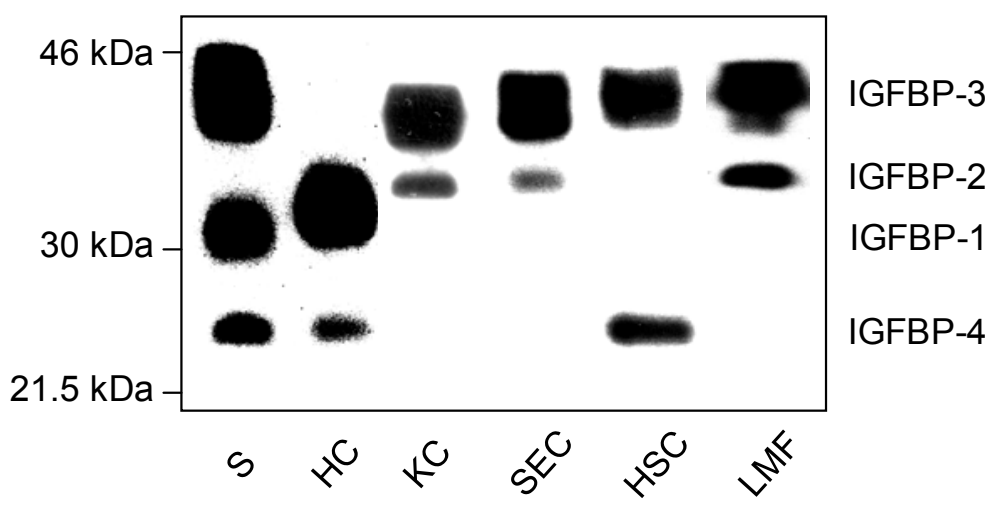

B

$$
\text { Ligand blot Immunoblot }
$$
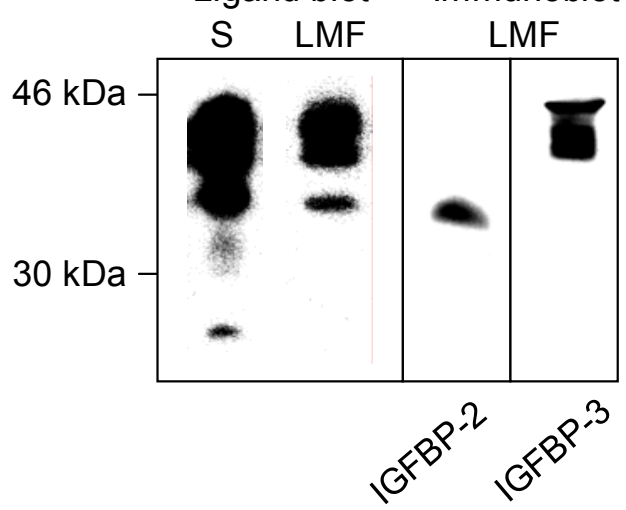

C

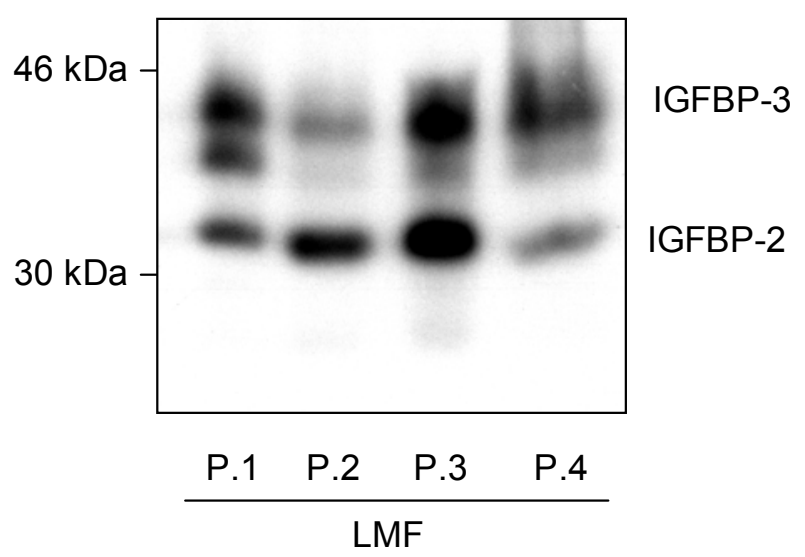

Figure 22. IGFBP secretion in rat liver cells. (A) $\left[{ }^{125} \mathrm{I}\right]-\mathrm{IGF}-\mathrm{I}$ ligand blot of rat serum (S) and of CM from rat hepatocytes (HCs), Kupffer cells (KCs), sinusoidal endothelial cells (SECs), hepatic stellate cells (HSCs; day 7 of culture) and LMFs. Cultures of rat liver cells were kept under serum-reduced conditions for 24-36 hours prior to further analysis. (B) $\left[{ }^{125} \mathrm{I}\right]-\mathrm{IGF}-\mathrm{I}$ ligand and immunoblot of rat serum (S) and of CM from LMFs. For immunoblot analysis of CM from LMFs, nitrocellulose membranes were incubated with the indicated IGFBP antiserum. (C) IGFBP secretion by LMFs during passaging. LMFs from passages 1-4 (P.1-P.4) were cultivated under serum-reduced conditions for 36 hours. CM were analyzed by [ $\left.{ }^{125} \mathrm{I}\right]-\mathrm{IGF}-\mathrm{I}$ ligand blotting. The positions of the molecular mass standards are indicated. 
In line with previous reports, IGFBP-2 and -3 were detected by ligand blotting in CM from KCs and SECs. Analysis of CM from hepatocytes revealed the presence of IGFBP species of 24, 30 and $34 \mathrm{kDa}$ identified as IGFBP-4, -1 and -2 (Scharf et al., 1995a; 1996a). CM from HSCs at day 7 of culture contained IGFBPs of 24, 41 and $45 \mathrm{kDa}$ corresponding to IGFBP-4, and IGFBP-3, respectively (Scharf et al., 1998).

A
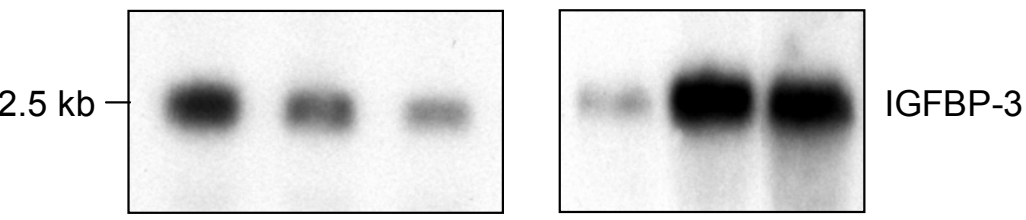

B
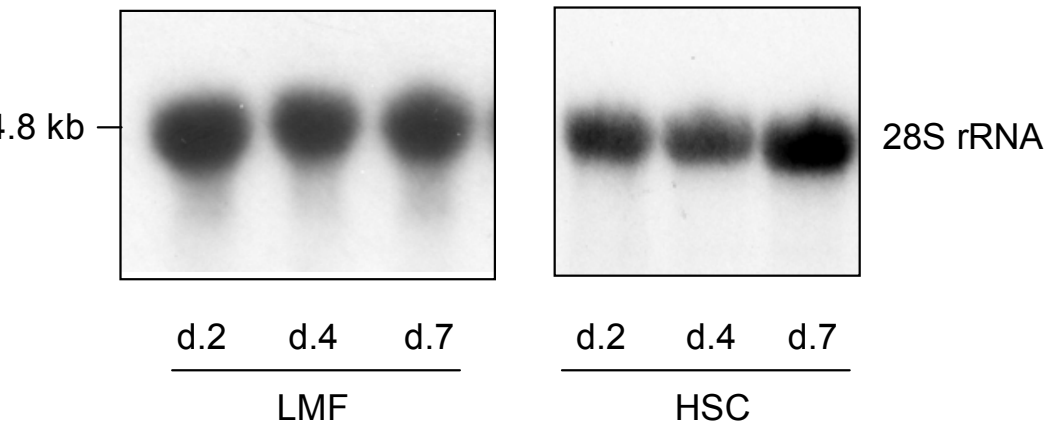

C

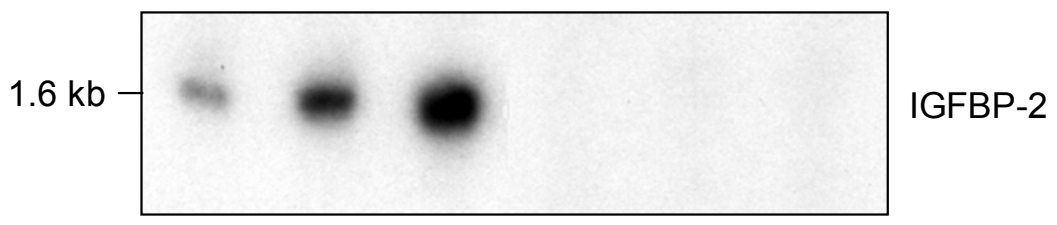

D

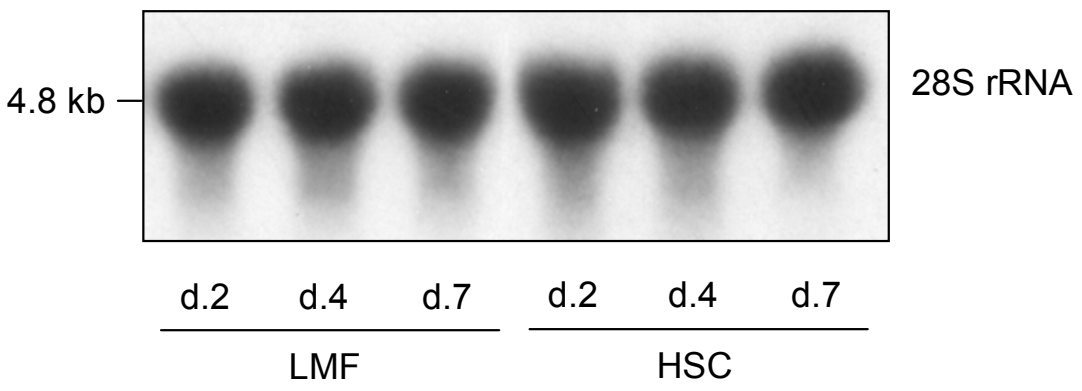

Figure 23. IGFBP mRNA expression in LMFs. $10 \mu \mathrm{g}$ of total RNA obtained from rat LMFs and HSCs at different days of culture as indicated, were separated by $1 \%$ agarose gel electrophoresis, blotted and hybridized with cDNAs specific for rat IGFBP-3 (A) and IGFBP-2 (C). Equal loading of RNA was demonstrated after stripping and rehybridization of membranes with an oligonucleotide complementary to $28 \mathrm{~S}$ rRNA (B, D). The sizes of the hybridization bands (in kb) are indicated on the left.

\subsubsection{IGFBP mRNA expression}

The ligand and immunoblot data were confirmed by Northern blot analysis of total RNA from LMFs, which revealed messenger RNA species for IGFBP-3 at $2.5 \mathrm{~kb}$ and IGFBP2 at $1.6 \mathrm{~kb}$ (Fig. 23). IGFBP-1 and -4 specific mRNA in LMFs were below the limits of 
detection (data not shown). Both IGFBP-2 and IGFBP-3 transcripts were detected in cells from different passages. A temporal IGFBP-3 mRNA expression was different in LMFs and HSCs during their cultivation in vitro (Fig. 23). With time of culture IGFBP-3specific transcripts decreased in LMFs but increased in HSCs, in parallel with their in vitro transformation. In contrast to IGFBP-3, IGFBP-2 mRNA expression was upregulated during cultivation of LMFs with maximal level of expression at day 7 of culture. In accordance with the ligand and immunoblotting data, no IGFBP-2-specific transcripts were detected in HSCs.

\subsubsection{Regulation of IGFBP Secretion}

The effect of hormones and growth factors, namely $\mathrm{GH}$, insulin, IGF-I, PDGF-BB and TGF- $\beta$, on IGFBP secretion was studied by ligand blotting of medium samples. In LMFs IGF-I and insulin at a concentration of $100 \mathrm{nmol} / \mathrm{L}$ as well as TGF- $\beta$ at a concentration of $10 \mathrm{ng} / \mathrm{mL}$ stimulated abundance of IGFBP-3 approximately 2.5-fold and that of IGFBP-2 1.5-fold, respectively. PDGF-BB inhibited secretion of both IGFBP-3 and -2 to $70 \%$ and $79 \%$ of controls, respectively. $\mathrm{GH}$ had only a moderate stimulatory effect on IGFBP secretion (Fig. 24). Furthermore, the addition of insulin or IGF-I time- (Fig. 25) and dose-dependently (Fig. 26) increased abundance of IGFBP-3 and of IGFBP-2 showing maximal effects at $100 \mathrm{nmol} / \mathrm{L}$ after 24 hours.

\subsubsection{Regulation of IGFBP mRNA Expression}

To inestigate whether stimulatory effect of insulin and IGF-I on IGFBP secretion in LMFs was transcriptionally regulated, total RNA obtained from rat LMFs treated with insulin or IGF-I was analyzed by Northern blot analysis. Both IGF-I and insulin time-dependently (Fig. 27) increased mRNA expression of IGFBP-2 and IGFBP-3. Thus, IGF-I and insulin stimulate de novo synthesis of the IGFBPs in LMFs. 
A

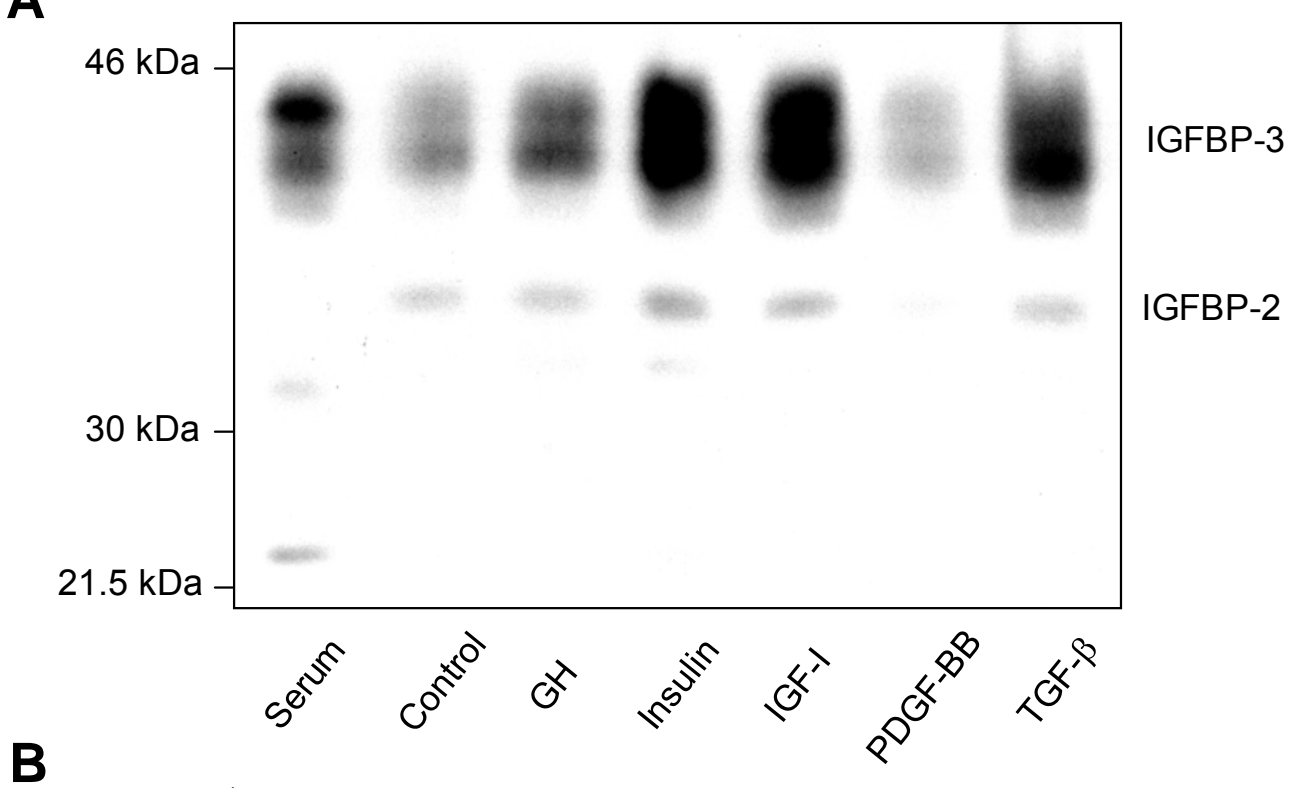

B

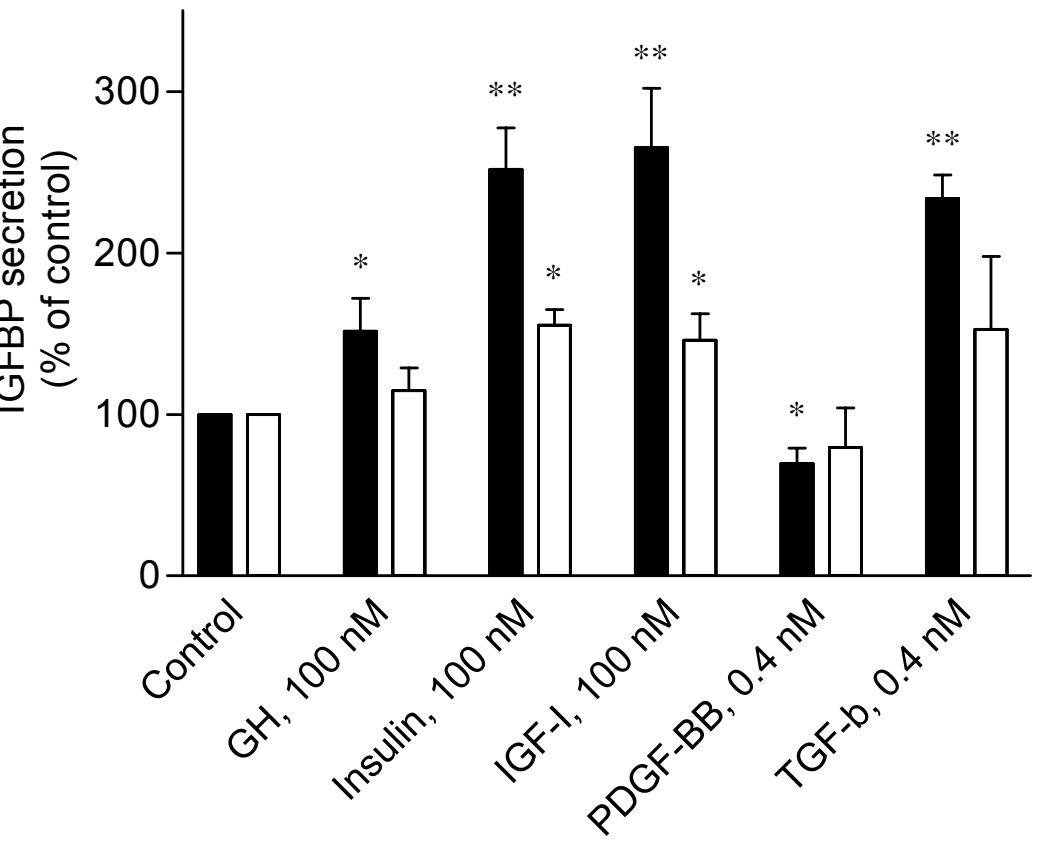

Figure 24. Effect of hormones and growth factors on IGFBP secretion in LMFs. (A) LMFs were incubated in serum-reduced medium in the presence or absence of $\mathrm{GH}(100 \mathrm{nmol} / \mathrm{L})$, insulin $(100 \mathrm{nmol} / \mathrm{L})$, IGF-I $(100 \mathrm{nmol} / \mathrm{L})$, PDGF-BB $(10 \mathrm{ng} / \mathrm{mL})$ and TGF- $\beta(10 \mathrm{ng} / \mathrm{mL})$ for 36 hours. CM were analyzed by [ $\left.{ }^{125} \mathrm{I}\right]-\mathrm{IGF}-\mathrm{I}$ ligand blotting. (B) The effect of hormones and growth factors was quantified after densitometric analysis of the respective bands. The relative densities of bands were expressed as the percentage of increase or decrease for IGFBP-3 (solid bars) and IGFBP-2 (open bars) compared with the respective untreated control. Data are shown as means $\pm \operatorname{SEM}(n=5)$. Statistically significant difference $\left(p<0.05^{*} ; p<0.01^{* *}\right.$; Student's $t$-test) compared with untreated control cultures. 
A

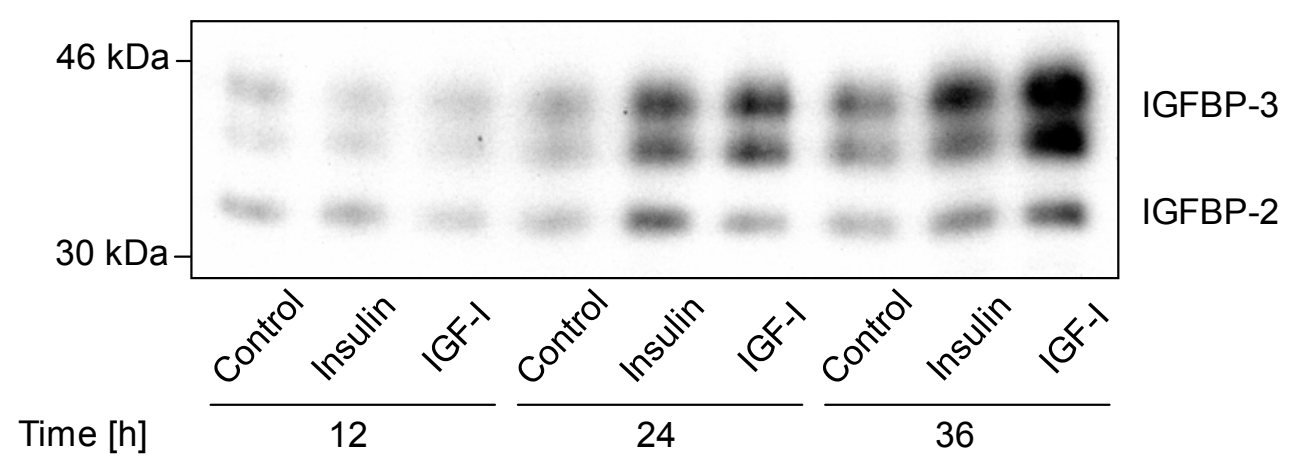

B

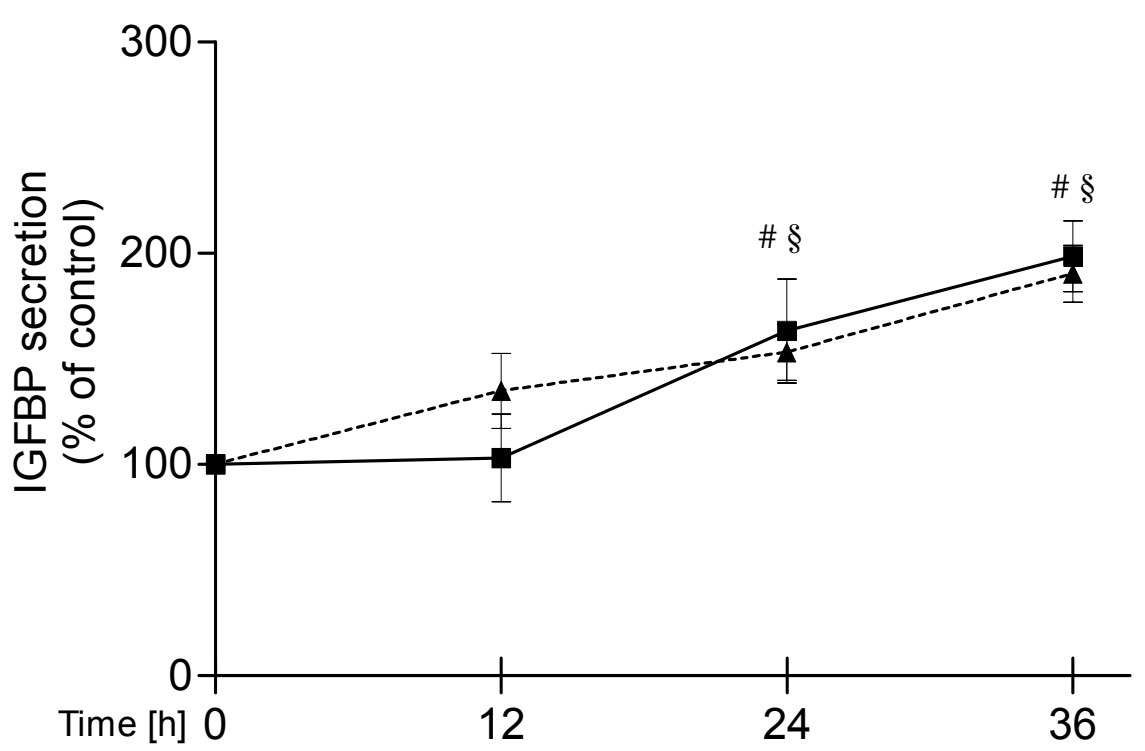

C

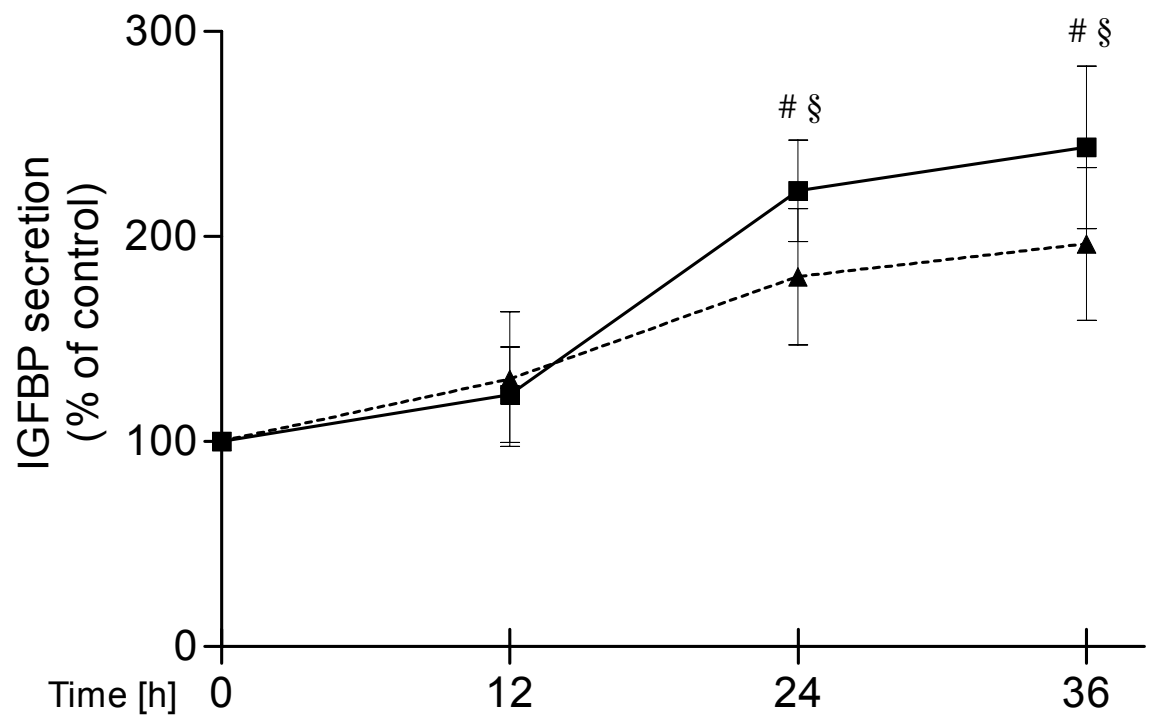

Figure 25. Time course of insulin and IGF-I stimulated IGFBP secretion in LMFs. (A) LMFs were incubated in serum-reduced medium in the presence or absence of insulin and IGF-I at $100 \mathrm{nmol} / \mathrm{L}$ for 12 , 24 and 36 hours. CM were analyzed by $\left[{ }^{125}\right.$ I]-IGF-I ligand blotting. Densitometric analysis of IGFBP secretion in LMFs after treatment with insulin (B) or IGF-I (C). The relative densities of bands were expressed as the percentage of increase for IGFBP-3 ( $\mathbf{\square})$ and IGFBP-2 ( $\mathbf{\Delta})$ compared with the respective untreated controls $(n=4)$. Statistically significant difference in IGFBP-3 $(\#)$ and IGFBP-2 $(\S)$ secretion $(p<0.05$, Student's $t$-test) compared with respective untreated control cultures. 
A
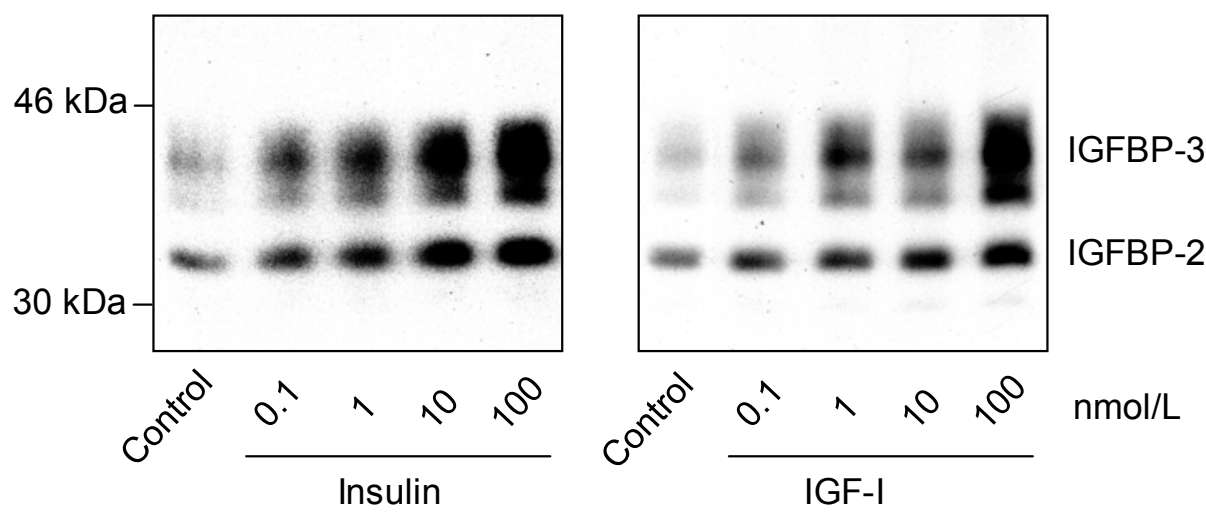

B
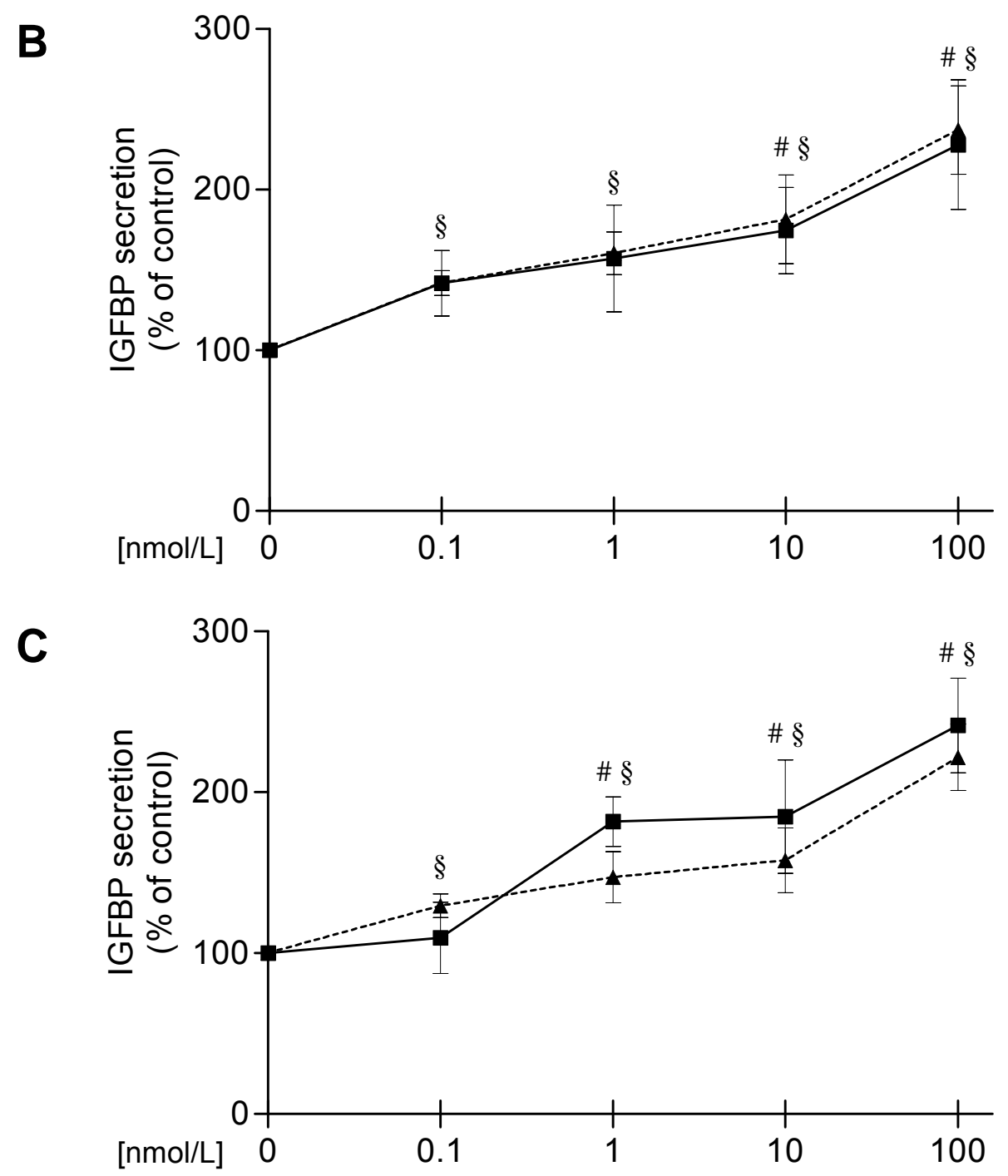

Figure 26. Dose-dependent effect of insulin and IGF-I on IGFBP secretion in LMFs. (A) LMFs were incubated in serum-reduced medium in the presence or absence of insulin and IGF-I at concentrations ranging from 0.1 to $100 \mathrm{nmol} / \mathrm{L}$ for 36 hours. CM were analyzed by [ $\left.{ }^{125} \mathrm{I}\right]-\mathrm{IGF}-\mathrm{I}$ ligand blotting. Densitometric analysis of IGFBP secretion in LMFs after treatment with insulin (B) or IGF-I (C). The relative densities of bands were expressed as the percentage of increase for IGFBP-3 (घ) and IGFBP-2 $(\mathbf{\Lambda})$ compared with the respective untreated controls $(n=4)$. Statistically significant difference in IGFBP-3 $(\#)$ and IGFBP-2 (§) secretion ( $p<0.05$, Student's $t$-test) compared with untreated control cultures. 
A

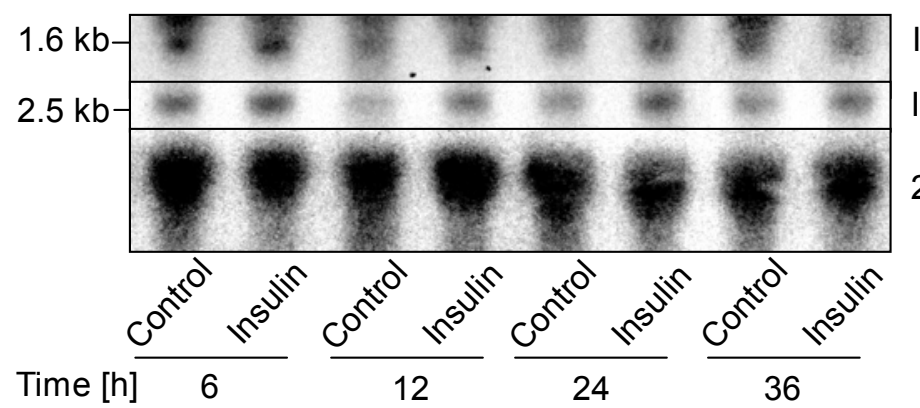

IGFBP-2

IGFBP-3

$28 \mathrm{~S}$ rRNA

B

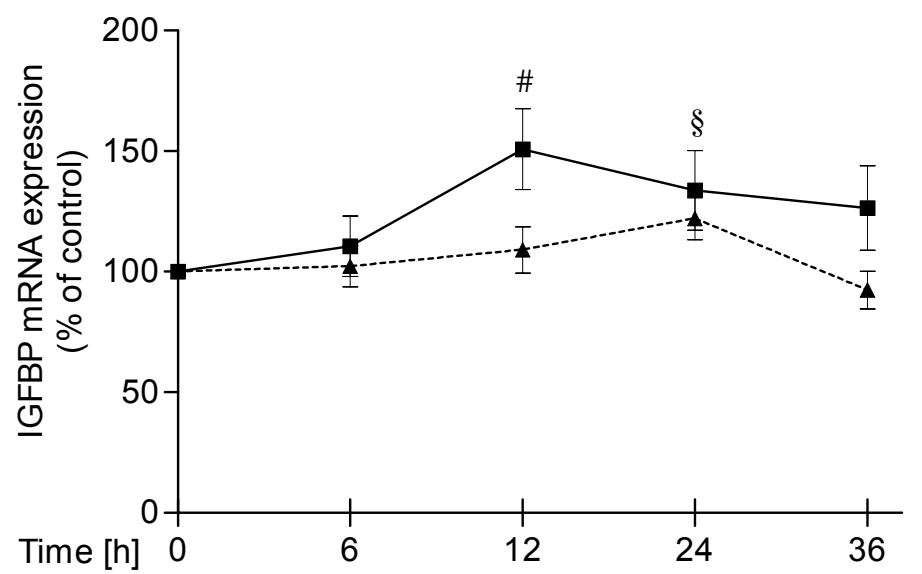

C

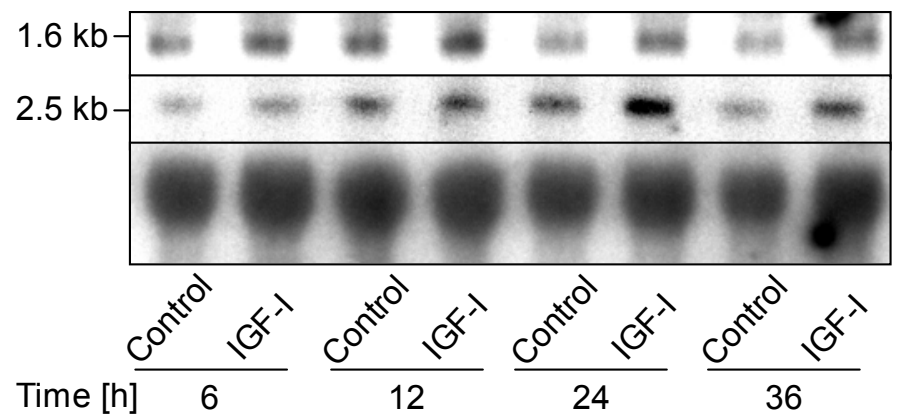

IGFBP-2

IGFBP-3

$28 \mathrm{~S}$ rRNA

D

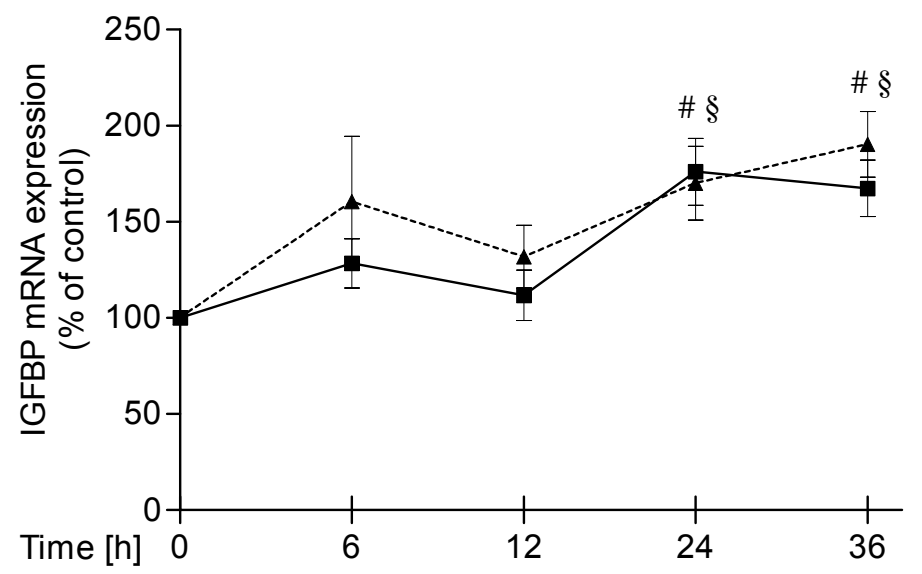

Figure 27. Time course of IGFBP mRNA expression in LMFs after treatment with insulin (A, B) and IGF-I (C, D). Upper panels: total RNA $(10 \mu \mathrm{g})$ isolated from LMFs incubated in the presence or absence of the indicated hormone were separated by $1 \%$ agarose gel electrophoresis, blotted and probed for IGFBP-2 and IGFBP-3, respectively. The sizes of the hybridization bands (in kb) are indicated on the left. Lower panels: equal loading of RNA was demonstrated after stripping and rehybridization of membranes with an oligonucleotide complementary to 28S rRNA. Densitometric analysis of insulin (B) and IGF-I (D) stimulated IGFBP mRNA expression in LMFs. The relative densities of bands were expressed as the percentual increase of IGFBP-3 mRNA ( $\square)$ and IGFBP-2 mRNA ( $\mathbf{\Delta})$ compared with the respective untreated controls $(n=3)$. Statistically significant difference in IGFBP-3 (\#) and IGFBP-2 (§) mRNA expression ( $p<0.05$, Student's $t$-test) compared with respective untreated control cultures. 


\subsubsection{IGFBP Proteolysis}

It has been shown that specific proteases are important regulators of IGFBP abundance in extracellular space (Bunn and Fowlkes, 2003). Therefore, conditioned media of LMFs were also analyzed in the IGFBP protease assay for IGFBP-3 and IGFBP-2 proteolytic activity. When protease activity was tested in CM from different passages of LMFs for 24 hours at neutral $\mathrm{pH}$ using iodinated recombinant human IGFBP-3 and -2, no fragmentation of the $29 \mathrm{kDa}$ non-glycosylated IGFBP-3 or the $31 \mathrm{kDa}$ IGFBP-2 was observed (Fig. 28). At pH 4.0, however, IGFBP-3 was fragmented by media conditioned by LMFs from different passages in contrast to IGFBP-2, which remained unaffected.

A
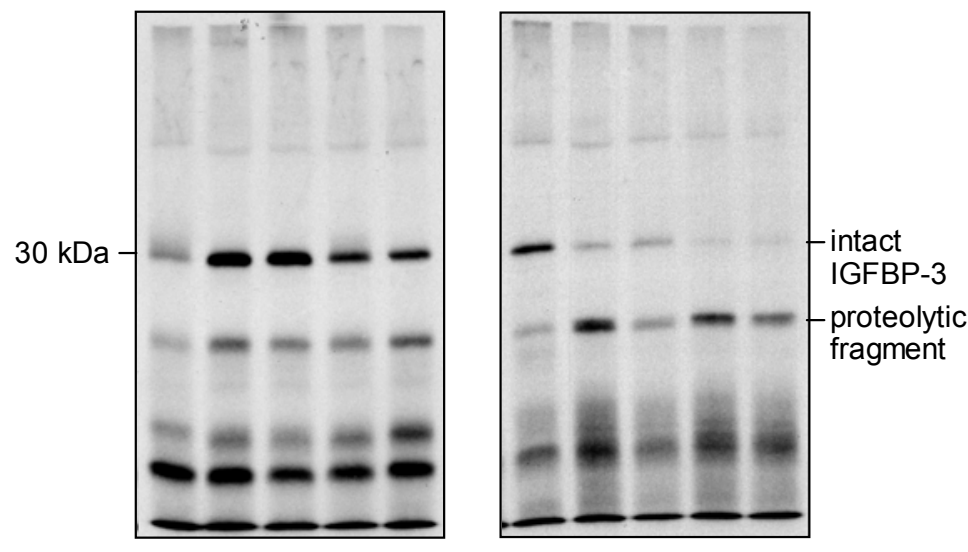

B

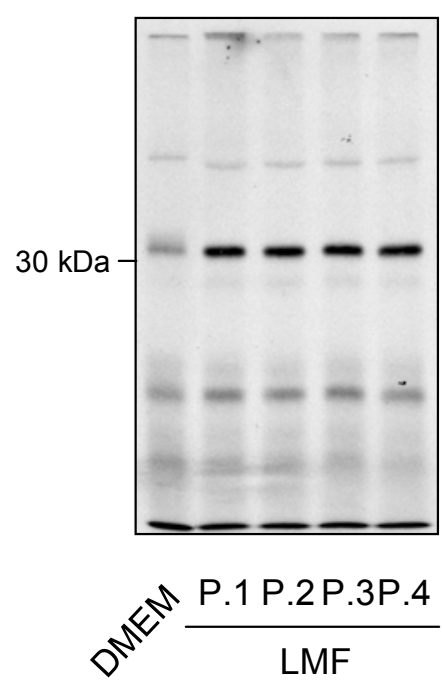

$\mathrm{pH} 7.4$

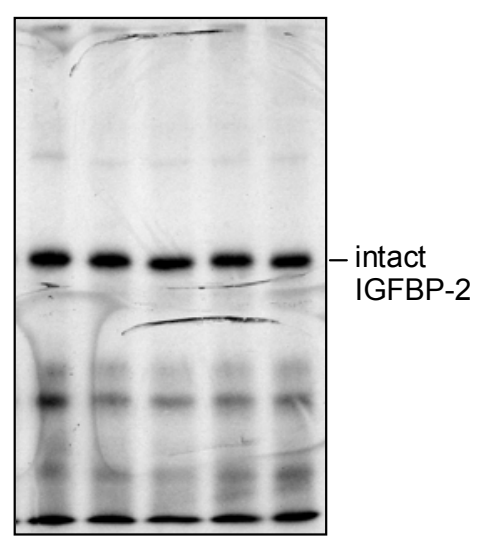

P.1 P.2 P.3P.4

LMF

$\mathrm{pH} 4.0$

Figure 28. IGFBP proteolysis in LMFs. $\left[{ }^{125}\right.$ I]-labelled recombinant human IGFBP-3 (A) and IGFBP-2 (B) were incubated with control medium (Dulbecco's modified Eagle medium supplemented with $0.3 \%$ of fetal calf serum) or with media conditioned by cultured LMFs (passages 1-4, P.1-P.4) for 24 hours at $37^{\circ} \mathrm{C}$ at $\mathrm{pH} 4.0$ or 7.4. Samples were further subjected to SDS-PAGE and autoradiography. The sizes of molecular weight standards are indicated. 


\subsubsection{Effect of IGF-I on DNA Synthesis}

To study whether the presence of the IGF-IR on LMFs might affect cell proliferation, the effect of $\mathrm{GH}$, insulin and IGF-I on DNA synthesis was examined by BrdU-incorporation assay. Incubation with insulin and IGF-I stimulated the DNA synthesis in cultured LMFs, whereas GH had no effect (Fig. 29). Of note, long-R ${ }^{3}-$ IGF-I, an IGF-I analogue which binds to the IGF receptor but not to IGFBPs, had no effect on DNA synthesis. It implies that mitogenic activity of IGF-I in LMFs requires endogenous IGF binding proteins.

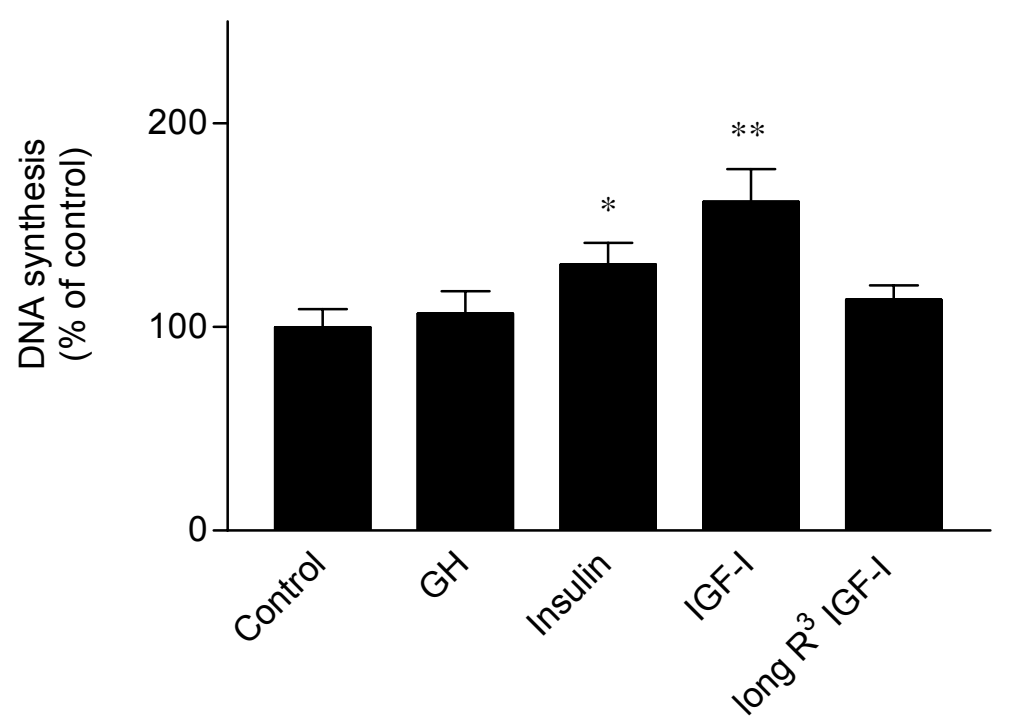

Figure 29. Effect of growth hormone, insulin and IGF-I on DNA synthesis in LMFs. After starvation in serum-reduced DMEM for 1 hour, cells were incubated in the presence or absence of $\mathrm{GH}(100 \mathrm{nmol} / \mathrm{L})$, insulin (100 nmol/L), IGF-I (100 nmol/L) or long-R ${ }^{3}-I G F-I ~(100 \mathrm{nmol} / \mathrm{L})$ for 24 hours and labelled with BrdU. Control cells were incubated with serum-reduced DMEM alone. Results are expressed as the percentage of incorporation \pm SEM relative to the untreated control $(n=3)$. Statistically significant difference $\left(p<0.05^{*} ; p<0.01^{* *} ;\right.$ Student's $t$-test) compared with untreated control cultures.

\subsubsection{Effect of IGF-I on Synthesis of Extracellular Matrix Proteins}

Regulation of ECM protein synthesis by IGF-I was studied by incubation of rat LMFs with increasing concentrations of IGF-I (1, 10 and $100 \mathrm{nmol} / \mathrm{L})$. Western blot analysis revealed synthesis of type I collagen, type IV collagen, fibronectin and laminin in LMFs (Fig. 30A). IGF-I caused a dose-dependent stimulation of type I collagen synthesis with maximal effect at $100 \mathrm{nmol} / \mathrm{L}$. In contrast, synthesis of other ECM proteins was not significantly altered after treatment with IGF-I. Moreover, the stimulatory effect of IGF-I on type I collagen production is transcriptionally regulated. As demonstrated by Northern blot analysis (Fig. 30B), the addition of IGF-I slowly and time-dependently increased mRNA expression of $\alpha_{2}(\mathrm{I})$ chain of type I procollagen showing maximal effect after 36 hours of treatment. 
A

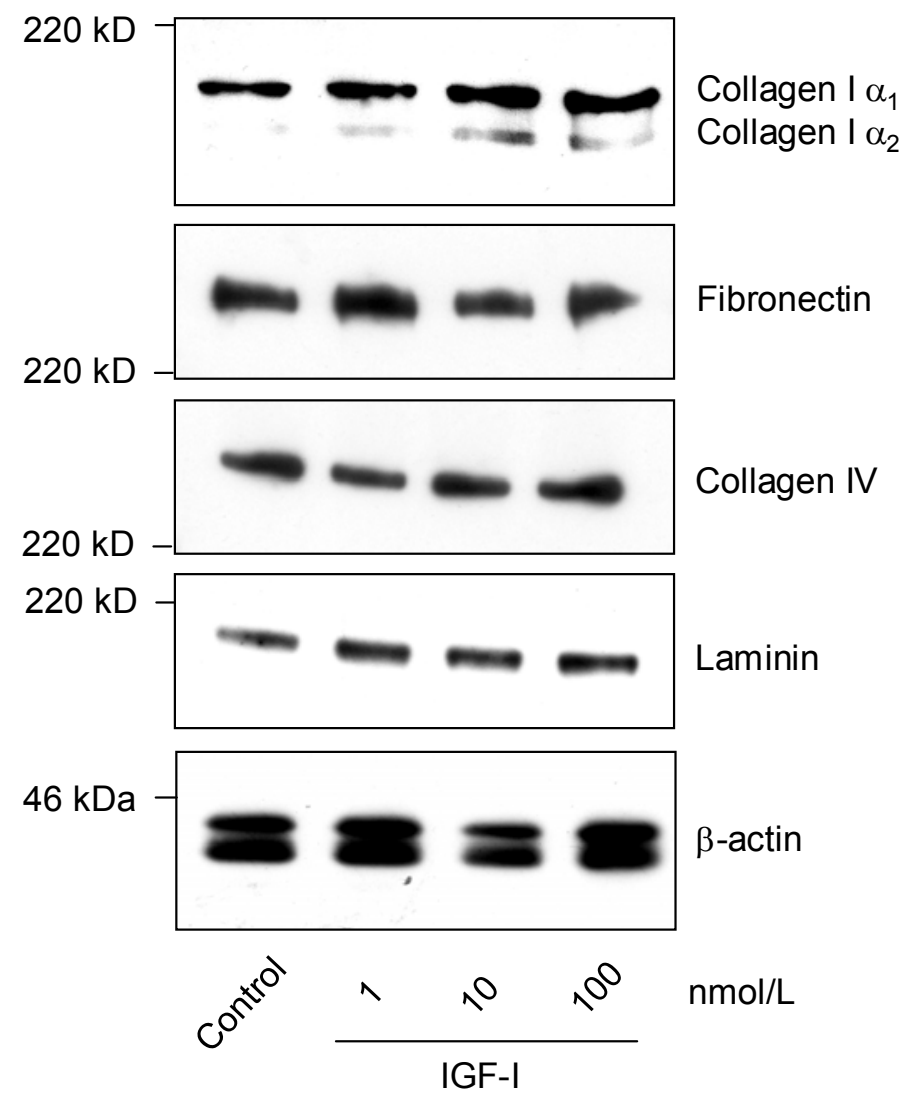

B

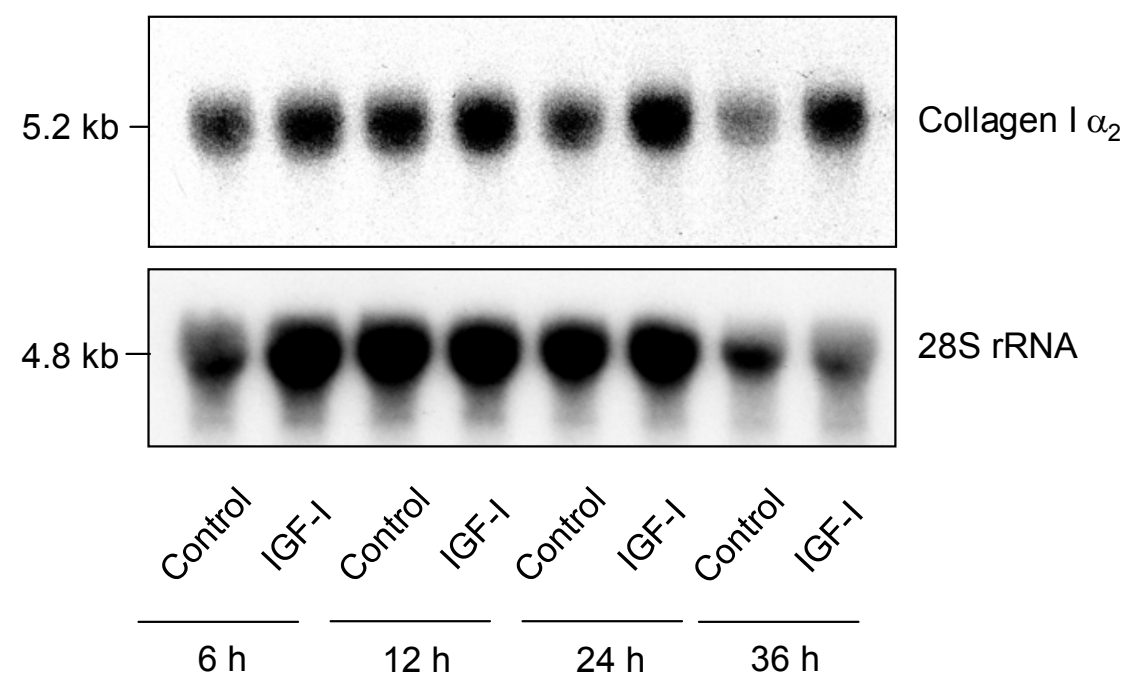

Figure 30. Effect of IGF-I on synthesis of extracellular matrix proteins in LMFs. (A) LMFs were incubated in serum-reduced medium in the presence of increasing concentrations of IGF-I $(1,10,100 \mathrm{nmol} / \mathrm{L})$ for 24 hours. Proteins $(25 \mu \mathrm{g})$ extracted from whole cell lysates were size-fractionated by SDS-PAGE, blotted and probed for certain ECM proteins using specific antibodies. The positions of the molecular weight standards are indicated on the left. Equal loading of proteins was demonstrated by immunoblotting with an antibody directed against $\beta$-actin. (B) For Northern blot analysis, $10 \mu \mathrm{g}$ of total RNA obtained from rat LMFs incubated in serum-reduced medium in the presence or absence of IGF-I (100 nmol/L) for 6, 12, 24 and 36 hours were separated by $1 \%$ agarose gel electrophoresis, blotted and hybridized with a cDNA specific for $\alpha_{2}(\mathrm{I})$ chain of type I procollagen. Equal loading of RNA was demonstrated after stripping and rehybridization of membranes with an oligonucleotide complementary to $28 \mathrm{~S}$ rRNA. The sizes of the hybridization bands (in kb) are indicated on the left. 


\subsubsection{Modulation of IGF-I-Stimulated DNA Synthesis by Exogenous IGFBP-2 and IGFBP-3}

In previous experiments (see section 4.2.10) it has been shown that mitogenic effect of IGF-I in LMFs appeared to require endogenous IGFBPs. Since IGFBP-3 and -2 have been detected in LMFs at both protein and mRNA levels, the effect of exogenously added rhIGFBP-3 and rhIGFBP-2 on IGF-I-stimulated DNA synthesis in cultures of LMFs was evaluated (Fig. 31). When LMFs were coincubated simultaneously with 100 $\mathrm{nmol} / \mathrm{L}$ of IGF-I and increasing concentrations of recombinant IGFBP-2 or -3, the rate of DNA synthesis was lower as compared with LMFs incubated with $100 \mathrm{nmol} / \mathrm{L}$ of IGF-I alone (Fig. 31A, 31B). After preincubation of LMFs with rhIGFBP-2 or -3 for 1 hour prior to the addition of $100 \mathrm{nmol} / \mathrm{L}$ of IGF-I, DNA synthesis was additionally stimulated compared with LMFs treated with IGF-I alone (Fig. 31A, 31B). For both rhIGFBP-2 and 3 , the most pronounced effect was observed when rhIGFBPs were added at the final concentration of $50 \mathrm{nmol} / \mathrm{L}$ resulting in a $1.8 \pm 0.1$-fold increase of BrdU incorporation for rhIGFBP-3 (Fig. 31A) and a $2.4 \pm 0.2$-fold increase of BrdU incorporation for rhIGFBP-2 (Fig. 31B).

\subsubsection{Inhibition of DNA Synthesis by IGFBP-3}

Recombinant IGFBP-3 applied alone at the concentration of $50 \mathrm{nmol} / \mathrm{L}$ led to substantial inhibition of DNA synthesis in rat LMFs as evaluated by BrdU incorporation assay (Fig. $31 \mathrm{~A}, 32)$. This mitoinhibitory effect of IGFBP-3 is not attributed to sequestration of endogenous IGF-I and appears to be IGF-I-independent because treatment of cultured LMFs with function-blocking anti-IGF-I antibodies did not affect DNA synthesis.

\subsubsection{Nuclear Accumulation of IGFBP-3}

IGFBP-3 contains classical nuclear localization signals (NLS) and is translocated to the nucleus via importin-beta-mediated pathway where IGFBP-3 is supposed to bind to certain transcription factors (Butt et al., 1999). This binding appears to be important for direct proapoptotic activity of IGFBP-3 in the cell (Liu et al., 2000). To test whether the intrinsic mitoinhibitory activity of IGFBP-3 observed in rat LMFs can be associated with nuclear accumulation of IGFBP-3, nuclear and cytoplasmic extracts obtained from LMFs were further subjected to ligand blot analysis. 
A

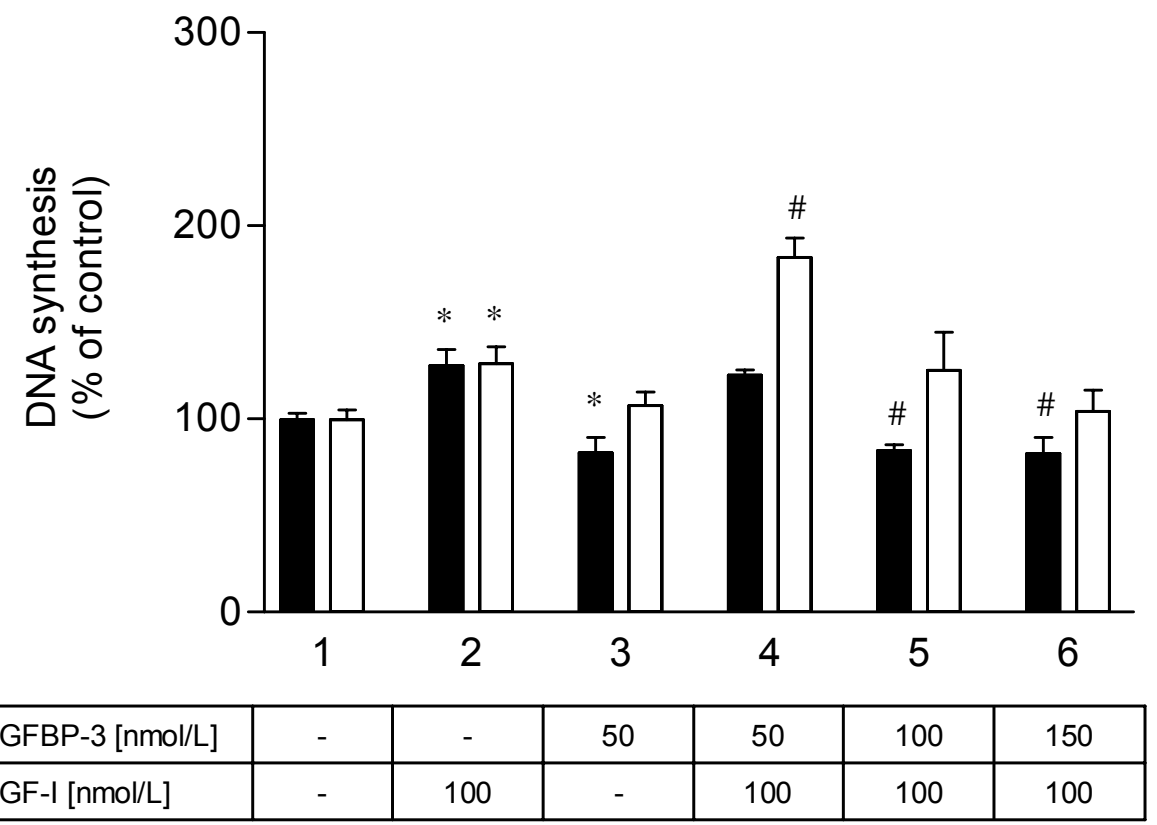

B

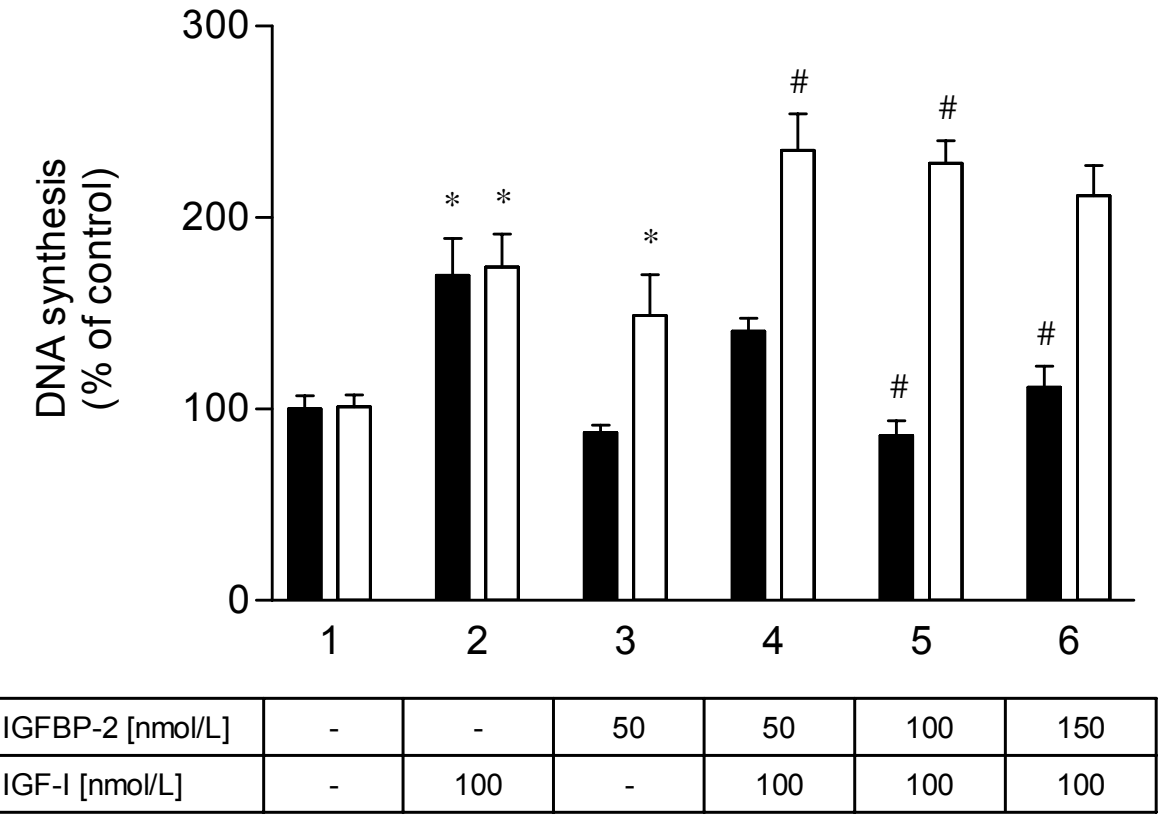

Figure 31. Effect of rhIGFBP-3 (A) and rhIGFBP-2 (B) on DNA synthesis in LMFs. After starvation in serum-reduced DMEM for 1 hour, cells were incubated for 24 hours with either rhIGFBP-3 or rhIGFBP-2. The effect of IGFBP on IGF-I-stimulated DNA synthesis was evaluated by simultaneous addition of rhIGFBP-3 or rhIGFBP-2 at concentrations of 50, 100 and $150 \mathrm{nmol} / \mathrm{L}$ (solid bars) with $100 \mathrm{nmol} / \mathrm{L}$ IGF-I. In a second approach, MF were preincubated with rhIGFBP-3 or rhIGFBP-2 at concentrations of 50, 100 and $150 \mathrm{nmol} / \mathrm{L}$ (open bars) for 1 hour followed by the addition of $100 \mathrm{nmol} / \mathrm{L}$ IGF-I. Control cells were incubated for 24 hours with either serum-reduced DMEM alone (1) or $100 \mathrm{nmol} / \mathrm{L}$ IGF-I (2). Cells were labelled with BrdU for 24 hours. Results are expressed as the percentage of incorporation \pm SEM relative to the control $(n=3)$. Statistically significant difference $(p<0.05$; Student's $t$-test) compared with untreated control cultures $\left({ }^{*}\right)$ or IGF-I treated cultures (\#). 


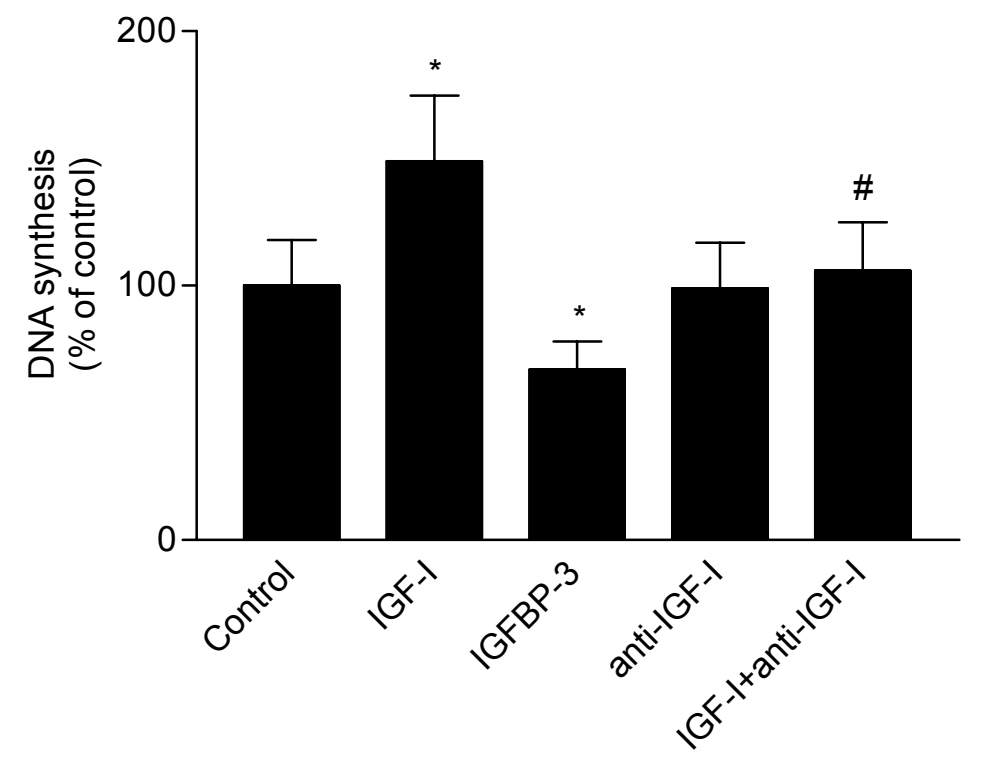

Figure 32. Intrinsic mitoinhibitory activity of IGFBP-3 in LMFs. After starvation in serum-reduced DMEM for 1 hour, cells were incubated in the presence or absence of IGF-I (100 nmol/L), rhIGFBP-3 $(50 \mathrm{nmol} / \mathrm{L})$ and function-blocking anti-IGF-I antibodies $(2.5 \mu \mathrm{g} / \mathrm{mL})$ for 24 hours and labelled with BrdU. Control cells were incubated with serum-reduced DMEM alone. Results are expressed as the percentage of incorporation \pm SEM relative to the untreated control $(n=3)$. Statistically significant difference $(p<0.05$; Student's $t$-test) compared with untreated control cultures (*) or IGF-I treated cultures (\#).

The edible mushroom (Agaricus bisporus) lectin ( $A B L$ ) was used as an inhibitor of NLSdependent import. This Galß1-3GalNAc ${ }_{\alpha}$ (TF antigen)-binding lectin has been shown to block NLS-dependent protein uptake into the nucleus without any apparent cytotoxic effects (Yu et al., 1999). The ligand blot data demonstrate that under normal conditions IGFBP-3 in cultures of rat LMFs is present in three compartments: (i) in the conditioned medium, (ii) in the cytoplasm, and a relatively high amount of IGFBP-3 is also observed (iii) in the nucleus. However, pretreatment of cells with $A B L$ for 6 hours prior to the readdition of serum-containing medium effectively inhibited the re-entry of IGFBP-3 into the nucleus (Fig. 33), thus demonstrating that IGFBP-3 in LMFs is translocated to the nucleus via importin-mediated pathway. Moreover, blockade of nuclear import with $A B L$ prior to the addition of IGF-I, one of the most potent stimulator of IGFBP-3 secretion in LMFs, was accompanied by a pronounced accumulation of IGFBP-3 in the conditioned medium compared with cells treated with IGF-I alone. Therefore, in LMFs a relatively high amount of newly synthesized IGFBP-3 after secretion undergoes re-uptake by cells with subsequent translocation to the nucleus. 
A

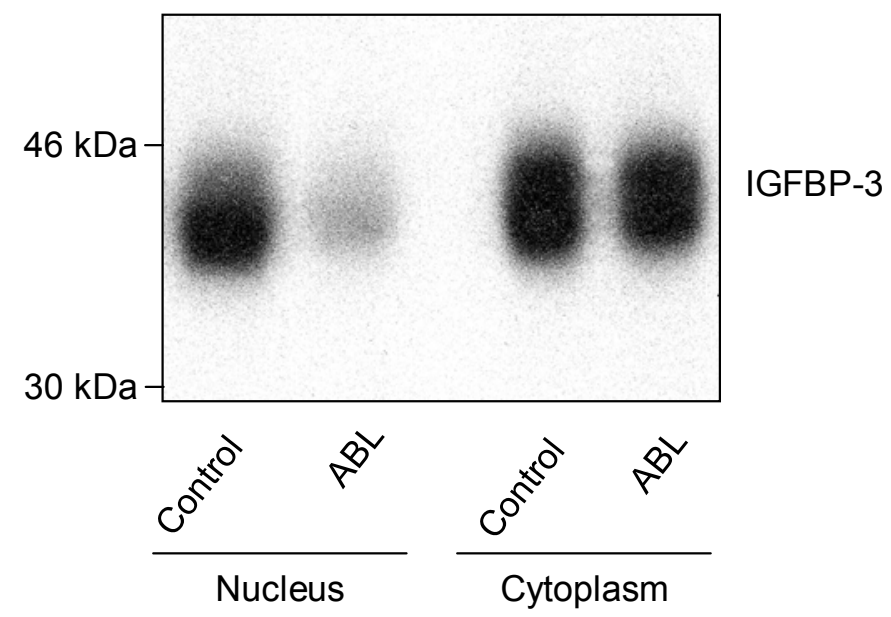

B

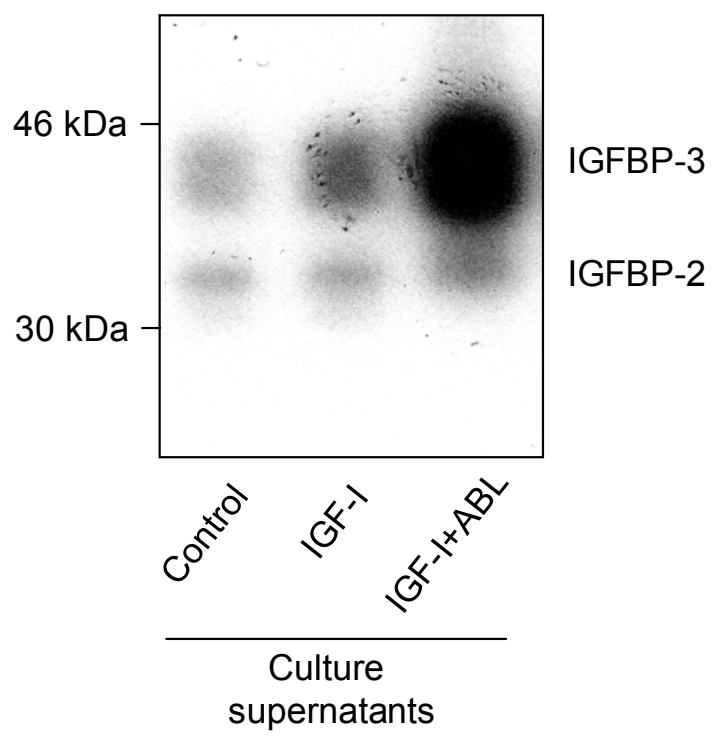

Figure 33. Nuclear accumulation of IGFBP-3 in LMFs. After starvation in serum-reduced DMEM for 1 hour, cells were incubated in the presence or absence of the edible mushroom (Agaricus bisporus) lectin (ABL) $(20 \mu \mathrm{g} / \mathrm{mL})$ for 5 hours and re-fed in serum-containing medium for 18 hours. Alternatively, growtharrested LMFs after 5-hour preincubation with $A B L(20 \mu \mathrm{g} / \mathrm{mL})$ were also cultured in serum-reduced medium supplemented with IGF-I (100 nmol/L) for 18 hours. Nuclear and cytoplasmic protein extracts (50 $\mu \mathrm{g})(\mathrm{A})$ as well as conditioned media (B) were subjected to SDS-PAGE and $\left.{ }^{125} \mathrm{I}\right]-$ IGF-I ligand blot analysis. The positions of the molecular weight standards are indicated. 


\subsection{Cross-Talk between PDGF and IGF-I Receptors in Liver Myofibroblasts}

\subsubsection{IGF-I-Induced Down-Regulation of IGF-IR and IRS-1}

In liver cirrhosis reduced hepatic IGF-I expression and serum IGF-I levels are associated with adverse clinical outcome and complications (Moller et al., 1995; Scharf et al., 1996b). Moreover in a rat model of liver cirrhosis, administration of exogenous IGF-I is accompanied by improvement of liver function and reduction of liver damage and fibrosis (Castilla-Cortazar et al., 1997). In agreement with these findings, the data presented here clearly demonstrate that high concentrations of IGF-I effectively inhibit the IGF-IR expression in rat LMFs. As shown by Northern blot analysis, IGF-I reduced the IGF-IR mRNA expression in cultures of LMFs whereas GH and insulin had no effect (Fig. 34A). In turn, Western blot analysis revealed that incubation of LMFs with IGF-I resulted in a dose-dependent inhibition of synthesis of the IGF-IR $\beta$ subunit (Fig. 34B). The inhibitory effect of IGF-I on the IGF-IR $\beta$ production was observed only at high concentrations (50 and $100 \mathrm{nmol} / \mathrm{L}$ ). Moreover, biosynthesis of IRS-1, a principal signalling element of the IGF-IR, was also dose-dependently inhibited by IGF-I. This effect was specific because synthesis of another IRS protein, Gab-1, was unaffected by increasing concentrations of IGF-I.

\subsubsection{Expression of PDGF Receptors}

In contrast to IGF-I, expression of PDGFs in cirrhotic tissue is considerably higher compared with normal liver tissue. To identify the cellular targets for PDGFs in the liver, Northern blot analysis of the PDGFR expression has been performed using total RNA isolated from different rat liver cells. Transcripts encoding rat PDGFR $\alpha$ were detected at 6.5 and $4.7 \mathrm{~kb}$ and mRNA species specific for rat PDGFR $\beta$ at $5.4 \mathrm{~kb}$ (Fig. 35A). Total RNA obtained from hepatocytes showed no hybridization signals with the radiolabelled PDGFR $\alpha$ and PDGFR $\beta$ probes. In total RNA obtained from KCs only mRNA species coding for the PDGFR $\alpha$ were detected. Transcripts encoding both PDGFR $\alpha$ and PDGFR $\beta$ were highly abundant in LMFs and HSCs. In LMFs, steady levels of transcripts encoding the PDGFR $\alpha$ and PDGFR $\beta$ were unaffected by serial passages of cells. PDGFR expression was substantially up-regulated with increasing cell density during cultivation of LMFs and during in vitro transformation of HSCs (Fig. 35B). Increased PDGFR mRNA expression in cultures of LMFs had direct functional consequence. As demonstrated by BrdU incorporation assay, PDGF-BB stimulated 
DNA synthesis in LMFs and this effect was more pronounced in cell cultures with higher cell density (Fig. 35C).

A

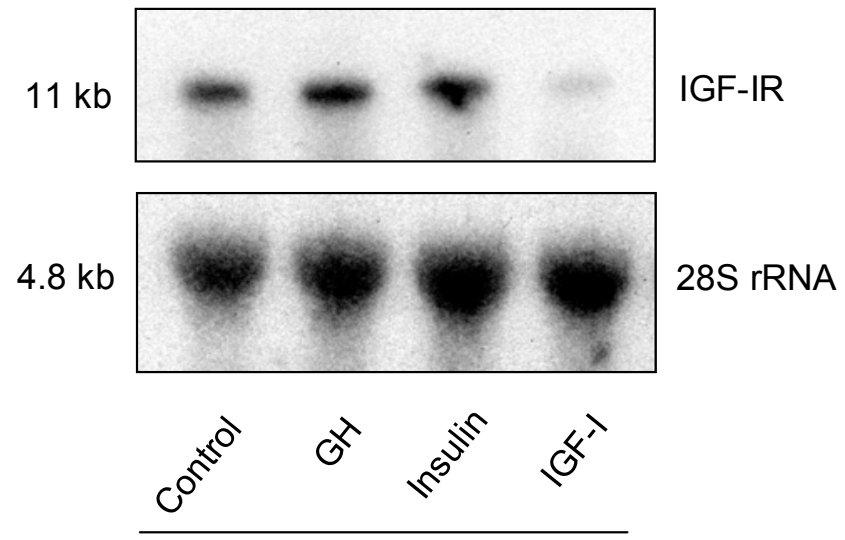

$36 \mathrm{~h}$

B
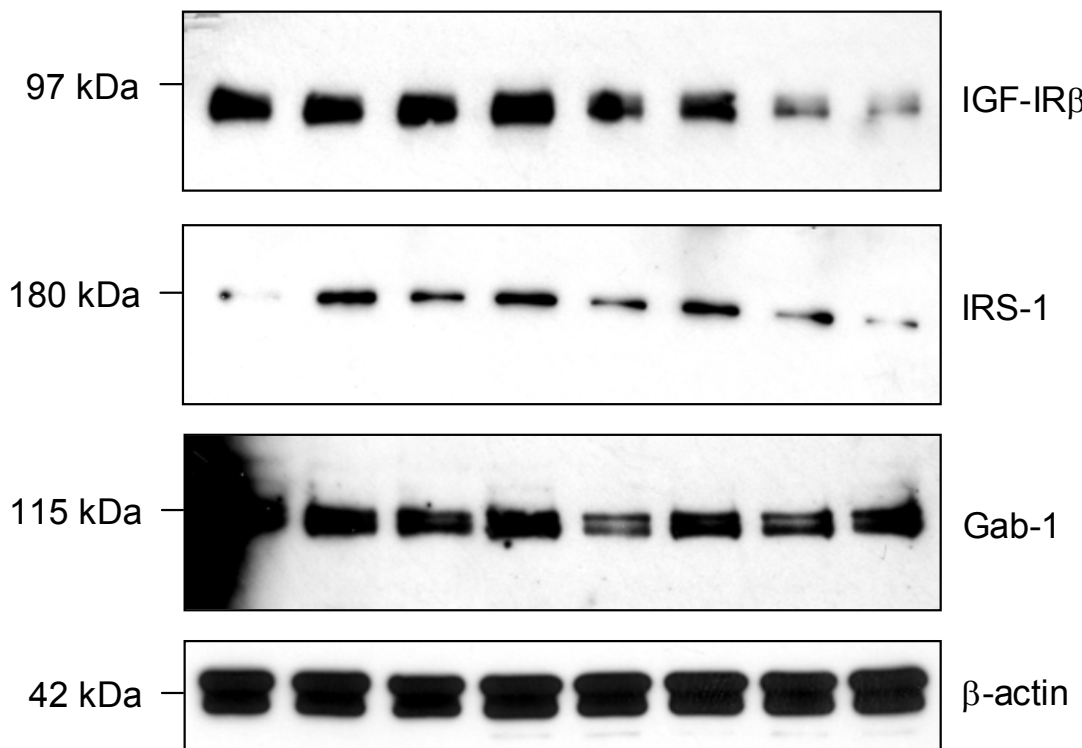

\begin{tabular}{lllllllll} 
IGF-I, nmol/L & 0 & 1 & 2.5 & 5 & 10 & 25 & 50 & 100 \\
\hline
\end{tabular}

$36 \mathrm{~h}$

Figure 34. IGF-I-induced down-regulation of the IGF-IR in LMFs. (A) Upper panel: total RNA (10 $\mu \mathrm{g})$ isolated from LMFs incubated in the presence or absence of GH, insulin and IGF-I at concentration of 100 $\mathrm{nmol} / \mathrm{L}$ for 36 hours were separated by $1 \%$ agarose gel electrophoresis, blotted and probed for rat IGF-IR. Lower panel: equal loading of RNA was demonstrated after stripping and rehybridization of membranes with an oligonucleotide complementary to 28S rRNA. The sizes of the hybridization bands (in kb) are indicated on the left. (B) LMFs were incubated in serum-reduced medium in the presence of increasing concentrations of IGF-I $(0,1,2.5,5,10,25,50$ and $100 \mathrm{nmol} / \mathrm{L})$ for 36 hours. Proteins $(25 \mu \mathrm{g})$ extracted from whole cell lysates were size-fractionated by SDS-PAGE and immunoblotted with anti-IGF-IR $\beta$, antiIRS-1 and anti-Gab-1 antibodies. Equal loading of proteins was demonstrated by immunoblotting with an antibody directed against $\beta$-actin. The sizes of proteins are indicated on the left. 
A

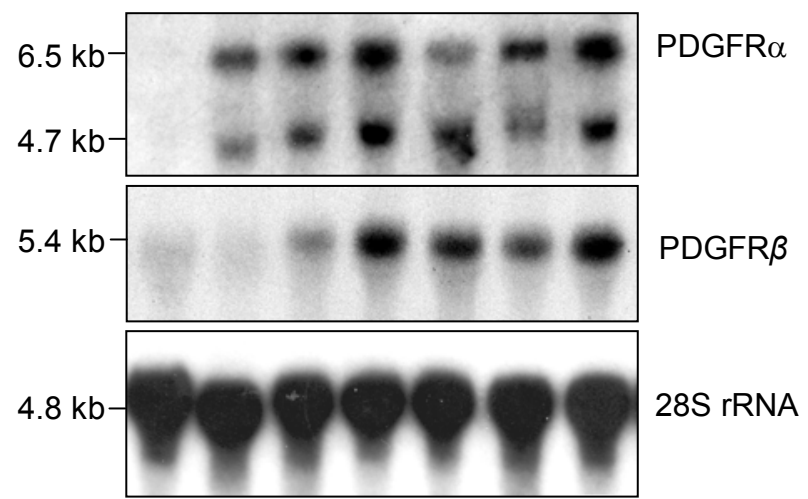

\begin{tabular}{llllll} 
HC KC & P.1 & P.2 & P.3 & P.4 & P.7 \\
\hline
\end{tabular} LMF

B

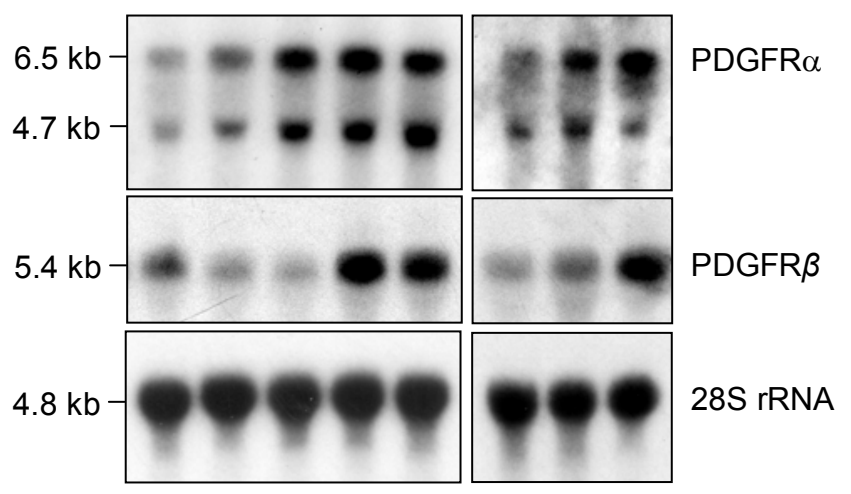

$$
\frac{\mathrm{d} .2 \mathrm{~d} .4 \mathrm{~d} .7 \mathrm{~d} .10 \mathrm{~d} .14}{\text { LMF }} \frac{\mathrm{d} .2 \mathrm{~d} .4 \mathrm{~d} .7}{\mathrm{HSC}}
$$

C

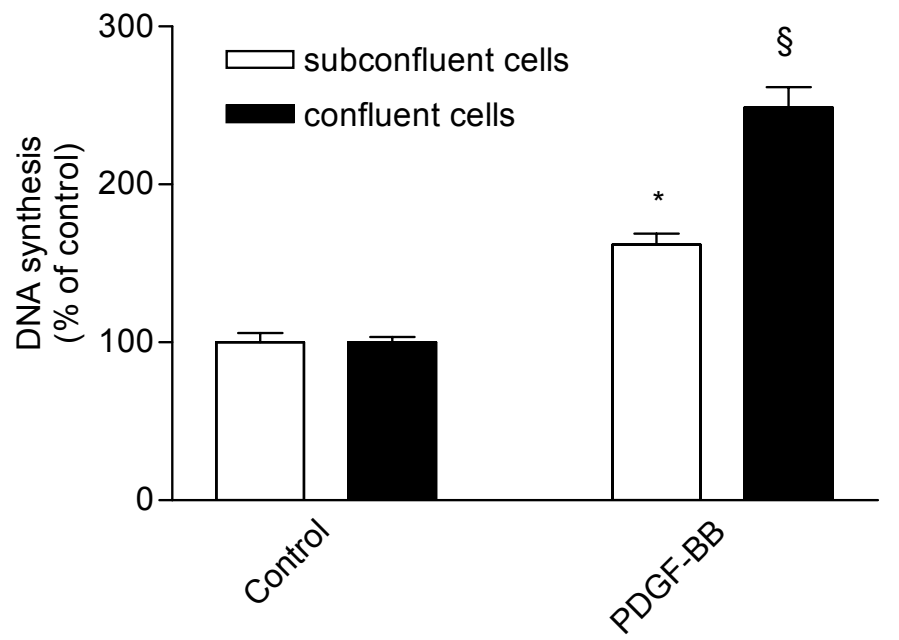

Figure 35. PDGF receptor mRNA expression in LMFs (A, B). Upper panels: $10 \mu \mathrm{g}$ of total RNA obtained from rat LMFs (passages 1-7, P.1-P.7), hepatocytes (HCs), Kupffer cells (KCs) and hepatic stellate cells (HSCs) at different time points of culture as indicated, were separated by $1 \%$ agarose gel electrophoresis, blotted and hybridized with cDNAs specific for rat PDGFR $\alpha$ and PDGFR $\beta$, respectively. Equal loading of RNA was demonstrated after stripping and rehybridization of membranes with an oligonucleotide complementary to $28 \mathrm{~S}$ rRNA. The sizes of the hybridization bands (in $\mathrm{kb}$ ) are indicated on the left. Effect of cell density on mitogenic response to PDGF-BB in rat LMFs (C). After starvation in serum-reduced DMEM for 1 hour, subconfluent (open bars) and confluent (solid bars) cultures of LMFs were incubated in the presence or absence of PDGF-BB (10 ng/mL) for 24 hours. DNA synthesis was evaluated by BrdU incorporation assay. Results are expressed as the percentage of incorporation \pm SEM relative to the untreated control $(n=3)$. Statistically significant difference $(p<0.05$; Student's $t$-test) compared with untreated control cultures $\left(^{*}\right)$ or PDGF-BB treated subconfluent cultures $(\S)$. 


\subsubsection{Effect of IGF-IR Blockade on IGF-I- and PDGF-Stimulated DNA Synthesis}

To test whether a functional IGF-IR is required for mitogenic activity of PDGF in LMFs as it has been demonstrated formerly in mouse embryo fibroblasts (DeAngelis et al., 1995), the effect of tyrphostin I-Ome-AG 538, a selective inhibitor of the IGF-IR kinase, on PDGF-induced mitogenic activity was evaluated in BrdU incorporation assay. Recombinant PDGF-BB stimulated DNA synthesis in LMFs and this effect was similar to that of IGF-I. Coincubation of LMFs with PDGF-BB and IGF-I has demonstrated synergism in their mitogenic effect. Blockade of the IGF-IR kinase with tyrphostin IOme-AG 538 completely abrogated IGF-I- and PDGF-induced mitogenesis in cultures of rat LMFs (Fig. 36). Thus, presence of the IGF-IR appears to be necessary for PDGFinduced mitogenic activity in LMFs.

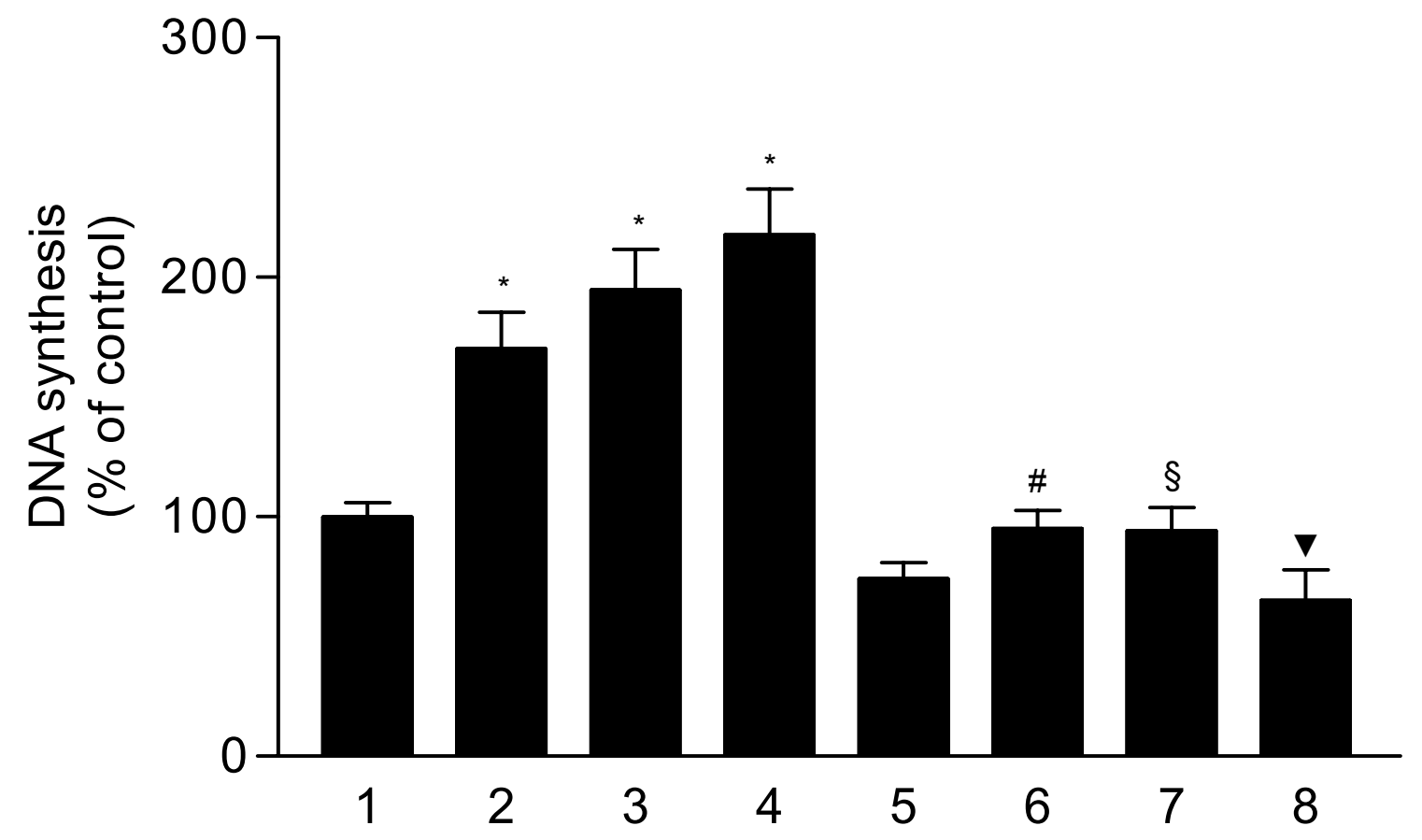

\begin{tabular}{|c|c|c|c|c|c|c|c|c|}
\hline IGF-I, $100 \mathrm{nmol} / \mathrm{L}$ & - & + & - & + & - & + & - & + \\
\hline PDGF-BB, $10 \mathrm{ng} / \mathrm{mL}$ & - & - & + & + & - & - & + & + \\
\hline I-OMe-AG $538,20 \mu \mathrm{mol} / \mathrm{L}$ & - & - & - & - & + & + & + & + \\
\hline
\end{tabular}

Figure 36. Effect of IGF-IR blockade on IGF-I- and PDGF-stimulated DNA synthesis in LMFs. After starvation in serum-reduced DMEM for 1 hour, cells were incubated for 24 hours with IGF-I (100 nmol/l) and/or PDGF-BB $(10 \mathrm{ng} / \mathrm{mL})$ in the presence or absence of tyrphostin I-OMe-AG $538(20 \mu \mathrm{mol} / \mathrm{L})$, a selective inhibitor of the IGF-IR tyrosine kinase. Control cells were incubated for 24 hours with serumreduced DMEM alone. DNA synthesis was evaluated by BrdU incorporation assay. Results are expressed as the percentage of incorporation \pm SEM relative to the control $(n=3)$. Statistically significant difference $\left(p<0.05\right.$; Student's $t$-test) compared with untreated control cultures $\left({ }^{*}\right)$ or IGF-I (\#), PDGF-BB $(\S)$ and IGF-I/PDGF-BB ( $\mathbf{\nabla})$ treated cultures 


\subsubsection{Differential Regulation of IGF-IR and PDGFR mRNA Expression by PDGF and IGF-I}

PDGF-BB and IGF-I had divergent effects on the IGF-IR and PDGFR expression. As demonstrated by Northern blot analysis, recombinant PDGF-BB time-dependently increased the IGF-IR mRNA expression in cultures of LMFs showing maximal effect after 24 hours of treatment (Fig. 37A). These data were also confirmed by Western blot analysis which showed that incubation of LMFs with increasing concentrations of PDGF-BB resulted in a dose-dependent stimulation of the IGF-IR $\beta$ biosynthesis (Fig. 37B).

A

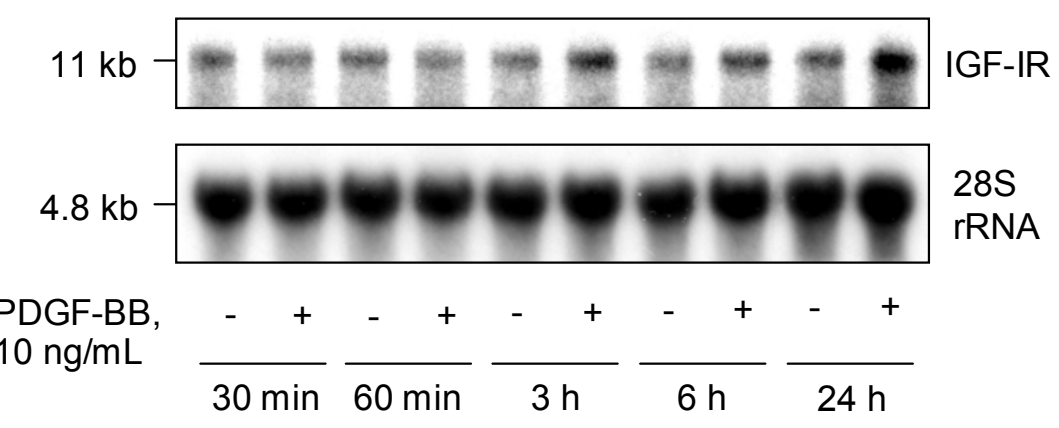

B

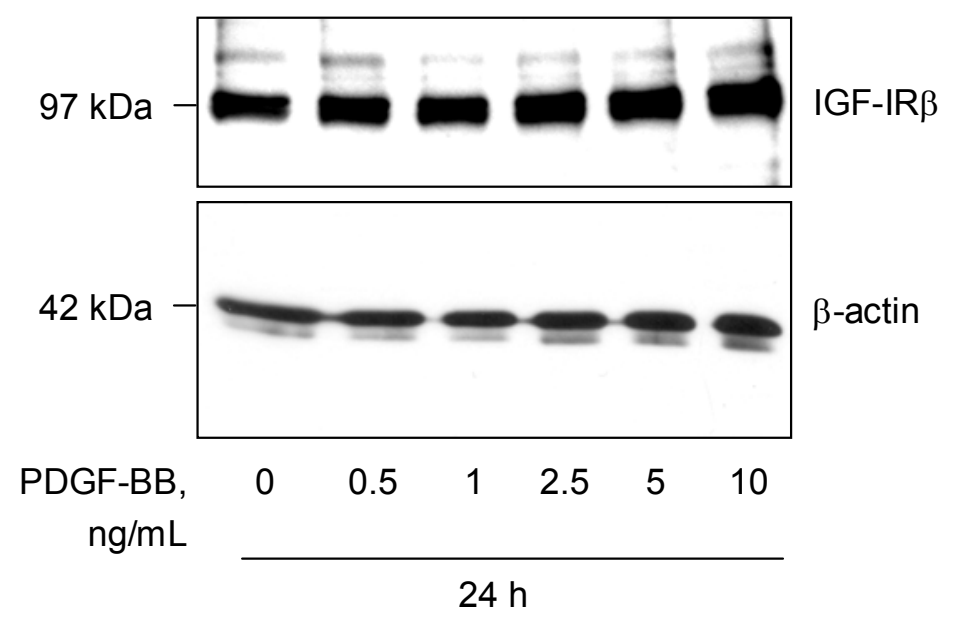

Figure 37. PDGF-induced up-regulation of the IGF-IR expression in LMFs. (A) Upper panel: $10 \mu \mathrm{g}$ of total RNA isolated from LMFs treated with PDGF-BB $(10 \mathrm{ng} / \mathrm{mL})$ for $30 \mathrm{~min}, 60 \mathrm{~min}, 3 \mathrm{~h}, 6 \mathrm{~h}$ and $24 \mathrm{~h}$ were separated by $1 \%$ agarose gel electrophoresis, blotted and probed for rat IGF-IR. Lower panel: equal loading of RNA was demonstrated after stripping and rehybridization of membranes with an oligonucleotide complementary to 28S rRNA. The sizes of the hybridization bands (in kb) are indicated on the left. (B) LMFs were incubated in serum-reduced medium in the presence of increasing concentrations of PDGF-BB $(0,0.5,1,2.5,5$ and $10 \mathrm{ng} / \mathrm{mL})$ for 24 hours. Proteins $(25 \mu \mathrm{g})$ extracted from whole cell lysates were size-fractionated by SDS-PAGE and immunoblotted with anti-IGF-IR $\beta$ antibody. Equal loading of proteins was demonstrated by immunoblotting with an antibody directed against $\beta$-actin. The sizes of proteins are indicated on the left. 
Furthermore, IGF-I-induced down-regulation of the IGF-IR was effectively prevented by addition of recombinant PDGF-BB (Fig. 38A). Remarkably, IGF-I inhibited mRNA expression of PDGFR $\alpha$, which was also partially restored by addition of PDGF-BB (Fig. 38B). However, IGF-I had no effect on the PDGFR $\beta$ gene expression (Fig. 38C). Interestingly, in contrast to the IGF-IR which undergoes ligand-induced down-regulation, gene expression of both PDGFR subunits was not inhibited by their natural ligand (Fig. 38B, 38C).

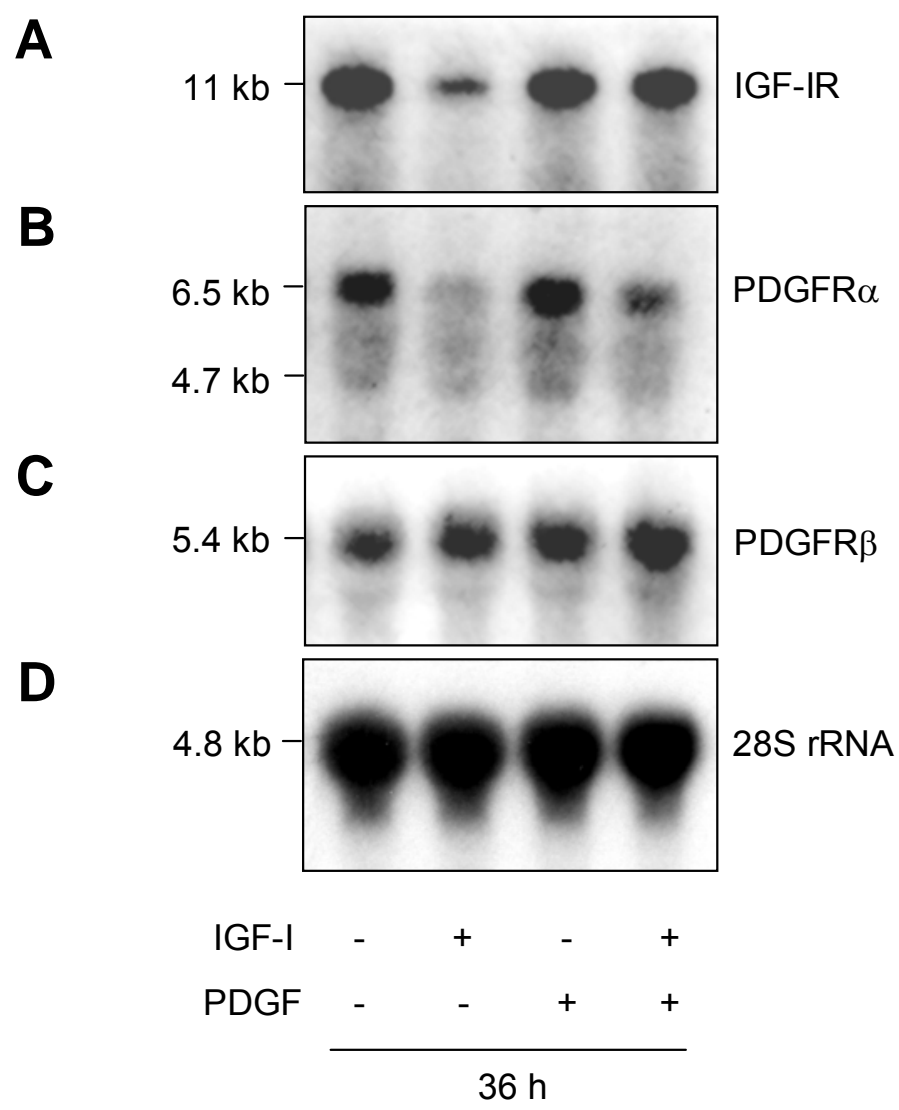

Figure 38. PDGF-induced stabilization of the IGF-IR and PDGFR mRNA expression in LMFs. (A, B, C) $10 \mu \mathrm{g}$ of total RNA isolated from LMFs treated with IGF-I (100 nmol/L) and/or PDGF-BB $(10 \mathrm{ng} / \mathrm{mL})$ for 36 hours were separated by $1 \%$ agarose gel electrophoresis, blotted and probed for rat IGF-IR (A), PDGFR $\alpha$ (B) and PDGFR $\beta$ (C), respectively. (D) Equal loading of RNA was demonstrated after stripping and rehybridization of membranes with an oligonucleotide complementary to $28 \mathrm{~S}$ rRNA. The sizes of the hybridization bands (in kb) are indicated on the left.

\subsubsection{IGF-I- and PDGF-Induced Tyrosine Phosphorylation of IGF-IR, PDGFR, IRS-1 and PLC $\gamma_{1}$}

Since transphosphorylation of heterologous receptors has been known to occur, next we wished to investigate whether the PDGFR and IGF-IR can directly transactivate each other. For this purpose, the IGF-IR, the PDGFR and their principal signalling 
elements, IRS-1 and PLC $\gamma_{1}$, respectively, were precipitated from lysed cells treated with IGF-I or PDGF-BB for 10 min under serum-free conditions.

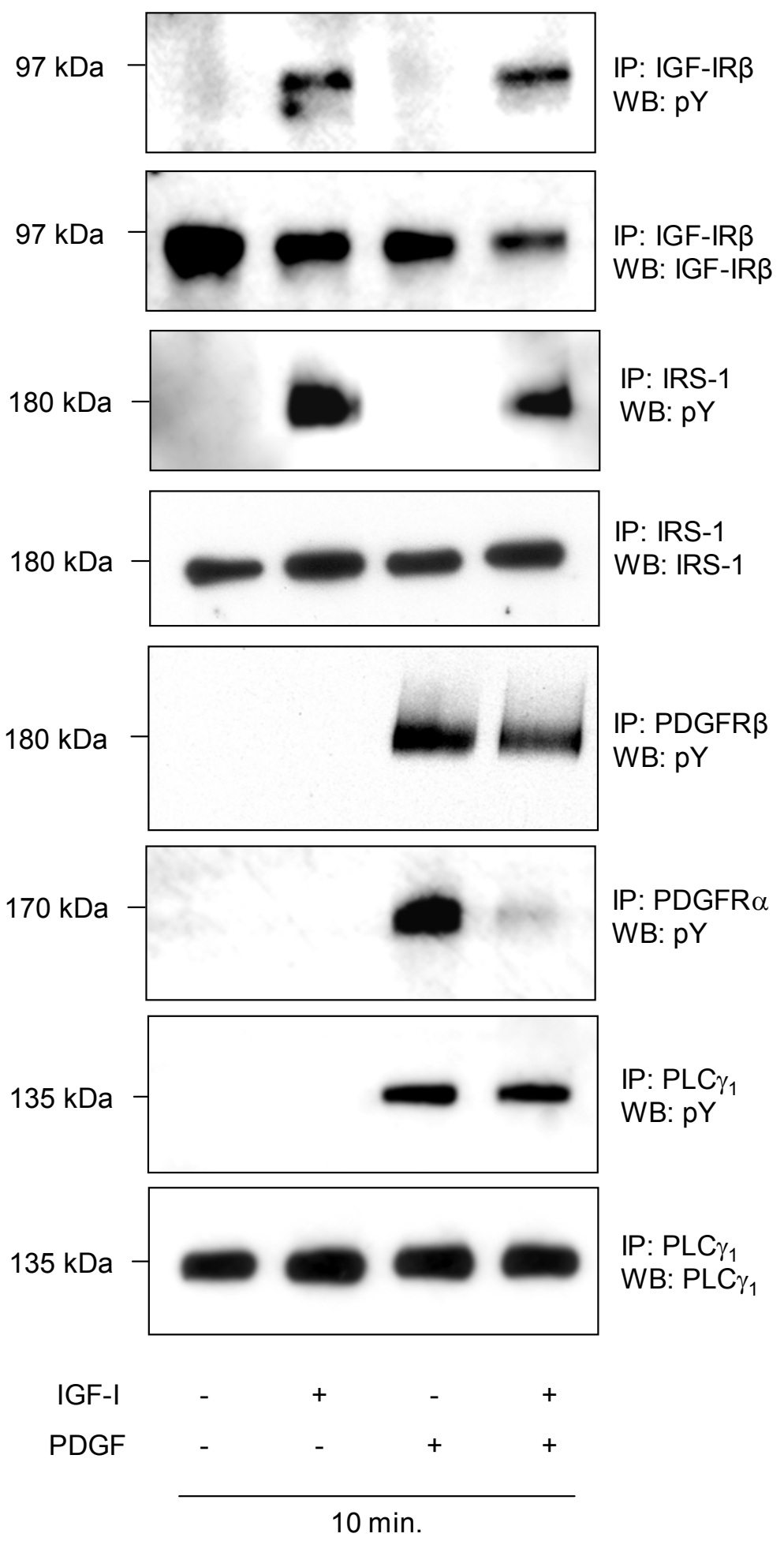

Figure 39. IGF-I- and PDGF-induced tyrosine phosphorylation of the IGF-IR $\beta$ subunit, PDGFR $\alpha$ and $\beta$ subunits, IRS-1 and PLC $\gamma_{1}$ in LMFs. Serum starved cells were stimulated with IGF-I (100 nmol/L) and/or PDGF-BB (10 ng/mL) for 10 minutes and immediately subjected to detergent lysis followed by immunoprecipitation (IP) of IGF-IR $\beta$, PDGFR $\alpha$, PDGFR $\beta$, IRS-1 and PLC $\gamma_{1}$. Subsequently, after SDSPAGE and electroblotting, tyrosine phosphorylation of the precipitated proteins was evaluated by Western blot analysis (WB) with anti-phosphotyrosine antibodies (anti-pY). Equal loading of proteins was ensured by reprobing immunoblots with antibodies used for immunoprecipitation. The sizes of proteins are indicated on the left. 
The activated status of the precipitated proteins was visualized by immunoblotting with an anti-phosphotyrosine antibody. Treatment with IGF-I resulted in the tyrosine phosphorylation of the $\beta$ subunit of the IGF-IR and IRS-1 (Fig. 39). In contrast, PDGFBB induced the tyrosine phosphorylation of both PDGFR subunits and PLC $\gamma_{1}$. Transactivation of IGF-IR by PDGFR and PDGFR by IGF-IR was not observed. In turn, transactivation of IRS-1 by PDGFR and PLC $\gamma_{1}$ by IGF-IR has been excluded as well. When IGF-I and PDGF-BB were applied together to cultured cells, there was no additive tyrosine phosphorylation of the receptors and their major signalling intermediates. Contrariwise, IGF-I inhibited the phosphorylation of the PDGFR, in particular of its $\alpha$ subunit, and the IGF-I-induced tyrosine phosphorylation of IRS-1 was attenuated by addition of PDGF-BB.

\subsubsection{Effect of MAPK Pathway Inhibitors on IGF-I- and PDGF-Stimulated DNA Synthesis}

The mechanism by which the IGF-IR cooperates with the PDGFR during mitogenic response is not understood. It has been suggested that the IGF-IR is probably more effective in inducing cell signalling through the MAPK cascade. To test this hypothesis, the effect of pharmacological inhibitors of MAPK pathway components on PDGF- and IGF-I-induced DNA synthesis has been investigated. For this purpose, LMFs at day 2 of culture were serum-starved for $1 \mathrm{~h}$ and stimulated with IGF-I (10 nmol/L) or PDGF-BB $(10 \mathrm{ng} / \mathrm{mL})$ in the presence or absence of the respective pharmacological inhibitor (10 and $20 \mu \mathrm{mol} / \mathrm{L}$ ) for $24 \mathrm{~h}$. Newly synthesized cellular DNA was labelled by BrdU. As demonstrated by BrdU incorporation assay, an inhibition of MEK by PD98059, p38 kinase by SB203580 and JNK by SP600125 effectively blocked IGF-I-induced mitogenic effect (Fig. 40). Likewise, mitogenic activity of PDGF-BB was abrogated when JNK and p38 kinase were inactivated. In contrast to IGF-I, however, the rate of PDGF-induced DNA synthesis was unaffected when activation of ERK1 and ERK2 was prevented. 
A

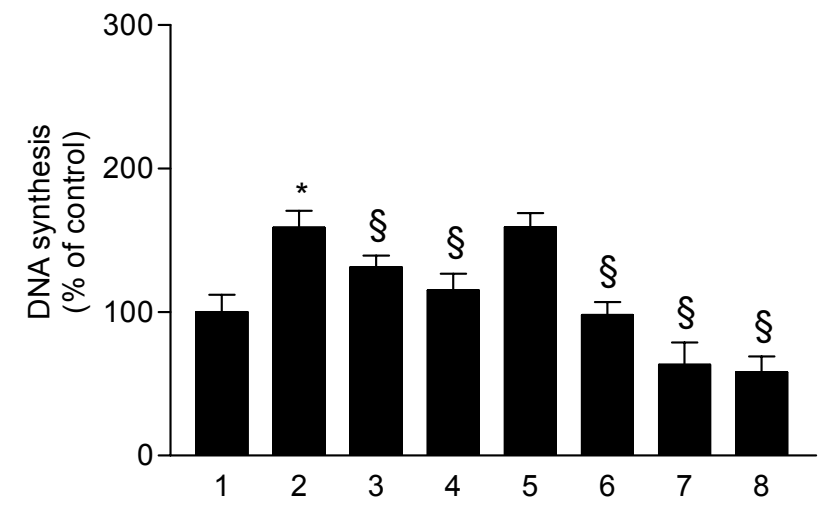

\begin{tabular}{|c|c|c|c|c|c|c|c|c|}
\hline IGF-I, nmol/L & - & 10 & 10 & 10 & 10 & 10 & 10 & 10 \\
\hline PD $98059, \mu \mathrm{mol} / \mathrm{L}$ & - & - & 10 & 20 & - & - & - & - \\
\hline SB $203580, \mu \mathrm{mol} / \mathrm{L}$ & - & - & - & - & 10 & 20 & - & - \\
\hline SP $600125, \mu \mathrm{mol} / \mathrm{L}$ & - & - & - & - & - & - & 10 & 20 \\
\hline
\end{tabular}

B

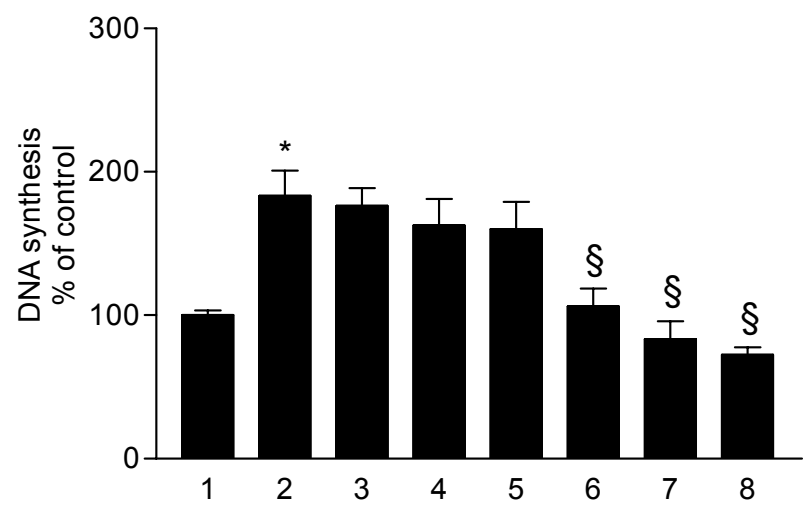

\begin{tabular}{|c|c|c|c|c|c|c|c|c|}
\hline PDGF-BB, $\mathrm{ng} / \mathrm{mL}$ & - & 10 & 10 & 10 & 10 & 10 & 10 & 10 \\
\hline PD $98059, \mu \mathrm{mol} / \mathrm{L}$ & - & - & 10 & 20 & - & - & - & - \\
\hline SB $203580, \mu \mathrm{mol} / \mathrm{L}$ & - & - & - & - & 10 & 20 & - & - \\
\hline SP $600125, \mu \mathrm{mol} / \mathrm{L}$ & - & - & - & - & - & - & 10 & 20 \\
\hline
\end{tabular}

Figure 40. Effect of MAPK pathway inhibitors on IGF-I- and PDGF-stimulated DNA synthesis in LMFs. After starvation in serum-reduced DMEM for 1 hour, cells were treated for 24 hours with IGF-I (100 $\mathrm{nmol} / \mathrm{l})(\mathrm{A})$ or PDGF-BB $(10 \mathrm{ng} / \mathrm{mL})(B)$ in the presence or absence of the MEK inhibitor PD98059, the p38 kinase inhibitor SB203580 and the JNK inhibitor SP600125 at concentrations of 10 and $20 \mu \mathrm{mol} / \mathrm{L}$. Control cells were incubated for 24 hours with serum-reduced DMEM alone. DNA synthesis was evaluated by BrdU incorporation assay. Results are expressed as the percentage of incorporation \pm SEM relative to the control $(n=3)$. Statistically significant difference $(p<0.05$; Student's $t$-test) compared with untreated control cultures $\left({ }^{*}\right)$ or growth factor $(\S)$ treated cultures. 


\subsubsection{Effect of IGF-I and PDGF on MAPK Activation}

To investigate whether IGF-I is more effective than PDGF in activating terminal MAP kinases, proteins extracted from LMFs treated with IGF-I and PDGF-BB for 10 min under serum-free conditions were further subjected to Western blot analysis with antibodies raised against dually phosphorylated forms of ERK1/2, JNK and p38 kinase. Although all terminal MAP kinases were phosphorylated in response to both growth factors, PDGF-BB was definitely more effective in activating MAP kinases than IGF-I (Fig. 41). Moreover, when both growth factors were simultaneously added to cells, IGF-I did not have an additive effect on MAP kinases activation. Cells simultaneously treated with IGF-I and PDGF-BB and cells treated with PDGF-BB alone had the same level of MAP kinases phosphorylation.

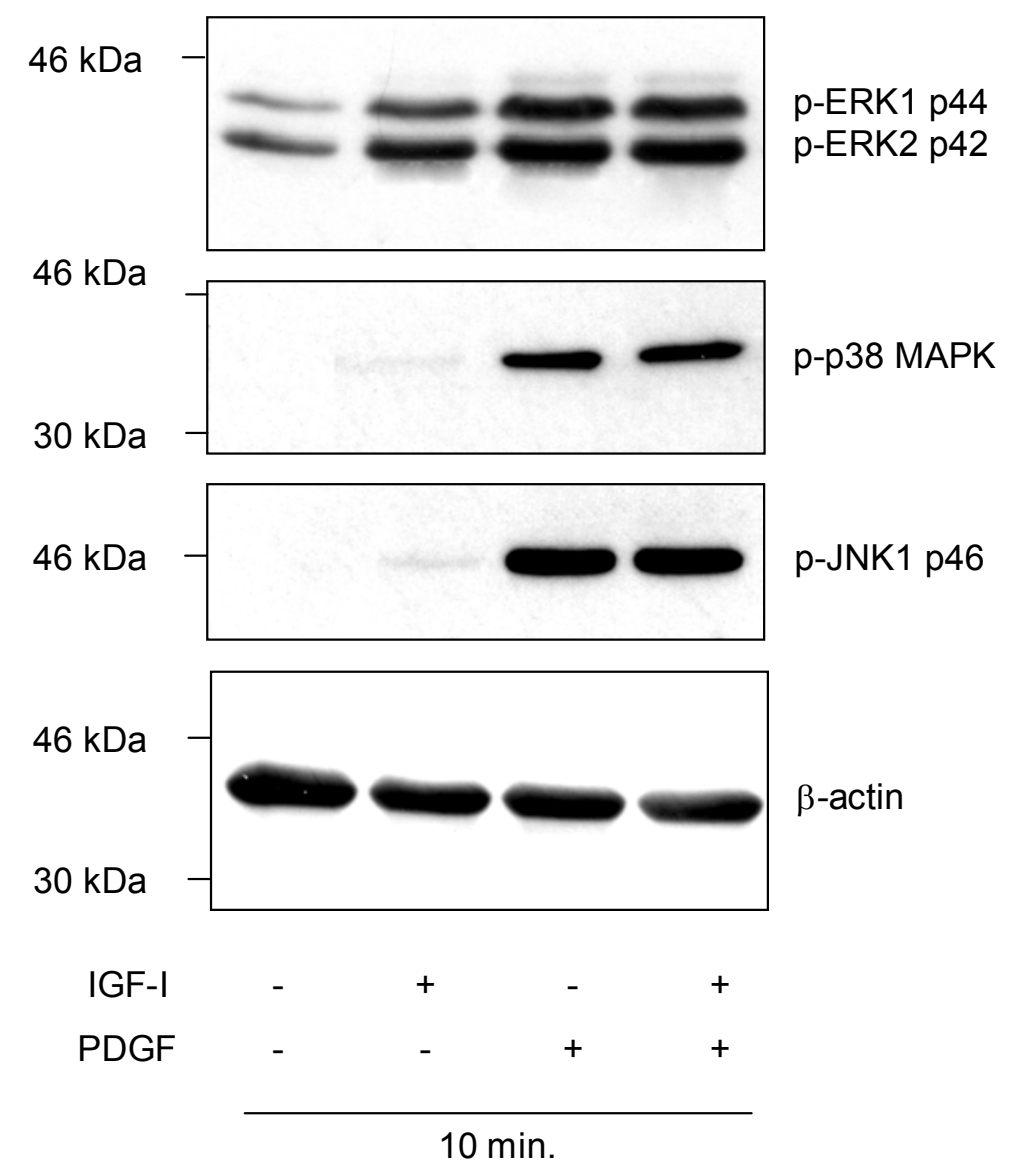

Figure 41. Effect of IGF-I and PDGF-BB on MAPK activation in LMFs. Serum starved cells were stimulated with IGF-I (100 nmol/L) and/or PDGF-BB (10 ng/mL) for 10 minutes and immediately subjected to detergent lysis. Proteins $(50 \mu \mathrm{g})$ extracted from whole cell lysates were size-fractionated by SDSPAGE and immunoblotted with antibodies raised against dually phosphorylated forms of ERK1/2, JNK and p38 kinase. Equal loading of proteins was demonstrated by immunoblotting with an antibody directed against $\beta$-actin. The positions of the molecular weight standards are indicated on the left. 


\subsubsection{Effect of PLC Inhibitor and Activator on DNA Synthesis}

Since it has previously been shown that phospholipase $C$ is required for amplification of cell signalling through the MAPK cascade, the role of PLC in PDGF- and IGF-I-induced mitogenesis in rat LMFs was investigated as well. Growth-arrested LMFs at day 2 of culture were treated with either IGF-I $(10 \mathrm{nmol} / \mathrm{L})$ or PDGF-BB $(10 \mathrm{ng} / \mathrm{mL})$ in the presence or absence of the specific PLC inhibitor U73122 (2.5 and $5 \mu \mathrm{mol} / \mathrm{L})$ for $24 \mathrm{~h}$. In parallel, cells were also treated with the specific PLC activator $\mathrm{m}-3 \mathrm{M} 3 \mathrm{FBS}(1 \mathrm{nmol} / \mathrm{L})$. As demonstrated by BrdU incorporation assay (Fig. 42), DNA synthesis of LMFs induced by both PDGF-BB and IGF-I was severely blunted in the presence of U73122. In contrast, m-3M3FBS could mimic the mitogenic effect induced by growth factors.

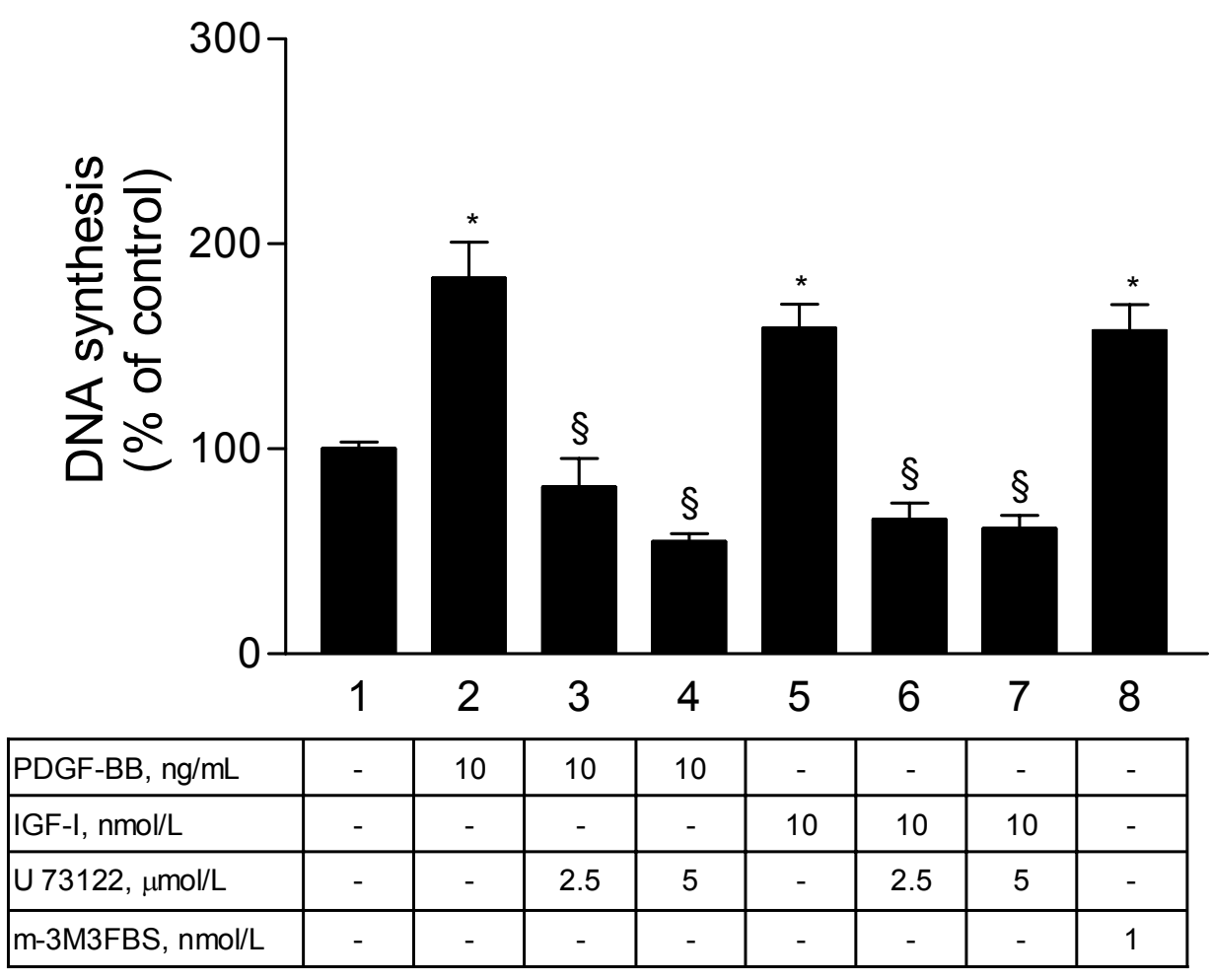

Figure 42. Effect of phospholipase C (PLC) inhibitor and activator on DNA synthesis in LMFs. After starvation in serum-reduced DMEM for 1 hour, cells were treated for 24 hours with IGF-I (100 nmol/l) or PDGF-BB $(10 \mathrm{ng} / \mathrm{mL})$ in the presence or absence of the specific PLC inhibitor U73122 (2.5 and $5 \mu \mathrm{mol} / \mathrm{L})$. Alternatively, cells were also treated with the specific PLC activator m-3M3FBS (1 nmol/L). Control cells were incubated for 24 hours with serum-reduced DMEM alone. DNA synthesis was evaluated by BrdU incorporation assay. Results are expressed as the percentage of incorporation \pm SEM relative to the control $(n=3)$. Statistically significant difference $(p<0.05$; Student's $t$-test) compared with untreated control cultures $\left(^{*}\right)$ or growth factor $(\S)$ treated cultures.

\subsubsection{Effect of IGF-IR Blockade on Tyrosine Phosphorylation of PLC $\gamma_{1}$}

It has been demonstrated in previous experiments (see section 4.3.6) that PLC $\gamma_{1}$, which appears to have an essential role for mitogenesis and cellular proliferation in LMFs (see section 4.3.9), is activated only in response to PDGF-BB but not to IGF-I. To investigate 
whether functional IGF-IR is required for full activation of PLC $\gamma_{1}$, subconfluent LMFs were growth-arrested in serum-free medium for $1 \mathrm{~h}$, pretreated with the selective inhibitor of the IGF-IR kinase I-OMe-AG 538 (20 $\mu \mathrm{mol} / \mathrm{L})$ for $10 \mathrm{~min}$, and stimulated with PDGF-BB (10 ng/mL) and/or IGF-I (100 nmol/L) for $10 \mathrm{~min}$. Consequently, PLC $\gamma_{1}$ was imunoprecipitated from whole cell lysates, subjected to SDS-PAGE, and, finally, the phosphorylated form of PLC $\gamma_{1}$ was visualized by immunoblotting with an antiphosphotyrosine antibody. In agreement with previous data, treatment of cells with IGF-I alone did not lead to the tyrosine phosphorylation of PLC $\gamma_{1}$ (Fig. 43). PDGF-BB effectively induced activation of PLC $\gamma_{1}$. However, blockade of the IGF-IR by a selective inhibitor was accompanied by a decreased activation of PLC $\gamma_{1}$ in cells treated with PDGF-BB. Interestingly, high concentrations of IGF-I also inhibited the phosphorylation of PLC $\gamma_{1}$ on tyrosine residues, most likely due to IGF-I-induced inhibition of the PDGFR $\alpha$ phosphorylation. Moreover, this inhibitory effect of IGF-I was additive to that of I-OMe-AG 538.

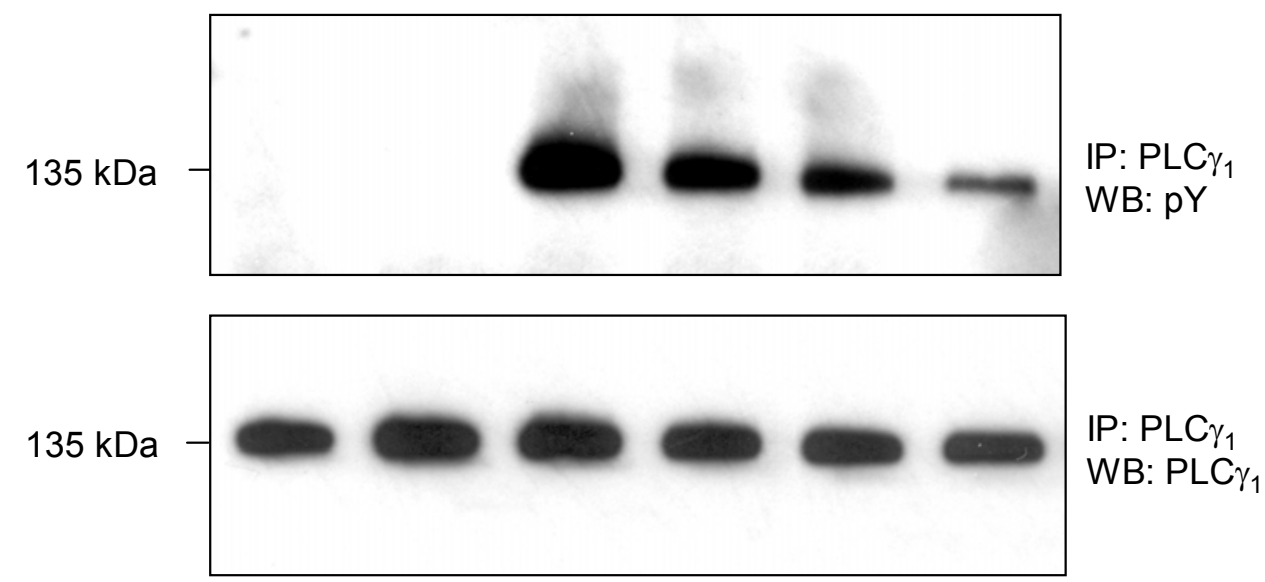

IGF-I

PDGF-BB

I-Ome-AG 538

\begin{tabular}{rrrrrr}
- & + & - & + & - & + \\
- & - & + & + & + & + \\
- & - & - & - & + & + \\
\hline
\end{tabular}

$10 \min$.

Figure 43. Effect of IGF-IR blockade on tyrosine phosphorylation of PLC $\gamma_{1}$ in LMFs. Subconfluent cultures of LMFs were growth-arrested in serum-free DMEM for $1 \mathrm{~h}$, pretreated with the selective inhibitor of the IGF-IR kinase I-OMe-AG $538(20 \mu \mathrm{mol} / \mathrm{L})$ for $10 \mathrm{~min}$, and stimulated with PDGF-BB $(10 \mathrm{ng} / \mathrm{mL})$ and/or IGF-I $(100 \mathrm{nmol} / \mathrm{L})$ for $10 \mathrm{~min}$. After treatment, cells were immediately subjected to detergent lysis followed by immunoprecipitation (IP) of PLC $\gamma_{1}$, SDS-PAGE and electroblotting. Tyrosine phosphorylation of PLC $\gamma_{1}$ was evaluated by Western blot analysis (WB) with anti-phosphotyrosine antibodies (anti-pY). Equal loading of protein was ensured by reprobing immunoblots with anti-PLC $\gamma_{1}$ antibody. The size of PLC $\gamma_{1}$ is indicated on the left. 


\subsubsection{Split Effect of PDGF on IGF-IR Signalling System}

Western blot analysis revealed divergent effects of PDGF-BB on the IGF-IR signalling system. PDGF-BB increased amount of the IGF-IR $\beta$ subunits in a concentrationdependent manner, whereas the biosynthesis of certain IRS proteins, in particular IRS1, IRS-2 and Gab-1, was dose-dependently inhibited (Fig. 44). This inhibitory effect appears to be specific because synthesis of PLC $\gamma_{1}$ was unaffected by increasing concentrations of PDGF-BB.

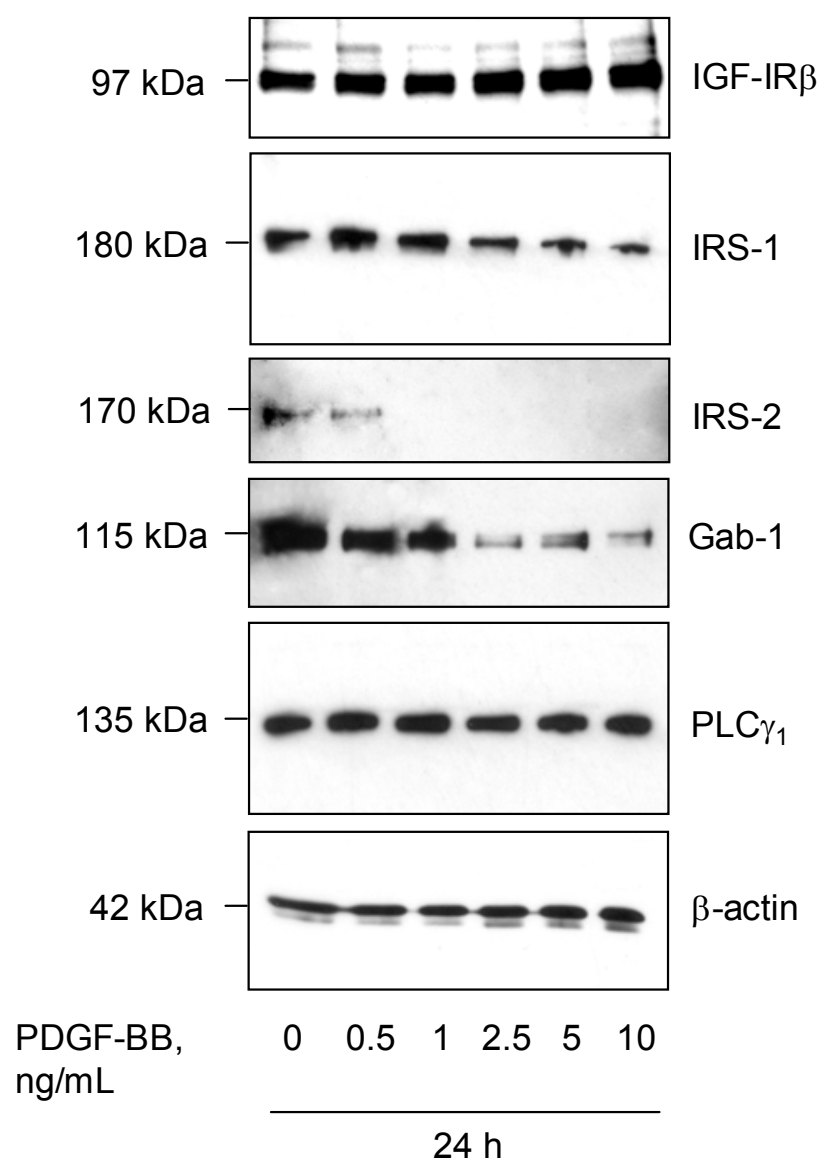

Figure 44. Effect of PDGF-BB on synthesis of components of the IGF-IR signalling system in LMFs. Cells were incubated in serum-reduced medium in the presence of increasing concentrations of PDGF-BB (0, $0.5,1,2.5,5$ and $10 \mathrm{ng} / \mathrm{mL})$ for 24 hours. Proteins $(25 \mu \mathrm{g})$ extracted from whole cell lysates were sizefractionated by SDS-PAGE and immunoblotted with anti-IGF-IR $\beta$, anti-IRS-1, anti-IRS-2, anti-Gab-1 and anti-PLC $\gamma_{1}$ antibodies. Equal loading of proteins was demonstrated by immunoblotting with an antibody directed against $\beta$-actin. The sizes of proteins are indicated on the left. 


\section{Discussion}

\subsection{IGF Axis in Liver Myofibroblasts}

Apart from HSC, (myo)fibroblasts located in periportal and pericentral areas within the liver have been identified as a second cell population involved in hepatic fibrogenesis (Knittel et al., 1999a; 1999b; Cassiman et al., 2002). During acute and chronic liver injury, proliferation of resident (myo)fibroblasts is believed to be stimulated by mitogens released from hepatocytes due to membrane damage and by cytokines and growth factors secreted at the site of necrosis by activated KCs/macrophages, SECs, HSCs, platelets and lymphocytes. Among other cytokines and growth factors, IGF-I might be a relevant mitogen for rat LMFs as it has been demonstrated for rat HSCs (Scharf et al., 1998; Skrtic et al., 1997; 1999a; 1999b, Issa et al., 2001). Therefore, the purpose of the present work was to study the expression of individual components of the IGF axis in rat LMFs. LMFs from different passages revealed a constitutive gene expression of IGF-I, the IGF-IR and IGF-II/M6-PR. IGF-I and to a lesser extent insulin induced DNA synthesis in LMFs while GH at high concentrations had only a moderate effect. In addition, gene expression and synthesis of type I collagen, one of the most abundant components of fibrotic matrix in cirrhotic liver (Ramadori et al., 1998), were stimulated by IGF-I as well. These data point to the IGF axis as a relevant system which might be involved in regulation of proliferation of LMFs and ECM production during liver injury. Indeed, several studies have proved the production of IGF-I in liver cell populations neighbouring LMFs, i.e. in hepatocytes (Scott et al., 1985; Kachra et al., 1991), KCs and SECs (Zindy et al., 1992; Scharf et al., 1998), HSCs (Pinzani et al., 1990; Scharf et al., 1998), platelets (Karey et al., 1989a; 1989b) and lymphocytes (Nyman and Pekonen, 1993). In line with previous reports demonstrating the IGF production by myofibroblasts adjacent to parenchymal cells in different organs (Pfeilschifter, 1994; Miller et al., 1998; Simmons et al., 1999) in the present study a constitutive IGF-I mRNA expression has been detected in LMFs that was unaffected in vitro during cultivation of cells and by repeated passaging.

So far, knowledge on the expression and function of IGF receptors in different liver cell populations is incomplete. The data of the present study demonstrate that LMFs had steady levels of transcripts encoding the IGF-IR and the IGF-II/M6-PR, which were not dependent on time of culture and cell passages. This finding extends previous studies demonstrating the presence of the IGF-IR in nonparenchymal cells such as KCs, SECs 
and HSCs (Zindy et al., 1992; Brenzel and Gressner, 1996; Scharf et al., 1997; 1998; Zimmermann et al., 2000) whereas hepatocytes, the major source of serum IGF-I, are lacking the IGF-IR (Caro et al., 1988; Hartmann et al., 1990; Scharf et al., 2000). Therefore, nonparenchymal liver cells are supposed to be susceptible for the mitogenic effects of the IGFs through the presence of the IGF-IR, whereas hepatocytes do not appear to be a major target for the actions of IGF-I. In contrast to the IGF-IR, expression of the IGF-II/M6-PR has been demonstrated in both hepatocytes and nonparenchymal liver cells including LMFs (Zindy et al., 1992; Schmitz et al., 1995; Scharf et al., 1997; 1998; Waguri et al., 2001). One of the major functions of the IGF-II/M6-PR is the regulation of extracellular levels of IGFs by mediating endocytosis and delivery of these growth factors to lysosomes for final degradation. Both hepatocytes and nonparenchymal liver cells do not only produce IGF-I, but also take up and degrade IGFs in the liver, thus providing an equilibrium of these growth factors under physiological conditions. The possible involvement of an IGF-independent action of the IGF-II/M6-PR during fibrogenesis has also to be considered because the IGF-II/M6-PR is involved in the activation of TGF- $\beta$, a strong profibrogenic cytokine (Braulke, 1999). Moreover, the data of the present study demonstrate that a soluble form of the IGFII/M6-PR, a bioactive molecule that also capable to bind and sequester IGF-II, is abundantly produced by hepatocytes and LMFs, the cell populations with highest levels of the IGF-II/M6-PR mRNA expression in the liver. Interestingly, in LMFs synthesis of the IGF-II/M6-PR and release of its soluble form appear to be stimulated by IGF-II and TGF- $\beta$, the principal ligands of the receptor. That might imply the existence of an important autoregulatory loop in LMFs, which is capable to neutralize excessive amounts of extracellular IGF-II and cease further undesirable activation of TGF- $\beta$.

The amount of local IGFs is modulated by the presence of six high affinity IGF binding proteins (IGFBPs) that do not only regulate the bioavailability of IGFs but also inhibit or enhance their action on target tissues. The production of IGFBPs by different cells of the fibroblast lineage has already been reported. Human dermal fibroblasts and fetal rat lung fibroblasts express IGFBP-3 and IGFBP-4 (Conover et al., 1994; Price et al., 2002), whereas human intestinal fibroblasts also produce IGFBP-5 (Simmons et al., 2002). In rat liver, biosynthesis of IGFBPs has been attributed to different cell populations. IGFBP-3 gene expression was observed in nonparenchymal liver cell populations (Takenaka et al., 1991; Villafuerte et al., 1994) including KCs, SECs (Villafuerte et al., 1994; Scharf et al., 1995a; 1996a; Zimmermann et al., 2000) and 
HSCs (Scharf et al., 1998). In the current work it has been found out that LMFs secrete IGFBP-3 and IGFBP-2. These results were also confirmed by Northern blot analysis, which revealed transcripts encoding IGFBP-3 and IGFBP-2 in LMFs as well. Thus, the data obtained strengthen the concept of anatomical compartmentalization of IGFBP biosynthesis in rat liver with hepatocytes as source of IGFBP-1 and nonparenchymal liver cells as source of IGFBP-3 (Scharf et al., 2001). Interestingly, temporal expression of IGFBP-3 was different in LMFs and HSCs during their cultivation in vitro. With time of culture, the gene expression of IGFBP-3, a negative growth regulator and proapoptotic factor for most cell types (Jones and Clemmons, 1995; Butt and Williams, 2001; Firth and Baxter, 2002), decreased in LMFs and increased in HSCs, in parallel with their in vitro transformation, which is accompanied by spontaneous apoptosis (Saile et al., 1997). In contrast, the gene expression of IGFBP-2 (Wolf et al., 2000), which has growth-promoting activity in certain cell types, was up-regulated during cultivation of LMFs. Of note, in contrast to LMFs, HSCs do not produce IGFBP-2, but IGFBP-4 (Scharf et al., 1998), a binding protein that has an IGF-dependent mitoinhibitory activity in virtually all cell types (Jones and Clemmons, 1995). Taken together, these data further support previous observations that LMFs and HSCs are distinct liver cell populations, and point to the IGFBPs as possible important regulators of cell growth and apoptosis in these cell populations.

It is noteworthy that in LMFs IGF-I had mitogenic effect, whereas long-R ${ }^{3}-I G F-I$, an IGFI analogue that has high affinity for the IGF receptors but poorly binds to IGFBPs, failed to induce DNA synthesis. That implies that mitogenic activity of IGF-I in LMFs requires cooperation with endogenous IGFBPs. In line with these data, in the present work it has also been found out that in LMFs simultaneous addition of IGF-I and equimolar or excessive amounts of recombinant IGFBP-3 or -2 resulted in an inhibition of BrdU incorporation, whereas preincubation of cells with IGFBP-3 or -2 prior to the addition of IGF-I (at the IGFBP/IGF-I molar ratio of 1:2) substantially potentiated DNA synthesis induced by IGF-I. It is well known that under different physiological conditions, IGFBPs can either enhance or attenuate biological effects of the IGFs. This complexity, however, is incompletely understood. Inhibition of IGF-I activity as observed after simultaneous addition of IGF-I with the IGFBPs most likely results from sequestration of the peptide thus preventing the activation of the IGF-IR. In contrast, the potentiation of mitogenic activity of IGF-I after preincubation of cells with IGFBP-3 might be explained by binding of IGFBP-3 to ECM or cell membranes thus causing slow and steady release 
of IGF-I and facilitating optimal stimulation of the IGF-IR. In line with the data obtained, in fibroblast cultures it has been demonstrated that simultaneous incubation of IGFBP-3 with IGF-I inhibited the mitogenic effect of IGF-I, whereas preincubation of cells with recombinant IGFBP-3 prior to the addition of IGF-I potentiated IGF-I action. It has been found out that these opposing effects were attributed to the soluble and membranebound forms of IGFBP-3. Soluble IGFBP-3 inhibited the mitogenic effect of IGF-I by forming inactive complexes with IGF-I, which in turn block IGF-I/IGF-IR interaction (De Mellow and Baxter, 1988), whereas membrane-bound IGFBP-3 had a 10-fold lower affinity for IGF-I resulting in enhanced local IGF-I bioavailability and mitogenic activity (Conover, 1992).

Likewise, IGFBP-2 has also been reported to exert dual effects on cell proliferation, which were cell type dependent. In most studies, IGFBP-2 has been shown to inhibit IGFs actions (Jones and Clemmons, 1995; Wolf et al., 2000). For instance, increased expression of IGFBP-2, IGF-II and the IGF-II/M6-PR in rat lung alveolar epithelial cells was associated with cell proliferation arrest (Cazals et al., 1994; Mouhieddine et al., 1994). However, numerous studies found a positive correlation between IGFBP-2 expression and cell proliferation, particularly in tumor-derived cell lines (Wolf et al., 2000). IGFBP-2 exerted modest inhibitory effects on growth of normal prostate epithelial cells, whereas pronounced stimulatory activity on cell proliferation was observed in prostate cancer cells (Moore et al., 2003). Similarly, IGFBP-2 also promoted malignant transformation of $\mathrm{Y} 1$ mouse adrenocortical cells through unknown IGF-independent mechanisms (Fottner et al., 2004). The mechanism of growth-promoting activity of IGFBP-2 remains poorly understood. It is well known, however, that IGFBP-2 is capable to bind to $\alpha_{5} \beta_{1}$-integrin through its $R G D$ sequence and affect classical integrin intracellular signalling (Firth and Baxter, 2002). In this regard it is important to note that ligand occupancy of integrins is also necessary for full activation of the IGF-IR and its principal docking molecule, IRS-1, by IGF-I (Zheng et al., 1998; Maile et al., 2001). Therefore, the possibility of potentiation of IGF-mediated effects by IGFBP-2 through the integrin signalling should be definitely in the focus of further investigation.

Moreover, there is accumulating evidence that IGFBP-3 has intrinsic mitoinhibitory and proapoptotic activity that is independent from IGFs, and some of these antiproliferative effects appear to require nuclear translocation of IGFBP-3. The IGFBP-3 molecule contains classical nuclear localization signals (NLS) and is translocated to the nucleus via importin- $\beta$-mediated pathway where it binds to retinoid $X$ receptor $\alpha(R X R \alpha)$ (Butt et 
al., 1999; Liu et al., 2000). This binding appears to be important for direct proapoptotic activity of IGFBP-3 because IGFBP-3-induced apoptosis was abolished in cells with a targeted disruption of the $R X R \alpha$ gene. It has been established recently that mitosis of the cell is associated with binding of RXR to the nuclear orphan receptor nur77 (Li et al., 2000). In response to IGFBP-3, however, nur77 is released from this complex and translocated to the cytoplasm, where it targets mitochondria with subsequent release of cytochrome c, activation of caspase cascade and induction of apoptosis (Li et al., 2000; Cohen et al., 2002). In the present work BrdU incorporation assay revealed mitoinhibitory activity of exogenous IGFBP-3 in LMFs. This antiproliferative activity of IGFBP-3 was not related to sequestration of endogenous IGF-I and therefore was IGF-Iindependent because treatment of cells with IGF-I-neutralizing antibodies did not affect DNA synthesis. Moreover, [ $\left.{ }^{125} \mathrm{I}\right]-\mathrm{IGF}-\mathrm{I}$ ligand blotting data demonstrate that in LMFs a relatively high amount of secreted IGFBP-3 undergoes re-uptake by cells under physiological conditions. Subsequently, IGFBP-3 is translocated to the nucleus where it presumably acts as an internal negative regulator of growth and proliferation of LMFs.

Humoral regulation of IGFBP production is complex and depends on cell type. In rat KCs insulin and IGF-I did not affect secretion of IGFBPs. In contrast, in cultures of rat hepatocytes IGFBP-1 and IGFBP-2 synthesis was inhibited by insulin and IGF-I, whereas IGFBP-4 secretion was inversely affected (Scharf et al., 1996a). In turn, data of the present study demonstrate that insulin and IGF-I stimulate IGFBP-3 and IGFBP-2 secretion in rat LMFs in a concentration- and time-dependent manner. In general, the regulation of IGFBP-3 abundance occurs at either transcriptional or posttranslational level and appears to be cell type specific. In human HSCs and dermal fibroblasts IGF-I stimulated release of IGFBP-3 at posttranslational level, by binding and subsequent release of cell-associated IGFBP-3 (Martin et al., 1992; Gentilini et al., 1998). In contrast, in the current study it has been found out that biosynthesis of IGFBP-3 in LMFs was regulated by IGF-I via induction of IGFBP-3 gene expression, and IGFBP-3 mRNA levels positively correlated with the amount of secreted protein. Interestingly, PDGF, an important mitogenic factor for cells of mesenchymal origin, inhibited secretion of IGFBP-3, whereas TGF- $\beta$, whose mitoinhibitory activity has been described in a variety of cells, stimulated release of IGFBP-3 in LMFs. Therefore, it is reasonable to suggest that opposing effects of PDGF and TGF- $\beta$ on cell proliferation may also be related, at least in part, to the regulation of IGFBP-3 secretion. In this context, it is important to note that in human breast cancer cells IGFBP-3 has been identified as a 
major antiproliferative factor and a key element in TGF- $\beta$-induced growth inhibition (Oh et al., 1995; Rajah et al., 1997).

Since it has been demonstrated that specific proteases are important regulators of IGFBP levels, proteolytical activity of CM from LMFs was analyzed in a cell-free IGFBP protease assay. When CM from LMFs were tested for protease activity at neutral $\mathrm{pH}$, no fragmentation of recombinant IGFBPs was observed. At acidic pH, IGFBP-3, but not IGFBP-2, was fragmented in the presence of CM from LMFs. Although these results are in agreement with other studies demonstrating acid-activated IGFBP proteolysis in CM from a variety of cell types and tissue extracts, their physiological significance remains unclear. Many acid-activated IGFBP proteases belong to the family of cathepsins, which are secreted as inactive precursors, and are activated at low $\mathrm{pH}$. It can be speculated that an extracellular acidic microenvironment may exist at sites of inflammation or necrosis during an ongoing liver injury resulting in an activation of cathepsin precursor forms. Alternatively, the proteolytical activity of CM from LMFs might also reflect the ability of acidic proteases localized on the cell surface and/or in intracellular organells, e.g. in endosomal recycling compartment and lysosomes, to cleave IGFBP-3. It is noteworthy that LMFs do not produce proteases against IGFBP-2, which substantially potentiates mitogenic effects induced by IGF-I, though they secrete proteases that induce degradation of IGFBP-3, which has IGF-I-independent mitoinhibitory activity. Therefore, production of IGFBP-3 proteases may represent an important mechanism facilitating proliferation of LMFs during liver injury.

LMFs have recently been found morphologically and functionally distinct from HSCs and have been identified as a second liver cell population involved in the production and deposition of altered ECM during hepatic fibrogenesis (Knittel et al., 1999a; 1999b; Cassiman et al., 2002). The different expression of the IGF axis components in HSCs and LMFs as demonstrated in the present work further support the concept of distinct liver cell populations with fibrogenic potential. LMFs had constitutive expression of IGF-I and the IGF receptors that was unaffected during cultivation of cells and after repeated cell passages. In contrast, expression pattern of the IGF axis components in HSCs was altered during their in vitro transformation from the quiescent to the myofibroblast-like phenotype. Quiescent HSCs expressed high levels of the IGF-IR, which were downregulated during their transformation to myofibroblast-like cells both in vitro and in vivo (Brenzel and Gressner, 1996; Scharf et al., 1998). On the other hand, expression of IGF-I and the IGF-II/M6-PR was low in quiescent HSCs and increased severalfold 
during their transformation (De Bleser et al., 1995; Scharf et al., 1998; Weiner et al., 1998). Consequently, due to high expression of the IGF-IR, mitogenic activity in quiescent HSCs was strongly induced by exogeneous IGF-I, whereas myofibroblast-like HSCs were refractory to the mitogenic effects of IGF-I (Scharf et al., 1998). These data point to a putative role of IGF-I for the activation of HSCs during initial phases of acute liver injury. In contrast to HSCs, due to the stable expression of the IGF-IR, LMFs remain sensitive to biological effects of IGF-I during an ongoing liver injury.

Moreover, LMFs and HSCs had different IGFBP profiles. LMFs produced IGFBP-3 and 2, whereas HSCs expressed IGFBP-3 and -4. The temporal IGFBP expression was also different. Expression of IGFBP-3, which possesses intrinsic mitoinhibitory activity in LMFs, decreased, whereas that of IGFBP-2, which is capable to enhance growthpromoting effects of IGF-I, increased during cultivation of LMFs. In contrast, in HSCs expression of both IGFBP-3 and IGFBP-4, which in most cases inhibit mitogenic activity of IGF-I, was up-regulated severalfold during their in vitro transformation.

Taken together, these findings highlight the significance of the IGF axis for the proliferative activity of LMFs during chronic liver injury. This view is in accordance with recent reports demonstrating different life spans and regulation of cell cycle in rat HSCs and LMFs (Saile et al., 2002; 2004). The current data are also supported by a study of Knittel et al. (1999a), who has shown in vivo an exclusive accumulation of HSCs within damaged liver tissue during acute liver injury, whereas in chronically injured livers both HSCs and LMFs were involved in fibrogenesis.

In summary, this part of the work demonstrates that in vitro IGF-I possesses mitogenic and fibrogenic activity in LMFs, and that might be relevant for fibrogenesis in vivo during acute and, particularly, chronic liver injury. The high constitutive expression of the IGFIR renders LMFs susceptible to biological effects of IGF-I. It can be hypothesized that IGF-I released from neighbouring liver cells and inflammatory cells during liver injury might initiate proliferation of LMFs and collagen production, and, in turn, IGF-I produced by expanded population of LMFs in cooperation with the other components of the IGF axis might lead to a perpetuation of fibroproliferative response within the liver. 


\subsection{Cross-Talk between PDGF and IGF-I Receptors in Liver Myofibroblasts: Implication for Liver Fibrogenesis}

Although in vitro data of the present work clearly demonstrate that rat LMFs constitutively express the IGF-IR rendering cells susceptible to the mitogenic and fibrogenic effects of IGF-I, it remains unclear why in vivo, despite high hepatic and circulating levels of IGF-I, there is no fibroproliferative process in normal liver. Moreover, in liver cirrhosis hepatic IGF-I expression and serum IGF-I levels are reduced (Caufriez et al., 1991; Hattori et al., 1992; Buzzelli et al., 1993; Moller et al., 1993; Scharf et al., 1996b), but reverted very rapidly after successful orthotopic liver transplantation (Bassanello et al., 2004). Low circulating IGF-I levels are associated with adverse clinical outcome and frequent complications of advanced cirrhosis such as malnutrition (Mendenhall et al., 1989; Inaba et al., 1999), insulin resistance (Shmueli et al., 1994; 1996), impaired immunity (Mendenhall et al., 1997), osteopenia (Gallego-Rojo et al., 1998; Cemborain et al., 1998; Tanaka et al., 2003), wasting of skeletal muscle (GayanRamirez et al., 1998), hypogonadism (Castilla-Cortazar et al., 2000; 2004a) and jejunal microvilli atrophy (Castilla-Cortazar et al., 2004b). It is also puzzling why administration of exogenous IGF-I, a potential mitogen for LMFs, is accompanied by improvement of liver function and reduction of liver damage and fibrosis in experimental models of liver cirrhosis (Castilla-Cortazar et al., 1997; Muguerza et al., 2001; Mirpuri et al., 2002; Canturk et al., 2003). On the other hand, PDGF, a growth factor that shares many common features with IGF-I, has a totally different expression pattern in cirrhotic liver tissue. Normal liver tissue reveals an almost undetectable expression of PDGFs and their receptors, and healthy individuals have low serum PDGF levels. In contrast, in liver cirrhosis, hepatic expression and circulating levels of PDGFs are considerably higher and positively correlate with the severity of disease (Pinzani et al., 1996; Zhang et al., 2003). Moreover, blockade of PDGF receptor expression in vivo has a beneficial effect in experimental liver cirrhosis (Borkham-Kamphorst et al., 2004). Therefore, aim of the current work was to unravel a pathophysiological link between different expression patterns of IGF-I and PDGFs.

The data of the present study demonstrate that in rat liver only cells with fibrogenic potential, i.e. LMFs and HSCs, express both subunits of the PDGFR. Furthermore, the PDGFR expression is substantially up-regulated during cultivation of LMFs and HSCs in vitro, and this up-regulation positively correlates with mitogenic response to PDGF. Intriguingly, in mouse embryo fibroblasts it has been demonstrated that the IGF-IR is required for the mitogenic activity of the PDGFR (DeAngelis et al., 1995). Cells derived 
from mouse embryos with a targeted disruption of the IGF-IR gene were unable to proliferate after the addition of PDGF. In turn, overexpression of the PDGFR $\beta$ in IGF-IR negative cells did not restore the capability of these cells to proliferate in response to PDGF. And only reintroduction of the IGF-IR restored PDGF-mediated cell proliferation (DeAngelis et al., 1995). Similar data were obtained in the present study. Simultaneous incubation of cells with PDGF-BB and I-OMe-AG538, a selective inhibitor of the IGF-IR kinase, completely abrogated PDGF-induced mitogenic response in LMFs.

The molecular mechanisms that account for the necessity of the IGF-IR for PDGFmediated mitogenesis remain poorly understood, though it has been demonstrated that PDGF increased the promoter activity of the IGF-IR gene and stimulated expression and/or secretion of endogenous IGF-I in certain cell types (Clemmons, 1985; Pinzani et al., 1990; Delafontaine et al., 1991; Rubini et al., 1994). Thus, although several tyrosine kinase receptors may independently induce mitogenesis, a hierarchy may exist with the IGF-IR being most effective in inducing mitogenic response.

In LMFs, PDGF-BB affected neither gene expression nor secretion of endogenous IGF-I (data not shown). However, PDGF-BB increased gene expression and synthesis of the IGF-IR in a concentration- and time-dependent manner, and this effect was opposite to that of IGF-I. The ability of IGF-I to induce a down-regulation of the IGF-IR is well known and has been published elsewhere (Rosenfeld and Dollar, 1982; Conover and Powell, 1991; Eshet et al., 1993; Hernandez-Sanchez et al., 1997; Bostedt et al., 2001). In line with these reports, the data of the current work demonstrate that in LMFs high concentrations of IGF-I effectively inhibited the IGF-IR expression at both mRNA and protein level. Furthermore, expression of IRS-1, a principal signalling element of the IGF-IR, was also dose-dependently inhibited by IGF-I, presumably via induction of the ubiquitin-mediated proteasome degradation of IRS-1 (Lee et al., 2000). IGF-I-induced down-regulation of the IGF-IR and IRS-1 in LMFs is an important finding that might be relevant for the situation in vivo. It clarifies, at least in part, why fibrogenesis does not occur in normal liver and why exogenous IGF-I has a beneficial effect in liver cirrhosis. Moreover, IGF-I-induced down-regulation of the IGF-IR was effectively prevented by addition of PDGF-BB. Interestingly, IGF-I substantially inhibited gene expression of the PDGFR $\alpha$, though the PDGFR $\beta$ mRNA levels have not been affected by IGF-I that apparently is associated with different functions of both PDGFR subunits in LMFs. It is well known that two PDGFR subunits mediate similar, but not identical, cellular effects (Heldin et al., 1998). It has been shown in several cell types that PDGF-BB, which binds 
to all types of the PDGFR, effectively stimulated activation of MAPK and PI3-K pathways, whereas PDGF-AA, which binds only to the PDGFR $\alpha \alpha$ dimer, failed to induce activation of PI3-K pathway, but was a strong activator of MAP kinases (Karenberg et al., 1994; Thömmes et al., 1996). It is also noteworthy that in contrast to the IGF-IR, the expression of both PDGFR subunits in LMFs was not inhibited by their natural ligand that might be an important mechanism underlying the perpetuation of fibroproliferative response in the liver in vivo.

Since transphosphorylation of receptors, even heterologous receptors, has been known to occur, one of the questions addressed in the current work was whether the PDGFR and IGF-IR can directly transactivate each other or cross-talk at the level of their principal signalling intermediates. In LMFs, however, transactivation of neither IGF-IR by PDGFR nor PDGFR by IGF-IR was observed. A possible transactivation of IRS-1 by PDGFR and PLC $\gamma_{1}$ by IGF-IR has been ruled out as well. Addition of IGF-I to cultures of LMFs along with PDGF-BB did not result in an additive tyrosine phosphorylation of the PDGFR and PLC $\gamma_{1}$. Conversely, IGF-I inhibited the phosphorylation of the PDGFR, in particular its $\alpha$ subunit. Therefore, taken together these results and the data mentioned above, it can be speculated that the hepatoprotective effect of high concentrations of IGF-I in vivo could be explained by down-regulation of the IGF-IR, IRS-1 and PDGFR $\alpha$ as well as by inhibition of the PDGFR activation.

Nevertheless, the question by which mechanism the IGF-IR cooperates with the PDGFR during mitogenic response remains open. It has been described that substantial fractions of IRS-1 (Prisco et al., 2002; Tu et al., 2002) and IRS-2 (Sun et al., 2003) can be translocated to the nucleus in transformed cells expressing certain oncogenes (v-src, SV40 T antigen) as well as in IGF-I-stimulated normal cells (Prisco et al., 2002; Tu et al., 2002; Sun et al., 2003). In the nucleus, IRS-1 and IRS-2 are accumulated mainly in the nucleoli, where they interact with the upstream binding factor, which regulates RNA polymerase I activity, and stimulate the ribosomal DNA promoter, thereby positively regulating rRNA synthesis (Tu et al., 2002; Sun et al., 2003). Therefore, it appears that beside their signalling role, certain IRS proteins may also function as positive regulators of cell growth per se. As an attractive hypothesis it has been proposed that probably PDGF requires a functional IGF-IR in order to translocate IRS-1 from the cytoplasm to the nucleus with subsequent long-term stimulation of cellular growth. However, in LMFs nuclear accumulation of IRS-1 was not observed. Moreover, IRS-1 was localized 
exclusively in the cytoplasm, and neither IGF-I nor PDGF-BB induced its translocation to the nucleus (data not shown).

Alternatively, it has also been proposed that the IGF-IR probably is more effective in cell signalling through the MAPK cascade. However, the data of the present study demonstrate that PDGF-BB effectively induced phosphorylation of all terminal MAP kinases in LMFs in contrast to IGF-I, which had only a weak effect. Addition of IGF-I to cells treated with PDGF-BB was not accompanied by an additive effect on MAP kinases activation. Inhibition of MEK, p38 kinase and JNK effectively blocked IGF-I-induced mitogenic activity in LMFs. Likewise, inactivation of JNK and p38 kinase also resulted in abrogation of mitogenic effects induced by PDGF-BB. However, the rate of PDGFinduced DNA synthesis was unaffected when phosphorylation of ERK1 and ERK2 was prevented by blockade of MEK, although PDGF-BB induced pronounced activation of ERK1 and ERK2. It is well known that some key transcription factors involved in cell division and proliferation, e.g. Elk-1 and ATF-2, can be equally activated by all terminal MAP kinases. Therefore, it is likely that during PDGF-induced mitogenesis ERK blockade is compensated by JNK and p38 kinase, which are markedly phosphorylated in response to PDGF and very weakly in response to IGF-I. But, again, that implies that PDGF-induced MAPK signalling is much more effective than that induced by IGF-I.

Although several studies have shown the importance of MAPK and PI3-K pathways induced by PDGF and IGF-I for liver fibrogenesis (Skrtic et al., 1999a; Svegliati-Baroni et al., 1999; Gentilini et al., 2000; Pinzani, 2002), the role of PLC $\gamma_{1}$ signalling pathway has not yet been established. It is well known that certain mitogens, including PDGF, elicit breakdown of phospholipids in cell membranes via activation of PLC $\gamma_{1}$ that results in a rapid accumulation of diacylglycerol and inositol phosphates with corresponding increase of cytoplasmic $\mathrm{Ca}^{2+}$ levels and subsequent activation of several protein kinase $\mathrm{C}$ isoforms, which can alternatively activate MAP kinases through a Ras-independent pathway (Heldin et al., 1998). The data of the present study demonstrate that in LMFs PLC $\gamma_{1}$ is a key signalling element that plays a pivotal role during mitogenic response. Inhibition of PLC was associated with a substantial reduction of both PDGF- and IGF-Iinduced mitogenic activity, although in LMFs PLC $\gamma_{1}$ was activated only in response to PDGF-BB, but not to IGF-I. These results presumably point to an essential role of PLC $\gamma_{1}$ in the cell and imply that mitogenic and antiapoptotic effects of IGF-I can not overcome a loss of PLC $\gamma_{1}$ activity. 


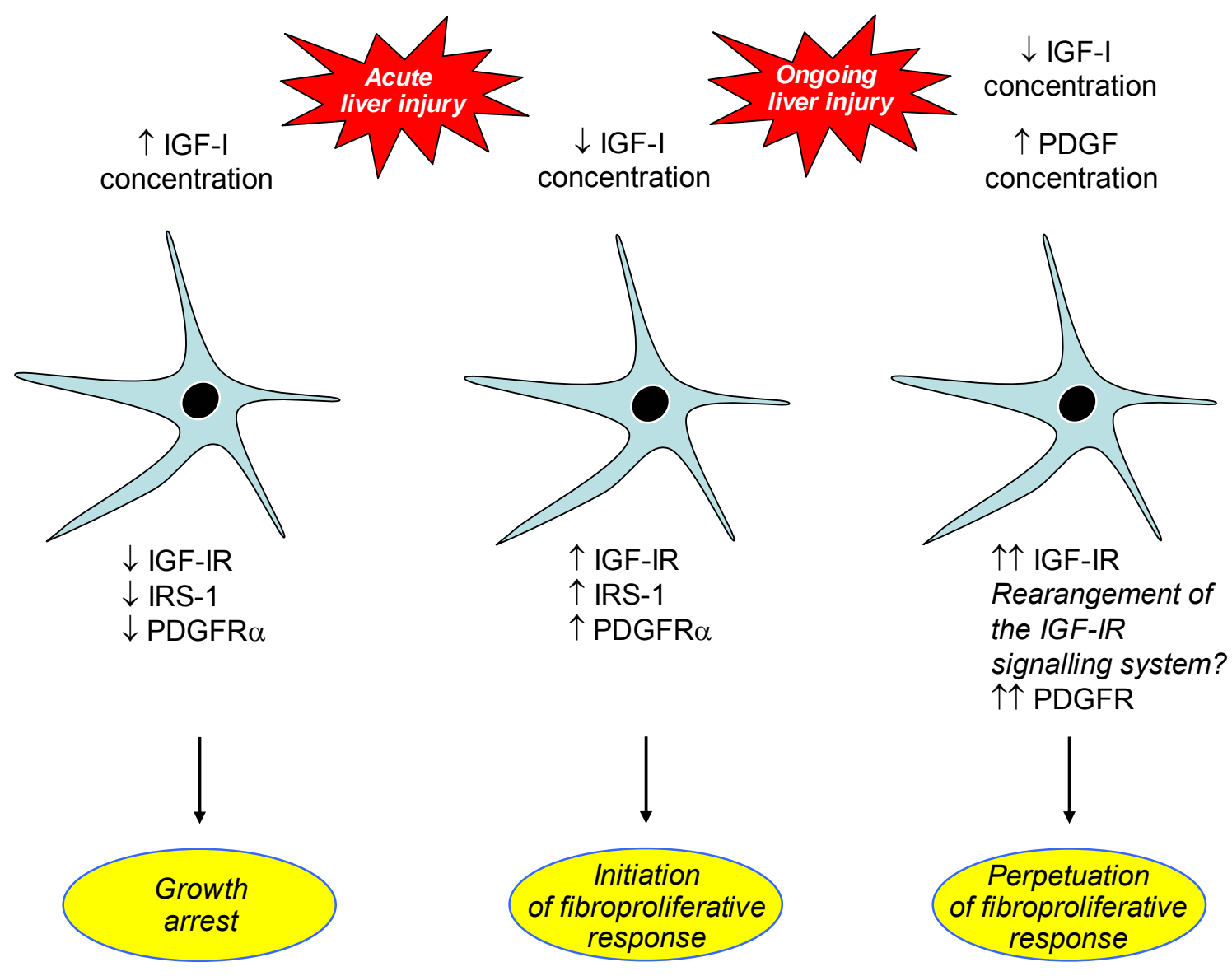

Figure 45. Proposed model for the actions of IGF-I, PDGF and their receptors in liver fibrogenesis. In normal liver, fibrogenesis does not occur because proliferation of LMFs is repressed by high hepatic and serum levels of IGF-I, which down-regulate the IGF-IR, IRS-1, PDGFR $\alpha$ expression and attenuate the PDGFR activation. The restoration of normal receptor expression and sensitivity to IGF-I in LMFs probably occurs with progressive liver injury when IGF-I levels in the circulation decline due to a loss of hepatocytes, which provide most of the IGF-I in the circulation. It results presumably in initiation of fibroproliferative response. PDGF, which is secreted in injured liver by inflammatory and mesenchymal cells, stabilizes and further up-regulates the IGF-IR followed by rearrangement of the IGF-IR signalling system. Cooperation between the IGF-IR and PDGFR facilitates PDGF signalling, and permanently increasing number of PDGFR and IGF-IR finally results in a perpetuation of fibroproliferative response in the liver.

This speculation is supported by data in vivo, which have demonstrated that homozygous deletion of the $P L C \gamma_{1}$ gene in mice caused embryonic lethality at early stages, at approximately embryonic day 9.0 (Ji et al., 1997). A quintessence of the present study was the finding that inhibition of the IGF-IR kinase considerably impaired the ability of PDGF-BB to stimulate PLC $\gamma_{1}$ activity in LMFs. Therefore, in LMFs the PDGFR requires a functional IGF-IR for full activation of PLC $\gamma_{1}$. So far, the mechanism of this inter-receptor cooperation remains unclear. The data of the present study, however, demonstrate that PDGF-BB has divergent effects on the IGF-IR signalling system in LMFs. On one hand, PDGF-BB increases the amount of the IGF-I receptors. 
On the other hand, PDGF-BB attenuates the IGF-I-induced tyrosine phosphorylation of IRS-1 and dramatically decreases the abundance of several IRS proteins in the cell, in particular IRS-1, IRS-2 and Gab-1. We hypothesize that this rearrangement in the IGFIR signalling system might reflect a substitution of conventional IRS proteins involved in the IGF-IR signalling for other docking molecules, which are probably capable to bind to PLC $\gamma_{1}$. These adaptor proteins presumably recruit PLC $\gamma_{1}$ from the cytoplasmic pool and present it to the activated PDGFR, thereby leading to effective downstream signalling. In conclusion, the presented data demonstrate that the IGF-IR and PDGFR via complex interactions play an important role in the proliferation of rat LMFs. It can be speculated that in normal liver fibrogenesis does not occur because proliferation of LMFs is repressed by high hepatic and serum levels of IGF-I, which, on one hand, downregulate the IGF-IR and its principal docking protein, IRS-1, and, on the other hand, inhibit the expression and phosphorylation of the PDGFR $\alpha$. The restoration of optimal receptor expression and sensitivity to IGF-I with subsequent induction of mitogenic activity in LMFs probably occurs in parallel with an ongoing liver injury while IGF-I levels in the circulation decline due to a loss of hepatocytes, major IGF-I secreting cells in the body. That leads presumably to initiation of fibroproliferative response in the liver. PDGF, which is secreted in the injured liver by inflammatory and mesenchymal cells, stabilizes and further up-regulates the IGF-IR expression with subsequent rearrangement of the IGF-IR signalling system. A cooperation between the IGF-IR and PDGFR facilitates cell signalling induced by PDGF, and permanently increasing number of PDGF and IGF-I receptors in LMFs finally results in a perpetuation of fibroproliferative response in the liver. 


\section{References}

1. Abbott AM, Bueno R, Pedrini MT, Murray JM and Smith RJ (1992): Insulin-like growth factor I receptor gene structure. J Biol Chem 267: 10759-63

2. Adamo ML, Neuenschwander S, LeRoith D and Roberts CT Jr (1993): Structure, expression, and regulation of the IGF-I gene. Adv Exp Med Biol 343: 1-11

3. Andress DL (1998): Insulin-like growth factor-binding protein-5 (IGFBP-5) stimulates phosphorylation of the IGFBP-5 receptor. Am J Physiol 274: E744-50

4. Arany E, Afford S, Strain AJ, Winwood PJ, Arthur MJ and Hill DJ (1994): Differential cellular synthesis of insulin-like growth factor binding protein-1 (IGFBP1) and IGFBP-3 within human liver. J Clin Endocrinol Metab 79: 1871-6

5. Bach LA (1999): Insulin-like growth factor binding protein-6: the "forgotten" binding protein? Horm Metab Res 31: 226-34

6. Baker J, Liu JP, Robertson EJ and Efstratiadis A (1993): Role of insulin-like growth factors in embryonic and postnatal growth. Cell 75: 73-82

7. Barlow DP, Stöger R, Herrmann BG, Saito K and Schweifer N (1991): The mouse insulin-like growth factor type-2 receptor is imprinted and closely linked to the Tme locus. Nature 349: 84-7

8. Baruch Y (2000): The liver: a large endocrine gland. J Hepatol 32: 505-7

9. Bassanello M, De Palo EF, Lancerin F, Vitale A, Gatti R, Montin U, Ciarleglio FA, Senzolo M, Burra P, Brolese A, Zanus G, D'Amico DF and Cillo U (2004): Growth hormone/insulin-like growth factor 1 axis recovery after liver transplantation: a preliminary prospective study. Liver Transpl 10: 692-8

10. Baxter RC (2000): Insulin-like growth factor (IGF)-binding proteins: interactions with IGFs and intrinsic bioactivities. Am J Physiol Endocrinol Metab 278: E967-76

11. Baxter RC (2001): Signaling pathways involved in antiproliferative effects of IGFBP-3: a review. Mol Pathol 54: 145-8

12. Baxter RC, Binoux MA, Clemmons DR, Conover CA, Drop SL, Holly JM, Mohan S, Oh $Y$ and Rosenfeld RG (1998): Recommendations for nomenclature of the insulin-like growth factor binding protein superfamily. J Clin Endocrinol Metab 83: 3213

13. Bobek G, Scott CD and Baxter RC (1992): Radioimmunoassay of soluble insulinlike growth factor-II/mannose 6-phosphate receptor: developmental regulation of receptor release by rat tissues in culture. Endocrinology. 130: 3387-94

14. Boisclair YR, Rhoads RP, Ueki I, Wang J and Ooi GT (2001): The acid-labile subunit (ALS) of the $150 \mathrm{kDa}$ IGF-binding protein complex: an important but forgotten component of the circulating IGF system. J Endocrinol 170: 63-70

15. Bondy CA, Werner H, Roberts CT Jr and LeRoith D (1990): Cellular pattern of insulin-like growth factor-I (IGF-I) and type I IGF receptor gene expression in early organogenesis: comparison with IGF-II gene expression. Mol Endocrinol 4: 138698 
16. Borkham-Kamphorst E, Herrmann J, Stoll D, Treptau J, Gressner AM and Weiskirchen R (2004): Dominant-negative soluble PDGF-beta receptor inhibits hepatic stellate cell activation and attenuates liver fibrosis. Lab Invest 84: 766-77

17. Bostedt KT, Schmid C, Ghirlanda-Keller C, Olie R, Winterhalter KH and Zapf J (2001): Insulin-like growth factor (IGF) I down-regulates type 1 IGF receptor (IGF $1 \mathrm{R})$ and reduces the IGF I response in A549 non-small-cell lung cancer and Saos2/B-10 osteoblastic osteosarcoma cells. Exp Cell Res 271: 368-77

18. Braulke T (1999): Type-2 IGF receptor: a multi-ligand binding protein. Horm Metab Res 31: 242-6

19. Brenzel A and Gressner AM (1996): Characterization of insulin-like growth factor (IGF)-I-receptor binding sites during in vitro transformation of rat hepatic stellate cells to myofibroblasts. Eur J Clin Chem Clin Biochem 34: 401-9

20. Brown J, Esnouf RM, Jones MA, Linnell J, Harlos K, Hassan AB and Jones EY (2002): Structure of a functional IGF2R fragment determined from the anomalous scattering of sulfur. EMBO J 21: 1054-62

21. Bunn RC and Fowlkes JL (2003): Insulin-like growth factor binding protein proteolysis. Trends Endocrinol Metab 14: 176-81

22. Butt AJ and Williams AC (2001): IGFBP-3 and apoptosis - a license to kill? Apoptosis 6: 199-205

23. Butt AJ, Firth SM and Baxter RC (1999): The IGF axis and programmed cell death. Immunol Cell Biol 77: 256-62

24. Butt AJ, Fraley KA, Firth SM and Baxter RC (2002): IGF-binding protein-3-induced growth inhibition and apoptosis do not require cell surface binding and nuclear translocation in human breast cancer cells. Endocrinology 143: 2693-9

25. Buzzelli G, Dattolo P, Pinzani M, Brocchi A, Romano S and Gentilini P (1993): Circulating growth hormone and insulin-like growth factor-I in non-alcoholic liver cirrhosis with or without superimposed hepatocarcinoma: evidence of an altered circadian rhythm. Am J Gastroenterol 88: 1744-8

26. Campbell PG and Andress DL (1997): Insulin-like growth factor (IGF)-binding protein-5-(201-218) region regulates hydroxyapatite and IGF-I binding. Am J Physiol 273: E1005-13

27. Campbell PG, Durham SK, Hayes JD, Suwanichkul A and Powell DR (1999): Insulin-like growth factor-binding protein-3 binds fibrinogen and fibrin. J Biol Chem 274: 30215-21

28. Campbell PG, Durham SK, Suwanichkul A, Hayes JD and Powell DR (1998): Plasminogen binds the heparin-binding domain of insulin-like growth factor-binding protein-3. Am J Physiol 275: E321-31

29. Canturk NZ, Canturk Z, Ozden M, Dalcik H, Yardimoglu M and Tulubas F (2003): Protective effect of IGF-1 on experimental liver cirrhosis-induced common bile duct ligation. Hepatogastroenterology 50: 2061-6

30. Carlsson-Skwirut C, Lake M, Hartmanis M, Hall K and Sara VR (1989): A comparison of the biological activity of the recombinant intact and truncated insulin-like growth factor 1 (IGF-1). Biochim Biophys Acta 1011: 192-7 
31. Caro JF, Poulos J, Ittoop O, Pories WJ, Flickinger EG and Sinha MK (1988): Insulin-like growth factor I binding in hepatocytes from human liver, human hepatoma, and normal, regenerating, and fetal rat liver. J Clin Invest 81: 976-81

32. Cassiman D, Libbrecht L, Desmet V, Denef C and Roskams T (2002): Hepatic stellate cell/myofibroblast subpopulations in fibrotic human and rat livers. J Hepatol 36: $200-9$

33. Castilla-Cortazar I, Diez N, Garcia-Fernandez M, Puche JE, Diez-Caballero F, Quiroga J, Diaz-Sanchez M, Castilla A, Casares AD, Varela-Nieto I, Prieto J and Gonzalez-Baron S (2004a): Hematotesticular barrier is altered from early stages of liver cirrhosis: Effect of insulin-like growth factor 1. World J Gastroenterol 10: 2529-34

34. Castilla-Cortazar I, Garcia M, Muguerza B, Quiroga J, Perez R, Santidrian S and Prieto J (1997): Hepatoprotective effects of insulin-like growth factor I in rats with carbon tetrachloride-induced cirrhosis. Gastroenterology 113: 1682-91

35. Castilla-Cortazar I, Garcia M, Quiroga J, Diez N, Diez-Caballero F, Calvo A, Diaz $M$ and Prieto J (2000): Insulin-like growth factor-I reverts testicular atrophy in rats with advanced cirrhosis. Hepatology 31: 592-600

36. Castilla-Cortazar I, Pascual M, Urdaneta E, Pardo J, Puche JE, Vivas B, DiazCasares A, Garcia M, Diaz-Sanchez M, Varela-Nieto I, Castilla A and GonzalezBaron S (2004b): Jejunal microvilli atrophy and reduced nutrient transport in rats with advanced liver cirrhosis: improvement by insulin-like growth factor I. BMC Gastroenterol 14: 12

37. Caufriez A, Reding P, Urbain D, Golstein J and Copinschi G (1991): Insulin-like growth factor I: a good indicator of functional hepatocellular capacity in alcoholic liver cirrhosis. J Endocrinol Invest 14: 317-21

38. Cazals V, Mouhieddine B, Maitre B, Le Bouc Y, Chadelat K, Brody JS and Clement A (1994): Insulin-lke growth factors, their binding proteins, and transforming growth factor- $\beta 1$ in oxidant-arrested lung alveolar epithelial cells. J Biol Chem 269: 14111-7

39. Cemborain A, Castilla-Cortazar I, Garcia M, Quiroga J, Muguerza B, Picardi A, Santidrian S and Prieto J (1998): Osteopenia in rats with liver cirrhosis: beneficial effects of IGF-I treatment. J Hepatol 28: 122-31

40. Cheng $\mathrm{HL}$ and Feldman EL (1998): Bidirectional regulation of p38 kinase and cJun N-terminal protein kinase by insulin-like growth factor-I. J Biol Chem 273: 14560-5

41. Chirgwin JM, Przybyla AE, MacDonald RJ and Rutter WJ (1979): Isolation of biologically active ribonucleic acid from sources enriched in ribonuclease. Biochemistry 18: 5294-9

42. Chorney MJ, Chorney K, Seese N, Owen MJ, Daniels J, McGuffin P, Thompson LA, Detterman DK, Benbow C, Lubinski D, Eley T and Plomin R (1998): A quantitative trait locus associated with cognitive ability in children. Psychol Sci 9:159-66

43. Clemmons DR (1985): Variables controlling the secretion of a somatomedin-like peptide by cultured porcine smooth muscle cells. Circ Res 56: 418-26 
44. Cohen P, Lamson G, Okajima T and Rosenfeld RG (1993): Transfection of the human insulin-like growth factor binding protein-3 gene into Balb/c fibroblasts inhibits cellular growth. Mol Endocrinol 7: 380-6

45. Cohen P, Liu B, Maronpo R, Mascarenas D and Lee KW (2002): Clinical roles of IGFBPs in malignant diseases. In: Abstracts of the symposium "Functional role of IGFBPs", Tübingen, November 1-3, 2002. Horm Res 58: 248

46. Collet C and Candy J (1998): How many insulin-like growth factor binding proteins? Mol Cell Endocrinol 139: 1-6

47. Conover CA (1992): Potentiation of insulin-like growth factor (IGF) action by IGFbinding protein-3: studies of underlying mechanism. Endocrinology 130: 3191-9

48. Conover CA and Powell DR (1991): Insulin-like growth factor (IGF)-binding protein-3 blocks IGF-I-induced receptor down-regulation and cell desensitization in cultured bovine fibroblasts. Endocrinology 129: 710-6

49. Conover CA, Clarkson JT and Bale LK (1994): Insulin-like growth factor-II enhancement of human fibroblast growth via a nonreceptor-mediated mechanism. Endocrinology 135: 76-82

50. Coppola D, Ferber A, Miura M, Sell C, D'Ambrosio C, Rubin R and Baserga R (1994): A functional insulin-like growth factor I receptor is required for the mitogenic and transforming activities of the epidermal growth factor receptor. Mol Cell Biol 14: 4588-95

51. Couce ME, Weatherington AJ and McGinty JF (1992): Expression of insulin-like growth factor-II (IGF-II) and IGF-II/mannose-6-phosphate receptor in the rat hippocampus: an in situ hybridization and immunocytochemical study. Endocrinology 131: 1636-42

52. Coverley JA and Baxter RC (1995): Regulation of insulin-like growth factor (IGF) binding protein-3 phosphorylation by IGF-I. Endocrinology 136: 5778-81

53. Coverley JA and Baxter RC (1997): Phosphorylation of insulin-like growth factor binding proteins. Mol Cell Endocrinol 128: 1-5

54. Coverley JA, Martin JL and Baxter RC (2000): The effect of phosphorylation by casein kinase 2 on the activity of insulin-like growth factor binding protein. Endocrinology 141: 564-70

55. Cui X, Lazard Z, Zhang P, Hopp TA and Lee AV (2003): Progesterone crosstalks with insulin-like growth factor signaling in breast cancer cells via induction of insulin receptor substrate-2. Oncogene 22: 6937-41

56. Daughaday WH, Hall K, Raben MS, Salmon WD Jr, van den Brande JL and van Wyk JJ (1972): Somatomedin: proposed designation for sulphation factor. Nature 235: 107

57. De Bleser PJ, Jannes $P$, van Buul-Offers SC, Hoogerbrugge CM, van Schravendijk CF, Niki T, Rogiers V, van den Brande JL, Wisse E and Geerts A (1995): Insulinlike growth factor-II/mannose 6-phosphate receptor is expressed on CCl4-exposed rat fat-storing cells and facilitates activation of latent transforming growth factor-beta in cocultures with sinusoidal endothelial cells. Hepatology 21: 1429-37

58. De Mellow JS and Baxter RC (1988): Growth hormone-dependent insulin-like growth factor (IGF) binding protein both inhibits and potentiates IGF-I-stimulated 
DNA synthesis in human skin fibroblasts. Biochem Biophys Res Commun 156: 199-204

59. De Meyts P, Wallach B, Christoffersen CT, Urso B, Gronskov K, Latus LJ, Yakushiji F, Ilondo MM and Shymko RM (1994): The insulin-like growth factor-I receptor. Structure, ligand-binding mechanism and signal transduction. Horm Res 42: $152-69$

60. DeAngelis T, Ferber A and Baserga R (1995): Insulin-like growth factor I receptor is required for the mitogenic and transforming activities of the platelet-derived growth factor receptor. J Cell Physiol 164: 214-21

61. Delafontaine P, Lou H and Alexander RW (1991): Regulation of insulin-like growth factor I messenger RNA levels in vascular smooth muscle cells. Hypertension 18: 742-7

62. Delhanty PJ, Scott CD, Babu S and Baxter RC (2001): Acid-labile subunit regulation during the early stages of liver regeneration: implications for glucoregulation. Am J Physiol Endocrinol Metab 280: E287-95

63. D'Ercole AJ and Wilkins JR (1984): Affinity labeled somatomedin-C-binding proteins in rat sera. Endocrinology 114: 1141-4

64. Doerr ME and Jones JI (1996): The roles of integrins and extracellular matrix proteins in the insulin-like growth factor I-stimulated chemotaxis of human breast cancer cells. J Biol Chem 271: 2443-7

65. Drop SL, Schuller AG, Lindenbergh-Kortleve DJ, Groffen C, Brinkman A and Zwarthoff EC (1992): Structural aspects of the IGFBP family. Growth Regul 2: 6979

66. Dupont J and LeRoith D (2001a): Insulin and insulin-like growth factor I receptors: similarities and differences in signal transduction. Horm Res 55 Suppl 2: 22-6

67. Dupont J, Khan J, Qu BH, Metzler P, Helman L and LeRoith D (2001b): Insulin and IGF-1 induce different patterns of gene expression in mouse fibroblast NIH3T3 cells: identification by cDNA microarray analysis. Endocrinology 142: 4969-75

68. Eshet R, Klinger B, Silbergeld A and Laron Z (1993): Modulation of insulin like growth factor I (IGF-I) binding sites on erythrocytes by IGF-I treatment in patients with Laron syndrome (LS). Regul Pept 48: 233-9

69. Fanayan S, Firth SM and Baxter RC (2002): Signaling through the Smad pathway by insulin-like growth factor-binding protein-3 in breast cancer cells. Relationship to transforming growth factor-beta 1 signaling. J Biol Chem 277: 7255-61

70. Feinberg AP and Vogelstein B (1983): A technique for radiolabeling DNA restriction endonuclease fragments to high specific activity. Anal Biochem 132: 613

71. Firth SM and Baxter RC (1999): Characterisation of recombinant glycosylation variants of insulin-like growth factor binding protein-3. J Endocrinol 160: 379-87

72. Firth SM and Baxter RC (2002): Cellular actions of the insulin-like growth factor binding proteins. Endocr Rev 23: 824-54

73. Fischer R, Cariers A, Reinehr R and Haussinger D (2003): Caspase 9-dependent killing of hepatic stellate cells by activated Kupffer cells. Gastroenterology 123: 845-61. 
74. Fottner Ch, Hoeflich A, Wolf E and Weber MM (2004): Role of the insulin-like growth factor system in adrenocortical growth control and carcinogenesis. Horm Metab Res 36: 397-405

75. Frasca F, Pandini G, Scalia P, Sciacca L, Mineo R, Costantino A, Goldfine ID, Belfiore A and Vigneri R (1999): Insulin receptor isoform A, a newly recognized, high-affinity insulin-like growth factor II receptor in fetal and cancer cells. Mol Cell Biol 19: 3278-88

76. Friedman SL (1993): Seminars in medicine of the Beth Israel Hospital, Boston. The cellular basis of hepatic fibrosis. Mechanisms and treatment strategies. $\mathrm{N}$ Engl J Med 328: 1828-35

77. Friedman SL (1999): Cytokines and fibrogenesis. Semin Liver Dis 19: 129-40

78. Friedman SL (2000): Molecular regulation of hepatic fibrosis, an integrated cellular response to tissue injury. J Biol Chem 275: 2247-50

79. Froesch Er, Buergi H, Ramseier Eb, Bally P and Labhart A (1963): Antibodysuppressible and nonsuppressible insulin-like activities in human serum and their physiologic significance. An insulin assay with adipose tissue of increased precision and specificity. J Clin Invest 42: 1816-34

80. Gallego-Rojo FJ, Gonzalez-Calvin JL, Munoz-Torres M, Mundi JL, FernandezPerez R and Rodrigo-Moreno D (1998): Bone mineral density, serum insulin-like growth factor I, and bone turnover markers in viral cirrhosis. Hepatology 28: 695-9

81. Gayan-Ramirez G, van de Casteele M, Rollier H, Fevery J, Vanderhoydonc F, Verhoeven G and Decramer M (1998): Biliary cirrhosis induces type Ilx/b fiber atrophy in rat diaphragm and skeletal muscle, and decreases IGF-I mRNA in the liver but not in muscle. J Hepatol 29: 241-9

82. Gentilini A, Feliers D, Pinzani M, Woodruff $K$ and Abboud $S$ (1998): Characterization and regulation of insulin-like growth factor binding proteins in human hepatic stellate cells. J Cell Physiol 174: 240-50

83. Gentilini A, Marra F, Gentilini P and Pinzani M (2000): Phosphatidylinositol-3 kinase and extracellular signal-regulated kinase mediate the chemotactic and mitogenic effects of insulin-like growth factor-I in human hepatic stellate cells. J Hepatol 32: 227-34

84. Gleeson LM, Chakraborty C, McKinnon T and Lala PK (2001): Insulin-like growth factor-binding protein 1 stimulates human trophoblast migration by signaling through alpha 5 beta 1 integrin via mitogen-activated protein kinase pathway. $\mathrm{J}$ Clin Endocrinol Metab 86: 2484-93

85. Gray SG, Stenfeldt Mathiasen I and De Meyts P (2003): The insulin-like growth factors and insulin-signalling systems: an appealing target for breast cancer therapy? Horm Metab Res 35: 857-71

86. Gui $Y$ and Murphy LJ (2001): Insulin-like growth factor (IGF)-binding protein-3 (IGFBP-3) binds to fibronectin (FN): demonstration of IGF-I/IGFBP-3/FN ternary complexes in human plasma. J Clin Endocrinol Metab 86: 2104-10

87. Gupta S, Barrett T, Whitmarsh AJ, Cavanagh J, Sluss HK, Derijard B and Davis R (1996): Selective interaction of JNK protein kinase isoforms with transcription factors. EMBO J 15: 2760-70 
88. Hallak H, Moehren G, Tang J, Kaou M, Addas M, Hoek JB and Rubin R (2002): Epidermal growth factor-induced activation of the insulin-like growth factor I receptor in rat hepatocytes. Hepatology 36: 1509-18

89. Han J, Lee JD, Bibbs L and Ulevitch RJ (1994): A MAP kinase targeted by endotoxin and hyperosmolarity in mammalian cells. Science 265: 808-811

90. Hartmann H, Schmitz F, Christ B, Jungermann K and Creutzfeldt W (1990): Metabolic actions of insulin-like growth factor-I in cultured hepatocytes from adult rats. Hepatology 12: 1139-43

91. Hasegawa Y, Hasegawa T, Fujii K, Konii H, Anzo M, Aso T, Koto S, Takada M and Tsuchiya $Y$ (1997): High ratios of free to total insulin-like growth factor-I in early infancy. J Clin Endocrinol Metab 82:156-8

92. Hasegawa $Y$, Hasegawa T, Takada M and Tsuchiya $Y$ (1996): Plasma free insulinlike growth factor I concentrations in growth hormone deficiency in children and adolescents. Eur J Endocrinol 134: 184-9

93. Hattori N, Kurahachi $\mathrm{H}$, Ikekubo K, Ishihara $\mathrm{T}$, Moridera K, Hino M, Saiki $\mathrm{Y}$ and Imura H (1992): Serum growth hormone-binding protein, insulin-like growth factorI, and growth hormone in patients with liver cirrhosis. Metabolism 41: 377-81

94. Heldin $\mathrm{CH}$, Ostman A and Ronnstrand L (1998): Signal transduction via plateletderived growth factor receptors. Biochim Biophys Acta 1378: F79-113

95. Hernandez-Sanchez C, Werner H, Roberts CT Jr, Woo EJ, Hum DW, Rosenthal SM and LeRoith D (1997): Differential regulation of insulin-like growth factor-I (IGF-I) receptor gene expression by IGF-I and basic fibroblastic growth factor. J Biol Chem 272: 4663-70

96. Heron-Milhavet L and LeRoith D (2002): Insulin-like growth factor I induces MDM2-dependent degradation of p53 via the p38 MAPK pathway in response to DNA damage. J Biol Chem 277: 15600-6

97. Herren B, Weyer KA, Rouge M, Lotscher P and Pech M (1993): Conservation in sequence and affinity of human and rodent PDGF ligands and receptors. Biochim Biophys Acta. 1173: 294-302

98. Holly J and Perks C (2002): Cross-talk between IGFBPs and integrin receptors: implications for IGFBP function. In: Abstracts of the symposium "Functional role of IGFBPs", Tübingen, November 1-3, 2002. Horm Res 58: 251

99. Hossenlopp P, Seurin D, Segovia-Quinson B, Hardouin S and Binoux M (1986): Analysis of serum insulin-like growth factor binding proteins using western blotting: use of the method for titration of the binding proteins and competitive binding studies. Anal Biochem 154: 138-43

100. Huang Y, Kim SO, Yang N, Jiang J and Frank SJ (2004): Physical and functional interaction of growth hormone and insulin-like growth factor-I signaling elements. Mol Endocrinol 18: 1471-85

101. Hwa V, Oh $Y$ and Rosenfeld RG (1999): The insulin-like growth factor-binding protein (IGFBP) superfamily. Endocr Rev 20: 761-87

102. Inaba T, Saito $H$, Inoue $T$, Han I, Furukawa $S$, Matsuda $T$, Ikeda $S$ and Muto $T$ (1999): Growth hormone/insulin-like growth factor 1 axis alterations contribute to disturbed protein metabolism in cirrhosis patients after hepatectomy. J Hepatol 31: 271-6 
103. Iredale JP, Benyon RC, Pickering J, McCullen M, Northrop M, Pawley S, Hovell C and Arthur MJ (1998): Mechanisms of spontaneous resolution of rat liver fibrosis. Hepatic stellate cell apoptosis and reduced hepatic expression of metalloproteinase inhibitors. J Clin Invest 102: 538-49

104. Issa R, Williams E, Trim N, Kendall T, Arthur MJ, Reichen J, Benyon RC and Iredale JP (2001): Apoptosis of hepatic stellate cells: involvement in resolution of biliary fibrosis and regulation by soluble growth factors. Gut 48: 548-57

105. Jaques G, Noll K, Wegmann B, Witten S, Kogan E, Radulescu RT and Havemann K (1997): Nuclear localization of insulin-like growth factor binding protein 3 in a lung cancer cell line. Endocrinology 138: 1767-70

106. Ji QS, Winnier GE, Niswender KD, Horstman D, Wisdom R, Magnuson MA and Carpenter G (1997): Essential role of the tyrosine kinase substrate phospholipase C-gamma1 in mammalian growth and development. Proc Natl Acad Sci USA 94: 2999-3003

107. Jones Jl and Clemmons DR (1995): Insulin-like growth factors and their binding proteins: biological actions. Endocr Rev 16: 3-34

108. Jones JI, Gockerman A, Busby WH Jr, Wright G and Clemmons DR (1993): Insulin-like growth factor binding protein 1 stimulates cell migration and binds to the alpha 5 beta 1 integrin by means of its Arg-Gly-Asp sequence. Proc Natl Acad Sci USA 90: 10553-7

109. Kabuta T, Hakuno F, Asano T and Takahashi S (2002): Insulin receptor substrate3 functions as transcriptional activator in the nucleus. J Biol Chem 277: 6846-51

110. Kachra Z, Barash I, Yannopoulos C, Khan MN, Guyda HJ and Posner BI (1991): The differential regulation by glucagon and growth hormone of insulin-like growth factor (IGF)-I and IGF binding proteins in cultured rat hepatocytes. Endocrinology 128: $1723-30$

111. Kahn CR and White MF (1988): The insulin receptor and the molecular mechanism of insulin action. J Clin Invest 82: 1151-6

112. Kang JX, Bell J, Beard RL and Chandraratna RA (1999): Mannose 6phosphate/insulin-like growth factor II receptor mediates the growth-inhibitory effects of retinoids. Cell Growth Differ 10: 591-600

113. Karenberg TA, Fenn A, Sachinidis A and Hoppe J (1994): The differential activation of phosphatidylinositol-3 kinase and mitogen-activated protein kinases by PDGF-AA and IGF-I might explain the synergistic effect of the two growth factors on the proliferation of AKR-2B fibroblasts. Exp Cell Res 213: 266-74

114. Karey KP and Sirbasku DA (1989a): Human platelet-derived mitogens. II. Subcellular localization of insulinlike growth factor $I$ to the alpha-granule and release in response to thrombin. Blood 74: 1093-100

115. Karey KP, Marquardt $H$ and Sirbasku DA (1989b): Human platelet-derived mitogens. I. Identification of insulinlike growth factors I and II by purification and $\mathrm{N}$ alpha amino acid sequence analysis. Blood 74: 1084-92

116. Katz NR, Nauck MA and Wilson PT (1979): Induction of glucokinase by insulin under the permissive action of dexamethasone in primary rat hepatocyte cultures. Biochem Biophys Res Commun 88: 23-9 
117. Kelly RB, Cozzarelli NR, Deutscher MP, Lehman IR and Kornberg A (1970): Enzymatic synthesis of deoxyribonucleic acid. XXXII. Replication of duplex deoxyribonucleic acid by polymerase at a single strand break. J Biol Chem 245: $39-45$

118. Khandwala HM, McCutcheon IE, Flyvbjerg A and Friend KE (2000): The effects of insulin-like growth factors on tumorigenesis and neoplastic growth. Endocr Rev 21: 215-44

119. Killian JK, Byrd JC, Jirtle JV, Munday BL, Stoskopf MK, MacDonald RG and Jirtle RL (2000): M6P/IGF2R imprinting evolution in mammals. Mol Cell 5: 707-16

120. Knittel T, Kobold D, Piscaglia F, Saile B, Neubauer K, Mehde M, Timpl R and Ramadori G (1999b): Localization of liver myofibroblasts and hepatic stellate cells in normal and diseased rat livers: distinct roles of (myo-)fibroblast subpopulations in hepatic tissue repair. Histochem Cell Biol 112: 387-401

121. Knittel T, Kobold D, Saile B, Grundmann A, Neubauer K, Piscaglia F and Ramadori G (1999a): Rat liver myofibroblasts and hepatic stellate cells: different cell populations of the fibroblast lineage with fibrogenic potential. Gastroenterology 117: $1205-21$

122. Knook DL and Sleyster EC (1976): Separation of Kupffer and endothelial cells of the rat liver by centrifugal elutriation. Exp Cell Res 99: 444-9

123. Kornfeld S (1992): Structure and function of the mannose 6-phosphate/insulin-like growth factor II receptors. Annu Rev Biochem 61: 307-30

124. Kuemmerle JF and Zhou H (2002): Insulin-like growth factor-binding protein-5 (IGFBP-5) stimulates growth and IGF-I secretion in human intestinal smooth muscle by Ras-dependent activation of p38 MAP kinase and Erk1/2 pathways. J Biol Chem 277: 20563-71

125. Kyriakis JM, Woodgett JR and Avruch J (1995): The stress-activated protein kinases. A novel ERK subfamily responsive to cellular stress and inflammatory cytokines. Ann NY Acad Sci 766: 303-19

126. Laemmli UK (1970): Cleavage of structural proteins during the assembly of the head of bacteriophage T4. Nature 227: 680-5

127. Lau MM, Stewart CE, Liu Z, Bhatt H, Rotwein P and Stewart CL (1994): Loss of the imprinted IGF2/cation-independent mannose 6-phosphate receptor results in fetal overgrowth and perinatal lethality. Genes Dev 8: 2953-63

128. Leal SM, Huang SS and Huang JS (1999): Interactions of high affinity insulin-like growth factor-binding proteins with the type $\mathrm{V}$ transforming growth factor-beta receptor in mink lung epithelial cells. J Biol Chem 274: 6711-7

129. Leal SM, Liu Q, Huang SS and Huang JS (1997): The type V transforming growth factor beta receptor is the putative insulin-like growth factor-binding protein 3 receptor. J Biol Chem 272: 20572-6

130. Lee AV, Gooch JL, Oesterreich S, Guler RL and Yee D (2000): Insulin-like growth factor I-induced degradation of insulin receptor substrate 1 is mediated by the $26 \mathrm{~S}$ proteasome and blocked by phosphatidylinositol 3'-kinase inhibition. Mol Cell Biol 20: $1489-96$ 
131. Lee KH, Bowen-Pope DF and Reed RR (1990): Isolation and characterization of the alpha platelet-derived growth factor receptor from rat olfactory epithelium. Mol Cell Biol 10: 2237-46

132. Lee KW, Liu B, Ma L, Li H, Bang P, Koeffler HP and Cohen P (2004): Cellular internalization of insulin-like growth factor binding protein-3: distinct endocytic pathways facilitate re-uptake and nuclear localization. J Biol Chem 279: 469-76

133. LeRoith D, Bondy C, Yakar S, Liu JL and Butler A (2001): The somatomedin hypothesis: 2001. Endocr Rev 22: 53-74

134. LeRoith D, Werner H, Beitner-Johnson D and Roberts ST (1995): Molecular and cellular aspects of the insulin-like growth factor I receptor. Endocr Rev 16: 143-63

135. Li H, Kolluri SK, Gu J, Dawson MI, Cao X, Hobbs PD, Lin B, Chen G, Lu J, Lin F, Xie Z, Fontana JA, Reed JC and Zhang X (2000): Cytochrome c release and apoptosis induced by mitochondrial targeting of nuclear orphan receptor TR3. Science 289: 1159-1164

136. Li W, Fawcett J, Widmer HR, Fielder PJ, Rabkin R and Keller GA (1997): Nuclear transport of insulin-like growth factor-I and insulin-like growth factor binding protein-3 in opossum kidney cells. Endocrinology 138: 1763-6

137. Liu B, Lee HY, Weinzimer SA, Powell DR, Clifford JL, Kurie JM and Cohen P (2000): Direct functional interactions between insulin-like growth factor-binding protein-3 and retinoid $X$ receptor-alpha regulate transcriptional signaling and apoptosis. J Biol Chem 275: 33607-13

138. Liu B, Weinzimer SA, Gibson TB, Mascarenhas D and Cohen P (2003): Type I alpha collagen is an IGFBP-3 binding protein. Growth Horm IGF Res 13: 89-97

139. Liu Q, Grubb JH, Huang SS, Sly WS and Huang JS (1999): The mannose 6phosphate/insulin-like growth factor-II receptor is a substrate of type V transforming growth factor-beta receptor. J Biol Chem 274: 20002-10

140. Louvi A, Accili D and Efstratiadis A (1997): Growth-promoting interaction of IGF-II with the insulin receptor during mouse embryonic development. Dev Biol 189: 3348

141. Lowe WL Jr, Adamo M, Werner H, Roberts CT Jr and LeRoith D (1989): Regulation by fasting of rat insulin-like growth factor I and its receptor. Effects on gene expression and binding. J Clin Invest 84: 619-26

142. Ludwig T, Eggenschwiler J, Fisher P, D'Ercole AJ, Davenport ML and Efstratiadis A (1996): Mouse mutants lacking the type 2 IGF receptor (IGF2R) are rescued from perinatal lethality in Igf2 and Igf1r null backgrounds. Dev Biol 177: 517-35

143. Maile LA, Badley-Clarke J and Clemmons DR (2001): Structural analysis of the role of the beta 3 subunit of the alpha $V$ beta 3 integrin in IGF-I signaling. J Cell Sci 114: 1417-25

144. Marinaro JA, Neumann GM, Russo VC, Leeding KS and Bach LA (2000): Oglycosylation of insulin-like growth factor (IGF) binding protein-6 maintains high IGF-II binding affinity by decreasing binding to glycosaminoglycans and susceptibility to proteolysis. Eur J Biochem 267: 5378-86

145. Martin JL, Ballesteros M and Baxter RC (1992): Insulin-like growth factor-I (IGF-I) and transforming growth factor-beta 1 release IGF-binding protein-3 from human fibroblasts by different mechanisms. Endocrinology 131: 1703-10 
146. Matzner U, von Figura K and Pohlmann R (1992): Expression of the two mannose 6-phosphate receptors is spatially and temporally different during mouse embryogenesis. Development 114: 965-72

147. Mendenhall CL, Chernausek SD, Ray MB, Gartside PS, Roselle GA, Grossman CJ and Chedid A (1989): The interactions of insulin-like growth factor I(IGF-I) with protein-calorie malnutrition in patients with alcoholic liver disease: V.A. Cooperative Study on Alcoholic Hepatitis VI. Alcohol Alcohol 24: 319-29

148. Mendenhall CL, Roselle GA, Grossman CJ and Gartside P (1997): II: the effects of recombinant human insulin-like growth factor-1 on immunological recovery in the malnourished alcoholic rat. Alcohol Clin Exp Res 21: 1682-9

149. Miller SM, Farrugia G, Schmalz PF, Ermilov LG, Maines MD and Szurszewski JH (1998): Heme oxygenase 2 is present in interstitial cell networks of the mouse small intestine. Gastroenterology 114: 239-244

150. Minden A, Lin A, Claret FX, Abo A and Karin M (1995): Selective activation of the JNK signaling cascade and c-Jun transcriptional activity by the small GTPases Rac and Cdc42Hs. Cell 81: 1147-57

151. Mirpuri E, Garcia-Trevijano ER, Castilla-Cortazar I, Berasain C, Quiroga J, Rodriguez-Ortigosa C, Mato JM, Prieto J and Avila MA (2002): Altered liver gene expression in $\mathrm{CCl} 4$-cirrhotic rats is partially normalized by insulin-like growth factor-I. Int J Biochem Cell Biol 34: 242-52

152. Moller S, Gronbaek M, Main K, Becker U and Skakkebaek NE (1993): Urinary growth hormone (U-GH) excretion and serum insulin-like growth factor 1(IGF-1) in patients with alcoholic cirrhosis. J Hepatol 17: 315-20

153. Moller S, Juul A, Becker U, Flyvbjerg A, Skakkebaek NE and Henriksen JH (1995): Concentrations, release, and disposal of insulin-like growth factor (IGF)-binding proteins (IGFBP), IGF-I, and growth hormone in different vascular beds in patients with cirrhosis. J Clin Endocrinol Metab 80: 1148-57

154. Monno S, Newman MV, Cook M and Lowe WL Jr (2000): Insulin-like growth factor I activates c-Jun N-terminal kinase in MCF-7 breast cancer cells. Endocrinology 141: $544-50$

155. Moore MG, Wetterau LA, Francis MJ, Peehl DM and Cohen P (2003): Novel stimulatory role for insulin-like growth factor binding protein-2 in prostate cancer cells. Int J Cancer 105: 14-9

156. Morrione A, Valentinis B, Xu SQ, Yumet G, Louvi A, Efstratiadis A and Baserga R (1997): Insulin-growth factor II stimulates cell proliferation through the insulin receptor. Proc Natl Acad Sci USA 94: 3777-82

157. Moschos SJ and Mantzoros CS (2002): The role of the IGF system in cancer: from basic to clinical studies and clinical applications. Oncology 63: 317-32

158. Mouhieddine OB, Cazals V, Maitre B, Le Bouc $Y$, Chadelat $K$ and Clement $A$ (1994): Insulin-like growth factor-II, type 2 IGF receptor, and IGF-binding protein-2 gene expression in rat lung epithelial cells: relation to proliferation. Endocrinology 135: $83-91$

159. Moxham CP and Jacobs S (1992): Insulin/IGF-I receptors hybrids: a mechanism for increasing receptor diversity. J Cell Biochem 48: 136-140 
160. Muguerza B, Castilla-Cortazar I, Garcia M, Quiroga J, Santidrian S and Prieto J (2001): Antifibrogenic effect in vivo of low doses of insulin-like growth factor-I in cirrhotic rats. Biochim Biophys Acta 1536: 185-95

161. Myers JC, Chu ML, Faro SH, Clark WJ, Prockop DJ and Ramirez F (1981): Cloning a cDNA for the pro-alpha 2 chain of human type I collagen. Proc Natl Acad Sci USA 78: 3516-20

162. Nakae J, Kido $Y$ and Accili D (2001): Distinct and overlapping functions of insulin and IGF-I receptors. Endocr Rev 22: 818-35

163. Nam T, Moralez A and Clemmons D (2002): Vitronectin binding to IGF binding protein-5 (IGFBP-5) alters IGFBP-5 modulation of IGF-I actions. Endocrinology 143: $30-6$

164. Nolan CM, Killian JK, Petitte JN and Jirtle RL (2001): Imprint status of M6P/IGF2R and IGF2 in chickens. Dev Genes Evol 211: 179-83

165. Nyman T and Pekonen F (1993): The expression of insulin-like growth factors and their binding proteins in normal human lymphocytes. Acta Endocrinol (Copenh) 128: $168-72$

166. O'Gorman DB, Costello M, Weiss J, Firth SM and Scott CD (1999): Decreased insulin-like growth factor-II/mannose 6-phosphate receptor expression enhances tumorigenicity in JEG-3 cells. Cancer Res 59: 5692-4

167. O'Dell SD and Day IN (1998): Insulin-like growth factor II (IGF-II). Int J Biochem Cell Biol 30: 767-71

168. Oh Y (2002): IGF-independent actions of IGFBP-3. In: Abstracts of the symposium "Functional role of IGFBPs", Tübingen, November 1-3, 2002. Horm Res 58: 254

169. Oh $Y$, Muller HL, Ng L and Rosenfeld RG (1995): Transforming growth factor-betainduced cell growth inhibition in human breast cancer cells is mediated through insulin-like growth factor-binding protein-3 action. J Biol Chem 270: 13589-92

170. Oh Y, Muller HL, Pham H and Rosenfeld RG (1993): Demonstration of receptors for insulin-like growth factor binding protein-3 on Hs578T human breast cancer cells. J Biol Chem 268: 26045-8

171. Pagan R, Llobera M and Vilaro S (1995): Epithelial-mesenchymal transition in cultured neonatal hepatocytes. Hepatology 21: 820-31

172. Pagan R, Martin I, Llobera M and Vilaro S (1997): Epithelial-mesenchymal transition of cultured rat neonatal hepatocytes is differentially regulated in response to epidermal growth factor and dimethyl sulfoxide. Hepatology 25: 598606

173. Pagan R, Sanchez A, Martin I, Llobera M, Fabregat I and Vilaro S (1999): Effects of growth and differentiation factors on the epithelial-mesenchymal transition in cultured neonatal rat hepatocytes. J Hepatol 31: 895-904

174. Pandini G, Vigneri R, Costantino A, Frasca F, Ippolito A, Fujita-Yamaguchi $Y$, Siddle K, Goldfine ID and Belfiore A (1999): Insulin and insulin-like growth factor-I (IGF-I) receptor overexpression in breast cancers leads to insulin/IGF-I hybrid receptor overexpression: evidence for a second mechanism of IGF-I signaling. Clin Cancer Res 5: 1935-44

175. Pedrini MT, Giorgino F and Smith RJ (1994): cDNA cloning of the rat IGF I receptors: structural analysis of rat and human IGF I and insulin receptors reveals 
differences in alternative splicing and receptor-specific domain conservation. Biochem Biophys Res Commun 202: 1038-46

176. Perks CM, Newcomb PV, Norman MR and Holly JM (1999): Effect of insulin-like growth factor binding protein-1 on integrin signaling and the induction of apoptosis in human breast cancer cells. J Mol Endocrinol 22: 41-50

177. Pfeilschifter J (1994): Mesangial cells orchestrate inflammation in the renal glomerulus. News Physiol Sci 9: 271-6

178. Pinzani M (1995): Novel insights into the biology and physiology of the lto cell. Pharmacol Ther 66: 387-412

179. Pinzani M (2002): PDGF and signal transduction in hepatic stellate cells. Front Biosci 7: d1720-6

180. Pinzani $M$ and Marra F (2001): Cytokine receptors and signaling in hepatic stellate cells. Semin Liver Dis 21: 397-416

181. Pinzani M, Abboud HE and Aron DC (1990): Secretion of insulin-like growth factorI and binding proteins by rat liver fat-storing cells: regulatory role of plateletderived growth factor. Endocrinology 127: 2343-9

182. Pinzani M, Milani S, Herbst H, DeFranco R, Grappone C, Gentilini A, Caligiuri A, Pellegrini G, Ngo DV, Romanelli RG and Gentilini P (1996): Expression of plateletderived growth factor and its receptors in normal human liver and during active hepatic fibrogenesis. Am J Pathol 148: 785-800

183. Pollak MN, Schernhammer ES and Hankinson SE (2004): Insulin-like growth factors and neoplasia. Nat Rev Cancer 4: 505-18

184. Powell DW, Mifflin RC, Valentich JD, Crowe SE, Saada JI and West AB (1999): Myofibroblasts. I. Paracrine cells important in health and disease. Am J Physiol 277: C1-9

185. Price WA, Moats-Staats BM and Stiles AD (2002): Pro- and anti-inflammatory cytokines regulate insulin-like growth factor binding protein production by fetal rat lung fibroblasts. Am J Respir Cell Mol Biol 26: 283-9

186. Prisco M, Santini F, Baffa R, Liu M, Drakas R, Wu A and Baserga R (2002): Nuclear translocation of insulin receptor substrate-1 by the simian virus $40 \mathrm{~T}$ antigen and the activated type 1 insulin-like growth factor receptor. J Biol Chem 277: 32078-85

187. Qiu RG, Chen J, Kirn D, McCormick F and Symons M (1995): An essential role for Rac in Ras transformation. Nature 374: 457-9

188. Rajah R, Valentinis B and Cohen P (1997): Insulin-like growth factor (IGF)-binding protein-3 induces apoptosis and mediates the effects of transforming growth factor-beta1 on programmed cell death through a p53- and IGF-independent mechanism. J Biol Chem 272: 12181-8

189. Rajaram S, Baylink DJ and Mohan S (1997): Insulin-like growth factor-binding proteins in serum and other biological fluids: regulation and functions. Endocr Rev 18: $801-31$

190. Ramadori G and Saile B (2002): Mesenchymal cells in the liver - one cell type or two? Liver 22: 283-294 
191. Ramadori G, Knittel T and Saile B (1998): Fibrosis and altered matrix synthesis. Digestion 59: 372-375

192. Ricort JM, Tanti JF, Van Obberghen E and Le Marchand-Brustel Y (1997): Crosstalk between the platelet-derived growth factor and the insulin signaling pathways in 3T3-L1 adipocytes. J Biol Chem 272: 19814-8

193. Rinderknecht E and Humbel RE (1976): Polypeptides with nonsuppressible insulin-like and cell-growth promoting activities in human serum: isolation, chemical characterization, and some biological properties of forms I and II. Proc Natl Acad Sci USA 73: 2365-9

194. Rinderknecht $E$ and Humbel RE (1978): The amino acid sequence of human insulin-like growth factor I and its structural homology with proinsulin. J Biol Chem 253: $2769-76$

195. Rosenfeld RG and Dollar LA (1982): Characterization of the somatomedinC/insulin-like growth factor I (SM-C/IGF-I) receptor on cultured human fibroblast monolayers: regulation of receptor concentrations by SM-C/IGF-I and insulin. $J$ Clin Endocrinol Metab 55: 434-40

196. Rotwein P, Pollock KM, Didier DK and Krivi GG (1986): Organization and sequence of the human insulin-like growth factor I gene. Alternative RNA processing produces two insulin-like growth factor I precursor peptides. J Biol Chem 261: 4828-32

197. Rubini M, Werner H, Gandini E, Roberts CT Jr, LeRoith D and Baserga R (1994): Platelet-derived growth factor increases the activity of the promoter of the insulinlike growth factor-1 (IGF-1) receptor gene. Exp Cell Res 211: 374-9

198. Saile B, DiRocco P, Dudas J, El-Armouche H, Sebb H, Eisenbach C, Neubauer K and Ramadori G (2004): IGF-I induces DNA synthesis and apoptosis in rat liver hepatic stellate cells (HSC) but DNA synthesis and proliferation in rat liver myofibroblasts (rMF). Lab Invest 84: 1037-49

199. Saile B, Knittel T, Matthes N, Schott P and Ramadori G (1997): CD95/CD95Lmediated apoptosis of the hepatic stellate cell. A mechanism terminating uncontrolled hepatic stellate cell proliferation during hepatic tissue repair. Am J Pathol 151: 1265-72

200. Saile B, Matthes N, Neubauer K, Eisenbach C, El-Armouche H, Dudas J and Ramadori G (2002): Rat liver myofibroblasts and hepatic stellate cells differ in CD95-mediated apoptosis and response to TNF-alpha. Am J Physiol Gastrointest Liver Physiol 283: G435-44

201. Salmon Wd Jr and Daughaday Wh (1957): A hormonally controlled serum factor which stimulates sulfate incorporation by cartilage in vitro. J Lab Clin Med 49: 82536

202. Sasaki N, Reese-Jones RW, Zick Y, Nissley SP and Rechler MM (1985): Characterization of insulin-like growth factor I-stimulated tyrosine kinase activity associated with the beta-subunit of type I insulin-like growth factor receptors of rat liver cells. J Biol Chem 260: 9793-804

203. Scharf J, Ramadori G, Braulke T and Hartmann H (1996a): Synthesis of insulinlike growth factor binding proteins and of the acid-labile subunit in primary cultures of rat hepatocytes, of Kupffer cells, and in cocultures: regulation by insulin, insulinlike growth factor, and growth hormone. Hepatology 23: 818-27 
204. Scharf JG and Braulke T (2003): The role of the IGF axis in hepatocarcinogenesis. Horm Metab Res 35: 685-93

205. Scharf JG, Dombrowski F and Ramadori G (2001): The IGF axis and hepatocarcinogenesis. Mol Pathol 54: 138-44

206. Scharf JG, Knittel T, Dombrowski F, Muller L, Saile B, Braulke T, Hartmann H and Ramadori G (1998): Characterization of the IGF axis components in isolated rat hepatic stellate cells. Hepatology 27: 1275-84

207. Scharf JG, Ramadori G and Dombrowski F (2000): Analysis of the IGF axis in preneoplastic hepatic foci and hepatocellular neoplasms developing after lownumber pancreatic islet transplantation into the livers of streptozotocin diabetic rats. Lab Invest 80: 1399-411

208. Scharf JG, Ramadori G and Hartmann H (1997): Contribution of Kupffer cells to the biosynthesis of the insulin-like growth factor system in rat liver. Kupffer Cell Foundation 6: 363-65

209. Scharf JG, Ramadori G, Braulke T and Hartmann H (1995a): Cellular localization and hormonal regulation of biosynthesis of insulin-like growth factor binding proteins and of the acid-labile subunit within rat liver. Prog Growth Factor Res 6: $175-80$

210. Scharf JG, Schmidt-Sandte W, Pahernik SA, Koebe HG and Hartmann H (1995b): Synthesis of insulin-like growth factor binding proteins and of the acid-labile subunit of the insulin-like growth factor ternary binding protein complex in primary cultures of human hepatocytes. J Hepatol 23: 424-30

211. Scharf JG, Schmitz F, Frystyk J, Skjaerbaek C, Moesus H, Blum WF, Ramadori G and Hartmann H (1996b): Insulin-like growth factor-I serum concentrations and patterns of insulin-like growth factor binding proteins in patients with chronic liver disease. J Hepatol 25: 689-99

212. Schedlich LJ, Le Page SL, Firth SM, Briggs LJ, Jans DA and Baxter RC (2000): Nuclear import of insulin-like growth factor-binding protein-3 and -5 is mediated by the importin beta subunit. J Biol Chem 275: 23462-70

213. Scheidegger KJ, Du J and Delafontaine $P$ (1999): Distinct and common pathways in the regulation of insulin-like growth factor-1 receptor gene expression by angiotensin II and basic fibroblast growth factor. J Biol Chem 274: 3522-30

214. Schmid C, Schlapfer I, Gosteli-Peter MA, Froesch ER and Zapf J (1996): Effects and fate of human IGF-binding protein-5 in rat osteoblast cultures. Am $\mathrm{J}$ Physiol 271: E1029-35

215. Schmitz F, Bresciani R, Hartmann H and Brauke T (1995): Effect of insulinlike growth factor II on uptake of arylsulfatase $A$ by cultured rat hepatocytes and Kupffer cells. J Hepatol 22: 356-363

216. Schütt BS, Langkamp M, Rauschnabel U, Ranke MB and Elmlinger MW (2004): Integrin-mediated action of insulin-like growth factor binding protein-2 in tumor cells. J Mol Endocrinol 32: 859-68

217. Scott CD and Weiss J (2000): Soluble insulin-like growth factor II/mannose 6phosphate receptor inhibits DNA synthesis in insulin-like growth factor II sensitive cells. J Cell Physiol 182: 62-8 
218. Scott CD, Ballesteros M, Madrid J and Baxter RC (1996): Soluble insulin-like growth factor-II/mannose 6-P receptor inhibits deoxyribonucleic acid synthesis in cultured rat hepatocytes. Endocrinology 137: 873-8

219. Scott CD, Martin JL and Baxter RC (1985): Production of insulin-like growth factor $\mathrm{I}$ and its binding protein by adult rat hepatocytes in primary culture. Endocrinology 116: 1094-101

220. Seglen PO (1973): Preparation of rat liver cells. 3. Enzymatic requirements for tissue dispersion. Exp Cell Res 82: 391-8

221. Senior PV, Byrne S, Brammar WJ and Beck F (1990): Expression of the IGFII/mannose-6-phosphate receptor mRNA and protein in the developing rat. Development 109: 67-73

222. Shimasaki $S$ and Ling $N$ (1991): Identification and molecular characterization of insulin-like growth factor binding proteins (IGFBP-1, -2, -3, -4, -5 and -6). Prog Growth Factor Res 3: 243-266

223. Shmueli E, Miell JP, Stewart M, Alberti KG and Record CO (1996): High insulinlike growth factor binding protein 1 levels in cirrhosis: link with insulin resistance. Hepatology 24: 127-33

224. Shmueli E, Stewart M, Alberti KG and Record CO (1994): Growth hormone, insulin-like growth factor-1 and insulin resistance in cirrhosis. Hepatology 19: 3228

225. Simmons JG, Pucilowska JB and Lund PK (1999): Autocrine and paracrine actions of intestinal fibroblast-derived insulin-like growth factors. Am J Physiol 276 (Gastrointest Liver Physiol 39): G817-27

226. Simmons JG, Pucilowska JB, Keku TO and Lund PK (2002): IGF-I and TGF-beta1 have distinct effects on phenotype and proliferation of intestinal fibroblasts. Am $J$ Physiol Gastrointest Liver Physiol. 283: G809-18

227. Sjögren K, Liu JL, Blad K, Skrtic S, Vidal O, Wallenius V, LeRoith D, Tornell J, Isaksson OG, Jansson JO and Ohlsson C (1999): Liver-derived insulin-like growth factor I (IGF-I) is the principal source of IGF-I in blood but is not required for postnatal body growth in mice. Proc Natl Acad Sci USA 96: 7088-92

228. Sklar MM, Kiess W, Thomas CL and Nissley SP (1989): Developmental expression of the tissue insulin-like growth factor II/mannose 6-phosphate receptor in the rat. Measurement by quantitative immunoblotting. J Biol Chem 264: 16733-8

229. Sklar MM, Thomas CL, Municchi G, Roberts CT Jr, LeRoith D, Kiess W and Nissley $P$ (1992): Developmental expression of rat insulin-like growth factorII/mannose 6-phosphate receptor messenger ribonucleic acid. Endocrinology 130: 3484-91

230. Skrtic S, Wallenius K, Gressner AM and Jansson JO (1999a): Insulin-like growth factor signaling pathways in rat hepatic stellate cells: importance for deoxyribonucleic acid synthesis and hepatocyte growth factor production. Endocrinology 140: 5729-35

231. Skrtic S, Wallenius K, Sjogren K, Isaksson OG, Ohlsson C and Jansson JO (2001): Possible roles of insulin-like growth factor in regulation of physiological and pathophysiological liver growth. Horm Res 55 Suppl 1: 1-6 
232. Skrtic S, Wallenius V, Ekberg S, Brenzel A, Gressner AM and Jansson JO (1997): Insulin-like growth factors stimulate expression of hepatocyte growth factor but not transforming growth factor beta1 in cultured hepatic stellate cells. Endocrinology 138: 4683-9

233. Skrtic S, Wallenius V, Ekberg S, Brenzel A, Gressner AM and Jansson JO (1999b): Hepatocyte-stimulated expression of hepatocyte growth factor (HGF) in cultured rat hepatic stellate cells. J Hepatol 30: 115-24

234. Sommer A, Spratt SK, Tatsuno GP, Tressel T, Lee R and Maack CA (1993): Properties of glycosylated and non-glycosylated human recombinant IGF binding protein-3 (IGFBP-3). Growth Regul 3: 46-49

235. Souza RF, Wang S, Thakar M, Smolinski KN, Yin J, Zou TT, Kong D, Abraham JM, Toretsky JA and Meltzer SJ (1999): Expression of the wild-type insulin-like growth factor II receptor gene suppresses growth and causes death in colorectal carcinoma cells. Oncogene 18: 4063-8

236. Steele-Perkins G, Turner J, Edman JC, Hari J, Pierce SB, Stover C, Rutter WJ and Roth RA (1988): Expression and characterization of a functional human insulin-like growth factor receptor. J Biol Chem 263: 11486-92

237. Strutz F, Zeisberg M, Ziyadeh FN, Yang CQ, Kalluri R, Muller GA and Neilson EG (2002): Role of basic fibroblast growth factor-2 in epithelial-mesenchymal transformation. Kidney Int 61: 1714-28

238. Su B and Karin M (1996): Mitogen-activated protein kinase cascades and regulation of gene expression. Curr Opin Immunol 8: 402-11

239. Sun H, Tu X, Prisco M, Wu A, Casiburi I and Baserga R (2003): Insulin-like growth factor I receptor signaling and nuclear translocation of insulin receptor substrates 1 and 2. Mol Endocrinol 17: 472-86

240. Svegliati-Baroni G, Ridolfi F, Di Sario A, Casini A, Marucci L, Gaggiotti G, Orlandoni P, Macarri G, Perego L, Benedetti A and Folli F (1999): Insulin and insulin-like growth factor-1 stimulate proliferation and type I collagen accumulation by human hepatic stellate cells: differential effects on signal transduction pathways. Hepatology 29: 1743-51

241. Taimr P, Higuchi H, Kocova E, Rippe RA, Friedman S and Gores GJ (2003): Activated stellate cells express the TRAIL receptor-2/death receptor-5 and undergo TRAIL-mediated apoptosis. Hepatology 37: 87-95

242. Takenaka A, Miura Y, Mori M, Hirosawa M, Kato H and Noguchi T (1991): Distribution of messenger RNAs of insulin-like growth factor (IGF)-binding proteins- 1 and -3 between parenchymal and non-parenchymal cells in rat liver. Agric Biol Chem 4: 1191-1193

243. Tanaka S, Tsurukami $H$, Sakai $A$, Okimoto $N$, Ikeda $S$, Otomo $H$ and Nakamura $T$ (2003): Effects of 1,25(OH)2D3 on turnover, mineralization, and strength of bone in growing rats with liver cirrhosis induced by administration of carbon tetrachloride. Bone 32: 275-83

244. Tannenbaum GS, Guyda HJ and Posner BI (1983): Insulin-like growth factors: a role in growth hormone negative feedback and body weight regulation via brain. Science 220: 77-9

245. Tartare S, Mothe I, Kowalski-Chauvel A, Breittmayer JP, Ballotti R and Van Obberghen E (1994): Signal transduction by a chimeric insulin-like growth factor-1 
(IGF-1) receptor having the carboxyl-terminal domain of the insulin receptor. J Biol Chem 269: 11449-55

246. Thömmes KB, Hoppe J, Vetter H and Sachinidis A (1996): The synergistic effect of PDGF-AA and IGF-1 on VSMC proliferation might be explained by the differential activation of their intracellular signaling pathways. Exp Cell Res 226: 59-66

247. Towbin H, Staehelin T and Gordon J (1979): Electrophoretic transfer of proteins from polyacrylamide gels to nitrocellulose sheets: procedure and some applications. Proc Natl Acad Sci USA 76: 4350-4

248. Toyoshima Y, Karas M, Yakar S, Dupont J, Lee Helman and LeRoith D (2004): TDAG51 mediates the effects of insulin-like growth factor I (IGF-I) on cell survival. J Biol Chem 279: 25898-904

249. Tu X, Batta P, Innocent N, Prisco M, Casaburi I, Belletti B and Baserga R (2002): Nuclear translocation of insulin receptor substrate-1 by oncogenes and lgf-I. Effect on ribosomal RNA synthesis. J Biol Chem 277: 44357-65

250. Twigg SM and Baxter RC (1998a): Insulin-like growth factor (IGF)-binding protein 5 forms an alternative ternary complex with IGFs and the acid-labile subunit. J Biol Chem 273: 6074-9

251. Twigg SM, Kiefer MC, Zapf J and Baxter RC (1998b): Insulin-like growth factorbinding protein 5 complexes with the acid-labile subunit. Role of the carboxylterminal domain. J Biol Chem 273: 28791-8

252. Twigg SM, Kiefer MC, Zapf J and Baxter RC (2000): A central domain binding site in insulin-like growth factor binding protein-5 for the acid-labile subunit. Endocrinology 141: 454-7

253. Ullrich A, Gray A, Tam AW, Yang-Feng T, Tsubokawa M, Collins C, Henzel W, Le Bon T, Kathuria S, Chen E et al (1986): Insulin-like growth factor I receptor primary structure: comparison with insulin receptor suggests structural determinants that define functional specificity. EMBO J 5: 2503-12

254. Valentinis B, Bhala A, DeAngelis T, Baserga R and Cohen $P$ (1995): The human insulin-like growth factor (IGF) binding protein-3 inhibits the growth of fibroblasts with a targeted disruption of the IGF-I receptor gene. Mol Endocrinol 9: 361-7

255. Van Obberghen $E$ (1994): Signalling through the insulin receptor and the insulinlike growth factor-I receptor. Diabetologia 37 Suppl 2: S125-34

256. Villafuerte BC, Koop BL, Pao CI, Gu L, Birdsong GG and Phillips LS (1994): Coculture of primary rat hepatocytes and nonparenchymal cells permits expression of insulin-like growth factor binding protein-3 in vitro. Endocrinology 134: $2044-50$

257. Vu TH and Hoffman AR (2000): Comparative genomics sheds light on mechanisms of genomic imprinting. Genome Res 10: 1660-3

258. Waguri S, Kohmura M, Kanamori S, Watanabe T, Ohsawa Y, Koike M, Tomiyama Y, Wakasugi M, Kominami E and Uchiyama Y (2001): Different distribution patterns of the two mannose 6-phosphate receptors in rat liver. J Histochem Cytochem 49: 1397-405

259. Walsh PT, Smith LM and O'Connor R (2002): Insulin-like growth factor-1 activates Akt and Jun N-terminal kinases (JNKs) in promoting the survival of T lymphocytes. Immunology 107: 461-71 
260. Wang ZQ, Fung MR, Barlow DP and Wagner EF (1994): Regulation of embryonic growth and lysosomal targeting by the imprinted Igf2/Mpr gene. Nature 372: 464-7

261. Weiner JA, Chen A and Davis BH (1998): E-box-binding repressor is downregulated in hepatic stellate cells during up-regulation of mannose 6phosphate/insulin-like growth factor-II receptor expression in early hepatic fibrogenesis. J Biol Chem 273: 15913-9

262. Werner H, Bach MA, Stannard B, Roberts CT Jr and LeRoith D (1992): Structural and functional analysis of the insulin-like growth factor I receptor gene promoter. Mol Endocrinol 6: 1545-58

263. Werner H, Woloschak M, Adamo M, Shen-Orr Z, Roberts CT Jr and LeRoith D (1989): Developmental regulation of the rat insulin-like growth factor I receptor gene. Proc Natl Acad Sci USA 86: 7451-5

264. White MF (2002): IRS proteins and the common path to diabetes. Am J Physiol Endocrinol Metab. 283: E413-22

265. Wolf E, Lahm H, Wu M, Wanke R and Hoeflich A (2000): Effects of IGFBP-2 overexpression in vitro and in vivo. Pediatr Nephrol 14: 572-8

266. Wu Y, Karas M, Dupont J, Zhao H, Toyoshima Y and Le Roith D (2004): Multiple signaling pathways are involved in the regulation of IGF-I receptor inhibition of PTEN-enhanced apoptosis. Growth Horm IGF Res 14: 52-8

267. Wylie AA, Pulford DJ, McVie-Wylie AJ, Waterland RA, Evans HK, Chen YT, Nolan $\mathrm{CM}$, Orton TC and Jirtle RL (2003): Tissue-specific inactivation of murine M6P/IGF2R. Am J Pathol 162: 321-8

268. Yakar S, Liu JL, Stannard B, Butler A, Accili D, Sauer B and LeRoith D (1999): Normal growth and development in the absence of hepatic insulin-like growth factor I. Proc Natl Acad Sci USA 96: 7324-9

269. Yamada $M$, Hasegawa $T$ and Hasegawa $Y$ (1998): Increase in free insulin-like growth factor-l levels in precocious and normal puberty. Endocr J 45: 407-12

270. Yang $J$ and Liu $Y$ (2001): Dissection of key events in tubular epithelial to myofibroblast transition and its implications in renal interstitial fibrosis. Am J Pathol 159: $1465-75$

271. Yang J and Liu Y (2002): Blockage of tubular epithelial to myofibroblast transition by hepatocyte growth factor prevents renal interstitial fibrosis. J Am Soc Nephrol 13: $96-107$

272. Yarden Y and Ullrich A (1988): Growth factor receptor tyrosine kinases. Annu Rev Biochem 57: 443-78

273. Yee D and Lee AV (2000): Crosstalk between the insulin-like growth factors and estrogens in breast cancer. J Mammary Gland Biol Neoplasia 5: 107-15

274. Yu LG, Fernig DG, White MR, Spiller DG, Appleton P, Evans RC, Grierson I, Smith JA, Davies H, Gerasimenko OV, Petersen OH, Milton JD and Rhodes JM (1999): Edible mushroom (Agaricus bisporus) lectin, which reversibly inhibits epithelial cell proliferation, blocks nuclear localization sequence-dependent nuclear protein import. J Biol Chem 274: 4890 -9

275. Zahradka P, Litchie B, Storie B and Helwer G (2004): Transactivation of the insulin-like growth factor-I receptor by angiotensin II mediates downstream 
signaling from the angiotensin II type 1 receptor to phosphatidylinositol 3-kinase. Endocrinology 145: 2978-87

276. Zaina S and Squire S (1998a): The soluble type 2 insulin-like growth factor (IGF-II) receptor reduces organ size by IGF-II-mediated and IGF-II-independent mechanisms. J Biol Chem 273: 28610-6

277. Zaina S, Newton RV, Paul MR and Graham CF (1998b): Local reduction of organ size in transgenic mice expressing a soluble insulin-like growth factor II/mannose6-phosphate receptor. Endocrinology 139: 3886-95

278. Zhang BB, Cai WM, Weng HL, Hu ZR, Lu J, Zheng M and Liu RH (2003): Diagnostic value of platelet derived growth factor-BB, transforming growth factorbeta1, matrix metalloproteinase-1, and tissue inhibitor of matrix metalloproteinase1 in serum and peripheral blood mononuclear cells for hepatic fibrosis. World $\mathrm{J}$ Gastroenterol 9: 2490-6

279. Zhang S, Han J, Sells MA, Chernoff J, Knaus UG, Ulevitch RJ and Bokoch GM (1995): Rho family GTPases regulate p38 mitogen-activated protein kinase through the downstream mediator Pak1. J Biol Chem 270: 23934-6

280. Zheng B and Clemmons DR (1998): Blocking ligand occupancy of the alphaVbeta3 integrin inhibits insulin-like growth factor I signaling in vascular smooth muscle cells. Proc Natl Acad Sci USA 95: 11217-22

281. Zimmermann EM, Li L, Hoyt EC, Pucilowska JB, Lichtman S and Lund PK (2000): Cell-specific localization of insulin-like growth factor binding protein mRNAs in rat liver. Am J Physiol Gastrointest Liver Physiol 278: G447-57

282. Zindy F, Lamas E, Schmidt S, Kirn A and Brechot C (1992): Expression of insulinlike growth factor II (IGF-II) and IGF-II, IGF-I and insulin receptors mRNAs in isolated non-parenchymal rat liver cells. J Hepatol 14: 30-4 


\section{Acknowledgements}

This study was performed in the Division of Gastroenterology and Endocrinology at the Department of Internal Medicine of Georg August University of Göttingen during years 2001-2004.

I am thankful to Deutsche Forschungsgemeinschaft (German Research Foundation) and University Hospital of Göttingen, which provided financial support of my work in the framework of the Postgraduate Program "Clinical, Cellular and Molecular Biology of Internal Organs" and the Forschungsförderungsprogramm 2004 (the Program of Research Support 2004).

I express my particular gratitude to my scientific supervisor, Dr. Jens-Gerd Scharf, for his outstanding supervision, support and contribution to my success.

I would like to thank sincerely Professor Giuliano Ramadori, director of the Division of Gastroenterology and Endocrinology, for inviting me to Göttingen and for providing excellent research facilities with a stimulating atmosphere. I am also greatful to Professor Gerhard Burckhardt, director of the Graduiertenkolleg 335, for giving me a chance to join the Postgraduate Program and for all the help and support during my PhD studies.

I am thankful to Professors Rüdiger Hardeland and Detlef Doenecke, for being official reviewers of the thesis. Their constructive criticism and suggestions are highly appreciated.

I would like to thank my collegues from the university, Drs. Jozsef Dudas, Kyrylo Tron, Darya Zibrova, Anatoly Samoylenko and Borislava Haralamova-llieva for their contributions to the study. I am also greatful to the technical personnel of the Division of Gastroenterology, in particular to Sieglinde Zachmann, Renate Klages, Sandra Georgi, Elke Neumann and Anke Herbst, for their significant help during these years.

I am indebted to Drs. Nicholas Ling and Shunichi Shimasaki (Whittier Institute for Diabetes and Endocrinology, La Jolla, CA, USA), Derek LeRoith and Charles Roberts (NIDDK, National Institutes of Health, Bethesda, MD, USA), Jürg Schwander and Jean Margot (Department of Internal Medicine, Kantonspital Basel, Switzerland), Steen Gammeltoft (Bispebjerg Hospital, Copenhagen, Denmark), Jeanne Myers (University of Pennsylvania, Philadelphia, PA, USA), Thomas Braulke (Department of Biochemistry, Children's Hospital, University Hospital Hamburg Eppendorf, Hamburg, Germany), Kenneth Siddle (University of Cambridge, UK) and Ronald Kahn (Joslin Diabetes Center, Harvard Medical School, Boston, MA, USA), who kindly donated cDNAs, antibodies and proteins used in the present work.

Finally, I owe my deepest gratitude to my mother Stefania, father Stepan and sister Iryna for their love, help, support, patience, encouragement and all the comfort and joy in our family. 


\section{Lebenslauf}

\section{Persönliche Daten}

Name

Vorname

Geburtsdatum

Geburtsort

Staatsangehörigkeit

1982-1990

1990-1993

1993

1993-1999

1999

1999-2001

2001-2004

2004
Novosyadlyy

Ruslan

14.08.1975

Ivano-Frankivsk, Ukraine

ukrainisch

\section{Studium und Berufliche Tätigkeit}

Schule N 11 in Ivano-Frankivsk

Gesamtnote: „1.0“, Abschluss mit Auszeichnung

Krankenpflegeschule

Ivano-Frankivsk, Ukraine

Diplom Krankenpflege

Gesamtnote: „1.0“, Abschluss mit Auszeichnung

Diplomstudiengang Humanmedizin

Staatliche Medizinische Akademie Ivano-Frankivsk, Ukraine

Diplom Humanmedizin Gesamtnote: „1.0“, Abschluss mit Auszeichnung

Wissenschaftlicher Mitarbeiter

Abteilung Medizinischer Mikrobiologie

Staatliche Medizinische Akademie Ivano-Frankivsk, Ukraine

Promotion im Rahmen des Graduiertenkollegs 335 „Klinische, Zelluläre und Molekulare Biologie Innerer Organe" und des Forschungsförderungsprogramms 2004 der Universitätsklinik Göttingen

Zentrum Innere Medizin

Abteilung Gastroenterologie und Endokrinologie Universitätsklinikum Göttingen

Angabe der vorliegenden Dissertation 